\title{
HISTÓRIA TÉRMICA E DINÂMICA DE HIDROCARBONETOS E FLUIDOS AQUOSOS EM FOLHELHOS PERMIANOS DA BACIA DO PARANÁ
}

\section{CARLOS ALBERTO SIRAGUSA TEIXEIRA}

Orientador: Dr. André Oliveira Sawakuchi

Coorientadora: Dra. Rosa Maria da Silveira Bello

\section{TESE DE DOUTORAMENTO}

Programa de Pós-Graduação em Geoquímica e Geotectônica

São Paulo 
Autorizo a reprodução e divulgação total ou parcial deste trabalho, por qualquer meio convencional ou eletrônico, para fins de estudo e pesquisa, desde que citada a fonte.

Serviço de Biblioteca e Documentação do IGc/USP

Ficha catalográfica gerada automaticamente com dados fornecidos pelo(a) autor(a) via programa desenvolvido pela Seção Técnica de Informática do ICMC/USP

Bibliotecários responsáveis pela estrutura de catalogação da publicação: Sonia Regina Yole Guerra - CRB-8/4208 | Anderson de Santana - CRB-8/6658

Siragusa Teixeira, Carlos Alberto

História Térmica e Dinâmica de Hidrocarbonetos e Fluidos Aquosos em Folhelhos Permianos da Bacia do Paraná / Carlos Alberto Siragusa Teixeira; orientador André Oliveira Sawakuchi; coorientadora Rosa Maria da Silveira Bello. -- São Paulo, 2019. $236 \mathrm{p}$.

Tese (Doutorado - Programa de Pós-Graduação em Geoquímica e Geotectônica) -- Instituto de Geociências, Universidade de São Paulo, 2019.

1. Bacia do Paraná. 2. LIP Paraná. 3. Inclusões Fuidas. 4. Refletância de Vitrinita. 5.

Aromaticidade de Querogênio. I. Oliveira Sawakuchi, André, orient. II. da Silveira Bello, Rosa Maria, coorient. III. Título. 


\section{UNIVERSIDADE DE SÃO PAULO \\ INSTITUTO DE GEOCIÊNCIAS}

\section{HISTÓRIA TÉRMICA E DINÂMICA DE HIDROCARBONETOS E FLUIDOS AQUOSOS EM FOLHELHOS PERMIANOS DA BACIA DO PARANÁ}

\section{CARLOS ALBERTO SIRAGUSA TEIXEIRA}

Orientador: Prof. Dr. André Oliveira Sawakuchi

Tese de Doutorado

№ 602

COMISSÃO JULGADORA

Dr. André Oliveira Sawakuchi

Dr. Claudio Riccomini

Dr. João Graciano Mendonça Filho

Dra. Lena Virgínia Soares Monteiro

Dra. Liliane Janikian Paes de Almeida

Dra. Milene Freitas Figueiredo

SÃO PAULO

2019 
"The greatest enemy of knowledge is not ignorance; it is the illusion of knowledge" -

Daniel Boorstin. 


\section{AGRADECIMENTOS}

Durante esta longa jornada o primeiro agradecimento é dedicado à minha família, um pouco distribuída por Portugal, Espanha e Venezuela. Obrigado pela fé, devoção e força. Um agradecimento especial à minha mulher e companheira de todas as lutas, obrigado pela amizade, amor e por acreditares em mim. O meu coração é teu. Agradeço aos meus pais pela concepção.

Ao meu orientador, Prof. Dr. André Oliveira Sawakuchi pela disposição, orientação, paciência e amizade demonstrada desde o início da minha jornada no Brasil. Pelas discussões e ideias transmitidas durante o desenvolvimento deste trabalho.

À Prof. Dra. Rosa Maria Silveira Bello, pelos ensinamentos, dedicação, perseverança e rigor científico. Obrigado também pelas discussões pertinentes, interpretações e por todo o aprendizado ao longo destes anos, decerto recordados para sempre.

Agradeço ao Petróleo Brasileiro S.A., Petrobras, especificamente, o Programa de Recursos Humanos da Petrobras em Geologia do Petróleo e Meio Ambiente (PRH-241), pela concessão de bolsa, financiamento da maioria das análises cientificas e atividades inerentes a este projeto. Agradeço também à CAPES pela concessão final de bolsa.

Ao Instituto de Geociências da Universidade de São Paulo pelas excelentes condições proporcionadas em todos os níveis e ao Programa de Pós-Graduação em Geoquímica e Geotectônica pela oportunidade de poder fazer parte de tão elevado padrão de ciência. Registro o meu sincero agradecimento a todos os que me ajudaram (direta e indiretamente) a desenvolver e concluir este trabalho, que eu espero que contribua para o conhecimento geológico no Brasil e comunidade geológica internacional.

Aos Laboratórios de Inclusões Fluidas do Núcleo de Apoio à Pesquisa Geoanalítica, Petrologia Sedimentar, Sedimentologia, Tratamento de Amostras, Isótopos Estáveis do Instituto de Geociências da Universidade de São Paulo e à Central Analítica do Instituto de Química da Universidade de São Paulo e, claro, respectivos colaboradores. Agradeço ao Departamento de Geociências, Ambiente e Ordenamento do Território da Faculdade de Ciências da Universidade do Porto pelo apoio no desenvolvimento das análises de reflectância de vitrinita. Agradeço também ao prof. Dr. Sérgio Brochsztain e equipa de pesquisadores da Universidade Federal do ABC em São Paulo, pela realização das análises de ressonância magnética nuclear e geoquímica orgânica.

Aos geólogos Bruno Boito Turra, André Luiz Silva Pestilho e André Stern pelas discussões e amizade. Aos geólogos Laura Furukawa, Maria Pelissari, Daílson José Bertassoli Junior pelo apoio e vivências durante as atividades de campo. Sem citar nomes (porque vocês sabem quem são), agradeço também aos geólogos amigos que me acompanharam durante este percurso e ajudaram a fazer do Brasil a minha segunda casa. 


\section{RESUMO}

A maioria das ocorrências documentadas de hidrocarbonetos em sistemas petrolíferos de bacias sedimentares, incluindo estudos sobre a história térmica e migração de fluidos são diretamente associadas a reservatórios convencionais (arenitos e calcários permeáveis). Apesar dos folhelhos representarem majoritariamente rochas geradoras de hidrocarbonetos, também são considerados importantes reservatórios não convencionais de hidrocarbonetos líquidos ou gasosos. Os folhelhos oleígenos da Formação Irati (Permiano) apresentam ampla distribuição na Bacia do Paraná e podem representar importante recurso energético não convencional. Nesse sentido, este estudo tem como objetivo prover novas informações sobre a geração e migração de hidrocarbonetos na Formação Irati e unidades adjacentes (formações Serra Alta e Corumbataí). A Formação Irati se diferencia por ser considerada sistema petrolífero não convencional e atípico, afetado por amplo evento magmático que contempla uma das maiores províncias ígneas (Large lgneous Province, LIP) remanescentes do continente Gondwana, a LIP Paraná (Eocretáceo). Este estudo se destaca por caracterizar inclusões fluidas aquosas (AqFl's) e compostas por hidrocarbonetos (HCFl's) hospedadas em minerais autigênicos (calcita e quartzo) da Formação Irati e de corpos ígneos da LIP Paraná.

Para análise de inclusões fluidas, foram empregados ensaios microtermométricos em inclusões fluidas e microscopia confocal de varredura (CSLM). Também foram realizadas análises de isótopos estáveis de carbono e oxigênio em veios de calcita, análises de ressonância magnética nuclear $\left({ }^{13} \mathrm{C} N M R C P / M A S\right)$ em querogênio e reflectância de vitrinita $(\mathrm{Ro})$ em matéria orgânica contida nos folhelhos da Formação Irati.

Os espectros de ${ }^{13} \mathrm{C} N M R$ CP/MAS do querogênio das amostras estudadas exibem duas bandas largas que indicam a presença de carbonos alifáticos (0 a 70 ppm) e aromáticos (100 a 180 ppm), e aromaticidade ( $f_{\text {ar }}$ ) do querogênio ao redor de $30 \%$. Os valores de Ro variam entre 0,4 a $0,8 \%$ com média de $0,6 \%$, apontando para um folhelho de maturidade baixa e temperaturas de soterramento entre 60 e $80^{\circ} \mathrm{C}$, em uma área com ausência de corpos magmáticos intrusivos. Estas evidências estão em contraste com as temperaturas de homogeneização (Th) em AqFl's, que variam entre 50 e $330^{\circ} \mathrm{C}$, coexistentes com HCFl's, que variam de 50 a $200^{\circ} \mathrm{C}$, obtidas em amostras localmente próximas a sill de diabásio no município de Limeira (SP) na borda leste da Bacia do Paraná. Parâmetro físico de fração volumétrica $\left(F_{v}\right)$ combinado com Th de HCFI's hospedadas em veios de calcita nas formações Irati e Corumbataí permitiu classificar os hidrocarbonetos líquidos aprisionados nas inclusões fluidas como black 
oil, ou seja, um óleo caracterizado por hidrocarbonetos leves a médios com pequena variação de densidade associado a fluidos de densidade média a baixa. O modelo Pressão-Volume-Temperatura (P-V-T) estimado para os fluidos aprisionados sugere abertura de veios extensionais e aprisionamento de HCFl's em regime de pressão subhidrostática a hidrostática ( 300 bar) e temperatura real de aprisionamento de $135^{\circ} \mathrm{C}$, o que apontaria para profundidade superior a $2 \mathrm{~km}$ alcançada pela Formação Irati durante o Eocretaceo, caso a história térmica tenha sido controlada somente por soterramento. Esta pressão está associada a um sistema petrolífero raso, cuja circulação pervasiva de fluido aquoso de origem substancialmente meteórica com mistura parcial de fluido de poro, pode ter sido responsável pela biodegradação de hidrocarbonetos na borda leste da Bacia do Paraná. Os dados obtidos no desenvolvimento deste estudo, sugerem que na borda leste da bacia, a Formação Irati pode ter atingido profundidade suficiente para gerar hidrocarbonetos líquidos heterogêneos ( ${ }^{\circ} \mathrm{API}$ entre 20-40) durante o Eocretáceo. 


\begin{abstract}
Most studies about thermal evolution and fluid migration in petroleum systems are focused on conventional reservoirs (sandstones and permeable limestones). Despite of shales represent most of the petroleum source rocks, they are considered important unconventional reservoirs of petroleum and natural gas. The oil shales of the Irati Formation (Permian) have widespread distribution in the Paraná Basin and might represent an important unconventional energy resource. This study aims to provide new insights on the generation and migration of hydrocarbons in the Irati Formation and adjacent units (Serra Alta and Corumbataí formations). The Irati Formation stands out as an unconventional and atypical petroleum system, which was affected by one of the world's largest igneous provinces (Large Igneous Province, LIP), the LIP Paraná (Early Cretaceous) in western Gondwana. Thus, this study stands out to characterize aqueous fluid inclusions (AqFl's) and hydrocarbon fluid inclusions (HCFl's) hosted in authigenic minerals of the Irati Formation and in intruded igneous bodies associated to the Paraná LIP.
\end{abstract}

Microthermometric and confocal scanning laser microscope (CSLM) analyzes were applied to aqueous and hydrocarbons fluid inclusions. Stable carbon (C) and oxygen $(\mathrm{O})$ isotopes analyzes were performed in calcite veins. Additionally, analyzes of solid-state carbon nuclear magnetic resonance with cross polarization at magic angle spinning $\left({ }^{13} \mathrm{C}\right.$ NMR CP/MAS) in kerogen and vitrinite reflectance (Ro) in shale samples of the Irati Formation shales were also performed.

The ${ }^{13} \mathrm{C}$ NMR CP/MAS spectra of the kerogen show two broad bands which indicate the presence of aliphatic (0-70 ppm) and aromatic carbons (100-180 ppm) and kerogen aromaticity $\left(f_{\mathrm{ar}}\right)$ around $30 \%$ in the southeastern part of the Paraná Basin. The Ro values varying between 0.4 and $0.8 \%$ with average of $0.6 \%$ suggest a low maturity kerogen for the studied Permian organic-rich shales and a temperature window between 60 and $80{ }^{\circ} \mathrm{C}$, in an area with absence of magmatic intrusive bodies. This paleotemperatures are relatively lower than the homogenization temperatures (Th) obtained in aqueous fluid inclusions $\left(50-330^{\circ} \mathrm{C}\right)$ coeval with hydrocarbon fluid inclusions (50-200 $\left.{ }^{\circ} \mathrm{C}\right)$ occurring in samples from shales nearly located to the diabase sill in the northeastern part of the basin. Physical parameter of vapor fraction volume (Fv) combined with the Th of the hydrocarbon fluid inclusions hosted calcite veins of the Corumbataí (overlaying the Irati Formation) and Irati Formation allowed the classification of the liquid hydrocarbons as black oil, which means an oil characterized by medium to light hydrocarbons with small variation of density associated with medium to low density fluids. The Pressure-Volume-Temperature (PVT) model estimated suggests the opening 
of subvertical extensional veins and hydrocarbon fluid inclusions entrapment within subhydrostatic to hydrostatic pressure regime ( 300 bar) and real trapping temperature of $135^{\circ} \mathrm{C}$ for hydrocarbons fluid inclusions, pointing out to $2 \mathrm{~km}$ depth achieved by the Irati Formation during the Early Cretaceous. This pressure is associated to a shallow petroleum system which a meteoric pervasive aqueous fluid circulation could be responsible for the biodegradation of hydrocarbons in the northeastern part of the Paraná Basin. The data obtained in this study suggest that the Irati Formation might have reached the temperature window to generate heterogeneous liquid hydrocarbons $\left({ }^{\circ} \mathrm{API}\right.$ between 20-40) during the Early Cretaceous. 


\section{LISTA DE FIGURAS}

\section{CAPÍTULO 3}

Figura 3.1. (A) Contexto regional da Bacia do Paraná na plataforma Sul-Americana. (B) Mapas geológicos das áreas de estudo (Estado de São Paulo e Estado do Paraná). (C) Coluna cronoestratigráfica da sequência sedimentar do Permiano ao Cretáceo da Bacia do Paraná e indicação de análise aplicada em amostras das unidades geológicas estudadas.

Figura 3.2. Equipamento utilizado em microtermometria no Laboratório de Inclusões Fluidas do instituto de Geociências da Universidade de São Paulo. (A) Microscópio de luz polarizadora com platina específica acoplada e sistema registrador das temperaturas. (B) Cilindro de nitrogênio líquido utilizado em laboratório.

Figura 3.3. Laboratório de microscopia confocal de varredura a laser na Central Analítica do Instituto de Química na Universidade de São Paulo.

\section{CAPÍTULO 4}

Figura 4.1. Orientações dos veios preenchendo fraturas e principais vectores de tensão. (A) Veios de calcita sub-verticais hospedados em sill associado à LIP Paraná. (B) Veios de calcita sub-verticais hospedados em capa de basalto na Formação Serra Geral. (C) Veios subhorizontais de calcita na Formação Corumbataí. (D) Veios sub-verticais de calcita na Formação Serra Alta. (E) Veios sub-verticais de quartzo e calcita na Formação Irati. O vector principal $\sigma 1$ (eixo de maior esforço) é vertical e $\sigma 3$ (eixo de menor esforço) é horizontal para todas as amostras exceto a Formação Corumbataí, onde o $\sigma 1$ é horizontal e o $\sigma 3$ é vertical.

Figura 4.2. Características macroscópicas dos veios estudados. (A) Veio de calcita sub-vertical com espessura milimétrica a centimétrica em sill pertencente à LIP Paraná (amostra SLIP-02); (A') Detalhe do veio $A$. (B) Veio de calcita sub-vertical com espessura milimétrica a centimétrica cortando siltitos e argilitos da Formação Irati (amostra calcite-03) (C) Veios de calcita e quartzo sub-horizontais com espessura centimétrica pertencentes à Formação Corumbataí (amostra CB01). Imagem retirada de Nomura (2012).

Figura 4.3. Fotomicrografias dos veios estudados. (A e B) Veios sintaxiais hospedados em sill associado à LIP Paraná (amostra SLIP-02). Cristais de calcita euédricos equidimensionais com clivagem perfeita, textura em mosaico e geminações paralelas (patchy twins - seta amarela). Polarizadores paralelos. (C) Veio antiaxial de calcita (veio beef) pertencente à Formação Corumbataí (amostra CB-01). Cristais longitudinais com textura fibrosa e crescimento cristalino desde a zona média (zona de sutura - seta amarela) em direção à borda do veio. Polarizadores paralelos. (D) Veio sintaxial de calcita na Formação Serra Alta (amostra IR-05). Cristais euédricos a subédricos com textura blocosa em mosaico, geminações paralelas e aparência escurecida devido à presença de inclusões fluidas e resíduos sólidos. (E e F) Veios sintaxiais de quartzo na Formação Irati (amostra quartz-04). Observa-se cristais de quartzo subédricos alongados com textura blocosa em mosaico e com taxas de crescimento desproporcionais entre alguns cristais. Nota-se trilhas de HCFI's secundárias, alinhadas em microfracturas cicatrizadas (setas amarelas). Polarizadores cruzados.

Figura 4.4. Fotomicrografia de assembleias de inclusões fluidas hospedadas em veios da Formação Irati e Corumbataí. (A) Inclusões fluidas aquosas (Tipo 1) de origem primária com morfologia irregular. Formação Irati, amostra calcite-01. (B) Inclusões fluidas compostas por hidrocarbonetos (Tipo 2) de origem primária. Apresentam cor marrom e morfologia irregular. Luz 
polarizada. (B') Fluorescência de cor amarela esbranquiçada sob o efeito de luz ultravioleta. Formação Irati, amostra calcite-01. (C) Inclusões fluidas compostas por hidrocarbonetos (Tipo 2) de origem primária, forma alongada e dimensões variadas. Apresentam fluorescência que varia entre amarelo e azul sob efeito de luz ultravioleta. Formação Corumbataí, veio antiaxial, amostra CB-01. (D) Inclusões fluidas compostas por hidrocarbonetos de origem primária com morfologia irregular. Apresentam fluorescência de cor amarela esbranquiçada sob efeito de luz ultravioleta. Formação Irati. Amostra quartz-04. (E) Inclusões fluidas compostas por hidrocarbonetos (Tipo 3) de origem primária, cor marrom escuro e morfologia irregular. Essas inclusões coexistem com inclusões fluidas aquosas (Tipo 1) de origem primária e morfologia irregular. Luz polarizada. (E') Fluorescência de cor laranja pálido sob efeito de luz ultravioleta. Formação Irati, amostra calcite03. (F) Presença de inclusões fluidas compostas por hidrocarbonetos de origem primária ricas em gás. Apresentam morfologia irregular, cor marrom e fase gasosa dominante. Essas inclusões coexistem com inclusão fluida composta por hidrocarbonetos (Tipo 3) de origem primária, e morfologia irregular. Formação Irati, amostra calcite-03. (G) Inclusões fluidas compostas por hidrocarbonetos (Tipo 2) de origem secundária e morfologia irregular. Apresentam fluorescência de cor amarela sob o efeito de luz ultravioleta e fase gasosa pequena. Formação Irati, amostra quartz-04. (H) Inclusões fluidas compostas por hidrocarbonetos (Tipo 2) de origem secundária e morfologia irregular. Fluorescência de cor amarela esbranquiçada sob o efeito de luz ultravioleta e fase gasosa pequena. Formação Irati, amostra quartz-04.

Figura. 4.5. Resultados microtermométricos de inclusões fluidas aquosas e compostas por hidrocarbonetos na Formação Irati. (A) Histograma de Th de inclusões aquo-salinas (Tipo 1). (B) Histograma de temperatura do ponto eutético. (C) Histograma de Tfg para inclusões Tipo 1. (D) Histograma representativo de salinidade (salinidade mínima) onde se distinguem dois grupos: um grupo dominante com salinidade moderadamente baixa, variando entre 0-5\% em peso de $\mathrm{NaCl}$ eq.; e outro grupo com salinidade elevada variando entre $16-21 \%$ em peso de $\mathrm{NaCl}$ eq. (E) Temperatura de fusão do gelo versus temperatura de homogeneização de inclusões do Tipo 1. (F) Histograma de Th de inclusões fluidas compostas por hidrocarbonetos (Tipo 2) de origem secundária em veios de quartzo. (G) Histograma de Th de inclusões fluidas compostas por hidrocarbonetos e aquosas coexistentes, de origem primária e pseudo-secundária em veios de quartzo. (G") Histograma de Th das HCFl's com fluorescência variada (Tipo 2 e Tipo 3).

Figura 4.6. Resultados microtermométricos de inclusões fluidas aquosas (Tipo 1) hospedadas em veios de calcita em basalto pertencente à Formação Serra Geral (amostra SG-01) e em sill associado à LIP Paraná (amostra SLIP-02).

Figura 4.7. Histograma de temperaturas de homogeneização de inclusões fluidas compostas por hidrocarbonetos (Tipo 2) em veio de calcita fibrosa pertencente à Formação Corumbataí (amostra CB-01).

Figura 4.8. Imagens obtidas através de microscópio confocal de varredura a laser para a inclusão fluida número doze de origem primária pertencente à Formação Irati (Tabela 4.3). (A) Modelo 3D onde é possível observar o comprimento de $30 \mu \mathrm{m}$ e a fase vapor (bolha) com formato esférico. ( $B$ e C) Imagens 2D onde é determinado o volume da fase liquida (B) e o volume da fase vapor (C) da inclusão com auxílio de software especializado. Inclusão fluida composta por hidrocarbonetos no 12 . Formação Irati. Amostra quartz-04.

Figura 4.9. Dados de reflectância de vitrinita em folhelhos da Formação Irati na borda SSE da Bacia do Paraná para as amostras estudadas.

Figura 4.10. Espectro de variação de aromaticidade do querogênio em amostras da Formação Irati, na borda SSE da Bacia do Paraná. (A) Amostra IR-07. (B) Amostra IR-08. (C) Amostra IR10. 


\section{CAPÍTULO 5}

Figura 5.1. Correlação entre aromaticidade $\left(f_{\mathrm{ar}}\right)$ e reflectância de vitrinita $(\mathrm{Ro})$ nos folhelhos da Formação Irati, borda SSE da Bacia do Paraná, em comparação com dados obtidos em folhelhos de outras unidades sedimentares da literatura. Carr \& Williams (1990) - África, Austrália, Europa e América do Norte; Solli et al. (1985) - Miocene shale; White et al. (1988) - Toarcian shale França.

Figura 5.2. Gráfico de correlação entre a $F_{v}$ e a Th que possibilita a classificação de hidrocarbonetos aprisionados nas inclusões fluidas. Baseado em Bourdet et al., (2008) e modificado de Pestilho \& Monteiro (2017).

Figura 5.3. Modelo P-V-T e respectiva curva $\beta(\alpha)$ de inclusões fluidas compostas por hidrocarbonetos aprisionadas em veios extensionais sub-verticais de quartzo na Formação Irati. SET A: (1) Descompressão isotérmica que ocorre com a diminuição de pressão em temperatura constante. (2) Aquecimento isobárico que ocorre com o aumento de temperatura para pressão constante. SET B testado para provar as flutuações de pressão (50 bar) durante a modelagem $\mathrm{P}-\mathrm{V}-\mathrm{T}$ dos fluidos aprisionados.

Figura 5.4. Evolução diagenética da Formação Irati e dos veios de calcita e quartzo que preenchem fraturas. Barras tracejadas representam incerteza no tempo paragenético.

Figura 5.5. Modelo de geração e circulação de paleofluidos (hidrocarbonetos líquidos e fluidos aquosos) no sistema petrolífero Irati-Pirambóia e Formação Serra Geral seccionadas por veios de calcita e quartzo na borda leste da Bacia do Paraná. (A) Perfil geológico NE-SW na borda leste da Bacia do Paraná; Adaptado de Zalán et al. (1990). (B) Detalhe do pacote estratigráfico das unidades aflorantes na área de estudo. (C) Modelo esquemático detalhado da geração e circulação de paleofluidos. Destaque para fluido aquoso em subsuperfície, de origem essencialmente meteórica, que circula por falhas e fraturas da bacia chegando a níveis mais profundos, e à ação de sill associado à LIP Paraná na geração e migração de hidrocarbonetos líquidos em veios autigênicos da Formação Irati e Corumbataí.

Figura 5.6. Isótopos estáveis de carbono e oxigênio em veios de calcita nas formações Irati, Serra Alta, Teresina e Serra Geral. Zona de diagênese meteórica com base em Oehlert \& Swart, 2014.

Figura 5.7. Gráfico de correlação entre salinidade versus Th de todos os veios estudados. 89

\section{APÊNDICE 1}

Figura 1.1. Exemplo de inclusão fluida aquosa bifásica à temperatura ambiente $\left(25^{\circ} \mathrm{C}\right)$. Retirado de amostra didática de topázio.

cxxvii

Figura 1.2. Diagrama de temperatura versus volume molar versus pressão (P-V-T), que mostra os limites das fases existentes, vapor, líquido + vapor e líquido, além dos campos de coexistência de fases para um sistema simples composto por $\mathrm{H}_{2} \mathrm{O}$ puro. O ponto A ilustra uma IF de fase liquida aprisionada em profundidade; o ponto G ilustra as condições de $\mathrm{P}$ e T de IF bifásicas após soerguimento.

CXXX 
Figura 1.3. Esquema ilustrativo da distribuição de inclusões fluidas primárias, secundárias e pseudo-secundárias no quartzo e fluorita. A) Quartzo, seção paralela ao eixo c; B) Fluorita, seção paralela à face do cubo (Modificado de Goldstein \& Reynolds, 1994).

cxxxi

Figura 1.4. Exemplo de inclusão fluida multifásica à temperatura ambiente. Retirado de amostra didática de topázio.

cxxxiii

Figura 1.5. Sequência de resfriamento-aquecimento de uma inclusão fluida aquosa. (E-A) etapa de resfriamento; (A) congelamento total contem gelo e vapor; $(C)$ temperatura do ponto eutético; (D) a caminho da temperatura ambiente a fusão do gelo está próxima; (E-H) etapa de aquecimento e $(\mathrm{H})$ temperatura de homogeneização para o estado líquido; (I) após o aquecimento, retornando-se à temperatura ambiente, a inclusão volta ao normal (Modificado de Coelho, 2005).

cxxxvi

Figura 1.6. (A) Diagrama esquemático P-V-T para sistema unitário $\mathrm{H}_{2} \mathrm{O}$ (superfícies metaestáveis omitidas). As linhas tracejadas são linhas de volume e densidade constante chamadas isócoras; (B) Projeção P-T de um sistema puro composto por $\mathrm{H}_{2} \mathrm{O}$ para condições diagenéticas. Visualiza-se o comportamento de uma inclusão aprisionada em $A$, no interior de um cristal diagenético, sob condições de resfriamento e soerguimento progressivos, com passagem pela curva de equilíbrio líquido $(\mathrm{L})$ - vapor $(\mathrm{V})$, até chegar à temperatura ambiente. Modificado de Goldstein \& Reynolds 1994.

cxxxviii

Figura 1.7. (A) Projeção P-T do sistema composto por $\mathrm{CH}_{4}$ e linhas de constante densidade (isócoras) $\mathrm{g} / \mathrm{cm}^{3}$; (B) Ampliação da área contornada por retângulo em A. Ponto Crítico a $-82,1 \stackrel{\circ}{\circ} \mathrm{C}$ e 46,3 bars e ponto triplo a $-182,5 \stackrel{\circ}{ } \mathrm{C}$ (Modificado de Goldstein \& Reynolds, 1994).

$\mathrm{cxl}$

Figura 1.8. Diagrama P-T de um sistema composto por $\mathrm{H}_{2} \mathrm{O}$ e $\mathrm{NaCl}$, mostrando a diferença nas posições das curvas de equilíbrio de fase L-V e também das isócoras, com adição de sal no sistema (Modificado de Goldstein \& Reynolds, 1994).

cxlii

Figura 1.9. Diagrama $\mathrm{T}-\mathrm{X}$ para baixa temperatura e baixa salinidade, de um sistema composto por $\mathrm{H}_{2} \mathrm{O}$ e $\mathrm{NaCl}$ (Modificado de Goldstein \& Reynolds, 1994).

cxliii

Figura 1.10. Curvas de solubilidade para $\mathrm{NaCl}$ e $\mathrm{KCl}$ em solução aquosa (Modificado de Shepherd et al., 1985).

cxliii

Figura 1.11. Assembleia de Inclusões fluidas em zona freática de baixa temperatura e respetivos comportamentos por reequilíbrio posterior (Modificado de Goldstein \& Reynolds, 1994). cxlv

Figura 1.12. Diagrama de fase P-T ilustrando o stretching de uma inclusão fluida líquida durante o aquecimento provocado pelo soterramento progressivo (Modificado de Goldstein \& Reynolds, 1994).

cxlvii

Figura 1.13. Diagrama esquemático ilustrando o comportamento de inclusões fluidas que foram submetidas a estiramento (stretching) e a escape e repreenchimento (leakage), causados por reequilíbrio térmico (Modificado de Goldstein \& Reynolds, 1994).

cxlvii

Figura 1.14. Fotomicrografia de inclusão fluida composta por hidrocarbonetos à temperatura ambiente $\left(25^{\circ} \mathrm{C}\right)$. (A) Luz transmitida; (B) Luz ultravioleta.

cxlix

Figura 1.15. Grau API de hidrocarbonetos e relação com cor de fluorescência (Modificado de Goldstein \& Reynolds, 1994). 
Figura 1.16. Diagrama de P-T de fases exibindo isócoras e curvas de imiscibilidade de quatro óleos genéricos (Modificado de Goldstein \& Reynolds, 1994).

Figura 1.17. Diagrama Fv versus Th a $20^{\circ} \mathrm{C}$, mostrando os campos de ocorrência para as principais classes de petróleo, de acordo com a classificação de McCain (1980), em inclusões fluidas testadas experimentalmente (Bourdet et al., 2008). Adaptado de Bourdet et al. (2008) e modificado de Pestilho \& Monteiro, (2017).

cliii

Figura 1.18. Diagrama de Fv versus Th, exibindo as tendências de conjuntos de valores de inclusões fluidas compostas por hidrocarbonetos que sofreram processos de aprisionamento posterior ou aprisionamento de diferentes populações de hidrocarbonetos. Modificado de Bourdet et al. (2008).

cliv

\section{LISTA DE TABELAS}

\section{CAPÍTULO 3}

Tabela 3.1. Informações sobre afloramentos amostrados, unidades geológicas, localização geográfica, códigos das amostras e método aplicado. Datum de coordenadas: SAT69.

\section{CAPÍTULO 4}

Tabela 4.1. Sumário da petrografia de inclusões fluidas estudadas.

Tabela 4.2. Resumo de resultados microtermométricos e das análises de microscopia confocal conjugados com o cálculo de volumes de fases de inclusões fluidas compostas por hidrocarbonetos pertencentes às formações Corumbataí e Irati.

Tabela 4.3. Resumo dos valores de $\delta^{13} \mathrm{C}$ e $\delta^{18} \mathrm{O}$ (PDB) obtidos em veios de calcita nas formações Irati, Serra Alta, Teresina e Serra Geral. O valor delta $(\delta)$ é expresso em valor per mil $(\%)$. Amostras da Formação Teresina retiradas de Nomura (2012) para contextualização.

Tabela 4.4. Resumo dos dados de COT e teor de querogênio dos folhelhos da Formação Irati e de reflectância de vitrinita e RMN (aromaticidade) do querogênio extraído dos respectivos folhelhos.

\section{CAPÍTULO 5}

Tabela 5.1. Sumário dos dados microtermométricos obtidos em estudos anteriores realizados na Bacia do Paraná. 


\section{SUMÁRIO}

AGRADECIMENTOS

RESUMO iii

ABSTRACT V v

LISTA DE FIGURAS vii

LISTA DE TABELAS xi

CAPÍTULO $1+17$

1. Introdução 19

1.1. Justificativa 21

1.2. Meta e Objetivos 22

CAPÍTULO 2

2. Fundamentação Teórica 25

2.1. Bacia do Paraná: Síntese geológica $\quad 25$

2.1.1. Unidades litoestratigráficas e sedimentação 26

2.1.2. Atividade tectônica e deformação Permo-Triássica 28

2.1.3. Potencial de geração de hidrocarbonetos 29

2.1.4. Paleofluidos no contexto tectônico 30

2.1. Províncias igneas (LIP's) no contexto de bacias cratônicas 30

2.1.1. A Formação Serra Geral e o magmatismo Eocretáceo 32

2.1.2. Magmatismo, maturidade térmica e geração de hidrocarbonetos 33

CAPÍTULO $3 \quad 35$

3. Materiais e Métodos 37

3.1. Levantamento de sessões geológicas e amostragem 37

3.2. Análises químicas do teor de carbono orgânico total (COT) e hidrogênio $(H) \quad 42$

3.3. Análises de isótopos estáveis de carbono (C) e oxigênio (O) 42

3.4. Estudo de inclusões fluidas 43

3.4.1. Microscopia ótica 43

3.4.2. Microtermometria 44

3.4.3. Microscopia confocal de varredura a laser (CSLM) 46

3.4.4. Modelo P-V-T dos fluidos aprisionados $\quad 47$

$\begin{array}{ll}\text { 3.5. Reflectância de vitrinita (\% Ro) } & 48\end{array}$

3.6. Espectroscopia por ressônancia magnética nuclear (RMN) em querogênio $\quad 49$

CAPÍTULO 4

4. Resultados 53

4.1. Orientação e características macroscópicas dos veios de calcita e quartzo 53

4.2. Microscopia óptica dos veios e das inclusões fluidas 55

4.3. Microtermometria de inclusões fluidas $\quad 61$

4.3.1. Inclusoes fluidas aquosas (AqFl's) 61

4.3.2. Inclusões fluidas compostas por hidrocarbonetos (HCFI's) 62

4.4. Microscopia confocal de carredura a laser (CSLM) 62

4.5. Isótopos estáveis de carbono e oxigênio em veios de calcita 67

4.6. Reflectância de vitrinita (\%Ro) 68

4.7. Ressonância magnética nuclear (RMN) em querogênio 69 
5. Discussões 73

5.1. Grau de evolução térmica e aromaticidade do querogênio na Formação Irati 73

5.2. Maturidade térmica de HCFl's com base em petrografia 75

5.3. Temperatura de aprisionamento de hidrocarbonetos 76

5.4. Classificação de hidrocarbonetos em veios de calcita e quartzo 77

5.4.1. P-V-T e propriedades dos fluidos aprisionados $\quad 79$

5.5. Circulação de paleofluidos e desenvovlvimento de veios autigênicos 82

5.5.1. Isótopos estáveis de carbono e oxigênio em veios de calcita

5.5.2. Modificações pós-aprisionamento nas inclusões 88

5.5.3. Condições de deformação da Formação Irati durante a circulação de paleofluidos registrados em veios de calcita $\quad 89$

CAPÍTULO $6 \quad 93$

6. Conclusões 95

REFERÊNCIAS ci

APÊNDICE I. Material Conceitual de Apoio cxvii

1. Sistemas petrolíferos cxix

1.1. Convencionais versus não convencionais $\quad$ cxix

2. Sistema Petrolífero Convencional cxx

2.1. Conceitos e definições cxx

2.1.1. Rocha Geradora cxx

2.1.1.1. Matéria Orgânica cxi

2.1.2. Rocha Reservatório cxxii

2.1.3. Rocha Selante cxii

2.1.4. Processos cxiii

2.1.4.1. Maturação cxxiii

2.1.4.2. Geração cxxiii

2.1.4.3. Migração cxxiv

2.1.5. Acumulação cxxiv

2.1.6. Caracterização e estrutura de hidrocarbonetos cxxv

3. O estudo de inclusões fluidas (IF's) em bacias sedimentares cxxvi

3.1. Síntese evolutiva cxxvi

3.2. Interpretações e considerações gerais cxxvii

3.3. Classificação segundo origem e modo de ocorrência cxxx

3.4. Classificação segundo composição e número de fases à temperatura ambiente $\left(\sim 22^{\circ} \mathrm{C}\right)$

cxxxii

3.5. Microtermometria e temperaturas importantes cxxxiii

3.6. Exemplos de sistemas químicos e mudanças de fase cxxxvi

3.7. Modo de ocorrência em ambiente diagenético de baixa temperatura e o efeito de reequilibrio térmico cxliv

3.8. Caracteristicas de inclusões fluidas compostas por hidrocarbonetos (HCFl's) cxlviii

3.8.1. Microtermometria e termodinâmica cl

ANEXO I. Fluid inclusions in calcite filled opening fractures of the Serra Alta Formation reveal paleotemperatures and composition of diagenetic fluids percolating Permian shales of the Paraná Basin clxi 
ANEXO II. Hydrocarbons generation in the Permian Irati organic-rich shales under the influence of the Early Cretaceous Paraná Large Igneous Province

clxxvii 
CAPÍTULO 1 


\section{CAPÍTULO 1}

\section{INTRODUÇÃO}

A maioria das ocorrências de hidrocarbonetos documentadas, que incluem estudos sobre a dinâmica de fluidos e história térmica de sistemas petrolíferos em bacias sedimentares, integrando o uso de métodos analíticos (destrutivos e não destrutivos), são diretamente associadas a reservatórios convencionais (arenitos e calcários) devido à demanda global por petróleo e ao incremento da atividade de exploração nas últimas décadas (Munz, 2001). Rochas sedimentares siliciclásticas ricas em argilo-minerais com elevado teor de matéria orgânica disseminada, macroporosidade reduzida e baixa permeabilidade, tais como "folhelhos orgânicos", também são consideradas importantes reservatórios não convencionais de hidrocarbonetos líquidos ou gasosos (Montgomery et al., 2005; Ross et al., 2008, 2009). O incremento na produção de petróleo e gás natural, além da ampla distribuição mundial de depósitos de folhelhos oleígenos, os quais abrangem sistemas de oil shale (folhelho pirobetuminoso) e shale gas (gás de folhelho) se tornaram alvos pertinentes do setor energético global (USGS, 2013; EIA/ARI, 2013). Assim, os folhelhos oleígenos da Formação Irati (Permiano) apresentam elevado potencial de desenvolvimento econômico e científico pela sua acessibilidade e ampla distribuição na Bacia do Paraná (Dyni, 2003). A Formação Irati contém intervalos de folhelhos, intercalados com siltitos, dolomitos e níveis de calcário (Milani et al., 2007a). Nesse sentido, este estudo tem como objetivo fornecer novas informações sobre o sistema petrolífero não convencional (Irati-Irati), afetado por intenso evento magmático no Eocretáceo (Souza et al., 2008; Santos et al., 2009). Este estudo também aborda unidades sedimentares adjacentes à Formação Irati e portadoras de folhelhos, as formações Serra Alta e Corumbataí. Alguns sistemas petrolíferos não convencionais, incluindo sistemas de shale gas, são um produto do efeito de corpos ígneos em folhelhos oleígenos (Othman et al., 2001; Baudino et al., 2004; Parnell, 2004; Monreal et al., 2009), onde os processos de geração e migração de hidrocarbonetos relacionados a corpos ígneos ainda não são bem compreendidos. Uma das razões para isso pode ser, possivelmente, a baixa ocorrência natural e a dificuldade em discriminar hidrocarbonetos associados a corpos ígneos daqueles relacionados a processos diagenéticos (soterramento) em áreas onde ambos coexistem (Monreal et al., 2009). Não obstante, grandes províncias ígneas (Large Igneous Provinces, LIP's) se destacam por sua influência térmica em sucessões 
sedimentares espessas que integram rochas sedimentares ricas em matéria orgânica, carbonáticas ou evaporíticas (Heimdal et al., 2018).

Ademais, nas últimas décadas, inúmeros estudos têm surgido relacionando o efeito de grandes eventos magmáticos a mudanças climáticas e expressivas extinções em massa, por processos de desgaseificação vulcânica em bacias sedimentares durante o Fanerozóico (Ernst \& Youbi, 2017). Esses eventos magmáticos estão associados à geração de grandes províncias ígneas (LIP's) distribuídas por todo o planeta, sendo a maioria exposta em porções continentais separadas pertencentes ao Gondwana (Sensarma et al., 2017), como a LIP do Atlântico Central (Marzoli et al., 1999), a LIP Afar na Etiópia (George et al., 1998), a LIP Paraná na Bacia do Paraná, sudeste do Brasil (Hurter \& Pollack, 1994), correlata à LIP Etendeka na África do Sul (Peate, 1997), a LIP de Karoo-Ferrar também na África do Sul (Svensen et al., 2006), a LIP Deccan na Índia (Coffin et al., 2006) e a LIP Kalkarindji na Austrália (Jourdan et al., 2014). Não expostas em porções do Gondwana, mas igualmente influentes no cenário paleoclimático são a LIP Emeishan na China (Zhu et al., 2010; Ganino \& Arndt, 2009) e as Trapps Siberianas na Rússia (Visscher et al., 2004; Retallack \& Jahren, 2008; Svensen et al., 2009) associadas a grandes eventos de extinção em massa e geração e emissão de gases efeito estufa.

A Bacia do Paraná está inserida num modelo de evolução térmica complexo devido ao magmatismo Eocretáceo (Magmatismo Serra Geral) (Janasi et al., 2011). Este evento vulcânico foi responsável pela geração de uma das maiores províncias ígneas não oceânicas do mundo denominada LIP Paraná com uma área de extensão aproximada de $10^{6} \mathrm{Km}^{2}$ (Hurter \& Pollack, 1994). O efeito do magmatismo Serra Geral sobre a geração de hidrocarbonetos e migração de paleofluidos na Bacia do Paraná tem sido tratado em poucos estudos (Araújo et al., 2000). O destaque tem incidido na influência térmica nos folhelhos permianos, porém com carência de dados sobre paleofluidos produzidos, além de existirem poucos dados sobre paleotemperatura, pressão, densidade e composição de sistemas diagenéticos (água, óleo e gás), e o provável efeito regional ou local do magmatismo Serra Geral sobre as rochas permianas e cretáceas da bacia. De fato, o magmatismo proporciona o aquecimento das rochas geradoras de hidrocarbonetos, contudo, este aquecimento pode apresentar grande variabilidade espacial e temporal em virtude de heterogeneidades litológicas e caráter episódico dos eventos magmáticos (Renne et al., 1996; Stewart et al., 1996; Ernesto et al., 2002; Thiede \& Vasconcelos 2010; Janasi et al., 2011). Ao mesmo tempo, tem sido verificado que os contatos entre diques/soleiras de diabásio e rochas sedimentares podem ter propiciado importantes caminhos para a migração dos hidrocarbonetos, além de influenciar as características petrofísicas das rochas que promovem alterações 
hidrostáticas, pressões de poro e de acumulação de hidrocarbonetos, a partir de microfraturas geradas durante esse evento (Thomaz Filho et al., 2008).

Nesse sentido, o desenvolvimento do presente trabalho pretende avançar no conhecimento da história térmica do pacote de rochas permianas da bacia do Paraná, sob influência do magmatismo Eocretáceo, elaborando um estudo evolutivo diagenético sobre os produtos autigênicos e o registo de processos diagenéticos regionais/locais atuantes ao longo da borda leste da Bacia do Paraná, capazes de influenciar maturidade térmica de folhelhos oleígenos, a interação rocha-fluido em subsuperfície e o preenchimento de sistemas de fraturas por minerais autigênicos. Assim, pretende-se caracterizar a composição de hidrocarbonetos pretéritos e suas condições de migração (pressão e temperatura) e aprisionamento sob a forma de inclusões fluidas. Deste modo, o estudo visa o reconhecimento de possíveis padrões de geração, migração e circulação de paleofluidos e o estabelecimento de possíveis relações com o magmatismo Serra Geral. O melhor entendimento sobre estes processos e conhecimento sobre as relações entre sistemas petrolíferos e magmatismo presente em bacias sedimentares, poderão servir de base para avaliação de bacias intracratônicas análogas, como por exemplo, as bacias do Solimões, Amazonas e Parnaíba no Brasil.

\subsection{Justificativa}

No Brasil, o uso de inclusões fluidas no estudo de sistemas petrolíferos em bacias sedimentares de origem diversa é ainda muito escasso e relativamente recente (e.g., Coelho, 2005; Oliveira, 2012; Nomura et al., 2014; Pestilho, 2018; Teixeira et al., 2018), revelando que a maioria das bacias carecem de estudos mais detalhados utilizando inclusões fluidas, tanto para a caracterização de sistemas petrolíferos, como no estudo da diagênese de rochas sedimentares, onde a Bacia do Paraná não é exceção.

O presente trabalho constitui um amplo estudo que integra a análise de produtos autigênicos (veios de calcita e quartzo) das formações Irati, Serra Alta e Corumbataí (Neopermiano) e da Formação Serra Geral (Eocretáceo), bem como, análises dos folhelhos oleígenos da Formação Irati. Esta pesquisa apresenta a interpretação integrada dos dados derivados da análise de inclusões fluidas e matéria orgânica dos folhelhos com vista ao conhecimento das condições diagenéticas de temperatura, pressão e estimativa composicional de hidrocarbonetos que migraram em sistema de fraturas e microfraturas. Estes resultados, no âmbito do conhecimento geológico das bacias sedimentares brasileiras incluindo a Bacia do Paraná, podem trazer novos conceitos sobre a evolução de sistemas petrolíferos não convencionais (oil shale ou shale gas), bem como, prover novos paradigmas que possam ser utilizados na 
discussão e desenvolvimento de modelos diagenéticos análogos em outras bacias sedimentares brasileiras.

\subsection{Meta e objetivos}

O presente trabalho visa o entendimento dos processos de geração e migração de paleofluidos diagenéticos como produto do efeito da LIP Paraná em um dos maiores depósitos de oil shale do mundo - Formação Irati, que integra o sistema petrolífero não convencional Irati-Irati (Dyni, 2003).

A meta passa por obter dados inéditos que permitam avançar no entendimento acerca dos paleofluidos diagenéticos percolantes do pacote de rochas do Grupo Passa Dois (Permiano) e Formação Serra Geral (Eocretáceo), visando o reconhecimento de suas relações termobarométricas e temporais. Propõe-se caracterizar a geração e desenvolvimento de veios formados por minerais de origem autigênica presentes em rochas sedimentares do Grupo Passa Dois na Bacia do Paraná, em termos de composição, densidade e salinidade de fluidos, bem como, estabelecer o fluxo de fluidos e possíveis rotas de migração de hidrocarbonetos.

Foram empregados procedimentos analíticos qualitativos e quantitativos, utilizando-se ensaios não destrutivos entre os quais; o estudo de inclusões fluidas em minerais autigênicos (calcita e quartzo) através de microscopia óptica convencional (Roedder, 1984; Fuzikawa, 1985; Goldstein \& Reynolds, 1994) e microscopia confocal de alta resolução (CSLM) em inclusões fluidas compostas por hidrocarbonetos (Bourdet et al., 2008). Dentro de análises quantitativas ou semi-quantitativas do estudo de inclusões fluidas destacam-se os ensaios não destrutivos como a microtermometria (Roedder, 1984). Para mais, foram realizadas análises de isótopos estáveis de carbono (C) e oxigênio $(\mathrm{O})$ em minerais de preenchimento de fraturas (calcita) e análises de geoquímica orgânica em folhelhos oleígenos da Formação Irati. Análises de geoquímica orgânica visam a determinação de aromaticidade do querogênio gerado e avaliação de maturidade térmica do folhelho, através do uso de ressonância magnética nuclear (RMN) e de reflectância de vitrinita (Ro) respectivamente.

Pretende-se elaborar um modelo sobre a geração e migração de fluidos diagenéticos e a caracterização da evolução térmica da Formação Irati na borda leste da Bacia do Paraná. Desta forma, a diagênese atuante em um sistema petrolífero não convencional considerado atípico, a percolação/migração de paleofluidos e possíveis rotas/pulsos de migração de hidrocarbonetos, assim como, o estabelecimento de relações com o magmatismo Serra Geral e corpos magmáticos intrusivos associados são escopo deste trabalho. 
CAPÍTULO 2 


\section{CAPÍTULO 2}

\section{FUNDAMENTAÇÃO TEÓRICA}

\subsection{Bacia do Paraná: Síntese geológica}

A Bacia do Paraná é uma estrutura sedimentar geológica de grande importância e magnitude da América do Sul, considerada uma sinéclise cratônica de formato alongado na direção NNE-SSW. Inclui porções territoriais do Brasil meridional, metade oriental do Paraguai, metade ocidental do Uruguai e nordeste da Argentina onde é

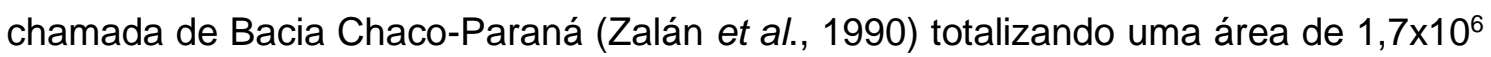
$\mathrm{Km}^{2}$ aproximadamente.

O seu preenchimento sedimentar é predominantemente siliciclástico e vulcânico, desde o Neo-Ordoviciano ( $\pm 450 \mathrm{Ma})$ ao Eocretaceo $( \pm 65 \mathrm{Ma})$ (Zalán et al., 1990$)$, e consiste em um registro descontínuo de sedimentação, onde as rochas depositadas chegam aos 7000 metros de espessura aproximadamente, na qual, cerca de 1700 metros correspondem aos derrames basálticos do magmatismo Serra Geral (Milani et al., 2007b).

A origem da Bacia do Paraná ainda é tema de discussão (Zalán et al. 1990; Milani, 2004). Seu embasamento é constituído por rochas e estruturas relacionadas a tectônica de formação do Gondwana. Discute-se se a bacia sofreu, durante um estágio de evolução inicial, uma fase rift e consequente subsidência mecânica relacionada ao primeiro episódio deposicional da bacia (Fúlfaro et al., 1982; Zalán et al., 1990; Milani, 2004). Vários trabalhos identificam que estruturas preexistentes do embasamento contribuíram na evolução tectônica da bacia através de reativações ao longo do tempo geológico, contribuindo para a geração e desenvolvimento de zonas de falhas, depocentros, altos estruturais internos e ocorrência de atividade sísmica sin-sedimentar (Fúlfaro et al., 1982; Zalán et al., 1990; Rostirolla et al., 1999, Riccomini et al., 2005).

Verifica-se que o preenchimento sedimentar da bacia é composto por sequências estratigráficas (sensu Vail et al., 1977) que representam períodos de subsidência e consequente deposição, marcadas por discordâncias regionais, referentes a períodos de erosão e/ou hiato deposicional (Soares et al., 1978; Zalán et al., 1990; Milani, 1997). Essa ciclicidade deposicional é uma característica comum em todas as sinéclises mundiais (Miall, 2000). Ademais, na Bacia do Paraná constata-se que os períodos de não deposição e erosão são mais amplos que os de sedimentação (Milani et al., 2007b). 


\subsubsection{Unidades litoestratigráficas e sedimentação}

Discordâncias regionais permitem a divisão do registro sedimentar da Bacia do Paraná em seis unidades de ampla escala (Milani, 1997) ou Supersequências deposicionais, de acordo com os critérios propostos por Vail et al. (1977), sendo elas: Rio Ivaí, Paraná, Gondwana I, Gondwana II, Gondwana III e Bauru. As três primeiras representam ciclos transgressivos-regressivos paleozóicos e as restantes representam depósitos continentais mesozóicos com magmatismo associado (Milani et al., 2007a). Devido à sua expressiva extensão a Supersequência Gondwana I corresponde ao pacote de rochas cientificamente mais estudados da Bacia do Paraná. Em conformidade com o escopo deste trabalho, apenas será descrita uma síntese da Supersequência Gondwana I.

A Supersequência Gondwana I engloba o maior volume sedimentar da Bacia do Paraná (espessura máxima em torno de 2500 metros, Milani et al., 2007a), aflorando num cinturão quase contínuo, de São Paulo ao Uruguai, e de modo esparso e descontínuo nos estados de Mato Grosso, Goiás e no Paraguai (Petri \& Fúlfaro, 1983). Este volume de rochas inclui o Grupo Itararé e Formação Aquidauana, Grupo Guatá, Grupo Passa Dois e formações Pirambóia e Sanga do Cabral (Milani et al., 2007a).

A base da Supersequência Gondwana I é representada pelo Grupo Itararé e Formação Aquidauna, depositados sob influência da glaciação permocarbonífera que se desenvolveu na porção sul do Gondwana. Os depósitos deltaicos e marinhos pósglaciais do Grupo Guatá correspondem a um evento transgressivo (Petri \& Fúlfaro, 1983), onde a Formação Palermo registra a máxima inundação da Supersequência Gondwana I (Milani et al., 2007a). Os grupos Guatá e Passa Dois tem sido alvo de inúmeras pesquisas devido à presença de minério nos leitos de carvão da Formação Rio Bonito, das ocorrências de urânio também nessa unidade e do potencial petrolífero - tanto pela presença de rochas geradoras como de rochas reservatório - que estão incluídas no Grupo Passa Dois. O grupo Passa Dois constitui-se pela Formação Irati, anteriormente elevada à categoria de Subgrupo por Hachiro (1996), e pelas formações Serra Alta, Teresina, Rio do Rasto e Corumbataí (Schneider et al., 1974). No Grupo Passa Dois, a Formação Irati representa um episódio singular na evolução da bacia, pela restrita circulação de águas entre a sinéclise e o oceano Panthalassa, que acabou por desenvolver um contexto ambiental hipersalino na bacia. Sob tais condições, acumularam-se carbonatos e evaporitos na porção norte, e folhelhos oleígenos nas porções sul e norte da bacia. Os folhelhos da Formação Irati são caracterizados por querogênio tipo I, com teores de hidrogênio elevados e carbono orgânico variando entre 8 e $13 \%$ com picos de 24 \% (Araújo et al., 2000; Milani et al., 2007a). O seu conteúdo 
fossilífero é rico em fósseis répteis Mesosaurus brasilienses (Permiano), que constituiu um elemento crucial na correlação com a África do Sul (Formação Whitehill) e corrobora a teoria da deriva continental (Du Toit, 1937). Na sucessão sedimentar, segue-se a Formação Serra Alta, que é constituída por uma sequência de folhelhos e siltitos cinza escuros a pretos maciços pouco ricos em matéria orgânica, entre 0,1 a 0,4 \%, com baixo potencial para geração de hidrocarbonetos apesar da sua posição estratigráfica (Teixeira, 2014). Esta unidade, no centro sul do Estado de São Paulo, apresenta laminação heterolítica, muitas vezes seccionada por diques clásticos e fraturas preenchidas por calcita. Quando intemperizada pode apresentar coloração cinza clara a cinza esverdeada. O seu conteúdo fossilífero é representado por restos de peixes e palinomorfos, e a sua espessura, na borda leste da bacia, está compreendida entre 60 e 90 metros (Meglhioratti et al., 2005). A Formação Serra Alta representaria a última incursão marinha da bacia (Milani et al., 2007a). Schneider et al., (1974) caracterizam a Formação Teresina pela alternância de argilitos e folhelhos com siltitos e arenitos muito finos de coloração cinza clara. Na porção basal, ocorrem folhelhos cinza escuros. No topo, ocorrem calcários, por vezes oolíticos, e niveís de coquina. Laminações onduladas, fendas de ressecamento, marcas onduladas e diques de arenitos são citados como estruturas sedimentares típicas desta unidade. Relata-se ainda a ocorrência de estromatólitos nas camadas carbonáticas (Méndez, 2012). O conteúdo fossilífero da Formação Teresina torna-se relevante pela sua diversidade, representado, principalmente, por conchas de bivalves, ostracodes, estromatólitos, restos de peixes, espículas de esponjas, esporos e plantas fósseis, sendo dominado por organismos endêmicos com afinidade a ambientes de água doce ou salina (Holz et al., 2010). O contato da Formação Serra Alta com a Formação Teresina subjacente seria concordante (Schneider et al., 1974; Holz et al., 2010). Para Schneider et al., (1974), as formações Serra Alta e Teresina ocorrem do Rio Grande do Sul ao nordeste do Paraná. Almeida (1981) estendem a zona de ocorrência destas formações até ao centro-sul do Estado de São Paulo, onde as cores predominantemente cinzentas ou esverdeadas com que se apresentam no Paraná e na vizinhança de São Paulo passam a cores avermelhadas, características da Formação Corumbataí. As formações Teresina, Corumbataí e Rio do Rasto representam a fase inicial de continentalização da bacia por sistemas deposicionais costeiros de água rasa (Holz et al., 2010), associados a sistemas fluviais e eólicos representados pelos sedimentos da Formação Pirambóia (Giannini et al., 2004). Assim, a Supersequência Gondwana I representa um ciclo transgressivoregressivo, que tem início nos sistemas deposicionais glaciais, atinge condições de inundação marinha e que transiciona para fase progradacional marcada pela deposição de sistemas costeiros e continentais já no início do Mesozóico (Milani et al., 2007a). 
Em síntese, durante a sedimentação Paleozóica configurava, conjuntamente com a porção sul do continente africano, uma bacia interior na margem oeste do Gondwana. $\mathrm{Na}$ proximidade da passagem entre as eras Paleozóica e Mesozóica, a bacia encontrava-se em fase de subsidência durante a aglutinação do supercontinente Pangea. O expressivo episódio de magmatismo Eocretáceo da Formação Serra Geral marca o início da ruptura do Pangea. Sobre essas rochas magmáticas, rochas mesocenozóicas registram nova fase de deposição, durante a abertura do Atlântico, já sobre o continente sul-americano.

\subsubsection{Atividade tectônica e deformação Permo-Triássica}

O contexto tectônico das sequências estratigráficas, bem como os mecanismos de subsidência da sinéclise são temas controversos.

Zalán et al., (1990) defendem que a atividade tectônica na Bacia do Paraná, ao longo de sua evolução, foi controlada principalmente por reativações de estruturas preexistentes herdadas do embasamento. $O$ arcabouço estrutural é definido por zonas de fraqueza do embasamento de direção NE e NW.

Milani \& Ramos (1998) propõem que episódios de subsidência flexural, resultantes dos eventos compressivos das orogenias paleozóicas (ciclo Brasiliano) na margem sulocidental do Gondwana, são os responsáveis pela ciclicidade do preenchimento da Bacia do Paraná.

O Permo-triássico na Bacia do Paraná é caracterizado por um período de reativações em resposta à tectônica da Orogenia Cabo La Ventana (Riccomini, 1995; Rostirolla et al., 2000).

Soares (1991) destaca o fim do Permiano e o Eotriássico como um período de atividade tectônica compressiva, geradora de falhas inversas, falhas transcorrentes, soerguimento e erosão. O mesmo autor associa esse período à colisão da Patagônia com o Gondwana, sendo responsável pela deformação nas Sierras La Ventana na Argentina.

Strugale et al., (2003) descrevem deformações predominantemente compressivas, como dobras e empurrões com feições locais de escorregamento e convoluções contemporâneas à Formação Rio do Rasto na Serra do Cadeado, no Estado do Paraná. A deformação é de idade neopermiana a eotriássica e relacionada à compressão do Cinturão Cabo-La Ventana.

A atividade tectônica sin-sedimentar no Permiano superior permanece visível em afloramentos da Formação Serra Alta, devido à ocorrência de enxame de diques clásticos, no município de Cesário Lange (Teixeira, 2014) e no Permotriássico na 
Formação Corumbataí no interior de São Paulo, região de Rio Claro-Piracicaba (Riccomini et al., 2005; Turra et al., 2006). Turra et al. (2006), revelam através de análise estrutural da orientação dos diques que o esforço horizontal máximo, de direção entre NNW e NE, seria compatível com a compressão do Cinturão Cabo-La Ventana. Esse período de atividade sísmica sin-sedimentar durante o Permotriássico é associado à reativação, transcorrente sinistral, da Zona de Cisalhamento Jacutinga (Riccomini et al., 2005).

\subsubsection{Potencial de geração de hidrocarbonetos}

A Bacia do Paraná compreende dois sistemas petrolíferos convencionais (Demaison \& Huizinga 1994) definidos como: Sistema Petrolífero Ponta Grossa Itararé/Rio Bonito (SPPGI), de idade Devoniana, e o Sistema Petrolífero IratiPirambóia/Rio Bonito (SPIP) de idade Permiana (Milani et al., 2007a). No entanto, o folhelho oleígeno da Formação Irati também é considerado como um emergente sistema petrolífero não convencional (EIA/ARI, 2013). No Permiano, a Formação Irati (unidade geradora do SPIP) apresenta teores de matéria orgânica distintos a norte e a sul do Arco de Ponta Grossa (APG). A Norte, a Formação Irati apresenta-se como uma intercalação de folhelho e calcário (ritmitos) sendo que os valores variam entre 0,80 a 1,82 \%. A Sul, a formação é restrita a folhelhos oleígenos com valores de carbono orgânico total variando entre 2,08 a 17,41\%, com alguns picos de até $24 \%$ (Araújo et al., 2000).

A presença de óleo no folhelho da Formação Irati, comumente associado a porções carbonáticas, é correlacionada aos eventos magmáticos da Formação Serra Geral (Araújo et al., 2000). Essas evidências são muitas vezes encontradas sob a forma de exudações de óleo viscoso biodegradado (Araújo et al., 2000) em fácies carbonática da Formação Irati e nos arenitos asfálticos da Formação Pirambóia (reservatório), no centro leste do Estado de São Paulo.

A Formação Serra Alta, sobrejacente à Formação Irati, contém menos de $0,5 \%$ de COT o que corresponde a um baixo potencial de geração (Teixeira et al., 2018); contudo dados de cromatografia gasosa em folhelhos da Formação Serra Alta, no Estado de São Paulo, demonstram potencial (ainda que baixo) para a geração de hidrocarbonetos $\left(\mathrm{CH}_{4}\right)$ na área estudada (Teixeira et al., 2018). Embora a Formação Serra Alta contenha baixo teor de COT, análises de inclusões fluidas mostram temperaturas de homogeneização superiores a $220^{\circ} \mathrm{C}$, permitindo inferir que se encontra em um estágio de maturação térmica elevado devido à circulação pervasiva de fluidos diagenéticos, possivelmente aquecidos pela espessa capa de basaltos associados à Formação Serra Geral (Teixeira et al., 2018). 


\subsubsection{Paleofluidos no contexto tectónico}

A atividade ígnea e eventos geológicos incomuns, como o impacto da cratera de Araguaínha, que atingiu a porção norte da Bacia do Paraná no Permo-triássico (Tohver et al., 2012), tiveram influência diferenciada no desenvolvimento do sistema hidrotermal (Nomura, 2012) e na preservação dos sistemas petrolíferos da bacia (Artur \& Soares, 2002). Esta atividade influenciou positivamente o sistema petrolífero por fornecer energia termal para a maturação da matéria orgânica e circulação de fluidos profundos, pela produção de reservatórios fraturados e pela formação de estruturas de aprisionamento. Simultaneamente, essas atividades provocaram o fraturamento das rochas selantes e estruturas trapeadoras que permitiram a percolação de fluidos subsuperficiais até ao interior da bacia (Artur \& Soares, 2002).

Na Bacia do Paraná, a circulação de paleofluidos seria favorecida durante os períodos de geração ou reativação de falhas profundas (Nomura, 2012). Neste caso, destaca-se a reativação de falhas da Bacia do Paraná durante o Permiano tardio (Rostirolla et al., 2000; Riccomini et al., 2005), Eocretáceo e Neocretáceo-Terciário (Strugale et al., 2007). No final do Permiano existe predomínio de estruturas tectônicas de direção preferencial NW.

Os lineamentos de Guapiara (NW) e Rio Paranapanema (W-E) (Zalán et al., 1987), as falhas da Jacutinga (NE) e Pitanga (NE) (Soares, 1991), e os altos estruturais de Anhembi, Morro do Bofete e Pitanga (Ipeúna) (Zalán et al., 1990) são as principais estruturas que delimitam o arcabouço estrutural da bacia na área de estudo. Neste contexto, nos afloramentos estudados no Estado de São Paulo, o lineamento de Mojiguaçu (Limeira), a falha de Jacutinga NNE a NE (Charqueada e Ipeúna) e estruturas subordinadas associadas a falhas regionais de direção NNW a NW, como o lineamento de Guapiara (Piraju), seriam as faixas estruturais regionais capacitadas para fomentar os caminhos de circulação e migração de paleofluidos em escala regional na borda leste da Bacia do Paraná.

\subsection{Províncias ígneas (LIP's) no contexto de bacias cratônicas}

Províncias ígneas, comumente designadas por LIP - "large igneous province", manifestam grandes volumes de rochas extrusivas máficas ricas em $\mathrm{Fe}$ e $\mathrm{Mg}$ e um grande número de derrames basálticos continentais (Continental flood basalts), originados a partir de processos magmáticos (Coffin et al., 2006).

Pesquisas realizadas nas últimas décadas sobre eventos magmáticos presentes em bacias sedimentares durante o Fanerozóico (Araújo et al., 2000; Aarnes et al., 2010; 
Ernst \& Youbi, 2017; Liu et al., 2017), têm discutido duas vertentes geológicas de vital importância: i) o papel do magmatismo no craqueamento térmico e consequentemente geração e exploração de hidrocarbonetos em bacias sedimentares; ii) a associação de LIP's a episódios de extinção em massa, devido à geração/liberação de gases efeito estufa através de processos de desgaseificação e metamorfismo de contato em rochas sedimentares.

Bacias cratônicas afetadas por LIP's apresentam evolução térmica e diagenética diferenciadas, o que torna os seus sistemas petrolíferos atípicos. O efeito térmico do magmatismo, que influencia a ocorrência de paleofluidos diagenéticos e hidrocarbonetos, é relatado em bacias cratônicas mundiais como, por exemplo, a Bacia Neuquén na Argentina (Monreal et al., 2009), a Bacia de Illinois (Stewart et al., 2005; Mastalerz et al., 2009) nos EUA, a Bacia Tunguska (Kontorovich et al., 1997) na Rússia, a Bacia Sichuan (Zhu et al., 2010) na China, a Bacia Gunnedah (Salmachi et al., 2016) na Austrália e na Bacia Karoo (Brown et al., 1998; Smithard et al., 2015) na porção SW Africana. No continente Sul-Americano a Bacia do Amazonas (Gonzaga et al., 2000), a Bacia do Solimões (Milani et al., 2007a) e a Bacia do Parnaíba (Thomaz-Filho et al., 2008) são as referências. Contudo, é na Bacia do Paraná em território brasileiro que se destaca uma das maiores províncias ígneas não oceânicas do planeta (LIP Paraná), com área aproximada de 1 milhão de $\mathrm{Km}^{2}$ abrangendo toda a região centro-sul do Brasil estendendo-se ao longo das fronteiras do Paraguai, Uruguai e Argentina (Janasi et al., 2011). Contabilizando as rochas ígneas correlatas na porção SW Africana (LIP ParanáEtendeka) a área estimada para toda a sequência de lavas expostas é de 1,2 milhões de $\mathrm{Km}^{2}$ (Rossetti et al., 2017). Esse evento é representado por uma espessa cobertura de lavas, um conjunto de diques cortando a inteira seção sedimentar e diversos níveis de soleiras intrudidas de modo concordante às camadas dos sedimentos paleozóicos. Atualmente, cerca de três quartos da área total da bacia estão recobertos pelas rochas ígneas da Formação Serra Geral (Milani et al., 2007a).

Por outro lado, grandes províncias ígneas têm sido comumente associadas a grandes perturbações globais no ciclo de carbono devido às grandes flutuações na assinatura isotópica de $\delta^{13} \mathrm{C}$ em função da liberação de gases efeito estufa $\left(\mathrm{CO}_{2}\right.$ e $\left.\mathrm{CH}_{4}\right)$ diretamente para a atmosfera. Esta liberação forte de gases para a atmosfera poderia contribuir para as grandes extinções em massa que ocorreram no final do Permiano e no início do Cretáceo (Black et al., 2012; Callegaro et al., 2014; Ernst \& Youbi, 2017; Rahman et al., 2018). A atividade intrusiva em rochas sedimentares (geradoras ou reservatório) também pode causar o rápido aquecimento e consequente geração/liberação de hidrocarbonetos por desgaseificação e/ou metamorfismo de contato. Estima-se que vários milhares de gigatoneladas de metano $\left(\mathrm{CH}_{4}\right)$ podem ser 
gerados durante a intrusão de corpos ígneos e metamorfismo de contato causando a liberação de gases efeito estufa (Svensen et al., 2009; Aarnes et al., 2010). Entre as maiores e mais importantes LIP's do planeta, alvos de estudos ambientais, destacamse a LIP Emeishan na China (Coffin et al., 2006), as Trapps Siberianas na Rússia (Retallack \& Jahren, 2008; Svensen et al., 2009), a LIP do Atlântico Central (Heimdal et al., 2018) e a LIP de Karoo na África do Sul (Svensen et al., 2006), correlata com a LIP Paraná na Bacia do Paraná, no sudeste do Brasil (Peate et al., 1992; Peate 1997).

\subsubsection{A Formação Serra Geral e o magmatismo Eocretáceo}

A primeira referência na literatura geológica às rochas vulcânicas da Formação Serra Geral foi no trabalho de White (1908) em uma das primeiras descrições estratigráficas da Bacia do Paraná. Posteriormente, no trabalho de Gordon Jr. (1947), a denominação Formação Serra Geral ganhou preponderância, sendo caracterizada por rochas vulcânicas extrusivas com intercalações de arenitos eólicos. Apesar de ocorrem intercalações entre os basaltos da Formação Serra Geral e os arenitos da Formação Pirambóia, Gordon Jr. (1947) descreve o contato entre as duas unidades como discordante. Considera-se que a Formação Serra Geral estaria relacionada ao vulcanismo fissural (derrames basálticos) que ocorreu durante a quebra do continente Gondwana (plataforma Sul Americana-África) e abertura do Oceano Atlântico Sul no Eocretáceo (Zalán et al., 1990). Alguns autores estudaram composições da sequência de lavas na Bacia do Paraná, sugerindo divisão das mesmas de acordo com a sua composição química e mineralógica (Janasi et al., 2007). A sequência basal e mais antiga de derrames da Formação Serra Geral na porção centro sul (Região de Porto Alegre) é empobrecida em $\mathrm{TiO}_{2},(<2 \%)$, denominados magmas de Gramado e Esmeralda, precedida por dacitos e riolitos associados, igualmente empobrecidos em $\mathrm{TiO}_{2}$ (vulcânicas de Palmas), enquanto que na porção centro norte (Região de Ourinhos - São Paulo), uma nova sequência de basaltos ricos em $\mathrm{TiO}_{2}(\geq 3 \%)$, denominados magmas de Pitanga e Paranapanema, completa o topo da sucessão (Peate et al., 1992; Peate, 1997). Em geral, as rochas magmáticas da Província Paraná apresentam composição bimodal, cerca de $90 \%$ de caráter composicional básico e apenas 2,5\% é representado por rochas de caráter ácido (Nardy et al., 2002).

Estimativa de idades e duração do magmatismo Serra Geral tem sido baseadas em datações radiométricas ${ }^{40} \mathrm{Ar} /{ }^{39} \mathrm{Ar}$ em rochas magmáticas dessa formação. Bueno et al. (2007), consideram um intervalo de idade compreendido entre 137-127 Ma. Stewart et al. (1996) obtiveram, em rochas ácidas e básicas de diferentes regiões da província Paraná, idades compreendidas entre 138-127 Ma, sugerindo um intervalo de 11 Ma para 
o magmatismo Serra Geral. Contudo, idades Ar-Ar combinadas com dados paleomagnéticos indicam duração menor que $2 \mathrm{Ma}$ (Renne et al., 1996). Apesar da falta de controle estratigráfico na coleta de amostras, Thiede \& Vasconcelos (2010), obtiveram, a partir das amostras de Stewart et al. (1996), idades ${ }^{39} \mathrm{Ar} /{ }^{40} \mathrm{Ar}$ versus ${ }^{36} \mathrm{Ar} /{ }^{40} \mathrm{Ar}$ entre $134,4 \pm 1,1 \mathrm{Ma}$ e $134,8 \pm 0,8 \mathrm{Ma}$, sugerindo idade Eocretácea e o início do magmatismo com duração de 1 milhão de anos. As datações U-Pb em zircão obtidas por SHRIMP disponíveis na literatura apontam para uma média de idades de 134,5 Ma (Pinto et al., 2010), bem próxima à média dos dados $\operatorname{Ar} / \mathrm{Ar}, 133,2 \pm 4,4 \mathrm{Ma}$ obtida nos trabalhos acima citados. A análise conjunta destes dados sugere que o evento magmático responsável pela formação da província magmática da Bacia do Paraná, assim como unidades correlatas nas bacias marginais brasileiras, é um evento Eocretáceo com idade de $134 \mathrm{Ma}$ aproximadamente e duração inferior a 2 Ma (Thiede \& Vasconcelos, 2010).

\subsubsection{Magmatismo, maturidade térmica e geração de hidrocarbonetos}

A atividade vulcânica proporciona um efeito catalisador e energia térmica importantes para a transformação e evolução da matéria orgânica em hidrocarbonetos. O efeito térmico da atividade vulcânica pode apresentar dupla função no processo de geração de hidrocarbonetos, no sentido de acelerar a maturação de rochas geradoras imaturas tornando-as maturas (Fjeldskaar et al., 2008), ou, por outro lado, tornando uma rocha matura em super matura destruindo todo potencial gerador de hidrocarbonetos, incluindo acumulações de óleo ou gás (Zhou et al., 2007). Pirita, zeólitas e olivinas vulcanogênicas podem servir como catalisadores na transformação de matéria orgânica em hidrocarbonetos (Wan et al, 2001). Rochas intrusivas também desempenham papel importante na transformação e evolução de matéria orgânica em rochas sedimentares. Estudos na Bacia de Illinois elaborados por Schimmelmann et al. (2009) mostram que valores de reflectância de vitrinita (Ro) aumentam de 0,62 a 5,03\% em um limite de 5 metros de proximidade da unidade de carvão a um corpo ígneo intrusivo de grande dimensão, enquanto para um corpo intrusivo menor os valores de Ro aumentam de 0,63 a 3,71 \% tendo como limite apenas 1 metro. George (1992) demonstra que essa intrusão poderia fazer aumentar os valores de Ro de 0,55 para 6,55 \% quando estudou a maturidade térmica do folhelho de Scottish Midland Valley, assumindo que o efeito térmico, induzido por determinado corpo ígneo, em rochas geradoras ricas em matéria orgânica depende fortemente do tamanho do próprio corpo ígneo. Hurter \& Pollack (1994) propuseram um modelo que explica o efeito térmico de derrames basálticos e soleiras associados ao magmatismo Serra Geral em rochas sedimentares adjacentes. 
De acordo com esse modelo, rochas sedimentares depositadas aproximadamente $1 \mathrm{~km}$ abaixo da capa de derrames basálticos com 900 m de espessura alcançam temperatura máxima de aproximadamente $200{ }^{\circ} \mathrm{C}$ após quinze mil anos, considerando uma temperatura superficial de $20^{\circ} \mathrm{C}$ e gradiente geotérmico de $26^{\circ} \mathrm{C} / \mathrm{km}$. Como o efeito térmico de sill e diques é caracterizado por picos de altas temperaturas dentro da zona intrudida, a temperatura máxima alcançada pelas rochas sedimentares, localizadas aproximadamente a $100 \mathrm{~m}$ de uma sucessão formada por 10 soleiras com 1 a $12 \mathrm{~m}$ de espessura, é cerca de $75^{\circ} \mathrm{C}$ (Hurter \& Pollack, 1994). Esta temperatura é alcançada por volta de cem anos após as intrusões. Deste modo, o aquecimento devido às intrusões compreende um intervalo de tempo de centenas de anos enquanto que o aquecimento influenciado pelo efeito da capa de basalto abrange centenas a milhares de anos. Naturalmente, o incremento de temperatura causado pelos derrames ou soleiras se tornará exponencialmente menor com o decorrer do tempo até se tornar insignificante depois de períodos de centenas a milhares de anos.

Fluidos hidrotermais contém muitos metais de transição, tais como, $\mathrm{Ni}, \mathrm{Co}, \mathrm{Cu}$, $\mathrm{Mn}, \mathrm{Zn}, \mathrm{Ti}, \mathrm{V}$, entre outros. Metais de transição constituem bons catalisadores para a degradação de matéria orgânica (Reuter \& Perdue, 1977; Mango, 1992). Na Bacia do Paraná, a existência de processos hidrotermais relacionados ao magmatismo Serra Geral é amplamente reconhecida (De Ros, 1998; Sant'Anna et al., 2006; Costa, 2006; Duarte et al., 2009; Nomura et al., 2014). Com base em estudo de minerais autigênicos, Sant'Anna et al. (2006) argumentam que toda a sucessão permiana da bacia foi afetada por um evento hidrotermal simultâneo ao magmatismo Serra Geral. O grau de transformação da esmectita em ilita indica paleotemperaturas entre 100 e $150{ }^{\circ} \mathrm{C}$ para as unidades permianas da borda leste da Bacia do Paraná e idades obtidas pelo método K-Ar em ilita (140-130 Ma) indicam que essas temperaturas ocorreram durante o Eocretáceo (Sant'Anna et al., 2006). Costa (2006) descreve a ocorrência de veios de quartzo e carbonatos em fraturas sub-verticais que cortam siltitos da Formação Corumbataí em Rio Claro (SP), os quais seriam produto de hidrotermalismo ligado ao magmatismo Serra Geral. De Ros (1998), interpreta a circulação de fluidos quentes através de fraturas relacionadas ao magmatismo Serra Geral e ao soerguimento do Arco de Ponta Grossa. Esta hipótese é sustentada pela presença de ilita diagenética com idades similares ao do magmatismo Serra Geral nos arenitos devonianos da Formação Furnas (Devoniano). A temperatura do magma pode ultrapassar os $1000^{\circ} \mathrm{C}$ e os fluidos hidrotermais associados podem exceder os $350^{\circ} \mathrm{C}$ tornando-se portadores de elevada energia térmica o que faz acelerar a maturidade da rocha geradora (Liu \& Meng, 2009). 
CAPÍTULO 3 


\section{CAPÍTULO 3}

\section{MATERIAIS E MÉTODOS}

\subsection{Levantamento de seções geológicas e amostragem}

As atividades de campo ocorreram no centro leste do Estado de São Paulo e no centro sul do Estado do Paraná, na borda leste da Bacia do Paraná. Os afloramentos estudados compreendem os municípios de Limeira, Saltinho, Paraisolândia (Charqueada), Rio Claro, Ipeúna, Anhembi e Piraju em São Paulo e Ponta Grossa e São Mateus do Sul no Paraná (Figura 3.1A e B). Todos os pontos de coleta foram efetuados em afloramentos de corte de estrada e em pedreiras (ativas e inativas) e foram selecionados com vista ao reconhecimento e caracterização das formações geológicas, incluindo o pacote de rochas do Grupo Passa Dois (formações Irati, Serra Alta e Corumbataí), e as rochas pertencentes à Formação Serra Geral (Eocretáceo), assim como corpos intrusivos associados. Vale ressalvar que a escolha dos pontos teve ainda em atenção a qualidade dos afloramentos, sua exposição e baixo grau de meteorização.

A Tabela 3.1 resume os pontos de amostragem (unidade geológica, localização, coordenadas, código e tipo de amostragem) e principais características macroscópicas dos afloramentos, com destaque para os afloramentos das formações Irati, Serra Alta, Corumbataí e Serra Geral.

Nos afloramentos estudados, foram ainda realizadas descrições de ocorrências de minerais autigênicos, observação de feições pós-deposicionais, como cimento carbonático $\left(\mathrm{CaCO}_{3}\right)$, reconhecimento de diques de diabásio, soleiras de basalto e fraturas com minerais de preenchimento, principalmente veios de calcita e quartzo. Medidas de direção, mergulho e espaçamento de fraturas preenchidas por minerais autigênicos foram tomadas para contextualização geológica regional.

Amostras de minerais de preenchimento de fraturas (calcita e quartzo) foram utilizadas para descrição petrográfica de luz transmitida e luz ultravioleta, constituindo objeto de estudo de inclusões fluidas. Amostras de veios de calcita também foram selecionadas para análise de isótopos estáveis de carbono e oxigênio. As direções de veios que preenchem fraturas e veios hospedados em sill serão apresentadas em estereogramas polares. 
Tabela 3.1. Informações sobre afloramentos amostrados, unidades geológicas, localização geográfica, códigos das amostras e método aplicado. Datum de coordenadas: SAT69.

\begin{tabular}{|c|c|c|c|c|c|c|c|}
\hline Formação & Estado & Município & $\begin{array}{c}\text { Coordenadas } \\
\text { GMS }\end{array}$ & $\begin{array}{l}\text { Código de } \\
\text { amostra }\end{array}$ & $\begin{array}{c}\text { Rocha } \\
\text { encaixante }\end{array}$ & Amostra & $\begin{array}{l}\text { Método } \\
\text { aplicado }\end{array}$ \\
\hline \multirow{8}{*}{ Irati } & \multirow{4}{*}{$\begin{array}{c}\text { São } \\
\text { Paulo }\end{array}$} & $\begin{array}{l}\text { Limeira / Rio } \\
\text { Claro }\end{array}$ & $\begin{array}{l}22^{\circ} 32^{\prime} 40^{\prime \prime} \mathrm{S} \\
47^{\circ} 26^{\prime} 42^{\prime \prime} \mathrm{W}\end{array}$ & calcite-01 & Folhelho & \multirow{4}{*}{ Veio } & \multirow{4}{*}{$\begin{array}{l}\text { Inclusões } \\
\text { fluidas / } \\
\text { Confocal }\end{array}$} \\
\hline & & Paraisolândia & $\begin{array}{l}22^{\circ} 31^{\prime} 45^{\prime \prime} \mathrm{S} \\
47^{\circ} 42^{\prime} 54^{\prime \prime} \mathrm{W}\end{array}$ & quartz-02 & Calcário & & \\
\hline & & Paraisolândia & $\begin{array}{l}22^{\circ} 31^{\prime} 30^{\prime \prime} \mathrm{S} \\
47^{\circ} 34^{\prime} 50^{\prime \prime} \mathrm{W}\end{array}$ & calcite-03 & Calcário & & \\
\hline & & Paraisolândia & $\begin{array}{l}22^{\circ} 31^{\prime} 59^{\prime \prime} \mathrm{S} \\
47^{\circ} 42^{\prime} 38^{\prime \prime} \mathrm{W}\end{array}$ & quartz-04 & Calcário & & \\
\hline & \multirow{4}{*}{ Paraná } & \multirow{4}{*}{$\begin{array}{c}\text { São Mateus do } \\
\text { Sul }\end{array}$} & $\begin{array}{l}25^{\circ} 53^{\prime} 36^{\prime \prime} \mathrm{S} \\
50^{\circ} 42^{\prime} 23^{\prime \prime} \mathrm{W}\end{array}$ & IR-07 & Folhelho & \multirow{4}{*}{$\begin{array}{l}\text { Rocha } \\
\text { Total }\end{array}$} & \multirow{4}{*}{$\begin{array}{c}\text { Reflectância } \\
\text { de vitrinita / } \\
\text { Ressonância } \\
\text { magnética } \\
\text { nuclear }\end{array}$} \\
\hline & & & $\begin{array}{l}25^{\circ} 49^{\prime} 34^{\prime \prime} \mathrm{S} \\
50^{\circ} 24^{\prime} 52^{\prime \prime} \mathrm{W}\end{array}$ & IR-08 & Folhelho & & \\
\hline & & & $\begin{array}{l}25^{\circ} 47^{\prime} 38^{\prime \prime} \mathrm{S} \\
50^{\circ} 25^{\prime} 30^{\prime \prime} \mathrm{W}\end{array}$ & IR-09 & Folhelho & & \\
\hline & & & $\begin{array}{l}25^{\circ} 47^{\prime}, 12^{\prime \prime} \mathrm{S} \\
50^{\circ} 25^{\prime} 58^{\prime \prime} \mathrm{W}\end{array}$ & IR-10 & Folhelho & & \\
\hline \multirow{2}{*}{ Serra Alta } & \multirow{4}{*}{$\begin{array}{c}\text { São } \\
\text { Paulo }\end{array}$} & Porangaba / & $\begin{array}{l}23^{\circ} 14^{\prime} 20^{\prime \prime} \mathrm{S} \\
48^{\circ} 06^{\prime} 59^{\prime \prime} \mathrm{W}\end{array}$ & IR-05 & Folholho & Voin & $\begin{array}{l}\text { Inclusões } \\
\text { fluidas / }\end{array}$ \\
\hline & & $\begin{array}{l}\text { Laranjal } \\
\text { Paulista }\end{array}$ & $\begin{array}{l}23^{\circ} 14^{\prime} 32^{\prime \prime} \mathrm{S} \\
48^{\circ} 06^{\prime} 09^{\prime \prime} \mathrm{W} \\
\end{array}$ & IR-06 & rolnelno & Velo & $\begin{array}{l}\text { Isótopos } \\
\text { estáveis }\end{array}$ \\
\hline Corumbataí & & Ipeúna & $\begin{array}{l}22^{\circ} 25^{\prime} 03^{\prime \prime} \mathrm{S} \\
47^{\circ} 42^{\prime} 50^{\prime \prime} \mathrm{W}\end{array}$ & CB-01 & Folhelho & Veio & $\begin{array}{l}\text { Inclusões } \\
\text { fluidas }\end{array}$ \\
\hline \multirow{2}{*}{ Serra Geral } & & $\begin{array}{l}\text { Piraju / } \\
\text { Ourinhos }\end{array}$ & $\begin{array}{l}23^{\circ} 11^{\prime} 10^{\prime \prime} \mathrm{S} \\
49^{\circ} 22^{\prime} 46^{\prime \prime} \mathrm{W}\end{array}$ & SG-01 & $\begin{array}{l}\text { Capa de } \\
\text { Basalto }\end{array}$ & Veio & \multirow{2}{*}{$\begin{array}{l}\text { Inclusões } \\
\text { fluidas / } \\
\text { Isótopos } \\
\text { estáveis }\end{array}$} \\
\hline & Paraná & Ponta Grossa & $\begin{array}{c}25^{\circ} 1 \text { ' } 33 \text { "'S } \\
50^{\circ} 18^{\prime} 53^{\prime \prime} \mathrm{W}\end{array}$ & SLIP-02 & $\begin{array}{c}\text { Sill } \\
\text { (associado à } \\
\text { LIP Paraná) }\end{array}$ & Veio & \\
\hline
\end{tabular}




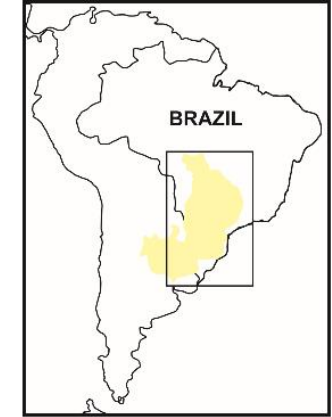
Parań Basin
Gondwana I Supersequence \ Microthermometric points 1 Jacutinga fautt 2 Tiéte lineament

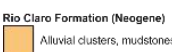

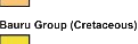

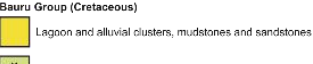

प

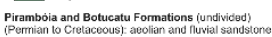
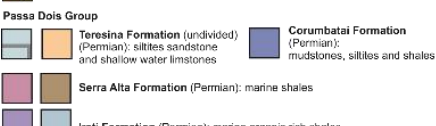

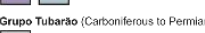

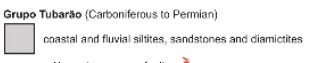

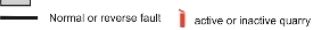

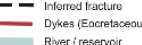
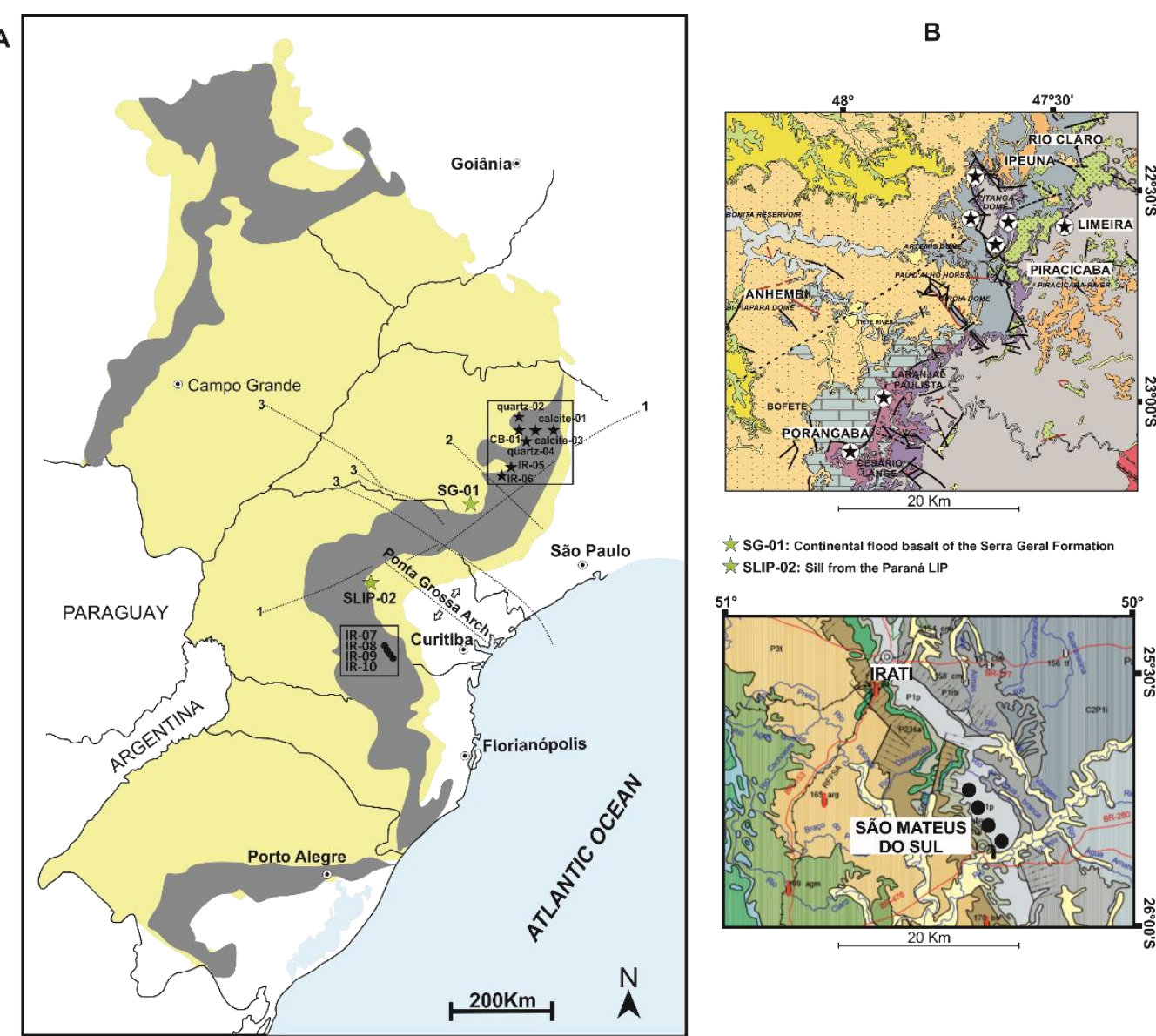

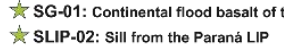
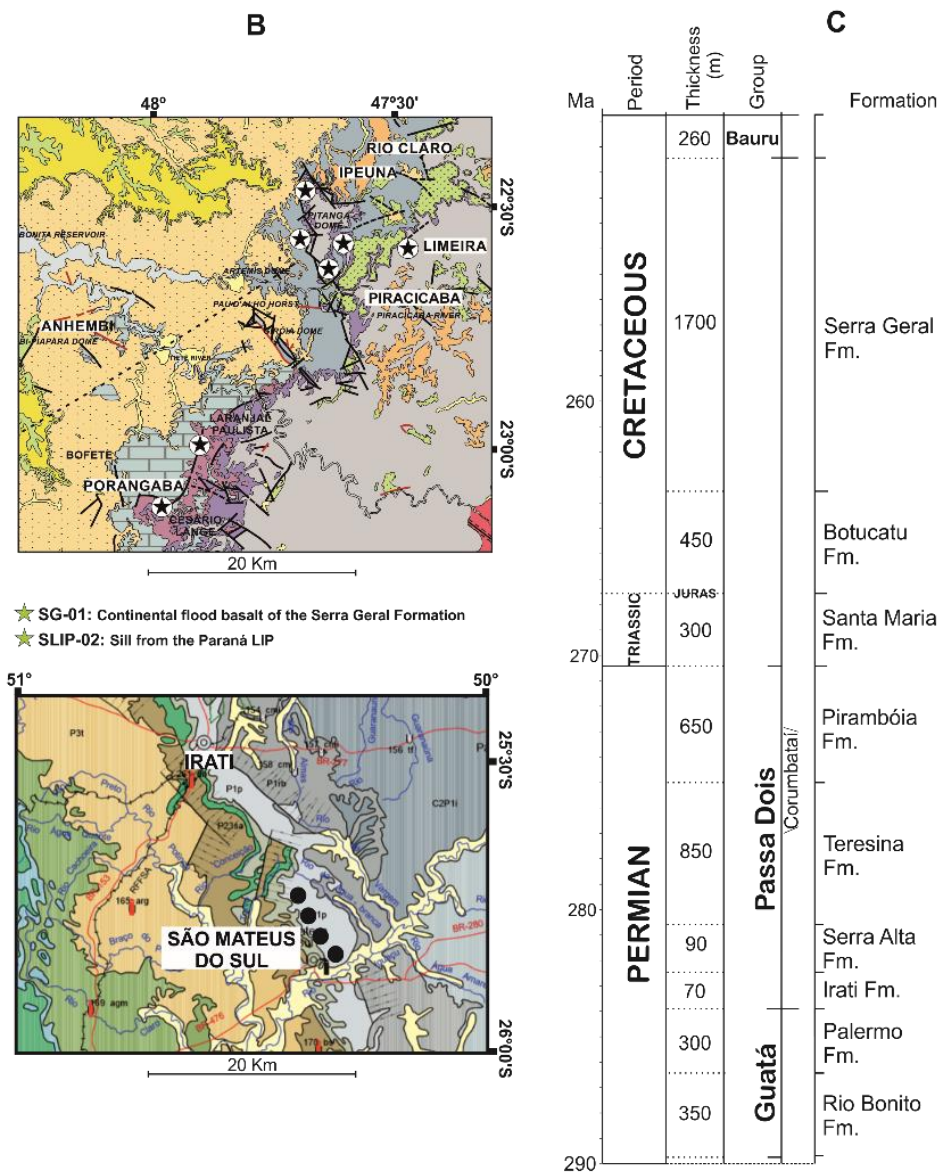

Samples

SG-01

SLIP-02

(1)

$\star$ IR-05/06

$\begin{array}{ll}\star & 01 / 02 / 03 / 04 \\ \text { IR-07/08/09/10 } & \end{array}$

$300 \mathrm{~m}$

Figura 3.1. (A) Contexto regional da Bacia do Paraná na plataforma Sul-Americana. (B) Mapas geológicos das áreas de estudo (Estado de São Paulo e Estado do Paraná). Modificado dos mapas geológicos de São Paulo e Paraná, escala 1:500.000 (IPT, 1981). (C) Coluna cronoestratigráfica da sequência sedimentar do Permiano ao Cretáceo da Bacia do Paraná, código de amostras das unidades geológicas estudadas e tipo de análise realizada. 


\subsection{Análises químicas do teor de carbono orgânico total (COT) e hidrogênio $(\mathrm{H})$}

O processo de preparação das amostras de folhelhos das formações Irati e Serra Alta consistiu nas etapas de fragmentação mecânica, pulverização para tamanhos específicos e ataque com ácido clorídrico para libertação do carbono inorgânico presente.

A fragmentação foi realizada com auxílio de prensa hidráulica e a pulverização foi efetuada no moinho de anéis para obtenção de granulometria aproximada de 0,004 mm (200\#). As amostras que se apresentavam úmidas foram previamente moídas no almofariz de mão e colocadas em estufa de secagem e esterilização (Modelo 315SE) a $60 \stackrel{\circ}{ } \mathrm{C}$ por um período de 24 horas. Após a pulverização, foram coletadas $10 \mathrm{~g}$ de cada amostra onde se atacou com $100 \mathrm{ml}$ de ácido clorídrico a $10 \%$ durante 24 horas. Posteriormente, o material foi filtrado com água destilada e seco em estufa a uma temperatura de $50{ }^{\circ} \mathrm{C}$ durante 48 horas. Este processo permitiu a obtenção/eliminação dos teores de carbono inorgânico, calculados pela diferença do peso inicial (10 g) e a pesagem do mesmo material depois de sujeito ao ataque com ácido clorídrico, limpeza com água destilada, filtração e secagem. Do total de material obtido anteriormente, foi separado aproximadamente $1,5 \mathrm{~g}$ que foi encaminhado à Central Analítica do Instituto de Química da Universidade de São Paulo para a realização das análises elementares. O equipamento utilizado na central analítica para determinação do teor de COT e hidrogênio foi o CHN 2400 Perkin-Elmer.

A fragmentação mecânica e a pulverização das rochas foram efetuadas no Laboratório de Tratamento de Amostras do Instituto de Geociências na Universidade de São Paulo e a etapa de ataque das amostras com ácido clorídrico foi realizada no Laboratório de Sedimentologia do Instituto de Geociências na Universidade de São Paulo. No total foram adquiridos dados de COT e de hidrogênio em amostras de folhelhos da Formação Irati e Formação Serra Alta.

\subsection{Análises de isótopos estáveis de carbono (C) e oxigênio (O)}

As análises de isótopos estáveis de carbono e oxigênio foram realizadas em amostras de veios de calcita nas formações Irati, Serra Alta, Teresina (contextualização), veios de calcita em sill associado ao magmatismo Eocretáceo (LIP Paraná) e os veios em basalto pertencentes à Formação Serra Geral. O material foi preparado no Laboratório de Sedimentologia do Instituto de Geociências na Universidade de São Paulo. Essa preparação foi dividida em duas etapas: a primeira 
passou pela britagem dos veios em almofariz de ágatas e a segunda teve como objetivo a catação manual de cristais de calcita com o auxílio de uma lupa estereoscópica de luz branca. Após esta preparação, as amostras foram encaminhadas para o Laboratório de Isótopos Estáveis no Centro de Pesquisas Geocronológicas do Instituto de Geociências na Universidade de São Paulo.

O equipamento utilizado foi um Espectrômetro de Massa de Razão Isotópica (IRMS, isotopic ratio mass spectrometer), modelo Delta $\mathrm{V}$ Advantage, acoplado a GasBench II - sistema para transferência de amostra para espectrômetro que permite análises por sistema de fluxo continuo (contínuos flow). A medição das razões de $\delta^{13} \mathrm{C}$ e $\delta^{18} \mathrm{O}$ é realizada pelo método de fluxo continuo através da reação com ácido fosfórico $\left(\mathrm{H}_{3} \mathrm{PO}_{4}\right)$. A precisão interna (desvio instrumental) indicada pelo fabricante para $\mathrm{o}$ equipamento utilizado é de $0,05 \%$ para $\delta^{13} \mathrm{C}$ e $0,07 \%$ para $\delta^{18} \mathrm{O}$ e o erro estimado das análises é $<0,1 \%$, conforme indicado na rotina replicada com os padrões internos.

Os valores de $\delta^{13} \mathrm{C}$ e $\delta^{18} \mathrm{O}$ foram normalizados em relação ao padrão internacional Vienna Pee Dee Belemnite (VPDB). O padrão PDB original refere-se ao fóssil belemnite da Formação Pee Dee, do Cretáceo, localizada no Estado de Carolina do Sul, EUA.

\subsection{Estudo de inclusões fluidas 3.4.1. Microscopia óptica}

A petrografia realizada neste método contempla a descrição de dezoito seções delgadas bipolidas com espessuras entre 100 e $120 \mu \mathrm{m}$. Essas seções correspondem a veios diagenéticos que preenchem fraturas e que constantemente cortam o pacote de rochas sedimentares do permiano e as rochas da Formação Serra Geral do cretáceo.

O mapeamento de assembleias de inclusões fluidas consiste na observação e seleção dos melhores cristais hospedeiros que contêm maior número possível de inclusões fluidas aquosas e/ou de hidrocarbonetos, sendo documentado na forma de desenhos auxiliares e fotomicrografias para uma melhor descrição e escolha dessas regiões. Neste caso, a melhor região para estudo microtermométrico é aquela que contém entre 5 a 20 inclusões que apresentam características representativas das condições iniciais de aprisionamento. Suas dimensões devem permitir tanto a observação das mudanças de fase dos constituintes da inclusão como o registro das temperaturas durante os processos de aquecimento e resfriamento respetivamente. Ademais, as inclusões escolhidas não devem apresentar feições indicativas de processos de leakage, necking down ou crepitação que ocorrem após o aprisionamento.

A microscopia óptica por fluorescência ultravioleta foi a última etapa da petrografia realizada, porque primeiramente é importante conhecer quais as regiões que contêm 
inclusões fluidas aquosas (AqFl's) para depois se observar a presença de inclusões fluidas compostas por hidrocarbonetos (HCFl's) coexistentes. Como mencionado anteriormente, HCFl's tornam-se fluorescentes (fase líquida do óleo) com a incidência de luz ultravioleta, distinguindo-se assim de AqFl's ou aquo-carbônicas.

A descrição petrográfica, o mapeamento de inclusões fluidas aquosas e compostas por hidrocarbonetos e a microscopia óptica por fluorescência UV foram realizadas no laboratório de Petrografia Sedimentar do Instituto de Geociências da Universidade de São Paulo em um microscópio petrográfico marca Zeiss, modelo Axioplan 2, equipado com duas fontes de luz branca HAL 100 polarizada transmitida e refletida, uma fonte de luz ultravioleta HBO 100 e uma câmara Leica Qwin 550 TM , bem como o software de visualização e processamento de imagem Leica Qwin, devidamente acoplado a um computador convencional.

\subsubsection{Microtermometria}

Foram realizados ensaios microtermométricos em, aproximadamente, 900 inclusões fluidas contabilizando inclusões aquosas (AqFl's) e inclusões compostas por hidrocarbonetos (HCFl's), distribuídas pelas formações Irati e Serra Geral (Anexo II), Corumbataí e Serra Alta (Anexo I). Isso permitiu a aquisição de 143 Th de inclusões fluidas compostas por hidrocarbonetos e 114 Th de inclusões aquosas coexistentes na Formação Irati (Figura 4.5G). Ademais, permitiu a obtenção de 720 Th, 425 Te, 510 Tfg e 391 resultados de salinidade para inclusões fluidas aquosas (Tipo 1), distribuídas pelas formações Irati, Serra Alta e Serra Geral. Durante os ensaios microtermométricos foi utilizada uma platina modelo CHAIXMECA MTM 85 (Figura 3.2A) calibrada com padrões Merck MSP para altas temperaturas $\left(>40^{\circ} \mathrm{C}\right)$.

Para calibrações de baixas temperaturas foram utilizadas: a) amostra de quartzo de Calanda, da Suíça, com inclusões de $\mathrm{CO}_{2}$ puro com ponto triplo $(-56,6 \stackrel{\circ}{\circ})$; b) mercúrio, ponto de fusão $-38,86^{\circ} \mathrm{C}$; c) água pura, ponto de fusão $0 \stackrel{\circ}{ } \mathrm{C}$. Também foi feita calibração por meio dos padrões SYN FLINC (Synthetic Fluid Inclusions) para as seguintes temperaturas: a) -56,6 ํㅡ, Padrão 1: composição $75 \mathrm{~mol} \%$ de $\mathrm{H}_{2} \mathrm{O}$ e $25 \mathrm{~mol}$ $\%$ de $\mathrm{CO}_{2}$; b) $-21,2{ }^{\circ} \mathrm{C}$, Padrão 2: composição eutética do sistema $\mathrm{H}_{2} \mathrm{O}+\mathrm{NaCl}, \operatorname{com~23,2}$ $\%$ em peso de $\mathrm{NaCl}$; c) $-10,7 \stackrel{\circ}{\circ}$, Padrão 3: composição eutética do sistema $\mathrm{H}_{2} \mathrm{O}+\mathrm{KCl}$, com 19,6\% em peso de $\mathrm{KCl}$; d) 0,0 ${ }^{\circ} \mathrm{C}$ e $374,1^{\circ} \mathrm{C}$, Padrão 4: Água pura (ponto triplo e ponto crítico, respetivamente); e) $573,0 \stackrel{\circ}{ } \mathrm{C}$, Padrão 5: transição do quartzo a para o quartzo $\beta$.

Em amostras de calcita, realizaram-se primeiramente as medidas de aquecimento. Posteriormente foram realizadas as medidas de resfriamento para 
estimativas das temperaturas do ponto eutético e de fusão do gelo. Com o resfriamento, a expansão de volume devido à formação de gelo pode causar estiramento das paredes da inclusão, principalmente em minerais como a calcita, de dureza baixa e clivagem perfeita em várias direções. Isso pode causar um aumento do volume da fase vapor com o consequente acréscimo nas temperaturas de homogeneização, cujos resultados finais seriam errôneos.

Assim, através da interpretação dos dados obtidos pelo estudo microtermométrico, é possível determinar as características físico-químicas do fluido original. Estas características incluem composição, densidade, bem como, pressão e temperatura na época do aprisionamento; assim, se as inclusões fluidas são primárias, as condições de pressão e temperatura da formação do próprio mineral ou da rocha podem ser determinadas (Roedder, 1984; Shepherd et al. 1985; Bello, 1996).

A microtermometria foi realizada no Laboratório de Inclusões Fluidas do Núcleo de Apoio à Pesquisa Geoanalítica do instituto de Geociências da Universidade de São Paulo, em um microscópio petrográfico de luz transmitida, marca Leitz (Alemanha) e modelo Wetzlar (Figura 3.2).
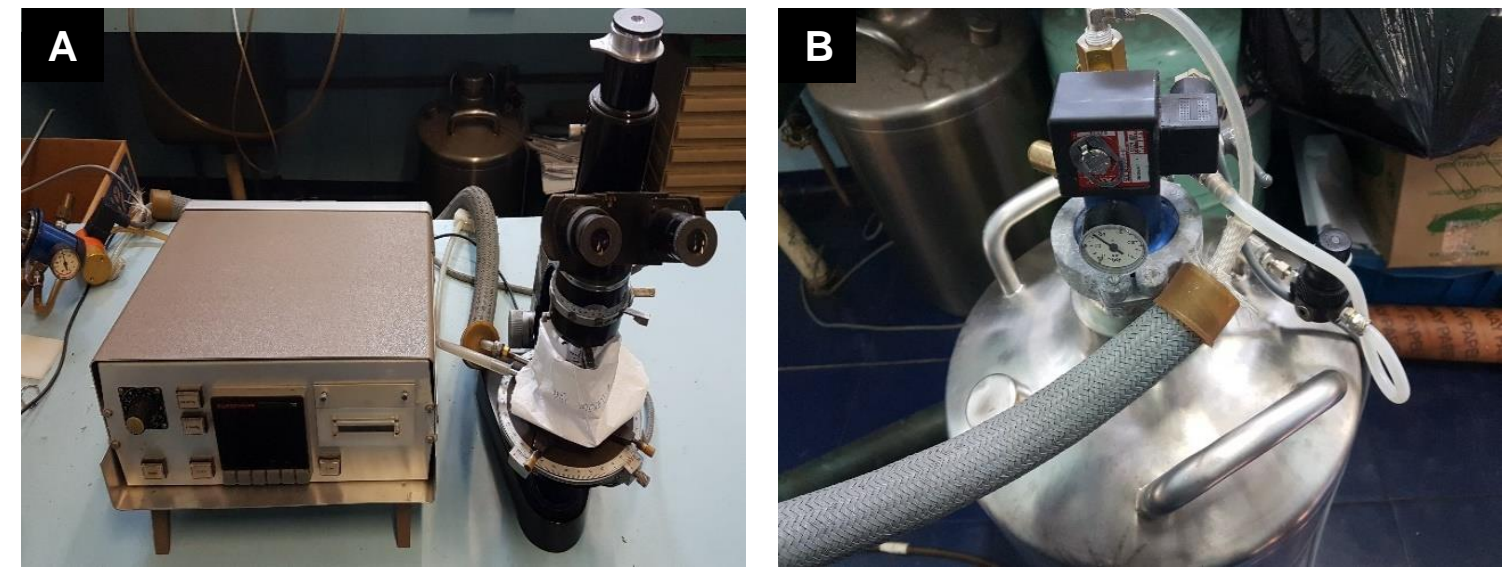

Figura 3.2. Equipamento utilizado em microtermometria no Laboratório de Inclusões Fluidas do instituto de Geociências da Universidade de São Paulo. (A) Microscópio de luz polarizadora com platina específica acoplada e sistema registrador das temperaturas. (B) Cilindro de nitrogênio líquido utilizado em laboratório. 


\subsubsection{Microscopia confocal de varredura a laser (CSLM)}

O método de microscopia confocal de varredura a laser foi aplicado para determinação do volume de inclusões fluidas compostas por hidrocarbonetos (análise semi-quantitativa). A determinação do volume da inclusão possibilita um avanço no conhecimento real do volume das fases do óleo e constitui um parâmetro importante na obtenção da composição (estimativa) e das condições de aprisionamento (P-T) reais das inclusões. Assim, o volume total de uma inclusão fluida composta por hidrocarbonetos e as respectivas temperaturas de homogeneização são vitais para uma inferência na composição global de hidrocarbonetos. Este procedimento também é válido no reconhecimento e identificação de processos de reequilíbrio térmico de inclusões fluidas devido a modificações pós-aprisionamento (Pironon et al., 1998; Aplin et al., 1999; Thiéry et al., 2002).

A microscopia confocal tem por base a filtragem da luz fluorescente emitida por um pinhole (Pironon et al., 1998). Um microscópio confocal é constituído por uma fonte de laser montada no iluminador superior do microscópio, que corresponde à fonte de luz projetada na amostra e que pode ter um comprimento de onda específico, um scanner que é um digitalizador por unidade, ou seja, move o laser de modo a focalizar a amostra linha por linha, o $Z$ control que permite a focagem da amostra e a aquisição da imagem em secções ao longo dos eixos $X$ e $Z$, os fotomultiplicadores (photomultipliers - PMT) que vão detectar os fótons emitidos e/ou refletidos pela amostra, um pinhole responsável pela emissão e filtragem da luz fluorescente, bem como, a profundidade e posição da imagem nos eixos X e Y; o Beam Splitter ou Via de Fluorescência, que é definida pela combinação dos espelhos dicroicos (principal e secundário) e filtros de emissão e, por último, as objetivas responsáveis pela aquisição, resolução e propriedades das imagens.

O método consiste em um feixe de luz laser que passa através do pinhole. Nesse pinhole circula somente a luz da inclusão que se origina no plano do ponto de laser focalizado. A fluorescência de áreas adjacentes ou fora do plano focal viaja pelos espelhos dicroicos e filtros de emissão, impedindo sua detecção, de modo que apenas uma imagem plana da região focal é detectada pela câmera. A resolução da profundidade aumenta com a diminuição do diâmetro do focal. A mudança de foco (seções $z$ - sequências obtidas em diferentes planos de foco) e a mudança de posições $\mathrm{X}$ e $\mathrm{Y}$ permite a construção de uma imagem tridimensional da inclusão (Pironon et al., 1998).

Esta etapa foi realizada na central analítica do Instituto de Química da Universidade de São Paulo no laboratório de microscopia confocal de varredura a laser 
(Figura 3.3). O equipamento corresponde a um microscópio confocal da marca Zeiss ${ }^{\circledR}$, modelo LSM 510-Meta, que possui 4 lasers possibilitando a excitação da amostra em diversos comprimentos de onda (351 nm, 364 nm, 458 nm, 477 nm, 488 nm, 514 nm, $543 \mathrm{~nm}$ e $633 \mathrm{~nm}$ ). As imagens foram capturadas com objetiva de 100x imersa em óleo.

O volume das inclusões fluidas compostas por hidrocarbonetos (fase vapor e fase liquida) foi determinado com o auxílio de software especializado em tratamento e modelagem de imagem (Image J (C) e plugins especializados.

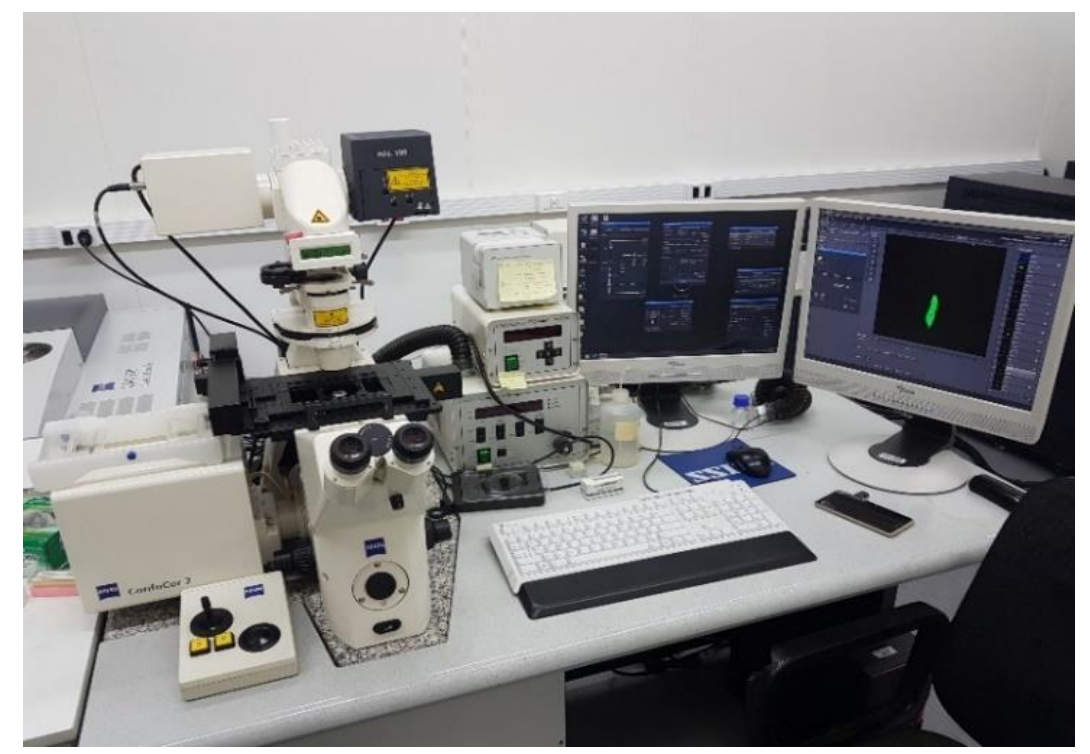

Figura 3.3. Laboratório de microscopia confocal de varredura a laser na Central Analítica do Instituto de Química na Universidade de São Paulo.

\subsubsection{Modelo P-V-T dos fluidos aprisionados}

O envelope de fases das inclusões fluidas compostas por hidrocarbonetos e 0 modelo P-V-T dos fluidos aprisionados em veios de quartzo e calcita foram determinados através de métodos baseados em parâmetros físicos e numéricos testados experimentalmente. Com este propósito as HCFl's foram modeladas com base nas premissas de Thiéry et al. (2002), devidamente associadas a equação de estado de Peng-Robinson (Peng \& Robinson, 1976) e o modelo de composição $\alpha-\beta$ desenvolvido por Montel (1993). Esta abordagem requer como parâmetros de entrada a temperatura de homogeneização (Th) e a fração vapor $\left(F_{v}\right)$ das inclusões fluidas compostas por hidrocarbonetos, fornecendo um conjunto de soluções possíveis representadas por uma curva $\beta$ ( $\alpha$ ) em um diagrama $\alpha-\beta$ (Thiéry et al., 2002). Ao definir os dados $F_{v}$ adquiridos em microscopia confocal, o software de simulação (PIT - Thiéry et al., 2000b apud Pestilho \& Monteiro, 2017) calcula o envelope de fases de HCFI's, a respectiva curva de equilíbrio $(L: V)$ e isócoras. Assim, dados volumétricos de inclusões fluidas de 
hidrocarbonetos combinados com a microtermometria (Th) de inclusões fluidas aquosas coexistentes, fornecerão novas condições de aprisionamento (P-V-T). Isto proporciona uma maneira simples de representar graficamente a composição de qualquer inclusão fluida composta por hidrocarbonetos naturais, bem como, a reconstrução dos caminhos isocóricos de inclusões fluidas aquosas cogenéticas (Pironon et al., 1998; Aplin et al., 1999; Bourdet et al., 2008).

\subsection{Reflectância de vitrinita (\% Ro)}

O método de reflectância de vitrinita consiste na comparação do poder refletor das vitrinitas (\% Ro) da amostra realizada com padrões de reflectância conhecidos, e assim determinar o grau de maturidade do folhelho. Nesta técnica, são atribuídos valores numéricos às medidas fotométricas de reflectância da vitrinita. Para rochas termicamente imaturas, o Ro é menor que $0,5 \%$, alcançando valores de 0,5 a 2,0 \% para rochas maturas e entre 2,0 e 4,0 \% para rochas super maturas. Tissot \& Welte (1984) ainda diferenciam o Ro para as rochas maturas, assumindo valores entre $0,5 \mathrm{e}$ 1,3 \% para as rochas que estão na janela de geração de petróleo e entre 1,3 e 2,0 \% para a zona de geração de gás e condensados.

As amostras de folhelho passaram por processos de trituração e moagem para obtenção de material com tamanho de grão inferior a 0,8mm e superior a 0,25. Posteriormente, foi colocado cerca de $20 \mathrm{~g}$ de amostra em um molde de superfície polida e foi preparada uma mistura de resina do tipo epóxi e endurecedor (Stach et al., 1982). Após o endurecimento (24 horas) as seções foram submetidas polimento com lixadeira rotativa e com lixas de placas de diamante de \#200, \#500, \#1200, \#2500, \#5000, por esta ordem. Após o lixamento, foi feito o polimento em politriz com suspensão de alumina de granulometria 0,3 $\mu \mathrm{m}$ e $0,05 \mu \mathrm{m}$ (Stach et al., 1982). Seguiu-se a fase de lavagem das superfícies com água e prensa de ar. Por fim, foi feita a análise petrográfica para reconhecimento do maceral vitrinita e medição do seu poder refletor. Este processo de amostragem baseou-se na rotina estabelecida do laboratório de Geoquímica Orgânica do Departamento de Geociências, Ambiente e Planeamento Regional da Universidade do Porto, Portugal.

Os dados de Ro foram obtidos em microscópio óptico LEICA DM 4000M, equipado com sistema Hilgers FOSSIL/MOT com luz branca e azul (fluorescência). A identificação e caracterização da matéria orgânica foram baseadas na classificação internacionalmente aceita pelo ICCP - Comitê Internacional de Carvão e Petrologia Orgânica (ICCP 1998, 2001). A determinação da refletância da vitrinita, que permite 
avaliar o grau de maturação do material orgânico (Tissot \& Welte, 1984), foi realizada com base nos procedimentos descritos na norma ASTM D7708 (2011).

\subsection{Espectroscopia por ressonância magnética nuclear (RMN) em querogênio}

Os folhelhos ricos em matéria orgânica sedimentar contêm frações de betume (porção líquida solúvel) e querogênio (porção sólida insolúvel). Apesar de não ser estruturalmente bem definido devido à sua complexidade e heterogeneidade, o querogênio representa a forma mais importante da matéria orgânica (Vandenbroucke \& Largeau, 2007).

Durante esta etapa, em uma primeira fase, as amostras de folhelho foram moídas (8-11 g) e extraídas num extrator de soxhlett durante 24 horas com mistura de solventes de diclorometano-metanol (9:1) para remover o betume solúvel. As amostras extraídas (alíquotas de $5 \mathrm{~g}$ ) foram então desmineralizadas por digestão ácida, agitando durante $24 \mathrm{~h}\left(60^{\circ} \mathrm{C}\right)$ com uma mistura de $40 \mathrm{ml}$ de $\mathrm{HCl} 6 \mathrm{M}+20 \mathrm{ml} \mathrm{HF} 40 \%$. Posteriormente, a mistura foi diluída com água $(1 \mathrm{~L})$ e o resíduo sólido foi filtrado, lavado copiosamente com água e finalmente seco ao ar. Após este período, as amostras de querogênio seco foram extraídas por soxhlett novamente, durante 24h com diclorometano-metanol (9:1), a fim de remover qualquer betume remanescente. Por fim, as amostras de querogênio resultantes foram secas ao ar e trituradas para análise de $\mathrm{RMN}$. Foi empregada a rotina ${ }^{13} \mathrm{C}$ NMR CP/MAS, amplamente usada em análises de RMN para caracterização de querogênio (Cao et al., 2013).

Todo o procedimento necessário à rotina de análise foi realizado em parceria com a Universidade Federal do ABC (UFABC) em São Paulo. Estes resultados associados aos dados de Ro, ambos obtidos em amostras localizadas no flanco SSE da Bacia do Paraná, poderão ajudar a estabelecer relações de convergência ou divergência de maturidade térmica e aromaticidade da matéria orgânica dos folhelhos. Desta forma, integrando dados microtermométricos e dados de RMN, ao longo da borda leste da Bacia do Paraná (Figura 3.1A e B), será possível estabelecer um modelo de evolução térmica acurado. 
CAPÍTULO 4 


\section{CAPÍTULO 4}

\section{RESULTADOS}

Neste capítulo, apresenta-se um resumo dos principais resultados obtidos. Os mesmos encontram-se descritos e discutidos detalhadamente no artigo científico (Teixeira et al., 2018) e no manuscrito submetido para publicação (Teixeira et al., submetido), ambos em anexos (Anexo I e II, respectivamente). Localização geográfica, unidade geológica, código de amostras e métodos aplicados podem ser consultados na Tabela 3.1.

\subsection{Orientação e características macroscópicas dos veios de calcita e quartzo}

Os veios de calcita e quartzo estudados preenchem fraturas que seccionam unidades geológicas permianas e cretáceas da Bacia do Paraná, em particular as formações Irati, Serra Alta, Corumbataí e Serra Geral (veio na capa de basalto e em sill associado à LIP Paraná). Os mesmos foram agrupados de acordo com sua orientação e ângulo de mergulho, distinguindo-se assim veios sub-horizontais e sub-verticais com direção preferencial NNE e NNW (Figura 4.1).

As amostras calcite-01, quartz-02, calcite-03 e quartz-04 correspondem a veios sub-verticais na Formação Irati com direção preferencial NNE e NNW, sugerindo um sistema de fraturas conjugado (Figura 4.1E). Contudo, não foi possível determinar, em escala de afloramento, relações de continuidade lateral e corte transversal (cross-cutting relations) entre as fraturas.

Os veios pertencentes à Formação Irati correspondem majoritariamente a fraturas sub-verticais com espaçamento milimétrico a centimétrico e continuidade vertical métrica ocorrendo tanto em siltitios como em fácies carbonática (Figura 4.2B). Os veios de calcita da Formação Serra Alta apresentam características similares aos veios da Formação Irati ocorrendo em camadas de siltitos acinzentados com laminação heterolítica (Figura 4 - Anexo I). Todos os veios apresentam espessura variável (milimétrica a centimétrica), atingindo o máximo de $4 \mathrm{~cm}$ no caso dos veios subhorizontais da Formação Corumbataí (Figura 4.2C). Alguns veios de calcita e quartzo das formações Irati e Teresina apresentam impregnações de betume e ocorrem intercalados às camadas de siltitos roxo-acinzentados com uma certa ondulação em relação ao acamamento, formando dobras abertas de amplitude decimétrica a métrica (Figura 4.2C). 
$\mathbf{A}$

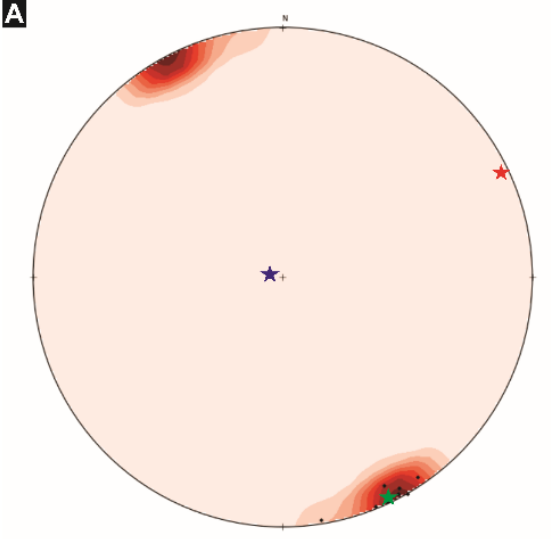

G

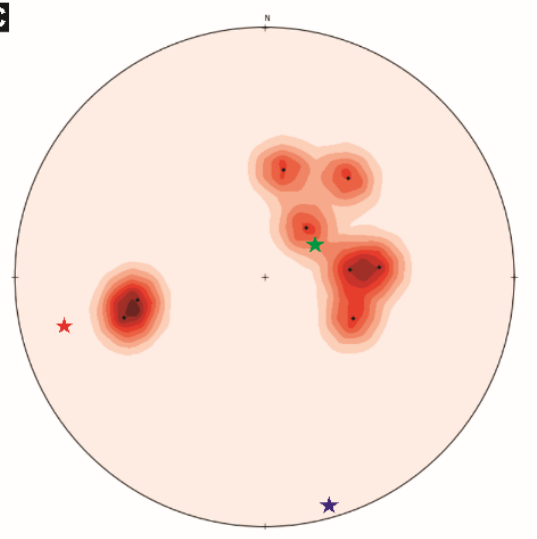

是

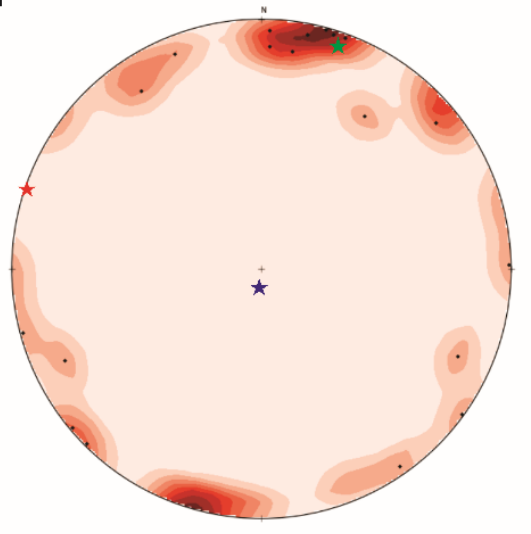

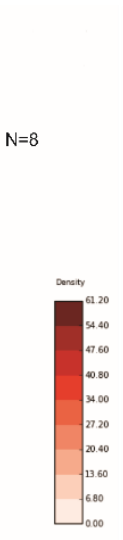

B
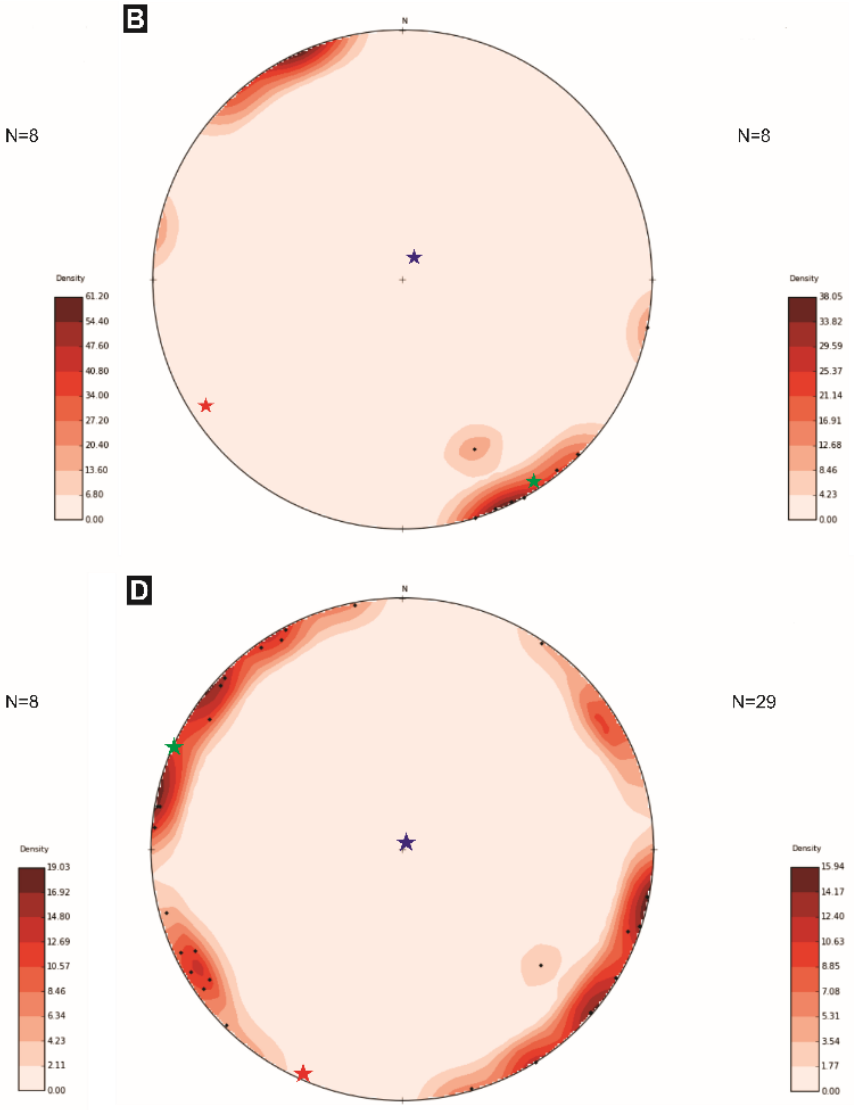

$N=19$

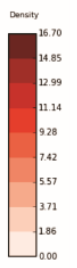

Figura 4.1. Orientações dos veios de calcita e quartzo que preenchem fraturas nas unidades estudadas. (A) Veios de calcita sub-verticais hospedados em sill associado à LIP Paraná. Amostra SLIP-02. (B) Veios de calcita sub-verticais hospedados em capa de basalto na Formação Serra Geral. Amostra SG-01. (C) Veios sub-horizontais de calcita na Formação Corumbataí. Amostra CB-01. (D) Veios sub-verticais de calcita na Formação Serra Alta. Amostras IR-05 e IR-06. (E) Veios sub-verticais de quartzo e calcita na Formação Irati. Amostras calcite-01, quartz-02, calcite-03, quartz-04. 


\subsection{Microscopia óptica dos veios e das inclusões fluidas}

Entre os veios de calcita e quartzo estudados se distinguem veios com crescimento cristalino de dois tipos: (a) sintaxial e (b) antiaxial (Figura 4.3). A petrografia de seções delgadas permitiu a descrição de veios de calcita (calcite-01, calcite-03; IR05, IR06, CB-01, SG-01 e SLIP-02) e quartzo (quartz-02 e quartz-04) cujas assembleias de inclusões fluidas foram posteriormente mapeadas e analisadas com auxílio de luz petrográfica e luz ultravioleta. Veios de calcita hospedados em sill associado à LIP Paraná (amostra SLIP-02) apresentam cristais euédricos equidimensionais com clivagem perfeita, textura em mosaico e geminações paralelas (Figura 4.3A e B). O veio antiaxial de calcita da Formação Corumbataí (amostra CB-01) apresenta cristais longitudinais com textura fibrosa e crescimento cristalino desde a zona média (zona de sutura) em direção à borda do veio (Figura 4.3C). Veios sintaxiais de calcita que seccionam a Formação Serra Alta (amostra IR-05) apresentam cristais euédricos a subédricos com textura blocosa em mosaico, geminações paralelas e aparência escurecida (Figura 4.3D). Mais detalhes podem ser consultados no ponto 4.6 do Anexo I. Veios sintaxiais de quartzo na Formação Irati (amostra quartz-04) apresentam cristais subédricos alongados com textura blocosa em mosaico e com taxas de crescimento desproporcionais entre alguns cristais (Figura 4.3E e F). Mais detalhes podem ser consultados no tópico 4.1 do Anexo II.

As inclusões fluidas aquosas (AqFl's) de origem primária e pseudo-secundária hospedadas em veios de calcita e quartzo da Formação Irati e em veios de calcita da Formação Serra Geral (veio na capa de basalto e em sill associado à LIP Paraná) apresentam morfologia irregular (monofásicas) tendendo a regular (bifásicas) com diâmetro normalmente inferior a $10 \mu \mathrm{m}$, podendo, em alguns casos atingir $15 \mu \mathrm{m}$ (inclusões do Tipo 1). Mais detalhes podem ser consultados no ponto 4.2 do Anexo II.

As inclusões fluidas compostas por hidrocarbonetos (HCFl's) de origem primária ou secundária, que ocorrem em veios de quartzo, apresentam morfologia irregular e diâmetro até $20 \mu \mathrm{m}$, normalmente inferior, fluorescência amarela, esbranquiçada ou azul (inclusões do Tipo 2) (Figura 4.4D; G e H). As HCFl's de origem primária e pseudosecundária hospedadas em outros veios de calcita e quartzo da Formação Irati apresentam morfologia irregular tendendo a regular, com diâmetro superior a $5 \mu \mathrm{m}$ podendo chegar até $25 \mu \mathrm{m}$ e com fluorescência amarela (Tipo 2) e, em outros casos apresentando fluorescência laranja ou marrom (Tipo 3) (Figura 4.4E e F).

O veio de calcita fibrosa da Formação Corumbataí hospeda inclusões fluidas compostas por hidrocarbonetos (HCFl's) de origem primária, forma alongada e dimensões variadas com fluorescência que varia entre amarelo e azul (Tipo 2) sob efeito 
de luz ultravioleta (Figura 4.4C). Os veios de calcita e quartzo da Formação Irati hospedam inclusões fluidas aquosas (AqFl's) de origem primária e pseudo-secundária coexistentes com inclusões fluidas compostas por hidrocarbonetos (HCFl's) de origem primária e pseudo-secundária. Algumas HCFI's possuem cor marrom, enquanto outras são incolores sob o efeito de luz transmitida e polarizadores paralelos. As HCFl's apresentam morfologia irregular e fluorescência de cor amarela a esbranquiçada (Tipo 2) sob o efeito de luz ultravioleta (Figura 4.4D). Geralmente, as HCFl's têm diâmetro inferior a $15 \mu \mathrm{m}$, com exceção das inclusões de origem primária ricas em gás que apresentam diâmetro $\geq 20 \mu \mathrm{m}$ e fase gasosa dominante (Figura 4.4F). Observam-se também, HCFl's de origem secundária e morfologia irregular com fluorescência de cor amarela e esbranquiçada (Tipo 2) sob o efeito de luz ultravioleta e fase gasosa de pequena dimensão (Figura 4.4G e H). Mais detalhes petrográficos das inclusões fluidas podem ser consultados na Tabela 4.1. 
Tabela 4.1. Sumário da petrografia de inclusões fluidas estudadas.

\begin{tabular}{|c|c|c|c|c|c|c|c|c|c|c|c|c|}
\hline Amostra & Formação & Localização & $\begin{array}{c}\text { Mineral / } \\
\text { Rocha } \\
\text { hospedeira }\end{array}$ & $\begin{array}{l}\text { Tipo de } \\
\text { inclusão }\end{array}$ & Composição & $\begin{array}{l}\text { № de } \\
\text { Fases }\end{array}$ & Forma & $\begin{array}{l}\text { Modo de } \\
\text { Ocorrência }\end{array}$ & Origem & $\begin{array}{c}\text { Diâmetro } \\
(\mu \mathrm{m})\end{array}$ & $\begin{array}{c}\text { Volume } \\
\text { fase vapor } \\
\text { (observado) }\end{array}$ & Fluorescência \\
\hline \multirow{2}{*}{$\begin{array}{c}\text { Calcite- } \\
01\end{array}$} & \multirow{8}{*}{ Irati } & \multirow{10}{*}{ São Paulo } & \multirow{2}{*}{$\begin{array}{l}\text { Calcita / } \\
\text { Folhelho }\end{array}$} & 1 & Aquosa & $\begin{array}{c}\text { Monofásicas } \\
\text { associadas } \\
\text { a bifásicas }\end{array}$ & $\begin{array}{l}\text { Irregular } \\
\text { a regular }\end{array}$ & $\begin{array}{c}\text { aleatória / } \\
\text { isolada / } \\
\text { micro fraturas }\end{array}$ & $\begin{array}{l}\text { primária e } \\
\text { pseudo- } \\
\text { secundária }\end{array}$ & 5 a 15 & 5 a $20 \%$ & - \\
\hline & & & & 2 & Hidrocarboneto & Bifásicas & Irregular & $\begin{array}{l}\text { aleatória / } \\
\text { isolada }\end{array}$ & primária & 10 a 20 & 5 a $15 \%$ & Amarelo \\
\hline \multirow{2}{*}{$\begin{array}{c}\text { Quartz- } \\
02\end{array}$} & & & \multirow{2}{*}{$\begin{array}{l}\text { Quartzo / } \\
\text { Calcário }\end{array}$} & 1 & Aquosa & $\begin{array}{c}\text { Monofásicas } \\
\text { associadas } \\
\text { a bifásicas }\end{array}$ & $\begin{array}{l}\text { Irregular } \\
\text { a regular }\end{array}$ & $\begin{array}{l}\text { aleatória / } \\
\text { isolada }\end{array}$ & primária & 5 a 15 & 5 a $15 \%$ & - \\
\hline & & & & 3 & Hidrocarboneto & Bifásicas & $\begin{array}{l}\text { Irregular } \\
\text { a regular }\end{array}$ & $\begin{array}{l}\text { aleatória / } \\
\text { isolada }\end{array}$ & primária & 5 a 25 & 5 a $20 \%$ & $\begin{array}{l}\text { Laranja / } \\
\text { Marrom }\end{array}$ \\
\hline \multirow{2}{*}{$\begin{array}{l}\text { Calcite- } \\
03\end{array}$} & & & \multirow{2}{*}{$\begin{array}{l}\text { Calcita / } \\
\text { Calcário }\end{array}$} & 1 & Aquosa & $\begin{array}{c}\text { Monofásicas } \\
\text { associadas } \\
\text { a bifásicas }\end{array}$ & $\begin{array}{l}\text { Irregular } \\
\text { a regular }\end{array}$ & $\begin{array}{c}\text { aleatória / } \\
\text { micro fraturas }\end{array}$ & $\begin{array}{l}\text { primária e } \\
\text { pseudo- } \\
\text { secundária }\end{array}$ & 5 a 15 & 5 a $10 \%$ & - \\
\hline & & & & 2 e 3 & Hidrocarboneto & Bifásicas & Irregular & $\begin{array}{c}\text { aleatória / } \\
\text { micro fraturas }\end{array}$ & $\begin{array}{c}\text { primária e } \\
\text { pseudo- } \\
\text { secundária }\end{array}$ & 5 a 25 & 5 a $15 \%$ & Amarelo \\
\hline \multirow{2}{*}{$\begin{array}{l}\text { Quartz- } \\
04\end{array}$} & & & \multirow{2}{*}{$\begin{array}{l}\text { Quartzo / } \\
\text { Calcário }\end{array}$} & 1 & Aquosa & $\begin{array}{c}\text { Monofásicas } \\
\text { associadas } \\
\text { a bifásicas }\end{array}$ & $\begin{array}{l}\text { Irregular } \\
\text { a regular }\end{array}$ & $\begin{array}{l}\text { aleatória / } \\
\text { micro fraturas } \\
\text { cicatrizadas }\end{array}$ & $\begin{array}{c}\text { primária e } \\
\text { secundária }\end{array}$ & 5 a 15 & 5 a $15 \%$ & - \\
\hline & & & & 2 & Hidrocarboneto & Bifásicas & Irregular & $\begin{array}{c}\text { aleatória / } \\
\text { micro fraturas } \\
\text { cicatrizadas }\end{array}$ & $\begin{array}{l}\text { primária e } \\
\text { secundária }\end{array}$ & 5 a 20 & 5 a $15 \%$ & Amarelo \\
\hline CB-01 & Corumbataí & & $\begin{array}{l}\text { Calcita / } \\
\text { Siltito }\end{array}$ & 2 & Hidrocarboneto & Bifásicas & Irregular & isolada & primária & 5 a 20 & 5 a $10 \%$ & Amarelo / Azul \\
\hline SG-01 & \multirow[t]{2}{*}{ Serra Geral } & & $\begin{array}{l}\text { Calcita / } \\
\text { Basalto }\end{array}$ & \multirow[t]{2}{*}{1} & \multirow[t]{2}{*}{ Aquosa } & \multirow{2}{*}{$\begin{array}{l}\text { Monofásicas } \\
\text { associadas } \\
\text { a bifásicas }\end{array}$} & \multirow{2}{*}{$\begin{array}{l}\text { Irregular } \\
\text { a regular }\end{array}$} & \multirow{2}{*}{$\begin{array}{l}\text { aleatória / } \\
\text { isolada }\end{array}$} & \multirow{2}{*}{$\begin{array}{l}\text { Primária e } \\
\text { pseudo- } \\
\text { secundária }\end{array}$} & \multirow[t]{2}{*}{5 a 15} & \multirow[t]{2}{*}{5 a $15 \%$} & - \\
\hline SLIP-02 & & Paraná & $\begin{array}{l}\text { Calcita / Sill } \\
\text { (associado à } \\
\text { LIP Paraná) }\end{array}$ & & & & & & & & & - \\
\hline
\end{tabular}



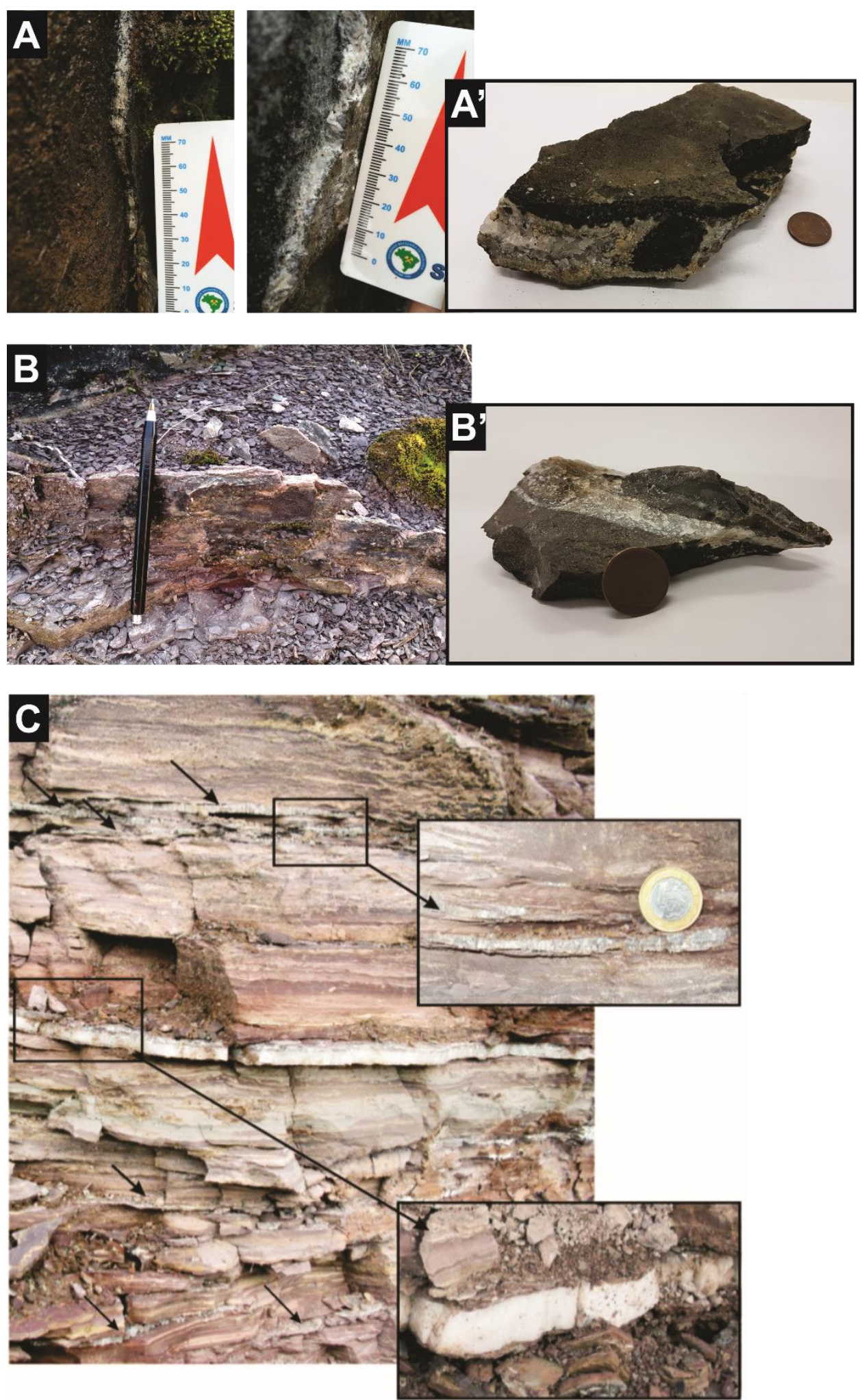

Figura 4.2. Características macroscópicas dos veios estudados. (A) Veio de calcita sub-vertical com espessura milimétrica a centimétrica em sill pertencente à LIP Paraná (amostra SLIP-02); (A') Detalhe do veio A. (B) Veio de calcita sub-vertical com espessura milimétrica a centimétrica cortando siltitos e argilitos da Formação Irati (amostra calcite-03) (C) Veios de calcita e quartzo sub-horizontais com espessura centimétrica pertencentes à Formação Corumbataí (amostra CB01). Imagem retirada de Nomura (2012). 

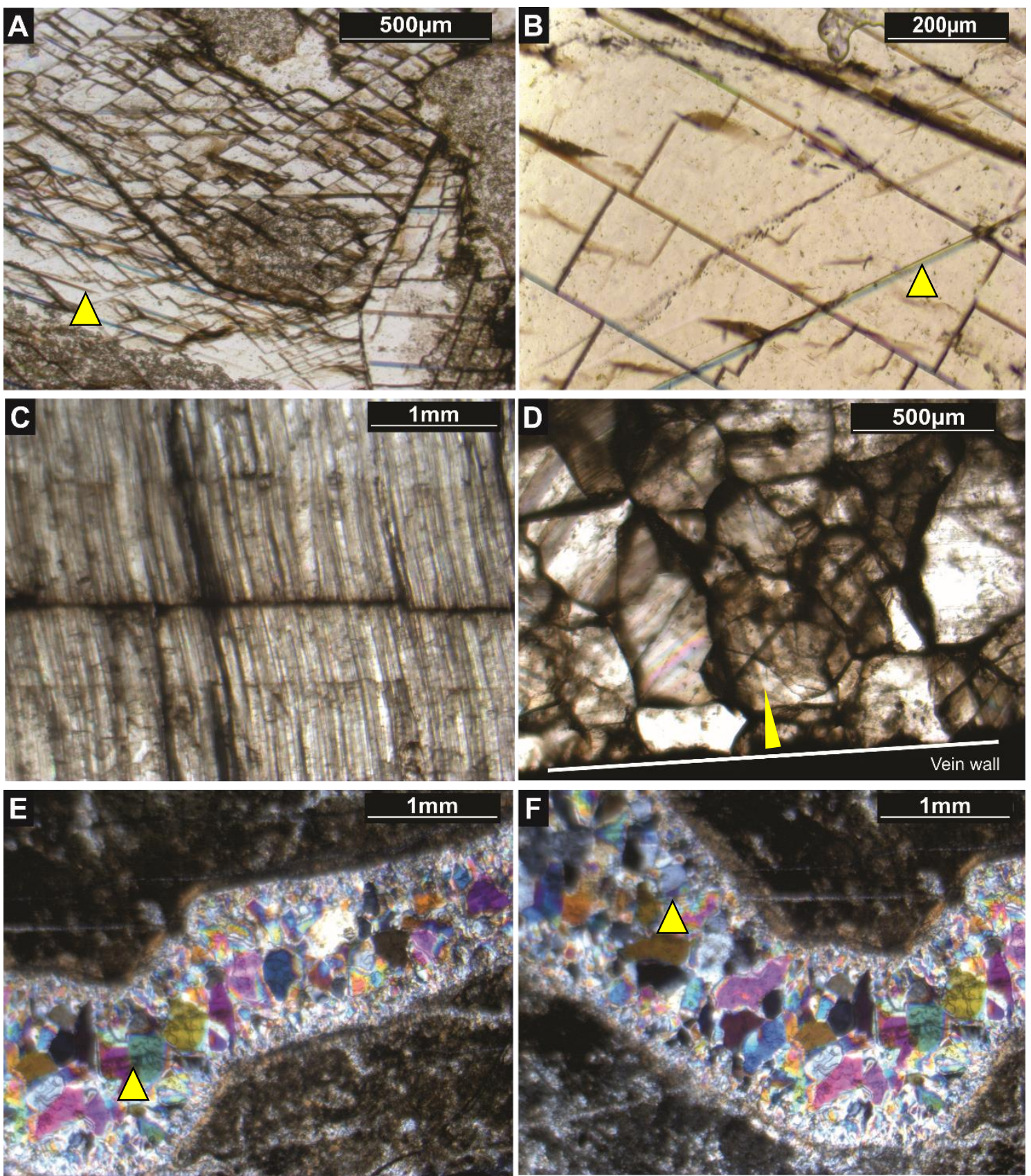

Figura 4.3. Fotomicrografias dos veios estudados. (A e B) Veios sintaxiais hospedados em sill associado à LIP Paraná (amostra SLIP-02). Cristais de calcita euédricos equidimensionais com clivagem perfeita, textura em mosaico e geminações paralelas (patchy twins - seta amarela). Polarizadores paralelos. (C) Veio antiaxial de calcita (veio beef) pertencente à Formação Corumbataí (amostra CB-01). Cristais longitudinais com textura fibrosa e crescimento cristalino desde a zona média (zona de sutura - seta amarela) em direção à borda do veio. Polarizadores paralelos. (D) Veio sintaxial de calcita na Formação Serra Alta (amostra IR-05). Cristais euédricos a subédricos com textura blocosa em mosaico, geminações paralelas e aparência escurecida devido à presença de inclusões fluidas e resíduos sólidos. (E e F) Veios sintaxiais de quartzo na Formação Irati (amostra quartz-04). Observam-se cristais de quartzo subédricos alongados com textura blocosa em mosaico e com taxas de crescimento desproporcionais entre alguns cristais. Notam-se trilhas de HCFI's secundárias, alinhadas em microfracturas cicatrizadas (setas amarelas). Polarizadores cruzados. (F) Continuação do mesmo veio para o braço esquerdo com detalhe para as trilhas de HCFl's secundárias alinhadas em microfraturas. 


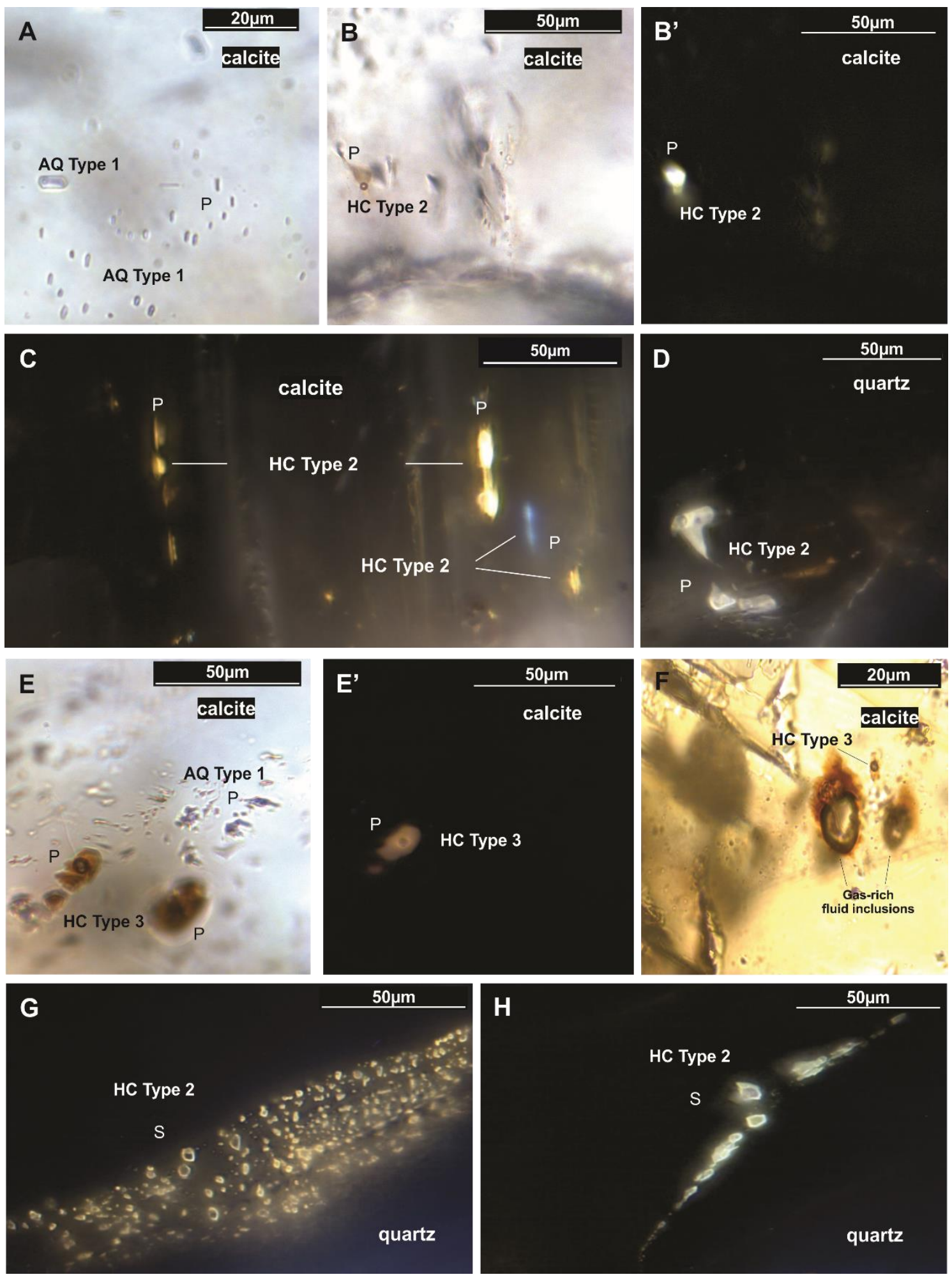

Figura 4.4. Fotomicrografia de assembleias de inclusões fluidas hospedadas em veios da Formação Irati e Corumbataí. (A) Inclusões fluidas aquosas (Tipo 1) de origem primária com morfologia irregular. Formação Irati, amostra calcite-01. (B) Inclusões fluidas compostas por hidrocarbonetos (Tipo 2) de origem primária. Apresentam cor marrom e morfologia irregular. Luz polarizada. (B') Fluorescência de cor amarela esbranquiçada sob o efeito de luz ultravioleta. Formação Irati, amostra calcite-01. (C) Inclusões fluidas compostas por hidrocarbonetos (Tipo 2) de origem primária, forma alongada e dimensões variadas. Apresentam fluorescência que varia entre amarelo e azul sob efeito de luz ultravioleta. Formação Corumbataí, veio antiaxial, amostra CB-01. (D) Inclusões fluidas compostas por hidrocarbonetos de origem primária com morfologia 
irregular. Apresentam fluorescência de cor amarela esbranquiçada sob efeito de luz ultravioleta. Formação Irati. Amostra quartz-04. (E) Inclusões fluidas compostas por hidrocarbonetos (Tipo 3) de origem primária, cor marrom escuro e morfologia irregular. Essas inclusões coexistem com inclusões fluidas aquosas (Tipo 1) de origem primária e morfologia irregular. Luz polarizada. (E') Fluorescência de cor laranja pálido sob efeito de luz ultravioleta. Formação Irati, amostra calcite03. (F) Presença de inclusões fluidas compostas por hidrocarbonetos de origem primária ricas em gás. Apresentam morfologia irregular, cor marrom e fase gasosa dominante. Essas inclusões coexistem com inclusão fluida composta por hidrocarbonetos (Tipo 3) de origem primária, e morfologia irregular. Formação Irati, amostra calcite-03. (G) Inclusões fluidas compostas por hidrocarbonetos (Tipo 2) de origem secundária e morfologia irregular. Apresentam fluorescência de cor amarela sob o efeito de luz ultravioleta e fase gasosa pequena. Formação Irati, amostra quartz-04. (H) Inclusões fluidas compostas por hidrocarbonetos (Tipo 2) de origem secundária e morfologia irregular. Fluorescência de cor amarela esbranquiçada sob o efeito de luz ultravioleta e fase gasosa pequena. Formação Irati, amostra quartz-04.

\subsection{Microtermometria de inclusões fluidas \\ 4.3.1. Inclusões fluidas aquosas (AqFl's)}

As AqFl's de origem primária e pseudo-secundária hospedadas em veios de calcita e quartzo da Formação Irati (amostras calcite-01; quartz-02; calcite-03; quartz04) exibem valores de temperatura de homogeneização (Th) que variam de 50 a 340 ${ }^{\circ} \mathrm{C}$, com média de $133^{\circ} \mathrm{C}$ (Figura 4.5A), temperaturas do ponto eutético (Te) que variam de -57 a $-42{ }^{\circ} \mathrm{C}$ (Figura 4.5B), temperaturas de fusão do gelo (Tfg) que variam, majoritariamente, de -5 a $0{ }^{\circ} \mathrm{C}$ (Figura 4.5C), o que corresponde a fluido com salinidade entre 0 e $5 \%$ (\% em peso de $\mathrm{NaCl}$ eq.) (Figura 4.5D). Uma vez que a maioria das inclusões fluidas aquosas estudadas apresentam dimensões $<10 \mu \mathrm{m}$, é importante ressaltar a dificuldade na observação dos eutéticos.

As AqFl's de origem primária e pseudo-secundária hospedadas em veios de calcita da Formação Serra Geral (veios na capa de basalto e em sill associado à LIP Paraná, amostras SG-01 e SLIP-02) exibem valores de Th que variam de 50 a $250{ }^{\circ} \mathrm{C}$, com média de $143^{\circ} \mathrm{C}$ e moda de $80^{\circ} \mathrm{C}$ (Figura 4.6A), Te que variam de -56 a $-47^{\circ} \mathrm{C}$ (Figura 4.6B) e Tfg que variam de -2 a $0{ }^{\circ} \mathrm{C}$ (Figura 4.6C), o que corresponde a fluido com salinidade entre 0 e $4 \%$ (Figura 4.6D). Um resumo dos valores de Th, Te, Tfg e salinidade das AqFl's hospedadas em veios de calcita e quartzo das formações Irati e Serra Geral é apresentado na Tabela 2 do Anexo II.

O resumo dos valores de Th, Te, Tfg e salinidade das AqFl's de origem primária e pseudo-secundária hospedadas em veios de calcita da Formação Serra Alta (amostras IR-05 e IR-06) estão apresentados na Tabela 4 e Figura 10 do Anexo I. 


\subsubsection{Inclusões fluidas compostas por hidrocarbonetos (HCFl's)}

As HCFl's de origem primária hospedadas em veios de calcita (amostras calcite01; calcite-03) e quartzo (amostra quartz-04) da Formação Irati coexistem com AqFl's de origem primária. Os valores de Th das HCFl's variam de 50 a $200^{\circ} \mathrm{C}$, com moda de $60^{\circ} \mathrm{C}$ e média de $96^{\circ} \mathrm{C}$, enquanto que os valores de Th das AqFl's coexistentes variam de 50 a $330^{\circ} \mathrm{C}$, com moda de $120^{\circ} \mathrm{C}$ e média de $135^{\circ} \mathrm{C}$ (Figura $4.5 \mathrm{G}$ ). Não foram observadas relações entre os valores de Th e fluorescência das HCFl's (Figura 4.5G"). As HCFl's de origem secundária exibem valores de Th que variam, majoritariamente, de 160 a $250^{\circ} \mathrm{C}$, com moda de $160^{\circ} \mathrm{C}$ e média de $173^{\circ} \mathrm{C}$, com alguns valores mais baixos entre 60 e $120^{\circ} \mathrm{C}$ (Figura 4.5F).

As HCFl's de origem primária hospedadas em veios de calcita da Formação Corumbataí (amostra CB-01) exibem valores de Th que variam de 50 a $160{ }^{\circ} \mathrm{C}$, com moda de $50^{\circ} \mathrm{C}$ e média de $103^{\circ} \mathrm{C}$ (Figura 4.7).

\subsection{Microscopia confocal de varredura a laser (CSLM)}

Microscopia confocal de varredura a laser (CSLM) foi realizada em amostras pertencentes à Formação Irati (quartz-04) e à Formação Corumbataí (CB-01) por apresentarem evidências de hidrocarbonetos líquidos sob a forma de inclusões fluidas. No total de 37 inclusões fluidas compostas por hidrocarbonetos estudadas foram obtidas aproximadamente 400 seções em 2D (Figura 4.8B e C), espaçadas em intervalo de profundidade constante $(0,5 \mu \mathrm{m})$, devido à dimensão das inclusões, geralmente menores que $15 \mu \mathrm{m}$. A partir dessa sequência de imagens foi possível a construção de modelos 3D de cada inclusão fluida composta por hidrocarbonetos (Figura 4.8A) e discernir sobre a forma da fase vapor (bolha) da inclusão (se elipsoide ou esférica).

Na Formação Irati as HCFl's hospedadas em veios de calcita e quartzo revelam volumes de fase vapor baixos, entre 0,1 e 53,2 $\mu^{3}$ com média de 6,8 $\mu^{3}$. Consequentemente, as HCFl's revelam volumes de fase liquida altos, que variam de 2,9 a $841,8 \mu \mathrm{m}^{3}$ com média de $124,4 \mu \mathrm{m}^{3}$.

$\mathrm{Na}$ Formação Corumbataí as HCFl's hospedadas em veio de calcita fibrosa revelam volumes de fase vapor baixos, entre 0,3 a 33,2 $\mu \mathrm{m}^{3}$ com média de 7,5 $\mu \mathrm{m}^{3}$. Por conseguinte, as HCFl's revelam volumes de fase liquida mais altos, que variam de 6,9 a $601,2 \mu \mathrm{m}^{3}$ com média de $140,5 \mu \mathrm{m}^{3}$.

A Tabela 4.2 resume a conjugação dos resultados obtidos durante os ensaios microtermométricos e de microscopia confocal de varredura nas formações Irati e Corumbataí. 
A

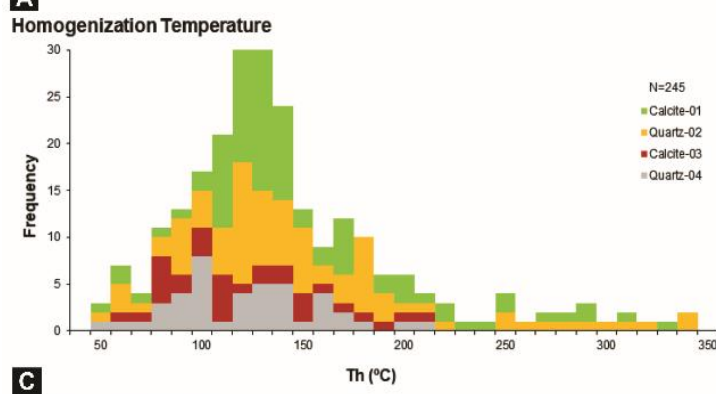

Ice Melting Temperatures

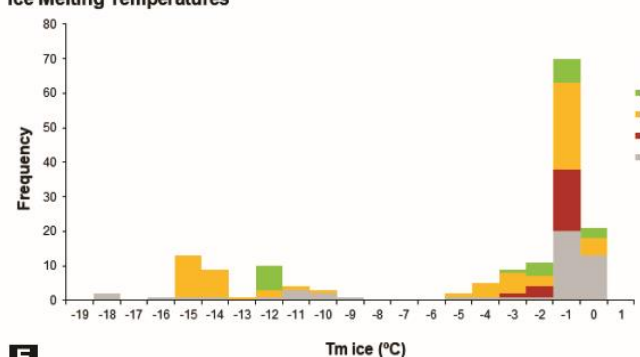

$\mathbf{E}$

Stretching reequilibration
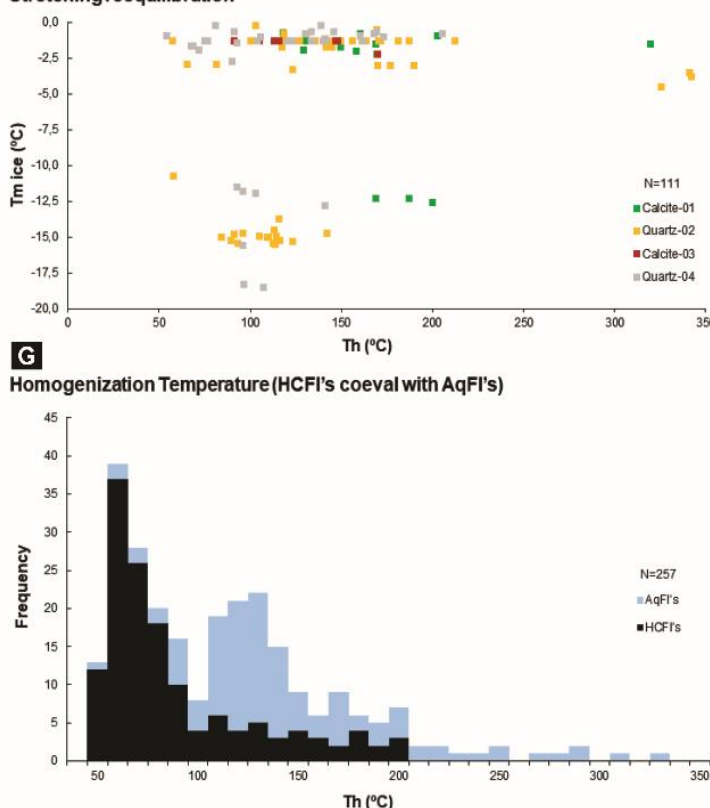

B

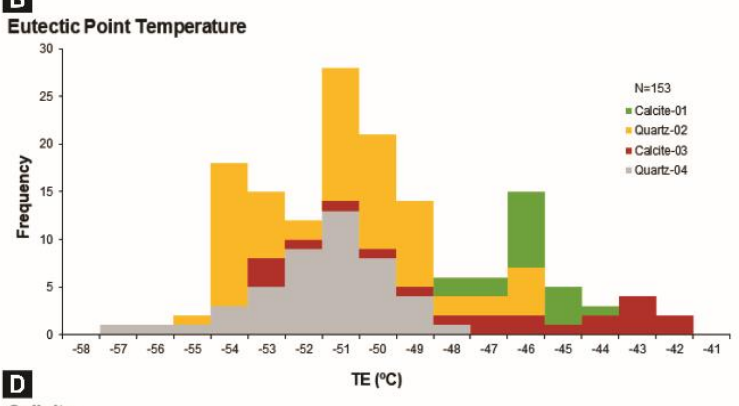

Salinity

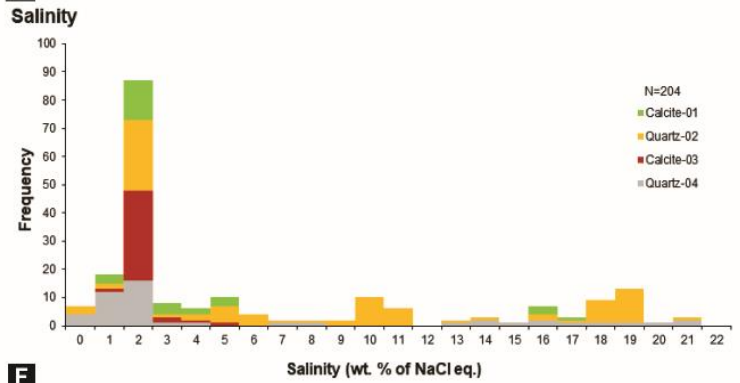

F
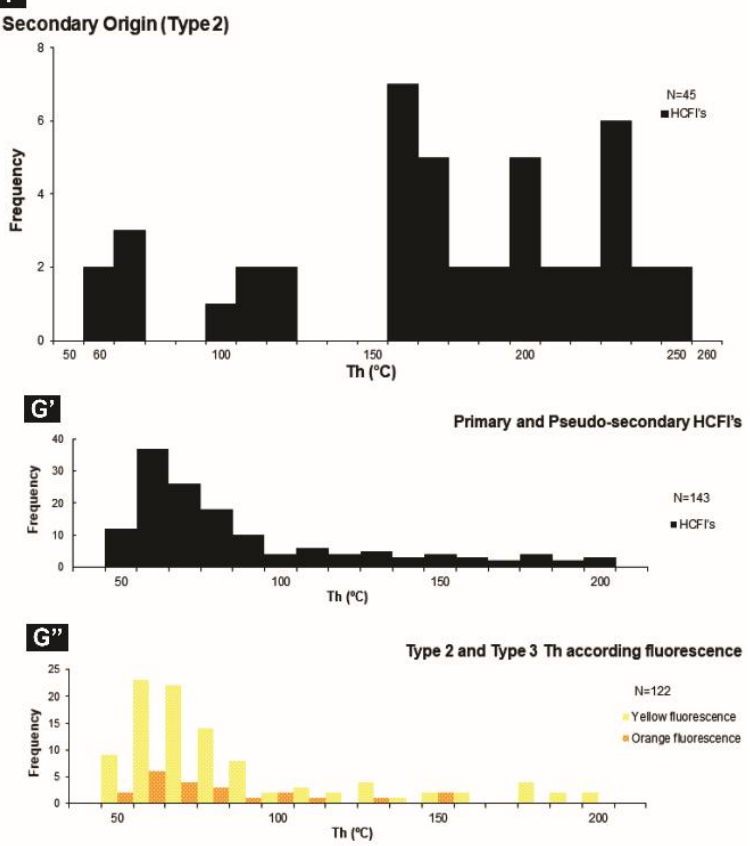

Figura. 4.5. Resultados microtermométricos de inclusões fluidas aquosas e compostas por hidrocarbonetos na Formação Irati. (A) Histograma de Th de inclusões aquo-salinas (Tipo 1). (B) Histograma de temperatura do ponto eutético. (C) Histograma de Tfg para inclusões Tipo 1. (D) Histograma representativo de salinidade onde se distinguem dois grupos: um grupo dominante com salinidade moderadamente baixa, que varia de $0-5 \%$ em peso de $\mathrm{NaCl}$ eq.; e outro grupo com salinidade elevada que varia de $16-21 \%$ em peso de $\mathrm{NaCl}$ eq. (E) Temperatura de fusão do gelo versus temperatura de homogeneização de inclusões do Tipo 1. (F) Histograma de Th de inclusões fluidas compostas por hidrocarbonetos (Tipo 2) de origem secundária em veios de quartzo. (G) Histograma de Th de inclusões fluidas compostas por hidrocarbonetos e aquosas coexistentes, de origem primária e pseudo-secundária em veios de quartzo. (G') Histograma de Th de inclusões fluidas compostas por hidrocarbonetos do Tipo 2. (G') Histograma de Th das HCFI's com fluorescência variada (Tipo 2 e Tipo 3). 
A

Homogenization Temperature

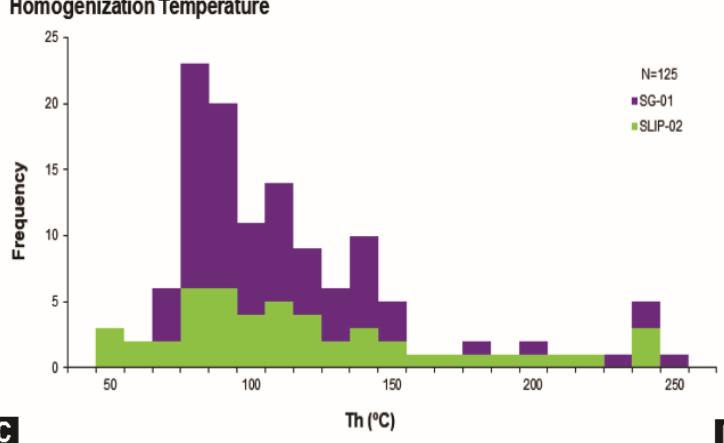

C Ice Melting Temperatures

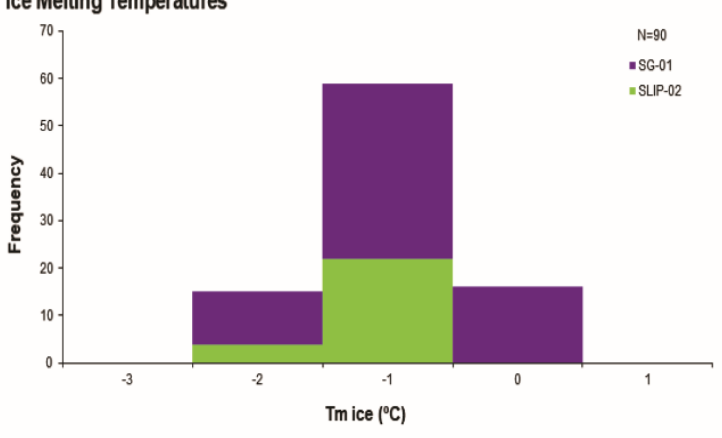

B

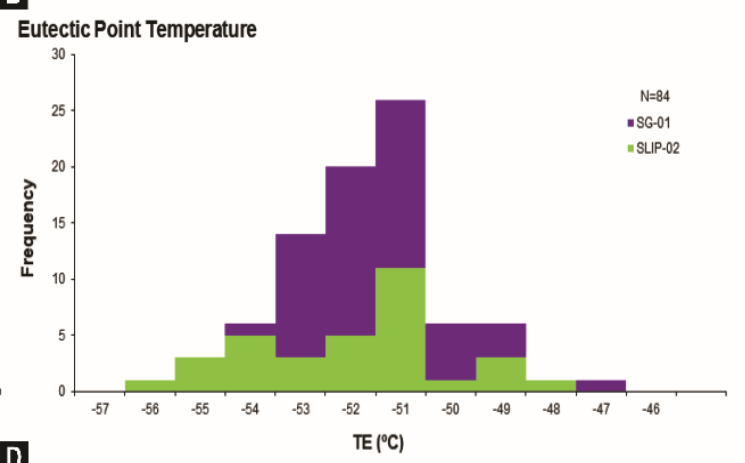

(1)

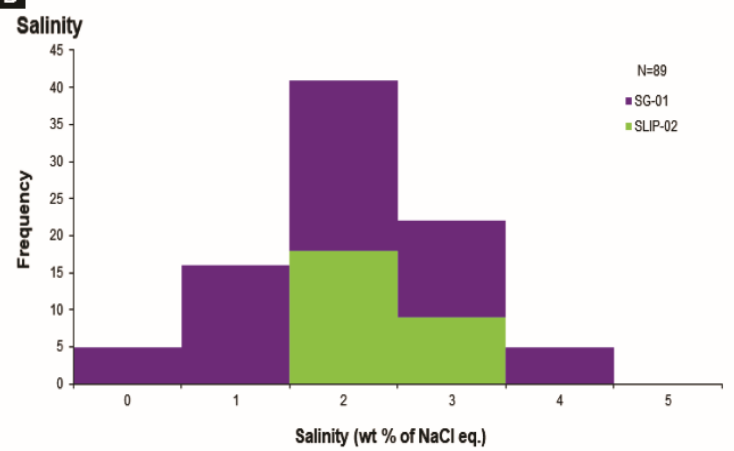

Figura 4.6. Resultados microtermométricos de inclusões fluidas aquosas (Tipo 1) hospedadas em veios de calcita em basalto pertencente à Formação Serra Geral (amostra SG-01) e em sill associado à LIP Paraná (amostra SLIP-02).

\section{Formação Corumbataí}

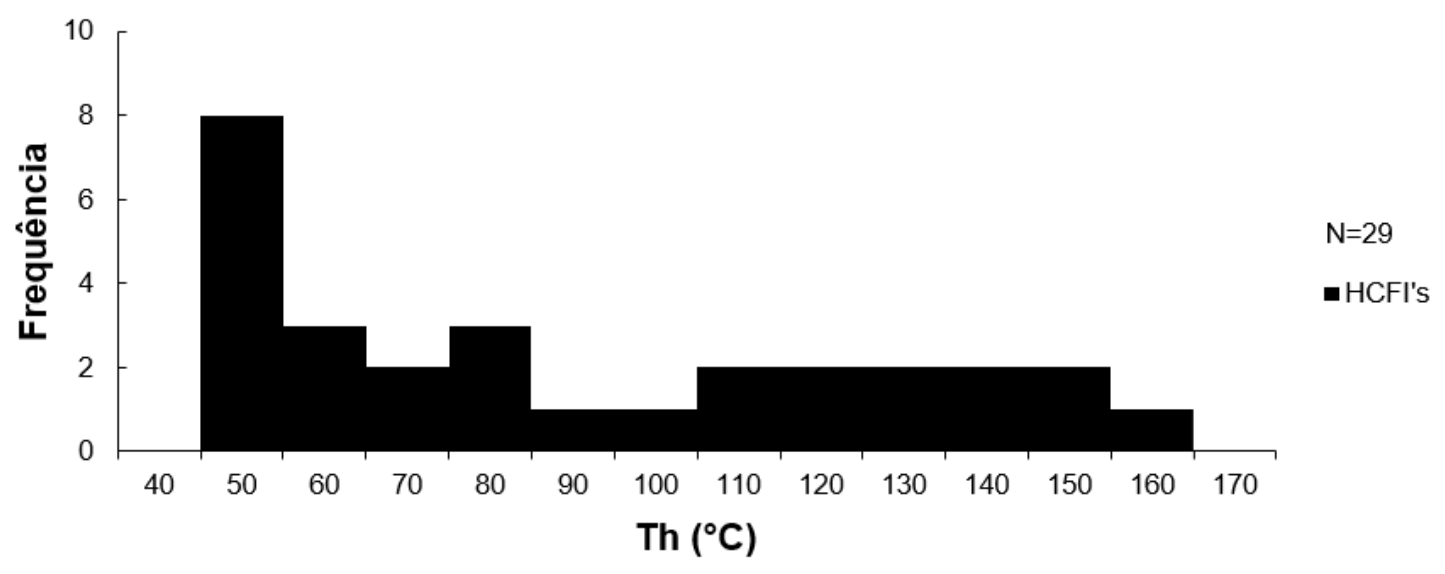

Figura 4.7. Histograma de temperaturas de homogeneização de inclusões fluidas compostas por hidrocarbonetos (Tipo 2) em veio de calcita fibrosa pertencente à Formação Corumbataí (amostra CB-01). 

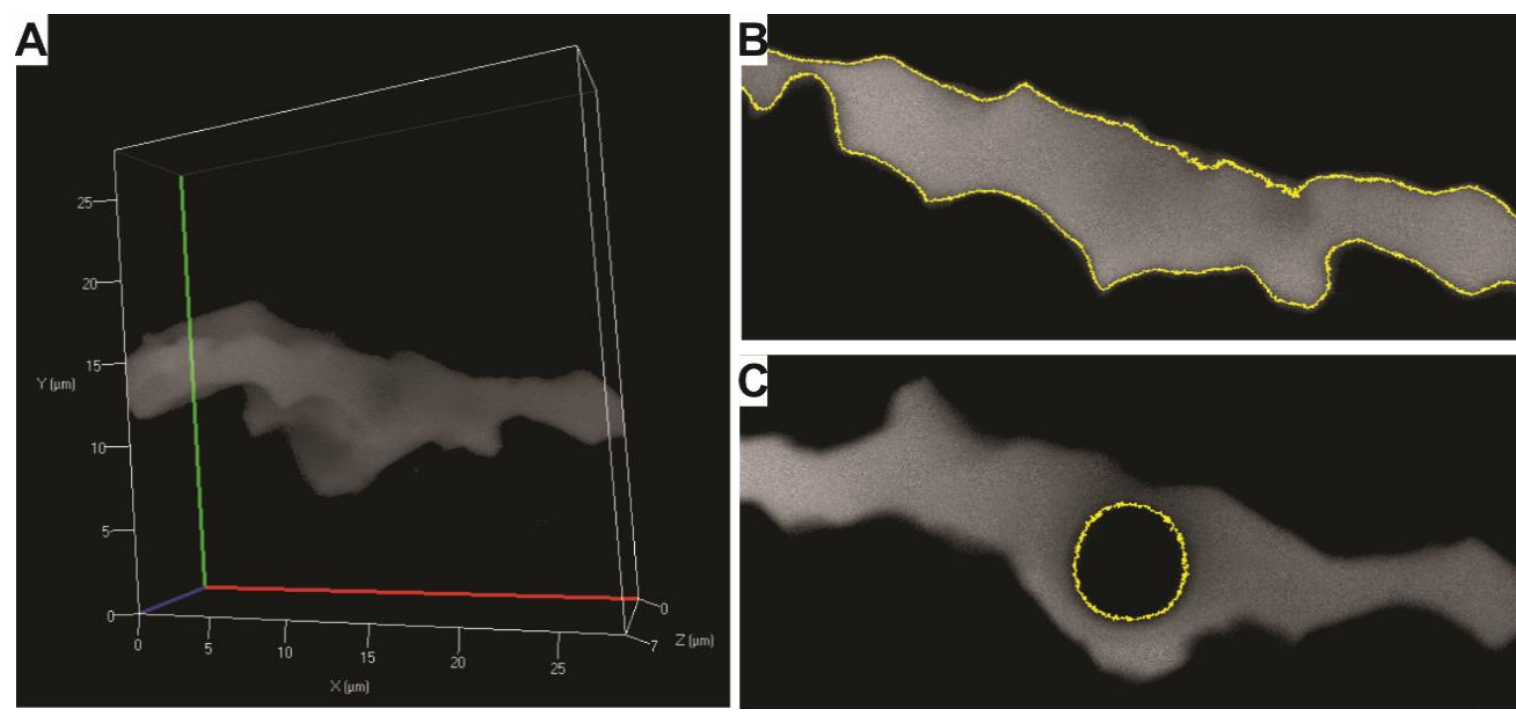

Figura 4.8. Imagens obtidas através de microscópio confocal de varredura a laser para a inclusão fluida número doze de origem primária pertencente à Formação Irati (Tabela 4.3). (A) Modelo 3D onde é possível observar o diâmetro de $25 \mu \mathrm{m}$ e a fase vapor (bolha) com formato esférico. (B e C) Imagens 2D onde é determinado o volume da fase liquida (B) e o volume da fase vapor (C) da inclusão com auxílio de software especializado. Inclusão fluida composta por hidrocarbonetos no 12 . Formação Irati. Amostra quartz-04. 
Tabela 4.2. Resumo de resultados microtermométricos e das análises de microscopia confocal conjugados com o cálculo de volumes de fases de inclusões fluidas compostas por hidrocarbonetos pertencentes às formações Corumbataí e Irati.

\begin{tabular}{|c|c|c|c|c|c|c|}
\hline \multirow[b]{2}{*}{ Unidade } & \multirow[b]{2}{*}{ IF } & Microtermometria & \multicolumn{3}{|c|}{ Confocal } & \multirow[b]{2}{*}{$\begin{array}{c}\text { Média } \\
\text { Fv }_{v}\end{array}$} \\
\hline & & $\operatorname{Th}\left({ }^{\circ} \mathrm{C}\right)$ & $\begin{array}{c}\text { Volume da } \\
\text { fase liquida } \\
\left(\mu m^{3}\right)\end{array}$ & $\begin{array}{c}\text { Volume da } \\
\text { fase vapor } \\
\left(\mu \mathrm{m}^{3}\right)\end{array}$ & $\begin{array}{c}\text { Fração } \\
\text { volumétrica } \\
\left(\% F_{v}\right)\end{array}$ & \\
\hline \multirow{18}{*}{$\begin{array}{l}\text { Formação } \\
\text { Corumbataí }\end{array}$} & 1 & 128,8 & 77,38 & 5,70 & 7,4 & \multirow{18}{*}{5,8} \\
\hline & 2 & 96,1 & 54,08 & 2,16 & 4,0 & \\
\hline & 3 & 59,7 & 250,44 & 10,59 & 4,2 & \\
\hline & 4 & 142,5 & 601,25 & 20,63 & 3,4 & \\
\hline & 5 & 118,7 & 40,75 & 2,12 & 5,2 & \\
\hline & 6 & 151 & 145,97 & 13,96 & 9,6 & \\
\hline & 7 & 120,6 & 442,17 & 33,26 & 7,5 & \\
\hline & 8 & 75,4 & 6,95 & 0,47 & 6,8 & \\
\hline & 9 & 107,9 & 21,91 & 1,25 & 5,7 & \\
\hline & 10 & 120,8 & 16,92 & 0,38 & 2,2 & \\
\hline & 11 & 151,7 & 166,68 & 5,58 & 3,3 & \\
\hline & 12 & 59,2 & 30,53 & 2,55 & 8,4 & \\
\hline & 13 & 138,5 & 14,38 & 0,83 & 5,8 & \\
\hline & 14 & 52,1 & 151,25 & 7,93 & 5,2 & \\
\hline & 15 & 147,2 & 112,20 & 4,51 & 4,0 & \\
\hline & 16 & 131,2 & 209,19 & 12,20 & 5,8 & \\
\hline & 17 & 66,1 & 23,41 & 2,66 & 11,4 & \\
\hline & 18 & 57,9 & 164,11 & 7,99 & 4,9 & \\
\hline \multirow{19}{*}{$\begin{array}{c}\text { Formação } \\
\text { Irati }\end{array}$} & 1 & 63,1 & 715,33 & 24,92 & 3,5 & \multirow{19}{*}{5,4} \\
\hline & 2 & 69,6 & 93,36 & 2,56 & 2,7 & \\
\hline & 3 & 63,8 & 24,12 & 1,15 & 4,8 & \\
\hline & 4 & 62,3 & 7,93 & 0,13 & 1,6 & \\
\hline & 5 & 69,9 & 251,5 & 14,75 & 5,9 & \\
\hline & 6 & 92,3 & 14,89 & 0,78 & 5,2 & \\
\hline & 7 & 137,4 & 24,73 & 1,50 & 6,0 & \\
\hline & 8 & 150 & 8,78 & 0,84 & 9,6 & \\
\hline & 9 & 83,9 & 41,99 & 2,41 & 5,7 & \\
\hline & 10 & 90 & 45,88 & 2,27 & 4,9 & \\
\hline & 11 & 139,7 & 17,42 & 1,43 & 8,2 & \\
\hline & 12 & 94,5 & 841,84 & 53,22 & 6,3 & \\
\hline & 13 & 150 & 24,85 & 1,99 & 8,0 & \\
\hline & 14 & 110,6 & 75,77 & 1,64 & 2,2 & \\
\hline & 15 & 113,2 & 27,65 & 0,99 & 3,6 & \\
\hline & 16 & 65,1 & 135,79 & 3,6 & 2,7 & \\
\hline & 17 & 139,5 & 6,76 & 0,54 & 8,0 & \\
\hline & 18 & 138,3 & 5,6 & 0,51 & 9,1 & \\
\hline & 19 & 93,5 & 2,98 & 0,16 & 5,4 & \\
\hline
\end{tabular}




\subsection{Isótopos estáveis de carbono e oxigênio em veios de calcita}

Foram realizadas análises de isótopos estáveis de carbono $(\mathrm{C})$ e oxigênio $(\mathrm{O})$ em amostras de veios hospedados nas formações Irati, Serra Alta, Teresina, em sill associado à LIP Paraná e na capa de basalto da Formação Serra Geral (Tabela 4.3). As amostras tendem a valores empobrecidos em ${ }^{13} \mathrm{C}$ e ${ }^{18} \mathrm{O}$ (ligeiramente negativos) em relação ao padrão. Os valores de $\delta^{13} \mathrm{C}$ e $\delta^{18} \mathrm{O}$ foram normalizados em relação ao padrão internacional Vienna Pee Dee Belemnite (VPDB). Este material de referência é utilizado em estudos de carbonatos de baixas temperaturas (Hoefs, 2004).

Os valores de $\delta^{13} \mathrm{C}$ e $\delta^{18} \mathrm{O}$ dos veios da Formação Irati (amostras calcite-01 e calcite-03) variam de $-5,97$ a -4,14 \%o com média de $-5,06 \%$, e de $-6,79$ a $-4.99 \%$ com média de $-5,89 \%$, respectivamente. Os valores de $\delta^{13} \mathrm{C}$ e $\delta^{18} \mathrm{O}$ dos veios da Formação Serra Alta (amostras IR-05 e IR-06) variam de -5,11 a -3,66 \%o com média de -4,55\%o, e de $-6,18$ a -4,46 \%o com média de $-5,48 \%$, respectivamente. Na Formação Teresina os valores de $\delta^{13} \mathrm{C}$ e $\delta^{18} \mathrm{O}$ variam de 1,07 a 1,95 \% com média de 1,49 \% e -8,14 a 2,84 $\%$ com média de $-4,29 \%$, respectivamente. Os veios hospedados em basalto da Formação Serra Geral (SG-01) e em sill associado à LIP Paraná (SLIP-02) apresentam valores de $\delta^{13} \mathrm{C}$ e $\delta^{18} \mathrm{O}$ que variam de $-11,52$ a $-7,93 \%$ com média de $-9,72 \%$ e, - 9,47 a $-7,66 \%$ com média de $-8,57 \%$, respectivamente (Tabela 4.3 ).

Tabela 4.3. Resumo dos valores de $\delta^{13} \mathrm{C}$ e $\delta^{18} \mathrm{O}$ (PDB) obtidos em veios de calcita nas formações Irati, Serra Alta, Teresina e Serra Geral. O valor delta $(\delta)$ é expresso em valor per mil (\%). Amostras da Formação Teresina retiradas de Nomura (2012) para contextualização.

\begin{tabular}{|c|c|c|c|c|c|c|c|c|}
\hline & \multicolumn{2}{|c|}{$\begin{array}{c}\text { FM. IRATI } \\
\text { (amostras calcite-01 } \\
\text { e calcite-03) }\end{array}$} & \multicolumn{2}{|c|}{$\begin{array}{l}\text { FM. SERRA ALTA } \\
\text { (amostras IR-05 e } \\
\text { IR06) }\end{array}$} & \multicolumn{2}{|c|}{$\begin{array}{l}\text { FM. TERESINA } \\
\text { (Nomura, 2012) }\end{array}$} & \multicolumn{2}{|c|}{$\begin{array}{l}\text { FM. SERRA GERAL } \\
\text { (amostras SG-01 e } \\
\text { SLIP-02) }\end{array}$} \\
\hline & $\delta^{13} \mathrm{C}$ & $\delta^{18} \mathrm{O}$ & $\delta^{13} \mathrm{C}$ & $\delta^{18} O$ & $\delta^{13} \mathrm{C}$ & $\delta^{18} \mathrm{O}$ & $\delta^{13} \mathrm{C}$ & $\delta^{18} \mathrm{O}$ \\
\hline MíNIMO & $-5,97$ & $-6,79$ & $-5,11$ & $-6,18$ & 1,07 & $-8,14$ & $-11,52$ & $-9,47$ \\
\hline MÁXIMO & $-4,14$ & $-4,99$ & $-3,66$ & $-4,46$ & 1,95 & 2,84 & $-7,93$ & $-7,66$ \\
\hline MÉDIA & $-5,06$ & $-5,89$ & $-4,55$ & $-5,48$ & 1,49 & $-4,29$ & $-9,72$ & $-8,57$ \\
\hline
\end{tabular}




\subsection{Reflectância de vitrinita (\% Ro)}

Foram analisadas quatro amostras de folhelho da Formação Irati, coletadas no sul do Estado do Paraná (Tabela 3.2). As amostras estudadas (IR-07, IR-08, IR-09 e IR-10) apresentam semelhanças composicionais, com grande quantidade de matriz mineral e de maceral inertinita; a presença de vitrinita é restrita a pequenos fragmentos que ocorrem dispersos na matriz (Figura 4.9).

Os valores de Ro para as quatro amostras de folhelhos estudadas variam entre 0,4 a 0,8 \% com média de 0,6\%. Foram encontrados alguns fragmentos do grupo da liptinita com maior poder refletor na amostra IR-07, Ro até 0,9, mas de baixa representatividade pela sua escassa ocorrência. Nas amostras IR-09 e IR-10 fragmentos de vitrinita com valores baixos de Ro, que varia entre 0,2 e 0,3\% foram observados, porém com ocorrência reduzida (Figura 4.9).
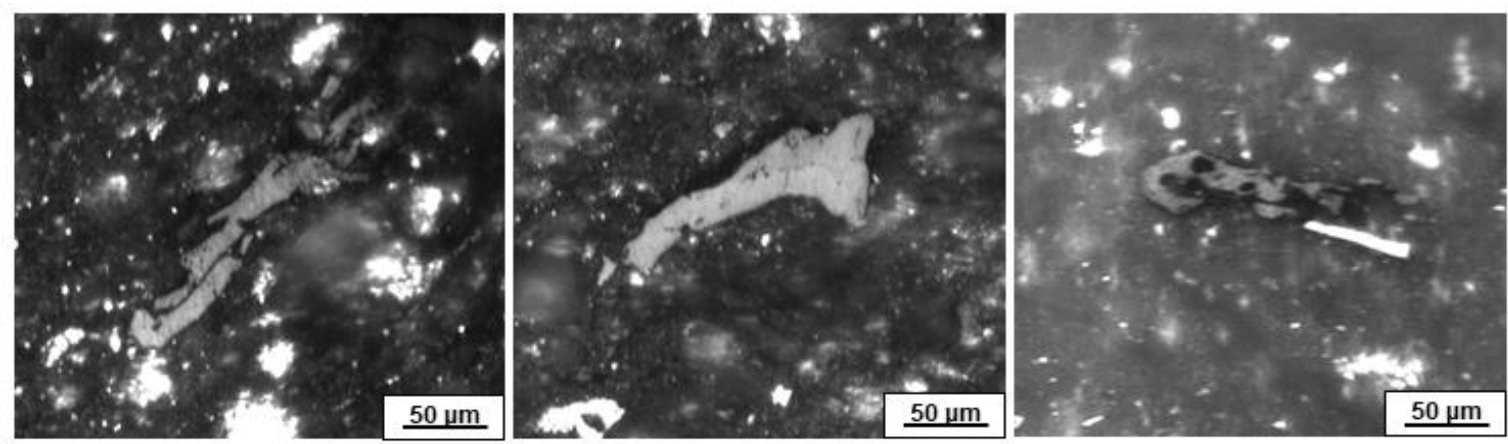

\section{$\underset{\substack{\text { IR-07 } \\(\mathrm{n}=78)}}{\mathrm{n}}$}

IR-08
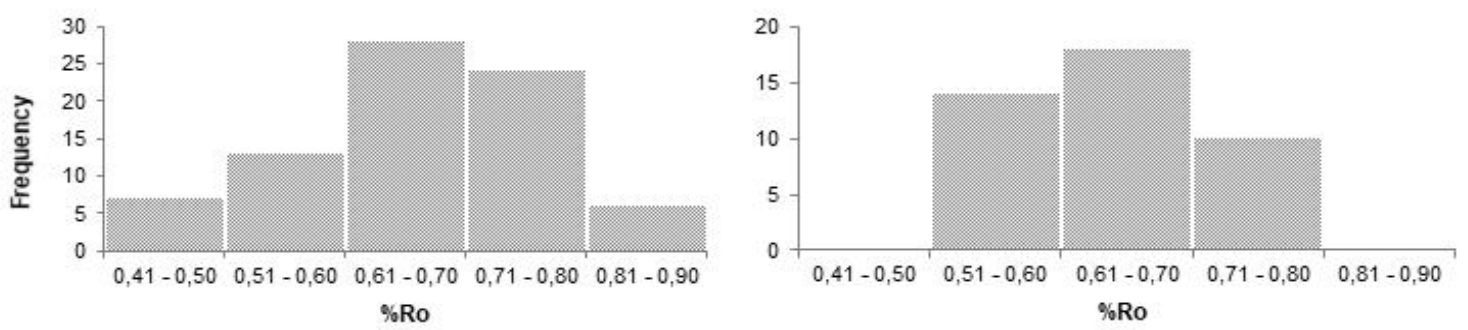

IR-09
$(n=38)$

IR-10
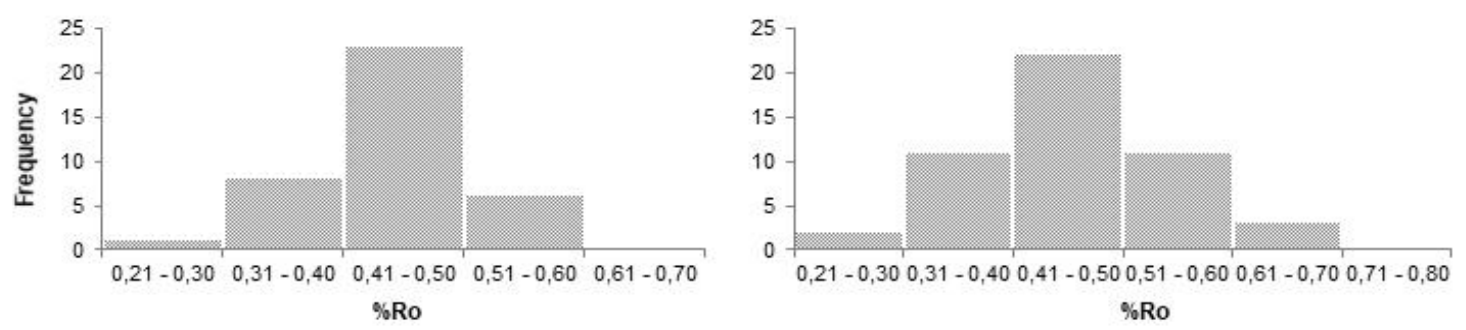

Figura 4.9. Dados de reflectância de vitrinita em folhelhos da Formação Irati na borda SSE da Bacia do Paraná para as amostras estudadas. 


\subsection{Ressonância magnética nuclear (RMN) em querogênio}

As características estruturais do querogênio isolado a partir da matéria orgânica contida nos folhelhos da Formação Irati foram obtidas através de RMN através da técnica de ${ }^{13} \mathrm{C}$ CP/MAS. Estas análises permitiram a obtenção do teor e aromaticidade $\left(f_{\text {ar }}\right)$ do querogênio extraído a partir dos folhelhos (Tabela 4.4).

Os espectros de ${ }^{13} \mathrm{C}$ NMR CP/MAS do querogênio nas diversas amostras (Figura 4.10), exibem duas bandas largas que indicam a presença de carbonos alifáticos ( 0 a 70 ppm) e aromáticos (100 a 180 ppm). No entanto, considerando o tempo de contato (1,5 ms), é suportado por vários estudos relatados com um erro de aproximadamente $20 \%$, uma tendência de subestimação de carbonos insaturados (Wei et al., 2005; Smernik et al., 2006; Kelemen et al., 2007; Solum et al., 2014). A razão sinal-ruído dos espectros $B$ e C (amostras IR-08 e IR-10, respectivamente) é inferior à do espectro $A$ (amostra IR-07) devido ao menor conteúdo de prótons no querogênio das amostras IR08 e IR-10 em comparação com o querogênio da amostra IR-07 (Figura 4.10).

Tabela 4.4. Resumo dos dados de COT e teor de querogênio dos folhelhos da Formação Irati e de reflectância de vitrinita e RMN (aromaticidade) do querogênio extraído dos respectivos folhelhos.

\begin{tabular}{c|c|c|c|c|c}
\hline AMOSTRA & COT & \% Ro & $\begin{array}{c}\text { Teor de } \\
\text { querogênio (\%) }\end{array}$ & Aromáticos C (\%) & Alifáticos C (\%) \\
\hline IR-07 & 6,16 & 0,65 & 10,7 & 25 & 75 \\
\hline IR-08 & 4,69 & 0,65 & 8,3 & 44 & 56 \\
\hline IR-10 & 2,05 & 0,45 & 6,2 & 23 & 77 \\
\hline
\end{tabular}




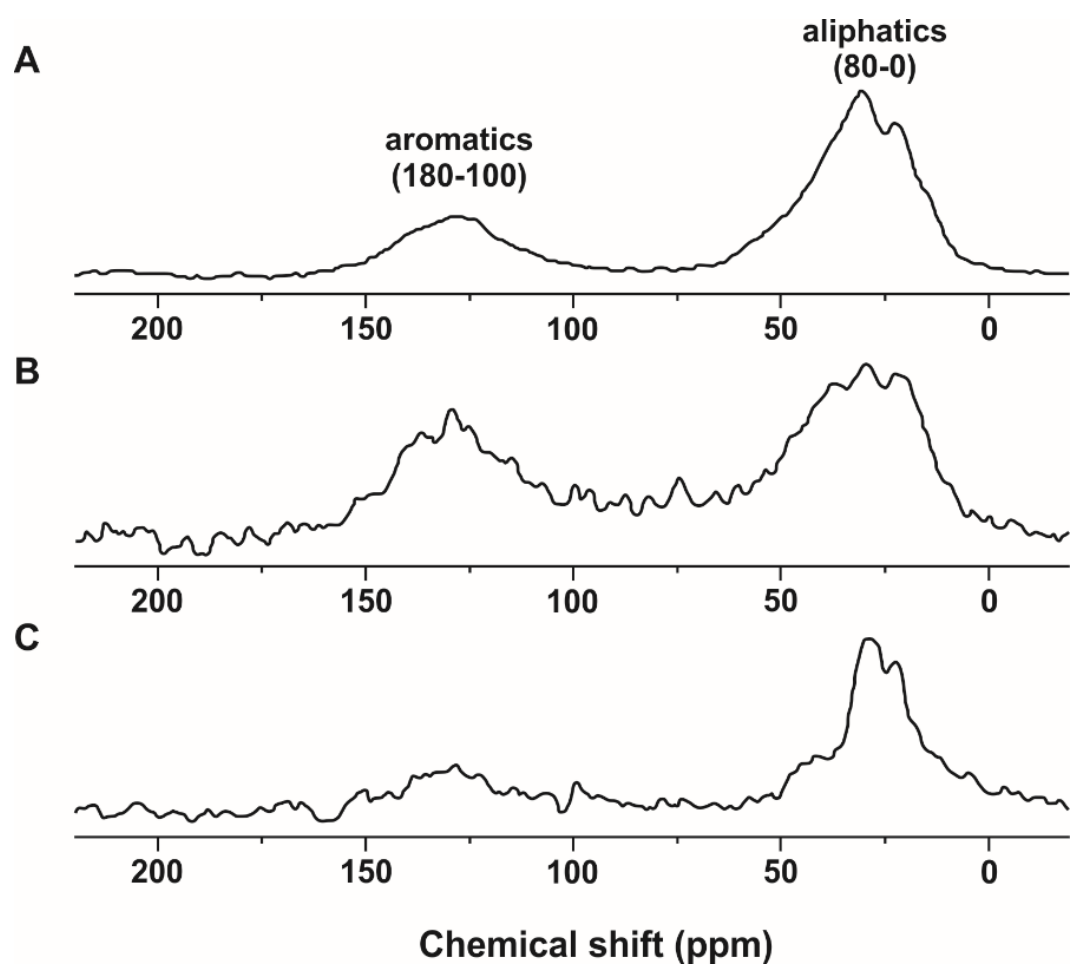

Figura 4.10. Espectro de variação de aromaticidade do querogênio em amostras da Formação Irati, na borda SSE da Bacia do Paraná. (A) Amostra IR-07. (B) Amostra IR-08. (C) Amostra IR10. 
CAPÍTULO 5 


\section{CAPÍTULO 5}

\section{DISCUSSÕES}

\subsection{Grau de evolução térmica e aromaticidade do querogênio na Formação Irati}

O poder refletor de vitrinita ou reflectância de vitrinita (\% Ro) provou ser um dos principais parâmetros físicos de avaliação de maturidade térmica do querogênio (Hood et al., 1975; Hutton \& Cook, 1980; Tissot \& Welte, 1984) e geração de petróleo e gás (Potter, 1998; Jarvie et al., 2007) mais empregados em sistemas petrolíferos de bacias sedimentares, porém ainda existem algumas limitações inerentes que não devem ser ignoradas. O principal problema relacionado ao uso de vitrinita é a supressão ou superestimação de Ro, ou seja, quando os valores de Ro se encontram mais baixos ou mais elevados do que o esperado para a maturidade térmica (Fang \& Jinayu, 1992). A supressão de vitrinita pode estar associada à presença de macerais com população dominante de exinita, alginita, resinita, etc, e a superestimação dos valores de Ro pode estar relacionada a condições deposicionais óxicas (Wenger \& Baker, 1987).

Souza et al. (2008) consideram a Formação Irati imatura em grande parte da Bacia do Paraná, porém quando em contato com rochas intrusivas ígneas inicia um processo de maturação atípico.

Na borda SSE da Bacia do Paraná, a média de valores de Ro $(0,6 \%)$ medida na Formação Irati aponta para um folhelho de maturidade baixa (Figura 4.9) e temperaturas de soterramento entre 60 e $80^{\circ} \mathrm{C}$, em uma área com ausência de corpos magmáticos intrusivos. Esses valores correspondem a maturidades de janela de óleo nas quais hidrocarbonetos líquidos podem ser gerados (Dembicki, 2013). Estas evidências estão em contraste com as temperaturas de homogeneização obtidas neste estudo em inclusões fluidas aquosas (AqFl's) coexistentes com inclusões fluidas compostas por hidrocarbonetos (HCFI's) que variam entre 50 e $330{ }^{\circ} \mathrm{C}$, apontando diferença térmica entre a rocha hospedeira e os veios que seccionam a Formação Irati na borda NNE da bacia. Apesar da possível presença de macerais do grupo da liptinita (exinita), os valores obtidos a partir de análises de ${ }^{13} \mathrm{C}$ RMN CP/MAS indicam convergência entre a aromaticidade $\left(f_{\mathrm{ar}}\right)$ do querogênio e maturidade térmica da vitrinita (Tabela 4.4). A aromaticidade (razão entre carbono aromático e alifático) é aceita como parâmetro confiável para avaliação de maturidade térmica do querogênio (Wang et al., 1995; Werner-Zwanziger et al., 2005). As amostras estudadas (IR-07; IR-08 e IR-10) mostram espectros de ${ }^{13} \mathrm{C}$ RMN CP/MAS que integram estruturas de carbono alifático e aromático (Figura 4.10). De fato, carbonos com ligações insaturadas, não necessariamente 
cíclicas, são observados em torno de 130 ppm (Figura 4.10). Desta forma, o sinal em frequências mais altas pode ser associado a uma mistura de carbonos aromáticos e alcenos.

Ao correlacionar os dados de Ro versus $f_{\mathrm{ar}}$, identifica-se uma relação não linear entre as amostras IR-08, IR-10 e vitrinita analisada em estudos anteriores (Figura 5.1), onde o $f_{\text {ar }}$ aumenta com o Ro (Carr \& Williamson, 1990), durante a maturação térmica natural causada por corpos ígneos ou por soterramento (Witte et al., 1988). Ademais, o aumento de aromaticidade (obtida através de análises de ${ }^{13} \mathrm{C}$ NMR CP/MAS) e 0 aumento de maturidade (Ro) é seguido pela perda de fração alifática (Witte et al., 1988; Miknis et al., 1993; Cao et al., 2013), o que não é o caso das amostras estudadas. Assim, estes dados sugerem um nível de maturidade térmica local relativamente baixo dentro de janela de geração de hidrocarbonetos líquidos (transição entre a diagênese e catagênese) na Formação Irati aflorante na borda SSE da Bacia do Paraná, bem como, uma influência significativa de fluidos hidrotermais induzidos por corpos magmáticos intrusivos (Liu et al., 2017) na borda NNE da bacia devido à discrepância entre Ro e Th nas amostras estudadas. Desta forma, a Formação Irati apresenta baixa maturidade em zona desprovida de ação térmica pela presença de corpos magmáticos intrusivos, ou seja, evolução térmica possivelmente controlada por soterramento devido à espessura de basalto pertencente à Formação Serra Geral $(\approx 1,7 \mathrm{Km})$ ou à espessa cobertura das rochas sedimentares sobrejacentes à Formação Irati (formações Pirambóia, Botucatu e Grupo Bauru $\approx 1,3 \mathrm{~km}$ ). Por outro lado, a Formação Irati apresenta potencial gerador de hidrocarbonetos termogênicos na borda leste da Bacia do Paraná. 


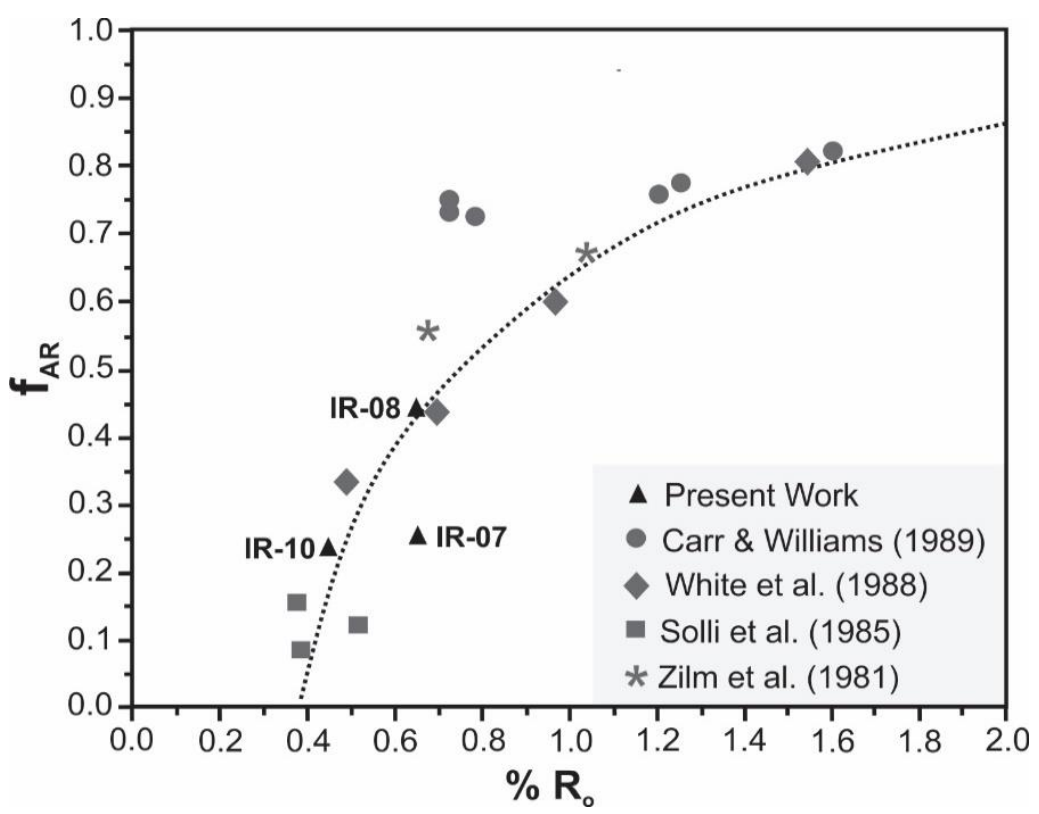

Figura 5.1. Correlação entre aromaticidade $\left(f_{\mathrm{ar}}\right)$ e reflectância de vitrinita $(\mathrm{Ro})$ nos folhelhos da Formação Irati, borda SSE da Bacia do Paraná, em comparação com dados obtidos em folhelhos de outras unidades sedimentares da literatura. Carr \& Williams (1990) - África, Austrália, Europa e América do Norte; Solli et al. (1985) - Miocene shale; White et al. (1988) - Toarcian shale França.

\subsection{Maturidade térmica de HCFl's com base em petrografia}

Através de microscopia óptica, observam-se inclusões fluidas compostas por hidrocarbonetos hospedadas em veios autigênicos da Formação Irati e da Formação Corumbataí na borda NNE da Bacia do Paraná com variações de fluorescência (Figura 4.4B'; C; D e E'). A fluorescência em tons diversos (laranja, amarela, azul e branca) indica que a densidade dos hidrocarbonetos foi sujeita a alterações químicas (variação de ${ }^{\circ} \mathrm{API}$ ) durante o crescimento dos cristais e desenvolvimento dos veios (Li \& Parnell, 2003; Ping et al., 2017). Estas variações sugerem ${ }^{\circ} \mathrm{API}$ entre 20-40 e a presença de hidrocarbonetos intermediários a mais leves hospedados nos veios autigênicos (Goldstein \& Reynolds, 1994). De acordo com Stasiuk \& Snowdon (1997), o espectro de fluorescência de $550 \mathrm{~nm}$ (Lmax), que está relacionado a um óleo com 40 a $50 \%$ de aromáticos, sugere que as inclusões fluidas compostas por hidrocarbonetos (fase líquida) podem conter entre 60 a $50 \%$ de compostos alifáticos (alcenos). Verna et al. (2012) discutem que inclusões fluidas primárias compostas por hidrocarbonetos com fluorescência amarela estão associadas a óleos de baixa maturidade com $n$-alcanos de cadeias longas e pequena fração de hidrocarbonetos aromáticos. Apesar da ausência de análises químicas completas (GC; GC - MS ou GC - IRMS) realizadas nas HCFI's, estes dados corroboram com a aromaticidade do querogênio ( $f_{\mathrm{ar}} \approx 30 \%$ ) e a fluorescência óptica das inclusões. Assim, a história térmica entre as inclusões fluidas 
compostas por hidrocarbonetos hospedados nos veios e o potencial gerador de hidrocarbonetos termogênicos leves é semelhante. Contudo, além da fluorescência ser influenciada pela origem da rocha geradora e maturidade térmica (Stasiuk \& Snowdon, 1997), modificações secundárias como biodegradação ou lixiviação por fluidos aquosos podem ocorrer em reservatórios de hidrocarbonetos ou em sistemas de fraturas (Tissot \& Welte, 1984).

\subsection{Temperatura de aprisionamento de hidrocarbonetos}

Os veios de quartzo e calcita da Formação Irati que contêm inclusões fluidas aquosas (AqFl's) coexistentes com inclusões de hidrocarbonetos (HCFl's) sugerem um sistema petrolífero ativo, além de um fluido diagenético com água parcialmente miscível em óleo durante o desenvolvimento dos veios. As HCFI's da Formação Irati apresentam temperaturas de homogeneização (Th) inferiores às das AqFl's coexistentes (Figura 4.5G). A diferença da média das Th entre as AqFl's ( $135^{\circ} \mathrm{C}$ ) e HCFl's $\left(96^{\circ} \mathrm{C}\right.$ ) não pode ser apenas explicada pelo declive das isócoras dos dois fluidos, assumindo condições de aprisionamento (P-T) idênticas (Permanyer et al., 2017), assim, esta diferença devese, possivelmente, pela presença de uma fase aquosa nas HCFl's, não visível em microscopia óptica, semelhante ao sistema de fraturas cimentadas no Mar do Norte (Oxtoby et al., 1995; Munz et al., 1998, 2004) e a história diagenética de reservatórios discutida por Munz et al (1999a). Na borda NNE da Bacia do Paraná, a migração de hidrocarbonetos pode ter ocorrido concomitantemente aos primeiros estágios de crescimento cristalino dos veios no Eocretáceo (Nomura et al., 2014; Teixeira et al., 2014), devido à presença de inclusões primárias compostas por hidrocarbonetos (Figura 4.4B' e D). Inclusões fluidas compostas por hidrocarbonetos de origem primária e pseudo-secundária de fluorescência amarela (Tipo 2) migraram pelas fraturas em temperaturas diagenéticas que variam entre 50 e $200{ }^{\circ} \mathrm{C}$ (Figura 4.5G). Um estágio tardio de migração, ou um pulso posterior de hidrocarbonetos, ocorreu em temperaturas superiores a $200{ }^{\circ} \mathrm{C}$ (Figura 4.5F). Estas temperaturas podem estar relacionadas a fluidos originados por diferenças de gradientes de pressão após a intrusão e consequente arrefecimento do sill (sill de Limeira, Carvalho et al., 1988) intercalado entre as formações Irati e Corumbataí (Figura 3.1B). Inclusões ricas em metano $\left(\mathrm{CH}_{4}\right)$ ou em dióxido de carbono $\left(\mathrm{CO}_{2}\right)$ que apresentam fase vapor dominante não foram observadas nos veios de calcita hospedados em basalto da Formação Serra Geral e em sill associado à LIP Paraná no Estado do Paraná (Ponta Grossa). Os dados microtermométricos das inclusões primárias e pseudo-secundárias representam as temperaturas mínimas alcançadas pelas HCFl's $\left(96^{\circ} \mathrm{C}\right)$ e AqFl's $\left(135^{\circ} \mathrm{C}\right)$, seguidas por 
um estágio de migração tardio representado por inclusões fluidas compostas por hidrocarbonetos de origem secundária (média $\mathrm{Th}=173^{\circ} \mathrm{C}$ ).

Ademais, na borda SSE da Bacia do Paraná, os dados de Ro $(0,6 \%)$ apontam para temperatura de soterramento entre 60 e $80^{\circ} \mathrm{C}$ (Hunt, 1996) e janela de geração de hidrocarbonetos líquidos (Dembicki, 2013). Isto significa que a Formação Irati, ao longo do flanco leste da Bacia do Paraná, pode ter atingido profundidade suficiente para gerar hidrocarbonetos líquidos heterogêneos ( ${ }^{\circ} \mathrm{API}$ entre 20-40) durante o Eocretáceo devido, essencialmente, pela espessura do basalto da Formação Serra Geral, sendo, neste caso, os corpos ígneos intrusivos responsáveis pela geração local (geração hidrotermal), migração e biodegradação (vide tópico 5.4.1) dos hidrocarbonetos. Matéria orgânica de baixa maturação disseminada em rochas sedimentares litificadas pode ser transformada em hidrocarboneto de origem hidrotermal pelo contato com fluidos quentes de origem meteórica, como acontece na Bacia de Tanganyika no leste Africano (Simoneit et al., 2000), ou em sistemas de rift continental como no México (Zaraté et al., 2005) e Golfo da Califórnia na Bacia de Guaymas (Simoneit et al., 1985).

\subsection{Classificação de hidrocarbonetos em veios de calcita e quartzo}

Hidrocarbonetos aprisionados sob a forma de inclusões fluidas permitiram estimar a determinação da composição original de hidrocarbonetos líquidos potencialmente gerados pelas formações Corumbataí (amostra CB-01) e Irati (amostra quartz-04). Microtermometria combinada com análises de microscopia confocal e varredura a laser (CSLM) possibilitam discriminar diferentes tipos de óleo aprisionado em inclusões fluidas. As inclusões de hidrocarboneto da amostra estudada revelam média de Th igual a $106{ }^{\circ} \mathrm{C}$ com fração volumétrica $\left(\% F_{v}\right)$ que varia desde 2,2 a 11,4 \% com média de 5,8 \% para a Formação Corumbataí. Na Formação Irati, os resultados são similares com Th média de $101,4{ }^{\circ} \mathrm{C}$ e fração volumétrica $\left(\% F_{v}\right)$ que varia desde 1,6 a 9,6 \% com média de $5,4 \%$ (Tabela 4.2). Estes dados permitem classificar os hidrocarbonetos aprisionados nas inclusões fluidas como black oil (Thiéry et al., 2002; Bourdet et al., 2008). Esta estimativa composicional (Figura 5.2) é semelhante aos casos de estudo em reservatórios no sul do Golfo do México (Gulf of Mexico) e amostras de poço do Mar no Norte (North Sea) interpretados por Bourdet et al. (2008). De acordo com Danesh (1998), black oil é o tipo mais comum de óleo encontrado em reservatórios, o qual é caracterizado por hidrocarbonetos leves a médios com pequena variação de densidade ( $\left.{ }^{\circ} \mathrm{API}\right)$, o que corresponde a fluidos de densidade média a baixa. Ademais, a geração de black oil em reservatórios pode ocorrer entre valores de \% Ro que variam de 0,6 até 1,1-1,2 (Dembicki, 2013). 
A combinação dos parâmetros de fração vapor $\left(F_{v}\right)$ versus Th revelam uma tendência de valores de $F_{v}$ com pequena variação para uma grande variação de valores de Th (Figura 5.2), sugerindo processos de reequilíbrio térmico posteriores nas inclusões (Bourdet et al., 2008). Assim, o pequeno volume da fase vapor das HCFl's observado à temperatura ambiente $\left(\sim^{\circ}{ }^{\circ} \mathrm{C}\right)$, o que indica que a fase liquida é dominante, e a variação de fluorescência em petrografia corroboram a classificação de black oil nas inclusões. Desta forma, a aplicação de análises de microscopia confocal combinadas com dados de microtermometria e petrografia apresentam elevado potencial na determinação de tipos de hidrocarbonetos e propriedades P-V-T (Aplin et al., 1999). Esta rotina pode ser aplicada em reservatórios ou possíveis caminhos de migração de hidrocarbonetos em outras bacias sedimentares intracratônicas brasileiras, como a Bacia do Amazonas, Solimões e Parnaíba.

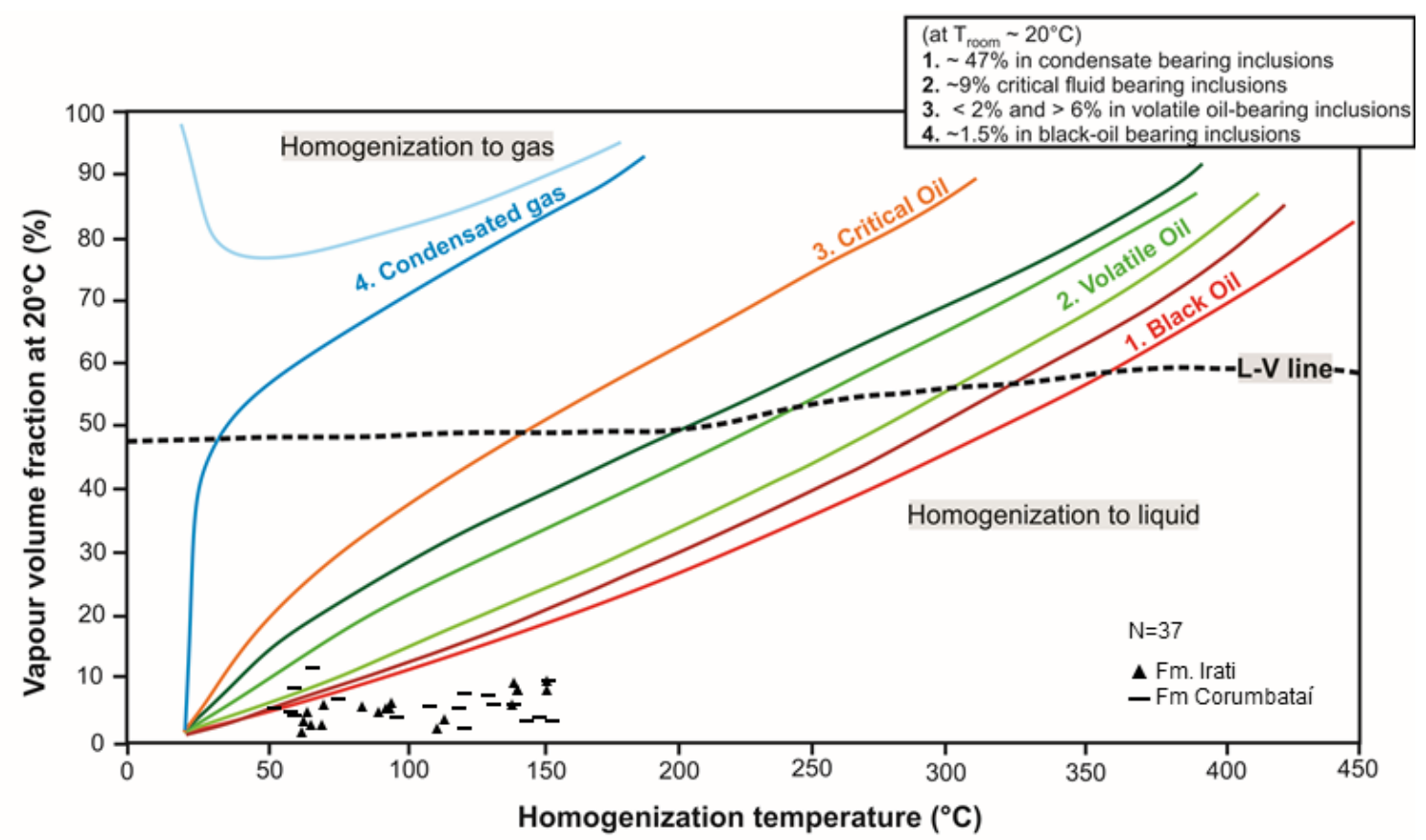

Figura 5.2. Gráfico de correlação entre a $F_{v}$ e a Th que possibilita a classificação de hidrocarbonetos aprisionados nas inclusões fluidas. Baseado em Bourdet et al., (2008) e modificado de Pestilho \& Monteiro (2017). 


\subsubsection{P-V-T e propriedades dos fluidos aprisionados}

Inclusões fluidas compostas por hidrocarbonetos são modeladas de forma eficiente se o fluido, usado como parâmetro de entrada nos cálculos, for geneticamente relacionado com o hidrocarboneto (Aplin et al., 1999). Desta forma, um modelo P-V-T integrando dois testes (set $A$ e o set $B$ ) foi realizado de acordo com o procedimento de Aplin et al. (1999) e Thiéry et al. (2002) para obtenção de resultados fidedignos. No primeiro set (SET A), a partir da reta que define o fluido foi escolhido um ponto que integra menor valor $\beta(0,011)$, que significa a quantidade de metano no sistema (Thiéry et al., 2002), tornando mais efetivo o modelo final. Desta forma, o modelo revela pressão de aprisionamento que varia de 496 a 296 bar para isotermas de inclusões de hidrocarbonetos entre 50 e $80^{\circ} \mathrm{C}$, respectivamente (Figura 5.3). Em relação ao segundo set (SET B), foi selecionado um ponto aleatório com maior valor $\beta(0,306)$ para testar possíveis flutuações de pressão. Nesse sentido, o modelo P-V-T revela pressões de aprisionamento que variam de 548 a 348 bar para as mesmas isotermas de 50 e $80^{\circ} \mathrm{C}$, respectivamente (Figura 5.3). Assim, assumindo o set A como o modelo mais fidedigno, estes dados revelam que a mínima pressão alcançada durante o aprisionamento de HCFl's hospedadas nos veios foi ao redor de 300 bar. Esta pressão sugere uma profundidade de soterramento superior a $2 \mathrm{~km}$ onde a temperatura média de homogeneização das AqFl's coexistentes $\left(135^{\circ} \mathrm{C}\right)$ com as de HCFI's são as temperaturas reais de aprisionamento consideradas (Munz, 2001). A pressão mais elevada de 496 bar é obtida através de inclusão com isoterma de $50{ }^{\circ} \mathrm{C}$ sugerindo a máxima pressão atingida nos veios. O segundo teste (SET B) comprova que não é possível determinar pressões de aprisionamento sem incertezas na ordem dos 50 bar aproximadamente (Thiéry et al., 2002). Apesar da variação de pressão entre os dois sets (52 bar) a precisão é suficiente para descriminar se o aprisionamento de hidrocarbonetos ocorre entre o regime hidrostático ou litostático. Assumindo o set $A$ como referência devido à ausência de metano nas inclusões (baixo valor de $\beta$ ), a variação de pressão pode ser interpretada como resultado de flutuações de pressão durante o fraturamento e desenvolvimento dos veios em sistema de cisalhamento (Faleiros et al., 2007). Contudo, condições diagenéticas de soterramento em reservatórios convencionais (arenitos) também indicam mudanças de pressão e temperatura simultânea (Thiéry et al., 2002). Este modelo sugere abertura de veios extensionais e aprisionamento de inclusões fluidas compostas por hidrocarbonetos sobre o regime de pressão sub-hidrostática a hidrostática devido, essencialmente, a descompressão isotérmica e aquecimento isobárico (Figura 5.3). Estas evidências refutam que durante o aprisionamento de HCFl's a Formação Irati se encontrava, no 
mínimo a $2 \mathrm{~km}$ de profundidade. Esta pressão está associada a um sistema petrolífero raso (abaixo da isoterma de $80^{\circ} \mathrm{C}$ ), o que não inviabiliza a atuação de processos de modificação posteriores como biodegradação. A circulação pervasiva de fluido aquoso de origem substancialmente meteórica com mistura parcial de fluido de poro (vide, item 5.5), pode ter sido responsável pela biodegradação de hidrocarbonetos. A fluorescência em tons laranja observada em algumas HCFl's e as condições de P-T estimadas corroboram a ocorrência de biodegradação.

As temperaturas de homogeneização de AqFl's coexistentes com HCFl's combinadas com a estimativa composicional dos hidrocarbonetos (Permanyer et al., 2017) e o modelo P-V-T dos fluidos sugerem um evento de aprisionamento de hidrocarbonetos de densidade média a baixa em temperaturas diagenéticas ao redor de $135^{\circ} \mathrm{C}$. 
SET A

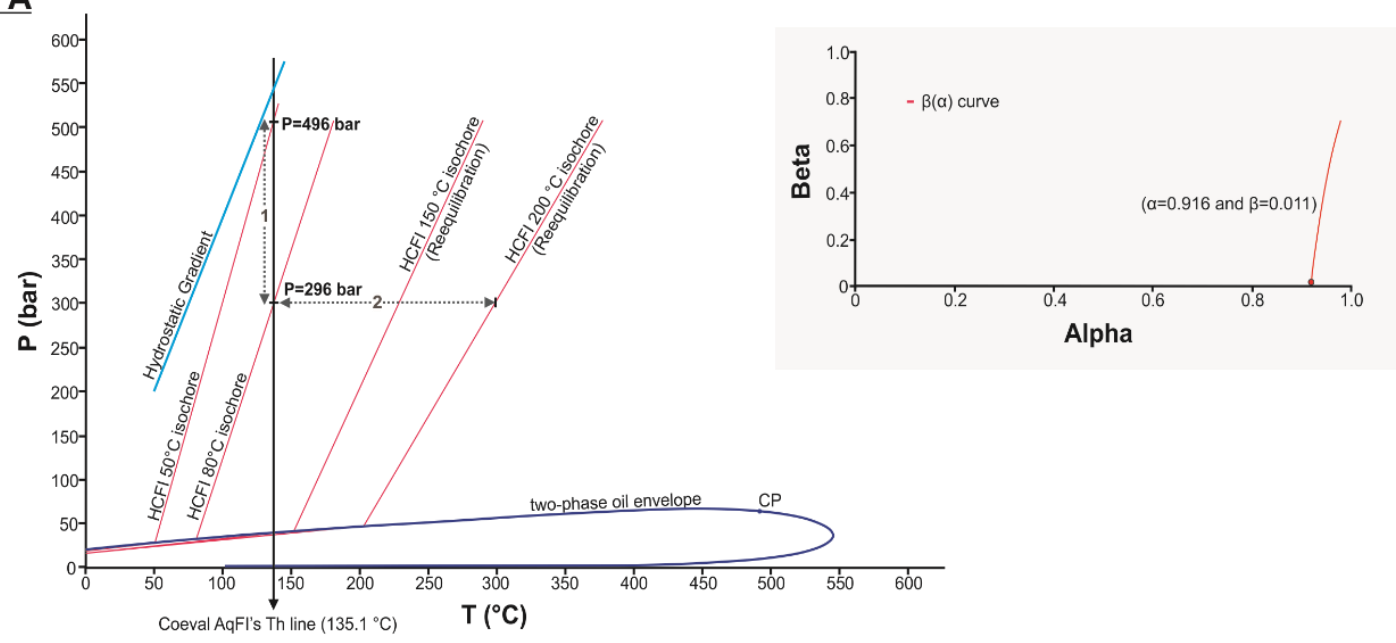

SET B

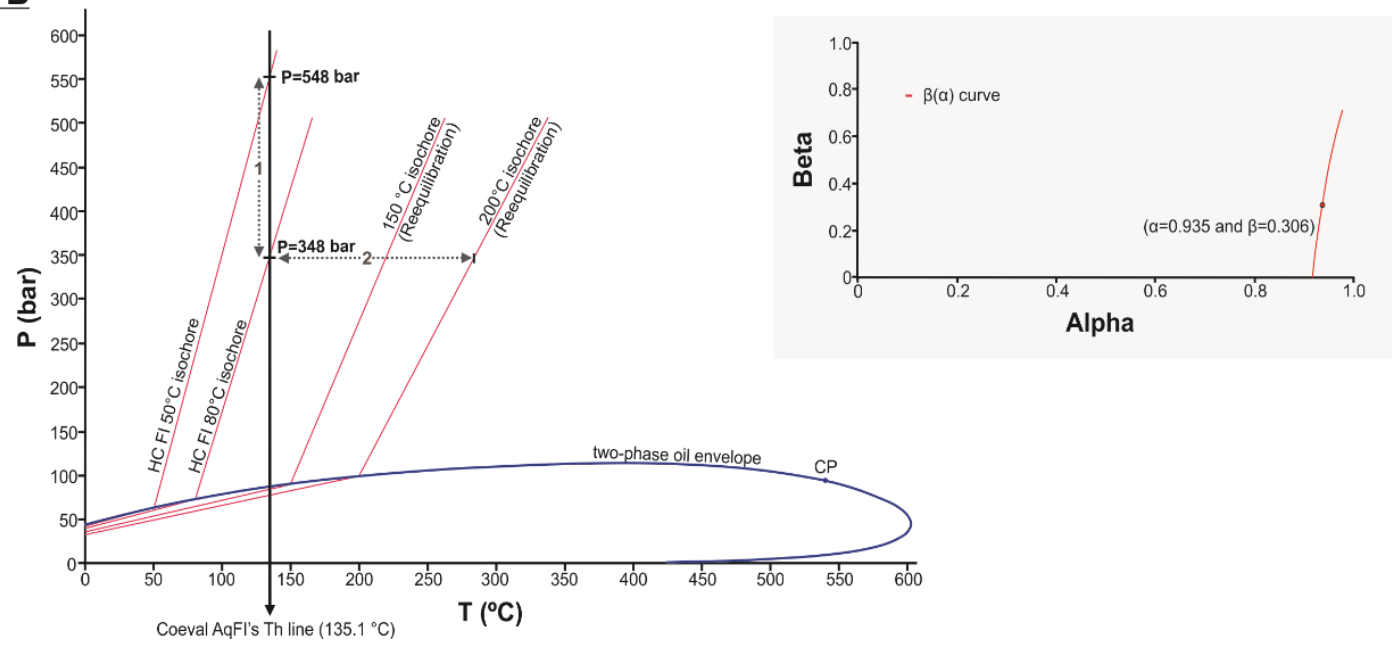

Figura 5.3. Modelo P-V-T e respectiva curva $\beta(\alpha)$ de inclusões fluidas compostas por hidrocarbonetos aprisionadas em veios extensionais sub-verticais de quartzo na Formação Irati. SET A: (1) Descompressão isotérmica que ocorre com a diminuição de pressão em temperatura constante. (2) Aquecimento isobárico que ocorre com o aumento de temperatura para pressão constante. SET B testado para provar as flutuações de pressão (52 bar) durante a modelagem $\mathrm{P}-\mathrm{V}$-T dos fluidos aprisionados. 


\subsection{Circulação de paleofluidos e desenvolvimento de veios autigênicos}

Estudos anteriores realizados em inclusões fluidas hospedadas em materiais autigênicos em rochas sedimentares permianas e devonianas, e rochas ígneas cretáceas da Bacia do Paraná podem ser consultados na Tabela 5.1.

Inclusões fluidas hospedadas em veios que preenchem fraturas em rochas sedimentares permianas (formações Teresina e Serra Alta), na borda leste da Bacia do Paraná, revelam temperaturas de homogeneização (Th) superiores a $200{ }^{\circ} \mathrm{C}$ (Nomura et al., 2014; Teixeira et al., 2018 - Anexo I). Teixeira et al. (2018) relatam uma ampla faixa de Th $\left(50\right.$ a $\left.250^{\circ} \mathrm{C}\right)$ obtida em AqFl's em veios de calcita na Formação Serra Alta (unidade sobrejacente à Formação Irati), apesar das amostras estudadas estarem fora do efeito direto de diques ou soleiras. As Th obtidas ( $>200^{\circ} \mathrm{C}$ ) em AqFl's hospedadas nos veios das formações Irati e Serra Alta e nos veios em basalto da Formação Serra Geral corroboram a hipótese de efeito térmico regional causado pela influência da capa de basaltos, e não apenas devido ao efeito térmico local causado pela presença de corpos magmáticos intrusivos (Teixeira et al., 2018). Esta hipótese certamente afetará a maturidade térmica alcançada pela Formação Irati sendo majoritariamente controlada por soterramento. A temperatura média de homogeneização $\left(\mathrm{Th}=166^{\circ} \mathrm{C}\right)$ obtida em AqFI's hospedadas em veio pertencente a sill associado à LIP Paraná (região de Ponta Grossa), estimam efeito térmico local associado ao período de arrefecimento do corpo ígneo especificamente.

De acordo com os dados microtermométricos obtidos na Formação Irati na borda NNE da bacia, dois tipos de fluidos aquosos podem ser reconhecidos através de intervalos de temperatura de fusão do gelo $(\mathrm{Tfg})$ e respectivos valores de salinidade em inclusões aquosas primárias (Tipo 1). O primeiro varia de 0 a $5 \%$ em peso de $\mathrm{NaCl}$ equivalente, e o segundo varia de 16 a $21 \%$ em peso de $\mathrm{NaCl}$ equivalente (Figura 4.5D). Salinidade moderadamente baixa ( 0 a $5 \%$ em peso de $\mathrm{NaCl}$ eq.) sugere reduzida interação rocha-fluido e fluido migrante de origem essencialmente meteórico. Salinidade elevada (16 a $21 \%$ em peso de $\mathrm{NaCl}$ eq.) pode ser representativa da forte interação rocha-fluido e consequente dissolução e lixiviação entre o fluido de poro e os níveis carbonáticos presentes na Formação Irati, durante a mesodiagênese.

A temperatura do ponto eutético aponta a sistema aquoso composto essencialmente por $\mathrm{H}_{2} \mathrm{O}+\mathrm{NaCl}+\mathrm{CaCl}_{2}$, (Roedder, 1984; Goldstein \& Reynolds, 1994). Nomura et al. (2014) discutem um cenário semelhante em inclusões fluidas aquosas primárias hospedadas em veios e materiais autigênicos da Formação Teresina (Neopermiano), devido à presença de siltitos intercalados com níveis carbonáticos e 
sequência de evaporitos. Isto sugere que o fluxo aquoso migrante aparenta continuidade vertical e circulação pervasiva pelo sistema de veios e rochas sedimentares permianas (formações Irati, Serra Alta e Teresina) até a capa de basalto da Formação Serra Geral. Temperaturas do ponto eutético inferiores a $-40{ }^{\circ} \mathrm{C}$ indicam presença de cátions divalentes ( $\mathrm{Ca}^{2+}$ e/ou $\mathrm{Mg}^{2+}$; Davis et al., 1990). A presença de $\mathrm{Ca}^{2+}$ é comum pela troca iônica entre o fluido e a calcita autigênica (Crawford \& Hollister, 1992), o que pode ocorrer em níveis carbonáticos da Formação Irati. Apesar da presença do grupo de inclusões com maior salinidade nos veios das amostras calcite-01 e quartzo-02 (Tfg que variam de $-18 \mathrm{a}-10^{\circ} \mathrm{C}$ ), a maioria das AqFl's apresentam Tfg que variam de -3 a $0{ }^{\circ} \mathrm{C}$ com média de $-1^{\circ} \mathrm{C}$, sugerindo um fluido de salinidade moderadamente baixa (Figura 4.5D) responsável pelo crescimento e desenvolvimento destes veios durante 0 Eocretáceo (Figura 5.4). Por conseguinte, a Figura 5.5 representa uma proposta de modelo de geração e circulação de fluidos diagenéticos (óleo e água) em rochas sedimentares permianas da Bacia do Paraná durante o Eocretáceo. Reconstruções da história de dinâmica de fluidos em veios de calcita e quartzo ou em acumulações de reservatórios são características determinantes em bacias sedimentares intracratônicas ou de outros contextos geológicos (e.g., Bodnar, 1990; Nedkvitne et al., 1993; George et al., 2007; Baron et al., 2008; Cao et al., 2010; Suchý et al., 2010; Bourdet et al., 2012). 
Tabela 5.1. Sumário dos dados microtermométricos obtidos em estudos anteriores realizados na Bacia do Paraná.

\begin{tabular}{|c|c|c|c|c|c|c|c|c|c|}
\hline Formação & $\begin{array}{l}\text { Mineral autigênico / } \\
\text { Rocha hospedeira }\end{array}$ & Tipo & Origem & Th (oC) & $\mathrm{Te}\left({ }^{\circ} \mathrm{C}\right)$ & $\operatorname{Tfg}\left({ }^{\circ} \mathrm{C}\right)$ & $\begin{array}{l}\text { Salinidade (\% } \\
\text { em peso de } \\
\mathrm{NaCl} \text { eq.) }\end{array}$ & Vvap (\%) & Autor \\
\hline Serra Geral & $\begin{array}{l}\text { Veio de calcita / dique } \\
\text { básico }\end{array}$ & Aquosalinas & Secundária & 80 a 260 & -35 a -51 & -2 a 0 & 0 a 3 & 5 a 10 & \multirow{6}{*}{$\begin{array}{l}\text { Nomura, } \\
2012\end{array}$} \\
\hline \multirow[t]{2}{*}{ Teresina } & \multirow{2}{*}{$\begin{array}{l}\text { Veios sub-horizontais de } \\
\text { calcita }\end{array}$} & Aquosalinas & Primária & 43,5 a 285 & $\begin{array}{l}{[-54 a-41] \text { e }[-} \\
\quad 53 a-27]\end{array}$ & $\begin{array}{c}{[-11 a-18] \text { e }} \\
{\left[\begin{array}{lll}-1 & a & -25]\end{array}\right.}\end{array}$ & 2 a 26 & \multirow[t]{2}{*}{ - } & \\
\hline & & Hidrocarbonetos & Secundária & 60 a 140 & - & - & - & & \\
\hline Teresina & $\begin{array}{l}\text { Veios sub-verticais de } \\
\text { calcita }\end{array}$ & Aquosalinas & Secundária & 60 a 90 & - & - & - & 5 a 10 & \\
\hline Corumbataí & \multirow{2}{*}{$\begin{array}{l}\text { Veios sub-verticais de } \\
\text { quartzo }\end{array}$} & Aquosalinas & Secundária & 110 a 380 & -41 a -52 & $\begin{array}{l}{[-2 \text { a }-6] \text { e }[-} \\
15 \text { a }-17]\end{array}$ & $\begin{array}{c}{[4,7 \text { a } 8,4] \text { e }} \\
{[11 \text { a } 15]}\end{array}$ & 15 a 20 & \\
\hline Corumbataí & & Hidrocarbonetos & Secundária & 60 a 220 & - & - & - & - & \\
\hline \multirow{2}{*}{ Irati } & \multirow{2}{*}{$\begin{array}{c}\text { Veio de calcita e quartzo } \\
\text { / Sill diabásio } \\
\text { (espessura }=20,6 \mathrm{~m})\end{array}$} & Aquosas & - & 40 a 240 & - & - & - & - & \multirow{4}{*}{$\begin{array}{l}\text { Araújo et } \\
\text { al. } 2000\end{array}$} \\
\hline & & Hidrocarbonetos & - & 60 a 260 & - & - & - & - & \\
\hline Irati & $\begin{array}{l}\text { Veio de calcita e quartzo } \\
\text { / Sill diabásio } \\
\text { (espessura }=27,2 \mathrm{~m} \text { ) }\end{array}$ & Aquosas & - & 40 a 150 & - & - & - & - & \\
\hline Palermo & - & Hidrocarbonetos & - & 50 a 130 & - & - & - & - & \\
\hline Furnas & $\begin{array}{l}\text { Quartzo em cimento } \\
\text { (amostra afloramento) }\end{array}$ & Aquosalinas & - & 11 a 156 & - & - & 16 a 28 & - & \multirow{2}{*}{$\begin{array}{l}\text { De Ros, } \\
1998\end{array}$} \\
\hline Furnas & $\begin{array}{l}\text { Quartzo em cimento } \\
\text { (amostra subsuperfície) }\end{array}$ & Aquosalinas & - & 83 a 110 & - & - & 16 a 19 & - & \\
\hline
\end{tabular}




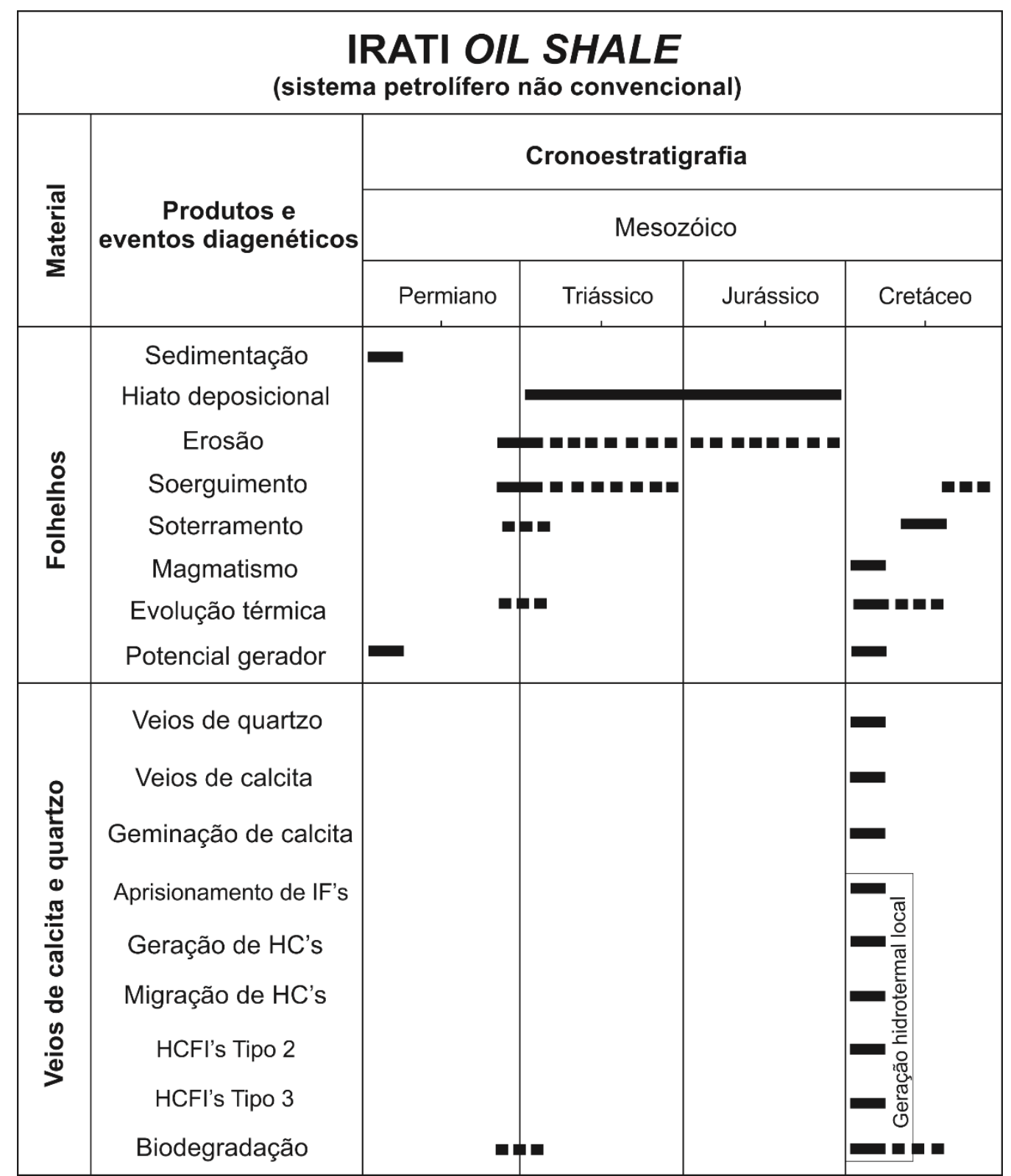

Figura 5.4. Evolução diagenética da Formação Irati e dos veios de calcita e quartzo que preenchem fraturas. Barras tracejadas representam incerteza no tempo paragenético. 


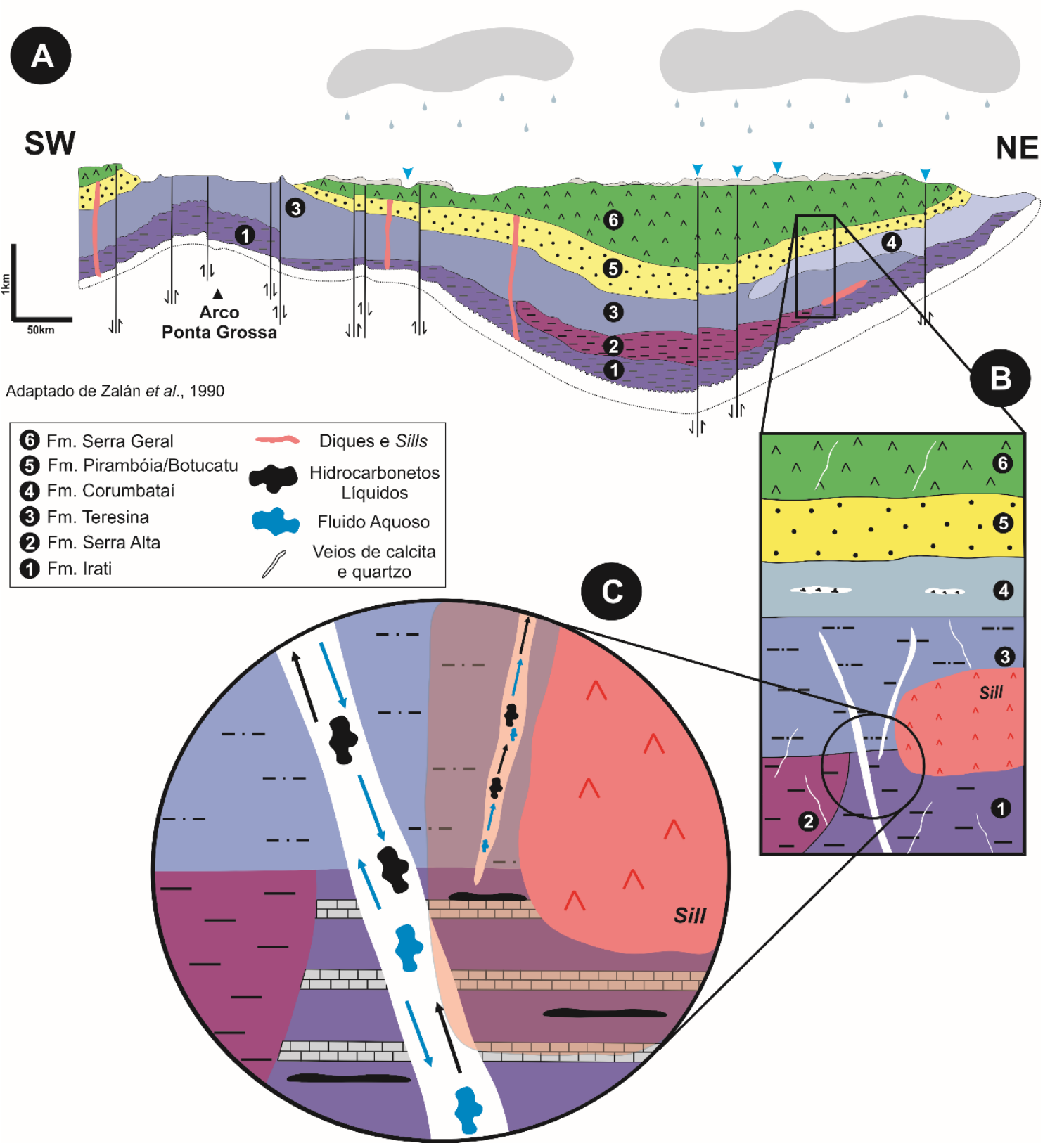

Figura 5.5. Modelo de geração e circulação de paleofluidos (hidrocarbonetos líquidos e fluidos aquosos) no sistema petrolífero Irati-Irati e Formação Serra Geral seccionadas por veios de calcita e quartzo na borda leste da Bacia do Paraná. (A) Perfil geológico NE-SW na borda leste da Bacia do Paraná; Adaptado de Zalán et al. (1990). (B) Detalhe da seção estratigráfica das unidades aflorantes na área de estudo. (C) Modelo esquemático detalhado da geração e circulação de paleofluidos. Destaque para fluido aquoso em subsuperfície, de origem essencialmente meteórica, que circula por falhas e fraturas da bacia chegando a níveis mais profundos, e à ação de sill associado à LIP Paraná na geração e migração de hidrocarbonetos líquidos em veios autigênicos da Formação Irati e Corumbataí. 


\subsubsection{Isótopos estáveis de carbono e oxigênio em veios de calcita}

Os valores de $\delta^{13} \mathrm{C}_{\mathrm{PDB}}$ e $\delta^{18} \mathrm{O}_{\mathrm{PDB}}$ dos veios pertencentes às formações Irati, Serra Alta e Serra Geral (veios hospedados em basalto) e em sill associado à LIP Paraná (Ponta Grossa), são dominados por valores negativos, isto é, são enriquecidos em ${ }^{12} \mathrm{C}$ e ${ }^{16} \mathrm{O}$ (Tabela 4.3). Carbonatos de origem meteórica/água doce enriquecida em ${ }^{12} \mathrm{C}$, apresentam valores negativos da razão de $\delta^{13} \mathrm{C}$ entre -15 e $-1 \%$ (Hoefs, 2004). Os carbonatos marinhos apresentam valores da razão de $\delta^{13} \mathrm{C}$ mais próximos de $\pm 0 \%$ (Hoefs, 2004). Os valores da razão de $\delta^{18} \mathrm{OPDB}_{\mathrm{PD}}$ da maioria das amostras estudadas revelam intervalo de variação isotópica de $-7,93$ a $-4,79 \%$, o que sugere um fluido homogêneo, de origem essencialmente meteórica (Hoefs, 2004; Sturrock et al., 2017). Apenas quatro amostras (três da Formação Teresina e uma da Formação Irati) apresentam valores da razão de $\delta^{18} \mathrm{O}_{\mathrm{PDB}}$ próximos de $0 \%$ (Figura 5.6). Nesse caso, os valores da razão de $\delta^{13} \mathrm{C}_{\mathrm{PDB}}$ variam entre 1,06 e 1,95\% apontando para um carbonato de origem marinha, e os valores da razão de $\delta^{18} \mathrm{O}_{\mathrm{PDB}}$ variam entre 2,84 e 3,24 \%o sugerindo uma contribuição de um fluido mais salino ou um fluido levemente modificado pela presença de fluido diagenético pré-existente (fluido de poro) uma zona de transição entre diagênese meteórica e marinha (Allen \& Mathews, 1982; Oehlert \& Swart, 2014). Desta forma, os dados isotópicos indicam que a precipitação dos veios de calcita das unidades estudadas se baseia em fluido de origem meteórica com salinidade moderadamente baixa, o que sugere um fluido aquoso migrante cogenético.

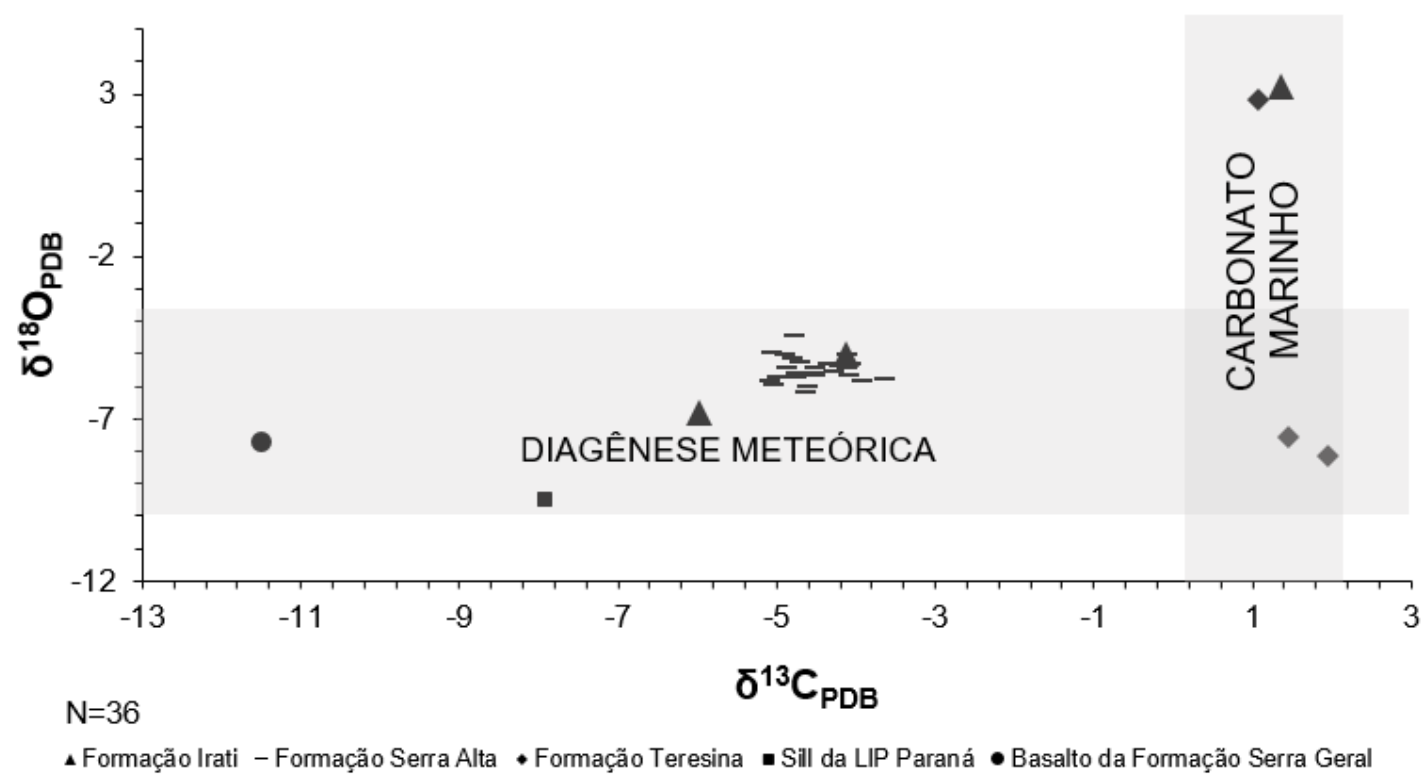

Figura 5.6. Isótopos estáveis de carbono e oxigênio em veios de calcita nas formações Irati, Serra Alta, Teresina e Serra Geral. Zona de diagênese meteórica com base em Oehlert \& Swart, 2014. 


\subsubsection{Modificações pós-aprisionamento nas inclusões}

A elevada variação de Th em inclusões do Tipo 1 hospedadas nos veios da Formação Irati (50 a $340{ }^{\circ} \mathrm{C}$ - Figura 4.5A) e em basalto da Formação Serra Geral (50 a $250{ }^{\circ} \mathrm{C}$ - Figura 4.6A) podem ser decorrentes de modificações das inclusões por processos de reequilíbrio térmico posterior (stretching ou leakage). No caso da Formação Irati (maioria das inclusões), essas variações encontram-se associadas a uma quantidade substancial de inclusões com Tfg relativamente constantes, situadas entre -5 e $0^{\circ} \mathrm{C}$ (Figura 4.5C) e na Formação Serra Geral, entre -2 e $0{ }^{\circ} \mathrm{C}$ (Figura 4.6C). Não obstante, no gráfico de correlação Tfg versus Th da Formação Irati (Figura 4.5E), observam-se dois comportamentos distintos; o primeiro reflete a ampla distribuição nos valores de Th para um fluido com salinidade mais baixa, enquanto, o segundo, exibe a menor distribuição nos valores de Th para um fluido com salinidade elevada, sendo que ambos sugerem reequilíbrio por stretching. Contudo, no segundo caso poderia existir também a influência da troca de fluidos, já que a salinidade é variável e alguns valores mais elevados podem estar associados a fluido de poro do folhelho após a expulsão para microfraturas ou também a trocas iônicas entre as soluções e as unidades sedimentares adjacentes. O mesmo comportamento não se verifica nas inclusões Tipo 1 hospedadas em veio de calcita no basalto pertencente à Formação Serra Geral e em sill associado à LIP Paraná (Ponta Grossa), o que sugere apenas reequilíbrio térmico por stretching (Figura 5.7). Dispersões acentuadas nos valores de Th para Tfg com pequenas variações sugerem a existência de reequilíbrios das inclusões por processos de dilatação inelástica (stretching) originados pelo aumento de temperatura (Figura 5.7). A expansão irreversível da inclusão através da sua deformação plástica causada por sobrepressões internas da própria inclusão fluida é denominada stretching. A temperatura de homogeneização total adquirida em laboratório corresponde à temperatura mínima do reequilíbrio por stretching (Prezbindowski \& Larese, 1987; Goldstein \& Reynolds, 1994). Assim, é relevante o fato de que as inclusões fluidas, os minerais hospedeiros e a rocha encaixante terem sido submetidas a temperaturas mais altas que as registradas (Goldstein \& Reynolds, 1994). Algumas inclusões fluidas podem se reequilibrar rápida e repetidamente (mais de uma vez) ou não reequilibrarem, dependendo dos diversos fatores que influenciam os reequilíbrios (dureza do mineral hospedeiro, forma, orientação e dimensão da inclusão, pressões internas confinantes na rocha, composição do fluido, etc). Teixeira et al. (2018) discutem o mesmo comportamento em inclusões fluidas primárias aquosas hospedadas em veios subverticais de calcita que seccionam a Formação Serra Alta onde revelam significativa variação nas Th $\left(60\right.$ a $200{ }^{\circ} \mathrm{C}$, podendo atingir até $320^{\circ} \mathrm{C}$ ) para inclusões com $\mathrm{Tfg}$ 
relativamente constantes (-2,5 a $0 \stackrel{\circ}{\circ}$ - Anexo I, Figura 11). Não obstante, a grande variação de Th de HCFl's primárias e pseudo-secundárias com pequena variação da fração vapor $\left(F_{v}\right)$ nas formações Irati e Corumbataí também apontam para reequilíbrio térmico, conforme discutido por Bourdet et al. (2008). Para mais, HCFl's de origem primária ricas em gases, sem fluorescência, forma irregular e com fase de vapor entre 40-60 \% do total da inclusão (Figura 4.3F), também podem ser resultado de processos de reequilíbrio térmico, assumindo a grande variação de Th nas HCFl's de origem primária e pseudo-secundária (Figura 4.5G’).

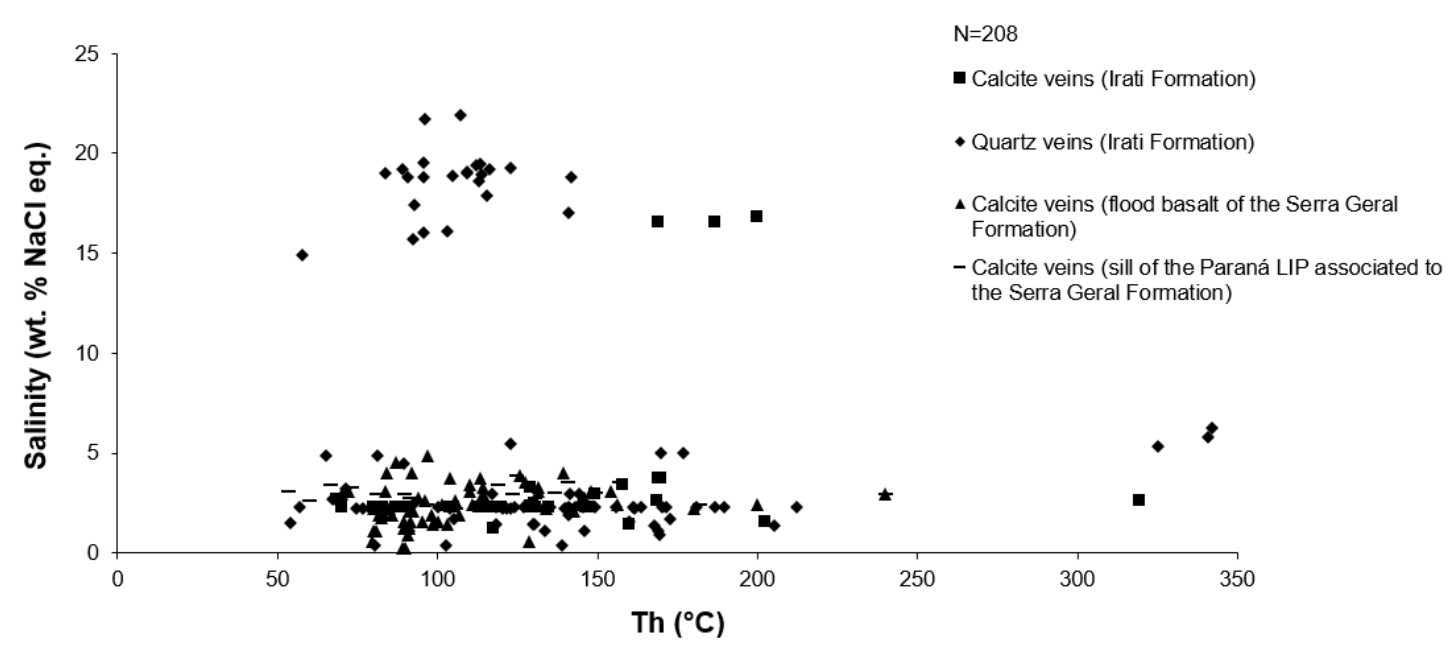

Figura 5.7. Gráfico de correlação entre salinidade versus Th de todos os veios estudados.

\subsubsection{Condições de deformação da Formação Irati durante a circulação de paleofluidos registrados em veios de calcita}

Os veios sub-verticais da Formação Irati apresentam crescimento cristalino do tipo sintaxial (veios extensionais), com exceção dos veios sub-horizontais da Formação Corumbataí, que possuem crescimento cristalino antiaxial (vide Figura 4.3C). A pressão aumenta constantemente com o aumento de profundidade na crosta e veios extensionais podem se formar em qualquer profundidade (Bons et al., 2012). Contudo, é relevante considerar que a pressão dos fluidos atua contra a pressão litostática, por isso, é preciso ser tomada em consideração (Bons et al., 2012). Quando a pressão de fluido ultrapassa o esforço horizontal mínimo e a resistência à tração (tensile strenght) da rocha, ela é submetida a uma pressão de fluido que vai causar sua ruptura. Este processo denomina-se fraturamento hidráulico. O tipo, disposição espacial e geometria das fraturas geradas por esse mecanismo, além de influenciadas reologia do material 
fraturado, dependem principalmente da magnitude do stress diferencial relacionado ao esforço operante na rocha ou sedimento (Cosgrove, 1995).

De acordo com o modelo P-V-T dos fluidos aprisionados, os veios extensionais da Formação Irati foram gerados em regime sub-hidrostatico a hidrostático, isto é, fraturas geradas por incremento de pressão do fluido. Falhas ou veios extensionais são exemplos naturais de estruturas que se formam perpendicularmente ao estiramento ou vetor de menor esforço $\sigma 3$, sob condições de tração paralelas ao vetor de esforço principal $\sigma 1$ (Fossen, 2012). Com base nas projeções estereográficas, os veios das formações Irati, Serra Alta, Serra Geral e os veios hospedados em sill associado à LIP Paraná, apresentam esforço máximo vertical (Figura 4.1). Assim, a ocorrência de veios sub-verticais pode ser interpretada como resultado de fraturamento por compressão vertical devido à pressão litostática. Neste caso, o esforço $\sigma 1$ vertical estaria associado à possível carga de corpos ígneos horizontais (soleiras), à espessura dos basaltos da Formação Serra Geral e/ou a espessura das unidades sedimentares sobrejacentes à Formação Irati (formações Teresina, Pirambóia, Botucatu e Grupo Bauru), que representam uma espessura máxima de $\approx 2 \mathrm{~km}$ de rocha. Crescimento cristalino sintaxial necessita apenas de um único evento de abertura (single cracking event) e ocorre quando os minerais crescem a partir da parede do veio em direção ao centro, por isso, apresentam textura alongada e blocosa (Bons et al., 2012).

Veios sub-horizontais de calcita (paralelos ao acamamento) interpretados como veios do tipo beef (sensu Rodrigues et al., 2009), ocorrem em siltitos da Formação Corumbataí na região de Limeira e em fácies heterolítica da Formação Teresina na região de Taguaí e Fartura no sul do Estado de São Paulo. Os veios beef na Formação Teresina estariam associados a compartimentos com sobrepressão que permitiram a saída de águas de poro de salinidade elevada, possivelmente combinada com a geração e expulsão de hidrocarbonetos durante o magmatismo Serra Geral (Nomura et al., 2014). Veios beef com crescimento cristalino antiaxial tem como característica uma linha média de sutura (zona média) onde se encontram os nutrientes necessários para o crescimento dos minerais, que por sua vez, ocorre em direção à parede do veio (Bons et al., 2012). Rochas sedimentares de baixa permeabilidade ricas em matéria orgânica, especialmente folhelhos, siltitos e argilitos apresentam comumente este tipo de veios associados à geração de hidrocarbonetos (Parnell et al., 2001; Rodrigues et al., 2009). Cobbold et al. (2013) descrevem veios do tipo beef como sendo formados por fibras verticais de calcita, mutuamente paralelas, oblíquas às camadas e que ocorrem no preenchimento de fraturas horizontais produzidas em zonas de expulsão de fluidos, ou seja, zona de sobrepressão ocasionada pela geração de hidrocarbonetos. A sobrepressão nas rochas dos veios beef seria resultante da dificuldade em expulsar o 
fluido de poro devido à baixa permeabilidade do folhelho durante a compactação e geração de hidrocarbonetos (Rodrigues et al., 2009; Cobbold et al., 2013). Este processo teria levado ao fraturamento hidráulico e à migração de fluidos aquosos de alta salinidade e hidrocarbonetos para camadas adjacentes.

$\mathrm{Na}$ generalidade, com exceção da Formação Corumbataí, os veios sub-verticais estudados apresentam direção NNE e NNW (Figura 4.1), sendo a direção NNE mais frequente. A direção NNE pode estar relacionada a eventos de reativação de lineamentos ou falhas profundas do embasamento no fim do Permiano início do Cretáceo, como a falha de Jacutinga (Riccomini et al., 2005). A elevada espessura da capa de basaltos da Formação Serra Geral e/ou a espessura das unidades sedimentares adjacentes à Formação Irati podem ser o principal fator responsável pela geração de esforço vertical $(\sigma 1)$ e em larga escala, capaz de reativar falhas profundas do embasamento. A direção NNW pode estar relacionada a estruturas subordinadas associadas a falhas regionais de direção NNW, como a falha de Guapiara que constitui o limite norte do Arco de Ponta Grossa (Strugale et al., 2007). Fraturas verticais de direção NW a NNW e NE a NNE seriam os principais caminhos de migração dos fluidos aquosos de poros e de hidrocarbonetos, além de permitirem a entrada de água meteórica em zonas mais profundas (Nomura et al., 2014). Este sistema de fraturas, eventualmente pode ser responsável pela migração de paleofluidos para zonas fora dos limites da Formação Irati, Serra Alta e Corumbataí podendo alcançar outras unidades da Bacia do Paraná. 
CAPÍTULO 6 


\section{CAPÍTULO 6}

\section{CONCLUSÕES}

A dinâmica de fluidos e evolução térmica das rochas sedimentares que compõem o Grupo Passa Dois da Bacia do Paraná (formações Irati, Serra Alta, Teresina e Corumbataí), e que integram um sistema petrolífero não convencional (Irati-Irati) considerado atípico devido ao magmatismo Serra Geral (Eocretáceo), são escopo do presente trabalho. O conhecimento das relações temporais e espaciais entre o evento de aprisionamento de paleofluidos em sistema de fraturas, principalmente fluido aquoso e petróleo, e o magmatismo permitiu a elaboração de um modelo diagenético temporal (Permiano-Cretáceo) para as unidades permianas da borda leste da bacia.

Com base nos resultados obtidos se conclui que o querogênio dos folhelhos da Formação Irati na borda SSE da Bacia do Paraná apresenta aromaticidade de 30 \% $\left(f_{\text {ar }}\right)$, em área desprovida de efeito térmico local por ação de corpos ígneos. Os valores médios de reflectância de vitrinita (Ro $=0,6 \%$ ) corroboram os baixos níveis de maturidade térmica e apontam para temperaturas de soterramento entre 60 e $80{ }^{\circ} \mathrm{C}$. Desta forma, a hipótese de geração de hidrocarbonetos líquidos heterogêneos, associados a fluidos de densidade média e baixa, por soterramento durante 0 Eocretáceo é viável (hidrocarboneto termogênico), sem efeito térmico direto do magmatismo Serra Geral, muito embora este possa ter um papel preponderante no soterramento devido à espessa capa de basaltos (espessura máxima $\approx 1,7 \mathrm{Km}$ de espessura) da Formação Serra Geral.

Dados de $\delta^{13} \mathrm{C}_{\mathrm{PDB}}$ e $\delta^{18} \mathrm{O}_{\mathrm{PDB}}$ de carbonatos pertencentes às formações Irati, Serra Alta Teresina e Formação Serra Geral (neste caso hospedados em basalto e em sill associado à LIP Paraná), corroboram que a precipitação dos veios de calcita na borda NNE da bacia se baseia em fluido de origem predominantemente meteórica com salinidade entre 0 e $5 \%$ em peso de $\mathrm{NaCl}$ equivalente. As Th de AqFl's primárias hospedadas nos veios revelam a percolação de fluido diagenético em temperaturas superiores a $250^{\circ} \mathrm{C}$. Em alguns casos, essas temperaturas foram obtidas em amostras localizadas fora do alcance direto de corpos magmáticos intrusivos, comprovando que o efeito térmico da LIP Paraná na borda NNE da bacia não corresponde diretamente à presença local de diques ou soleiras. Isto sugere a ocorrência de um sistema hidrotermal, com fluidos aquecidos em zonas próximas a corpos magmáticos (e.g. sill de Limeira), mas capazes de migrar para zonas distais.

Veios de quartzo e calcita da Formação Irati que contêm inclusões fluidas aquosas (AqFl's) coexistentes com inclusões de hidrocarbonetos (HCFI's) sugerem um sistema 
petrolífero ativo raso $(\approx 2 \mathrm{~km})$, além de um fluxo aquoso meteórico com água parcialmente miscível em óleo durante o desenvolvimento dos veios. Desta forma, este fluido migrou concomitantemente com hidrocarbonetos líquidos e pode ter favorecido processos secundários como a biodegradação.

As condições estimadas de P-V-T para os fluidos aprisionados atestam que o desenvolvimento de veios extensionais e aprisionamento de inclusões fluidas compostas por hidrocarbonetos ocorreu em regime de pressão sub-hidrostática e que a Formação Irati estaria no mínimo a $2 \mathrm{Km}$ de profundidade na borda NNE da bacia durante o desenvolvimento dos veios no Eocretaceo. Assim, um sistema petrolífero raso influenciado por fluidos hidrotermais, concomitante com o período de resfriamento do sill na região de Limeira após a intrusão, e constante aporte de fluidos meteóricos para zonas sub-superficiais, constituem condições favoráveis à ocorrência de biodegradação em hidrocarbonetos.

Inclusões fluidas primárias e pseudo-secundárias, compostas por hidrocarbonetos de fluorescência amarela (Tipo 2) e hospedadas em veios sub-verticais foram aprisionadas em temperaturas que variam entre 50 e $200{ }^{\circ} \mathrm{C}$. Fluidos originados por alteração do gradiente de pressão, após a intrusão e consequente arrefecimento do sill na região de Limeira (SP) intercalado entre as formações Irati e Corumbataí na área de estudo, podem ter originado um estágio tardio de migração ou um pulso posterior de geração de hidrocarbonetos, com Th superiores (160-250 $\left.{ }^{\circ} \mathrm{C}\right)$. Variação significativa de Th nas HCFl's primárias e pseudo-secundárias indicam processos de reequilíbrio térmico posterior originados por incremento de temperatura, o que neste caso pode ter sido motivado pela presença local do sill na região de Limeira (SP) e à sua proximidade com a área de amostragem deste estudo. A escassa presença de inclusões fluidas ricas em gás $\left(\mathrm{CH}_{4}\right.$ ou $\left.\mathrm{CO}_{2}\right)$, observadas apenas em veios hospedados na Formação Irati, sugere que as mesmas são produto de processos de reequilíbrio térmico. Dados de fração volumétrica $\left(F_{v}\right)$ e Th das HCFl's nas formações Irati e Corumbataí permitem a classificação dos hidrocarbonetos aprisionados nas inclusões fluidas como black oil, sendo um óleo heterogêneo caracterizado por hidrocarbonetos leves a médios com pequena variação de ${ }^{\circ} \mathrm{API}(20-40)$, o que corresponde a fluidos de densidade média a baixa. Não foram observadas com frequência inclusões fluidas ricas em gás $\left(\mathrm{CH}_{4}\right)$ ou inclusões carbônicas $\left(\mathrm{CO}_{2}\right)$ nas formações Serra Alta, Corumbataí e Serra Geral.

Estas evidências sugerem produção reduzida de gás $\left(\mathrm{CO}_{2}\right.$ e $\left.\mathrm{CH}_{4}\right)$ pela influência da LIP Paraná sobre os folhelhos orgânicos da Formação Irati (geradora) e unidades adjacentes, possivelmente devido ao curto período do magmatismo $(<1,5 \mathrm{Ma})$ ou, em alternativa, a elevada fugacidade dos voláteis inviabilizou o seu aprisionamento. 
Contudo, em termos paleoambientais estes indícios são exíguos e requerem mais argumentação e estudos científicos adicionais. 


\section{REFERÊNCIAS}

Aarnes, I., Svensen, H., Connolly, J.A.D., Podladchikov, Y.Y., 2010. How contact metamorphism can trigger global climate changes: Modeling gas generation around igneous sills in sedimentary basin. Geochemica et Cosmochimica Acta 74, 7179-7195.

Allen, J.R., Mathews, R.K., 1982. Isotopes signatures associated with early meteoric diagenesis. Sedimentology 29, 797-817.

Almeida, F.F.M., Melo, M.S.A., 1981. Bacia do Paraná e o vulcanismo Mesozóico. In: Instituto de Pesquisas Tecnológicas do Estado de São Paulo IPT. Mapa Geológico do Estado de São Paulo, São Paulo: IPT, v.1, 46-81. Escala I:500.000.

American Society for Testing and Materials (ASTM)., 2011. Standard test method for microscopical determination of the reflectance of vitrinite dispersed in sedimentary rocks: West Conshohocken, PA, ASTM International, Annual book of ASTM standards: Petroleum products, lubricants, and fossil fuels; Gaseous fuels; coal and coke 5.06, D7708-11, 823-830.

Aplin, A.C., Mcleod, G., Larter, S.R., Pedersen, K.S., Sorensen, H., Booth, T., 1999. Combined use of confocal laser microscopy and PVT simulation for estimating the composition and physical properties of petroleum in fluid inclusions. Marine and Petroleum Geology 16, 97-110.

Araújo L.M., Trigüis J.A., Cerqueira J.R., Freitas L.C.S., 2000. The atypical Permian petroleum system of the Paraná Basin, Brazil. In: Mello M.R., Katz B.J. (Eds.). Petroleum systems of South Atlantic margins. Tulsa, AAPG Memoir 73, 377-402.

Artur, P.C., Soares, P.C., 2002. Paleoestruturas e petróleo na Bacia do Paraná, Brasil. Revista Brasileira de Geociências 32, 433-448.

Baron, M., Parnell, J., Mark, D., Carr, A., Przyjalgowski, Feely, M., 2008. Evolution of hydrocarbon migration style in a fractured reservoir deduced from fluid inclusion data, Clair Field, west of Sheetland, UK. Marine and Petroleum Geology 25, 153-172.

Baudino, R., Rodríguez, F., Zencich, S., Calegari, R., 2004. Generation of hydrocarbons by thermal effect of magmatic intrusions: a non-conventional petroleum system. In: Abstracts IX Latin American Association of Organic Geochemistry Congress, Mérida, Mexico, 77p.

Bello, R.M.S., 1996. Apostila do curso sobre inclusões fluidas, Instituto de Geociências - USP. 
Bertassoli Jr., D.J., Sawakuchi, H.O., Almeida, N.S., Castanheira, B., Alem, V.A. T., Camargo, M.G.P., Krusche, A.V., Broschztain, S., Sawakuchi, A.O., 2016. Biogenic methene and carbon dioxide generation in organic-rich shales from southeastern in Brazil. International Journal of Coal Geology 162, 1-13.

Black, B.A., Elkins-Tanton, L.T., Rowe, M.C., Peate, I.U., 2012. Magnitude and consequences of volatile release from the Siberian Traps. Earth and Planetary Science Letters 317-318, 363-373.

Bodnar, R.J., 1990. Petroleum migration in the Miocene Monterey Formation, California, U.S.A.: Constraints from fluid-inclusion studies. Mineralogical Magazine 54, 295-304.

Bons, P.D., Elburg, M.A., Rivas, A.G. 2012. A review of the formation of tectonic veins and their microstructures. Journal of Structural Geology 43, 33-62.

Bourdet, J., Pironon, J., Levresse, G., Trittla, J., 2008. Petroleum type determination through homogenization temperature and vapour volume fraction measurements in fluid inclusions. Geofluids 8, 46-59.

Bourdet, J., Eadington, P., Volk, H., George, S.C., Pironon, J., Kempton, R., 2012. Chemical changes of fluid inclusion oil trapped during the evolution of an oil reservoir: Jabiru-1A case study (Timor Sea, Australia). Marine and Petroleum Geology 36, 118-139.

Bueno, G.V., Zacharias, A.A., Oreiro, S.G., Cupertino, J.A., Falkenhein, F.U.H., Neto, M.A., 2007. Bacia de Pelotas. Boletim de Geociências da Petrobras 15, 551-559.

Callegaro, S., Baker, D.R., De Min, A., Marzoli, A., Kalotina, G., Bertrand, H., Viti, C., Nestola, F., 2014. Microanalyses link sulfur from large igneous provinces and Mesozoic mass extinctions. Geology 42, 895-898.

Cao, J., Jin, Z., Hu, W., Zhang, Y., Yao, S., Wang, X., Zhang, Y., Tang, Y., 2010. Improved understanding of petroleum migration history in the Hongche fault zone, northwestern Junggar Basin (northwest China): Constrained by vein-calcite fluid inclusions and trace elements. Marine and Petroleum Geology 27, 61-68.

Cao, X., Yang, J., Mao, J., 2013. Characterization of kerogen using solid-state nuclear magnetic resonance spectroscopy: A review. International Journal of Coal Geology 108, 83-90.

Carr, A.D., Williamson, J.E., 1990. The relationship between aromaticity, vitrinite reflectance and maceral composition of coals: Implications for the use of vitrinite reflectance as a maturation parameter. Organic Geochemistry 16, 313-323.

Carvalho, S.G., Nardy, A.J.R., Oliveira de, M.A.F., Soares, P.C., Zanardo, A., Antônio, M.C., 1988. Aspetos geológicos e litoquimicos dos sills Borda de Mata e Limeira Cosmópolis (SP). Resultados preliminares. Congreso Brasileiro de Geologia, Belém (PA). Sociedade Brasileira de Geologia v.3. 
Cobbold, P.R., Zanella, A., Rodrigues, N., Loseth, H., 2013. Bedding-parallel fibrous veins (beef and cone-in-cone): Worldwide occurrence and possible significance in terms of fluid overpressure, hydrocarbon generation and mineralization. Marine and Petroleum Geology 2013, 1-20.

Coelho, C.E., 2005. O estudo de inclusões fluidas na exploração de petróleo. Boletim de Geociências da Petrobras, Rio de Janeiro, Boletim de Geociências da Petrobras 13, 61-80.

Coffin, M.F., Duncan, R.A., Eldholm, O., Godfrey, J.F., Frey, F.A., Larsen, H.C., Mahoney, J.J., Saunders, A.D., Schlich, R. and Wallace, P.J., 2006. Large Igneous Provinces and scientific ocean drilling. Status Quo and a look ahead. Oceanography 19, 150-160.

Cosgrove, J.W., 1995. The expression of hydraulic fracturing in rocks and sediments. In: AMEEN, M.S. (Eds.) Fractography: Fracture Topography as a Tool in Fracture Mechanics and Stress Analysis. Geological Society, London, Special Publications 92, 187-196.

Costa, M.N.S., 2006. Diagênese e alteração hidrotermal em rochas sedimentares da Formação Corumbataí, Permiano Superior, Mina Granusso, Cordeirópolis/SP. Tese de Doutoramento, UNESP, Rio Claro, 140p.

Crawford, M.L., Hollister, L.S., 1992. Fluid-rock interactions during Metamorphism. In: Walther, J.V., Wood, B.J. (Eds). Advances in Physical Chemistry 4, 1-35.

Danesh, A. 1998. PVT and Phase Behaviour of Petroleum Fluids, Developments in Petroleum Science, 47. Elsevier, Amsterdam, 387p.

Demaison, G., Huizinga, B.J., 1994. Genetic classification of petroleum systems. AAPG Bulletin 75, 1626-1643.

Dembicki, H., 2013. Challenges to Black Oil Production from Shales. Search and Discovery Article in Geoscience Technology Workshop, Hydrocarbon Charge Considerations in Liquid-Rich Unconventional Petroleum Systems. Vancouver, Canada.

De Ros, L.F., 1998. Heterogeneous generation and evolution of diagenetic quartz arenites in the SilurianeDevonian Furnas Formation of the Paraná Basin, southern Brazil. Sedimentary Geology 116, 99-128.

Duarte, L.C., Hartmann, L.A., Vasconcellos, M.A.Z., Medeiros, J.T.N., Theye, T., 2009. Epigenetic formations of amethyst-bearing geodes from Los Catalanes gemological district, Artigas, Uruguay, southern Paraná Magmatic Province. Journal of Vulcanology and Geothermal Research 184, 427-436.

Du Toit, A.L., 1937. Our wandering continents: a hypothesis of continental drift. Edinburgh and London, Oliver and Boyd, 366p. 
Dyni, J.R., 2003. Geology and resources of some world oil shale deposits: U.S. Geological Survey Scientific Investigations Report 5294, 42p.

Ernst, R.E., Youbi, N., 2017. How Large Igneous Provinces affect global climate, sometimes cause mass extinctions, and represent natural markers in the geological record. Palaeogeography, Palaeoclimatology, Palaeoecology 478, 3052.

Ernesto, M., Bellieni, G., Piccirillo, E.M., Marques, L.S., de Min, A., Pacca, I.G., Martins, G., Macedo, J.W.P., 2002. Paleomagnetic and geochemical constrains on the timing and duration CAMP activity in Northeastern Brazil. In: Hames, W.E., Renne, P.R., Ruppel C. (Eds.). The Central Atlantic Magmatic Province. American. Geophysical. Union Monography 136, 91-128.

EIA/ARI, 2013. EIA/ARI World Shale Gas and Shale Oil Assessment.

Faleiros, F.M., Campanhã, G.A., Bello, R.M.S., Fuzikawa, K., 2007. Fault-valve action and veins development during-strike slip faulting: An example from the Ribeira Shear Zone, Southeastern Brazil. Tectonophysics 438, 1-32.

Fang, H., Jianyu, C., 1992. The cause and mechanisms of vitrinite reflectance anomalies. Journal of Petroleum Geology 15, 419-434.

Fjeldskaar, W, Helset, H.M, Johansen, H., 2008. Thermal Modeling of Magmatic Intrusions in the Gjallar Ridge, Norwegian Sea: Implications for Vitrinite Reflectance and Hydrocarbon Maturation. Basin Research 20, 143-159.

Fossen, H., 2012. Geologia Estrutural. $1^{\text {st }}$ Edition. Oficina de Textos. São Paulo. Tradução Dr. Fábio R.D. Andrade. 584pp.

Fúlfaro, V.J., Saad, A.R., Santos, M.V., Vianna, R.B., 1982. Compartimentação e evolução tectônica da Bacia do Paraná. Revista Brasileira de Geociências 12, 590-610.

Fuzikawa, K., 1985. Inclusões fluidas: métodos usuais de estudo e aplicações. Contribuições à geologia e à petrologia. SBGM, 29-44.

Ganino, C., Arndt, N.T., 2009. Climate changes caused by degassing of sediments during the emplacement of large igneous provinces. Geology 37, 323326.

Giannini P.C.F., Sawakuchi A.O., Fernandes L.A., Donatti L.M., 2004. Paleoventos e Paleocorrentes Subaquosas do Sistema Deposicional Pirambóia no Estados de São Paulo e Paraná, Bacia do Paraná: estudo baseado em análise estatística de dados azimutais. Revista Brasileira de Geociências 34 (2), 282-29. 
George, S.C., 1992. Effect of Igneous Intrusion on the Organic Geochemistry of a Siltstone and an Oil Shale Horizon in the Midland Valley of Scotland. Organic Geochemistry 18, 705-723.

George, R., Rogers, N., Kelley, S., 1998. Earliest magmatism in Ethiopia: evidence for two mantle plumes in one flood basalt province. Geology 26, 923926.

George, S.C., Volk, H., Ahmed, M., 2007. Geochemical analysis techniques and geological applications of oil-bearing fluid inclusions, with some Australian case studies. Journal of Petroleum Science and Engineering 57, 119-138.

Goldstein, R.H., Reynolds, T.J., 1994. Systematics of fluid inclusions in diagenetic minerals. Estados Unidos da América, Tulsa: SEPM (Society for Sedimentary Geology), short courses 31, 199p.

Gordon Jr. M., 1947. Classificação das formações gondwânicas do Paraná, Santa Catarina e Rio Grande do Sul. Notas preliminares e Estudos, Rio de Janeiro, DNPM/DGM 38, 1-20.

Hachiro J., 1996. O Subgrupo Irati (Neopermiano) da Bacia do Paraná. Tese de Doutoramento, Instituto de Geociências, Universidade de São Paulo, São Paulo, 196p.

Heimdal., T.H, Svensen, H.H., Ramezani, J., Lyer, K., Pereira, E., Rodrigues, R., Jones., M.T., Callegaro, S., 2018. Large-scale sill emplacement in Brazil as a trigger for the end Triassic crisis. Nature, Scientific Reports 8 (141), 1-12.

Hoefs, J., 2004. Stable Isotope in Geochemistry, $5^{\text {th }}$ Edition. Springer-Verlag, Berlin, 244p.

Holz, M., França, A.B., Souza, P.A., lannuzi, R., Rohn, R., 2010. A stratigraphic chart of the Late Carboniferous/Permian succession of the eastern border of the Paraná Basin, Brazil, South America. Journal of South American Earth Sciences 29, 381-399.

Hood, A., Gutjahr, C.C.M., Heacock, R.L., 1975. Organic metamorphism and the generation of petroleum. American Association of Petroleum Geology 59, 986996.

Hunt, J.M., 1996. Petroleum Geochemistry and Geology. H. Freeman and Company, $2^{\text {nd }}$ Edition. New York. USA.

Hurter, S.J., Pollack, H.N., 1994. Effect of the Cretaceous Serra Geral igneous event on the temperatures and heat flow of the Parana Basin, southern Brazil. Basin Research 6, 239-244.

Hutton, A.C., Cook, A.C., 1980. Influence of alginite on the reflectance of vitrinite from Joadja, NSW, and some other coals and oil shales containing alginite. Fuel $59,711-714$. 
ICCP, 1998, The new vitrinite classification (ICCP System 1994): Fuel 77, 349358.

ICCP, 2001, The new inertinite classification (ICCP System 1994): Fuel 80, 459471.

Janasi, V.A., Montanheiro, T.J., Freitas, V.A., Reis, P.M., Negri, F.A., Dantas, F.A., 2007. Geology, petrography and geochemistry of the acid volcanism of the Paraná Magmatic Province in the Piraju-Ourinhos region, SE Brazil. Revista Brasileira Geociências 37, 745-759.

Janasi, V.A., De Freitas, V.A., Heaman, L.H., 2011. The onset of flood basalt volcanism, Northern Paraná Basin, Brazil: A precise U-Pb baddeleyite/zircon age for Chapecó-type dacite. Earth and Planetary Science Letters 302, 147-153.

Jarvie, D.M., Hill, R.J., Ruble, T.E., Pollastro, R.M., 2007. Unconventional shalegas systems: The Mississippian Barnett Shale of north-central Texas as one model for thermogenic shale-gas assessment. The American Association of Petroleum Geologists 91 (4), 475-499.

Jourdan, F., Hodges, K., 2014. High-precision dating of the Kalkarindji large igneous province, Australia, and synchrony with the Early-Middle Cambrian (Stage 4-5) extinction. Geology 42, 543-546.

Kelemen, S.R., Afeworki, M., Gorbaty, M.L., Sansone, M., Kwiatek, P.J., Walters, C.C., Freund, H., Siskin, M., Bence, A.E., Curry, D.J., Solum, M., Pugmire, R.J., Vandenbroucke, M., Leblond, M., Behar, F., 2007. Direct Characterization of Kerogen by X-ray and Solid-State ${ }^{13} \mathrm{C}$ Nuclear Magnetic Resonance Methods. Energy Fuels 21, 1548-1561.

Kontorovich, A.E., Khomenko, A.V., Burshtein, L.M., Likhanov, I.I., Pavlov, A.L., Staroseltsev, V.S., Ten, A.A., 1997. Intense basic magmatism in the Tunguska petroleum basin, eastern Siberia, Russia. Petroleum Geoscience 3, 359-369.

Li, R., Parnell, J., 2003. In situ microanalysis of petroleum fluid inclusions by Time of Flight-Secondary Ion Mass Spectrometry as an indicator of evolving oil chemistry: a pilot study in the Bohai Basin, China, Journal of Geochemical Exploration 78-79, 377-384.

Liu, J.Q., Meng, F.C., 2009. Hydrocarbon Generation, Migration and Accumulation Related to Igneous Activity. Natural Gas Industry.

Liu, E., Wuang, H., Uysal, T., Zhao, J., Wang, X., Feng, Y., Pan, S., 2017. Paleogene igneous intrusion and its effect on thermal maturity of organic-rich mudstones in the Beibuwan Basin, South China Sea. Marine and Petroleum Geology 86, 733-750.

Marzoli, A. Renne, P.E., Piccirillo, E.M., Ernesto, M., Bellieni, G., De Min, A., 1999. Extensive 200-million-year-old-continental flood basalts of the Central Atlantic Magmatic Province, Science 284, 616-618. 
Mastalerz, M., Drobniak, A., Schimmelmann, A., 2009. Changes in optical properties, chemistry, and micropore and mesopore characteristics of bituminous coal at the contact with dikes in the Illinois Basin. International Journal of Coal Geology 77, 310-319.

Mango, F.D., 1992. Transition Metal Catalysis in the Generation of Petroleum and Natural Gas. Geochimica Et Cosmochimica Acta 56, 553-555.

Meglhioratti, T., Rohn, R., Lourenço, A.T.A., 2005. Estratigrafia do grupo Passa Dois na região de Sapopema-Congoinhas/PR (Permiano, Bacia do Paraná). Simpósio de Geologia do Sudeste, Niterói, Rio de Janeiro.

Miall, A.D., 2000. Principles of sedimentary basin analysis. Third edition, SpringerVerlag, New York, 616p.

Miknis, F.P., Jiao, Z.S., Macgowan, D.B., Surdam, R.C., 1993. Solid-state NMR characterization of Mowry shale from the Powder River Basin. Organic Geochemistry 20, 339-347.

Milani, E.J., 1997. Evolução tectono-estratigráfica da Bacia do Paraná e seu relacionamento com a geodinâmica fanerozóica do Gondwana sul-ocidental. Tese de Doutoramento. Instituto de Geociências, Universidade Federal do Rio Grande do Sul, Porto Alegre.

Milani, E.J., Ramos, V.A., 1998. Orogenias Paleozóicas no domínio sul-ocidental do Gondwana e ciclos de subsidência da Bacia do Paraná. Revista Brasileira de Geociências 28, 473-484.

Milani, E.J., 2004. Considerações sobre a origem e evolução tectônica da Bacia do Paraná. In: Mantesso-neto, V., Bartorelli, A., Carneiro, C.D.R., Brito-Neves, B.B (Eds.). Geologia do continente sul-americano: Evolução da obra de Fernando Flávio Marques de Almeida, 265-279.

Milani, E.J., França, A.B., Medeiros, R.A., 2007a. Rochas Geradoras e rochas reservatório da bacia do Paraná, faixa oriental de afloramentos, estado de Paraná. In: Bacia do Paraná. Boletim de Geociências Petrobrás 15, 135-162.

Méndez J.D., 2012. Fácies carbonáticas da Formação Teresina. Dissertação de Mestrado, Instituto de Geociências, Universidade de São Paulo, São Paulo, 71p.

Monreal, F.R., Villar, H.J., Baudino, R., Delpino, D., Zencich, S., 2009. Modeling an atypical petroleum system: A case study of hydrocarbon generation, migration and accumulation related to igneous intrusions in the Neuquen Basin, Argentina. Marine and Petroleum Geology 26, 590-605.

Montel, F., 1993. Phase equilibria needs for petroleum exploration and production industry. Fluid Phase Equilibria 84, 343-367. 
Montgomery, S.L., Jarvie, D.M., Bowker, K.A., Pallastro, R.M., 2005. Mississippian Barnett Shale, Fort Worth basin, north-central Texas: gas-shale play with multi-trillion cubic foot potential. American Association of Petroleum Geologists 89, 155-175.

Munz, I.A., Iden, K., Johansen, H., Vagle, K., 1998. The fluid regime during fracturing of the Embla field, Central Trough, North Sea. Marine and Petroleum Geology 15, 751-768.

Munz, I.A., Johansen, H., Holm, K., Lacharpagne, J.C., 1999a. The petroleum characteristics of the Frøy field and the Rind discovery, Norwegian North Sea. Marine and Petroleum Geology 16, 633-651.

Munz, I.A., 2001. Petroleum inclusions in sedimentar basins: systematics, analytical methods and applications. Lithos 55, 195-212.

Munz, I., Wangen, M., Girard, J.P., Lacharpagne, J.C., Johansen, H., 2004. Pressure, temperature, time, composition (P-T-t-X) constraints of multiple petroleum charges in the Hid field, Norwegian North Sea. Marine and Petroleum Geology 21, 1043-1060.

Nardy, A.J.R., Oliveira, M.A.F., Betancourt, R.H.S., Verdugo, D.R.H., Machado, F. B., 2002. Geologia e estratigrafia da Formação Serra Geral. Revista Brasileira de Geociencias 21, 15-32.

Nedkvitne, T., Karlsen, D.A., Bjørlykke, K., Larter, S.R., 1993. Relationship between reservoir diagenetic evolution and petroleum emplacement in the Ula Field, North Sea. Marine and Petroleum Geology 10, 255-270.

Nomura, S.F., 2012. Hidrotermalismo na Formação Teresina evidenciado por minerais autigênicos e inclusões fluidas. Dissertação de Mestrado - Instituto de Geociências, Universidade de São Paulo, 146p.

Nomura, S.F., Sawakuchi, A.O., Bello, R.M.S., Méndez-Duque, J., Fuzikawa, K., Giannini, P.C.F., Dantas, M.S.S., 2014. Paleotemperatures and paleofluidos recorded in fluid inclusions from calcite veins from northern flank of the Ponta Grossa dyke swarm: Implications for hydrocarbon generation and migration in the Paraná Basin. Marine and Petroleum Geology 52, 107-124.

Oehlert, A.M., Swart, P.K., 2014. Interpreting carbonate and organic carbon isotope covariance in the sedimentary record. Nature Communications 5, 1-7.

Oliveira, A.F., 2012. Paleotemperaturas e paleofluidos da Formação Irati na borda leste da Bacia do Paraná: Implicações para a geração e migração de hidrocarbonetos. Tese de Mestrado. Instituto de Geociências, Universidade de São Paulo, 115p.

Othman, R., Arouri, K.R., Ward, C.R., McKirdy, D.M., 2001. Oil generation by igneous intrusions in the northern Gunnedah Basin, Australia. Organic Geochemistry 32, 1219-1232. 
Oxtoby, N.H., Mitchell, W., Gluyas, J.G., 1995. The filling and emptying of the Ula Oilfield: fluid inclusion constraints. Geological Society, London, Special Publications 86, 141-157.

Parnell, J., Middleton, D., Honghan, C., Hall, D., 2001. The use of integrated fluid inclusion studies in constraining oil charge history and reservoir compartmentation: examples from the Jeanne d'Arc basin, offshore Newfoundland. Marine and Petroleum Geology 18, 535-549.

Parnell, J., 2004. Titanium mobilization by hydrocarbon fluids related to sill intrusion in a sedimentary sequence, Scotland. Ore Geology Reviews 24, 155167.

Peate, D.W., Hawkesworth, C.J., Mantovani, M.S., 1992. Chemical stratigraphy of the Paraná lavas (South America): classification of magma types and their spatial distribution. Bulletin of Volcanology 55, 119-139.

Peate, D.W., 1997. The Paraná-Etendeka Province. In: Mahoney, J.J., Coffin, M.F. (Eds.) Large Igneous Provinces: Continental, Oceanic and Planetary Flood Volcanism. American Geophysical Union, Geophysical Monographs 100, 217245.

Peng, D.Y., Robinson, D.B., 1976. A new two-constant equation of state. Industrial Engineering Chemicals Fundamentals 15, 59-64.

Permanyer, A., Martin-Martin, J.D., Khile, J., Márquez, G., Marfil, R., 2017. Oil shows geochemistry and fluid inclusion thermometry of Mid Cretaceous carbonates from the eastern Basque Cantabrian Basin (N Spain). Marine and petroleum Geology 92, 255-299.

Pestilho, A.L.S., Monteiro, L.V.S., 2017. A review on the fundamentals of aqueous and petroleum fluid inclusion study. Terrae Didática 13 (2), 71-92.

Pestilho, A.L.S., 2018. Aplicação de inclusões fluidas à reconstrução da história de migração de hidrocarbonetos na Bacia Potiguar, RN, Tese de Doutorado, 485p.

Petri, S., Fúlfaro, V.J., 1983. Geologia do Brasil. São Paulo, EDUSP, 631p.

Ping, H., Chen, H., Thiéry, R. George, S.C., 2017. Effects of oil cracking on fluorescence color, homogenization temperature and trapping pressure reconstruction of oil inclusions from deeply buried reservoirs in the northern Dongying Depression, Bohai Bay Basin, China. Marine and Petroleum Geology $80,538-562$.

Pinto, V.M., Hartmann, L.A., Santos, J.O.S., Mcnaughton, N.J., Wildner, W., 2010. Zircon U Pb geochronology from the Paraná bimodal volcanic province support a brief eruptive cycle at 135 Ma. Chemical Geology 281, 93-102. 
Pironon, J., Canals, M., Dubessy, J., Walgenwitz, F., Laplace-Builhe, C., 1998. Volumetric reconstruction of individual oil inclusions by confocal scanning laser microscopy. European Journal of Mineralogy 10, 1143-1150.

Potter, J., Rankin, A.H., Treloar, P.J., Nivin, V.A., Ting, W., Ni, P., 1998. The preliminary studies of methane inclusions in alkaline igneous rock of the Kola igneous province, Russia: implications for the origin of methane in igneous rocks. European Journal of Mineralogy 10, 1167-1180.

Prezbindowski D.R., Larese R.E., 1987. Experimental stretching of fluid inclusions in calcite - implications for diagenetic studies. Geology 15, 333-336.

Price, L.C., Barker, C.E., 1985. Suppression of vitrinite reflectance in amorphousrich kerogen - A major unrecognized problem. Journal of Petroleum Geology 8, 59-84.

Pysklywec, R.N., Quintas, M.C.L., 2000. A mantle flow mechanism for the late Paleozoic subsidence of the Paraná Basin. Journal of Geophysical Research 105 (16), 359-370.

Rahman, M.W., Rimmer, S.M., Rowe, H.D., 2018. The impact of rapid heating by intrusion on the geochemistry and petrography of coals and organic-rich shales in the Illinois Basin. International Journal of Coal Geology 187, 45-53.

Rossetti, L., Lima, E.F., Waichel, B.L., Hole, M.J., Simões, M.S., Scherer, C.M.S., 2017. Lithostratigraphy and volcanology of the Serra Geral Group, ParanáEtendeka Igneous Province in Southern Brazil: Towards a formal stratigraphical framework. Journal of Volcanology and Geothermal Research 355, 98-114.

Renne, P.R., Deckart, K., Ernesto, M., Féraud, G., Piccirillo, E.M., 1996. Age of the Ponta Grossa dyke swarm (Brazil), and implications to Paraná flood volcanism. Earth Planetary Science Letter 144, 199-211.

Reuter, J.H, Perdue, E.M., 1977. Importance of Heavy Metal-Organic Matter Interactions in Natural Waters. Geochimica Et Cosmochimica Acta 41, 325-334.

Riccomini, C., 1995. Tectonismo gerador e deformador dos depósitos sedimentares Pós-Gondwânicos da porção centro-oriental do Estado de São Paulo e áreas vizinhas. Tese de Livre-Docência, Instituto de Geociências, Universidade de São Paulo, 100p.

Riccomini C., Almeida R.P., Turra B.B., Chamani M.A.C., Fairchild T.R., Hachiro J., 2005. Reativação de falha do embasamento causa sismicidade no permotriássico da Bacia do Paraná. 12ํㅗ Simpósio Nacional de Estudos Tectônicos - IV International Symposium on Tectonics, Curitiba, Boletim de Resumos Expandidos, 18-20.

Retallack, G.J., Jahren, A.H., 2008. Methane release from igneous intrusion of coal during late permian extinction events. Journal of Geology 116, 1-20. 
Rodrigues, N., Cobbold, P.R., Loseth, H., Ruffet, G., 2009. Widespread beddingparallel veins of fibrous calcite ('beef') in a mature source rock (Vaca Muerta Fm, Neuquén Basin, Argentina): evidence for overpressure and horizontal compression. Journal of the Geological Society 166, 695-709.

Roedder, E., 1984. Fluid inclusions. In: Ribbe, P.H. (Eds.). Reviews in Mineralogy, Mineralogical Society of America 12, 646p.

Ross, D.J.K., Bustin, R.M., 2008. Characterizing the shale gas resource potential of Devonian-Mississippian strata in the western Canada Sedimentary Basin: application of an integrated formation evaluation. American Association of Petroleum Geologists Bulletin 92, 87-125.

Ross, D.J.K., Bustin, R.M., 2009. The importance of shale composition and pore structure upon gas storage potential of shale gas reservoirs. Marine and Petroleum Geology 26, 917-927.

Rostirolla, S.P., Assine, M.L., Fernandes, L.A., Artur, P.C., 2000. Reativação de paleolineamentos durante a evolução da Bacia do Paraná - o exemplo do Alto Estrutural de Quatiguá. Revista Brasileira de Geociências 30 (4), 639-648.

Salmachi, A., Rajabi, M., Reynolds, P., Yarmohammadtooski, Z., Wainman, C., 2016. The effect of magmatic intrusions on coalbed methane reservoir characteristics: A case study from the Hoskissons coalbed, Gunnedah Basin, Australia. International Journal of Coal Geology 165, 278-289.

Sant'Anna, L.G., Clauer, N., Cordani, U.G., Riccomini, C., Velázquez, V.F., Liewig, N., 2006. Origin and migration timing of hydrothermal fluids in sedimentary rocks of the Paraná Basin, South America. Chemical Geology 230, $1-21$.

Santos R.V., Dantas, E.L., Oliveira, C.G., Alvarenga, C.J.S., Anjos, C.W.D., Guimarães, E.M., Oliveira, F.B., 2009. Geochemical and thermal effects of a basic sill on black shales and limestones of the Permian Irati Formation. Journal of South Ammerican Earth Sciences 28, 14-24.

Sensarma, S., Storey, B.C., Malviya, V.P., 2017. Gondwana Large Igneous Provinces (LIPS): distribution, diversity and significance. From: Sensarma, S., Storey, B.C. (Eds.) Large Igneous Provinces from Gondwana and Adjacent Regions. Geological Society, London, Special Publications, 463.

Schimmelmann, A., Mastalerz, M., Gao, L., 2009. Dike Intrusions into Bituminous Coal, Illinois Basin: H, C, N, O Isotopic Responses to Rapid and Brief Heating. Geochimica Et Cosmochimica Acta 20, 6264-6281.

Schneider, R.L., Muhlmann, H., Tommasi, E., Medeiros, R.A., Daemon, R.F., Nogueira, A.A., 1974. Revisão estratigráfica da Bacia do Paraná. In: Congresso Brasileiro de Geologia 28, 41-65. 
Shepherd, T.J., Ranking, A.H., Alderton, D.H., 1985. A practical guide to fluid inclusions studies. Blackie and Son Ltd, New York, 239p.

Simoneit, B.R.T., 1985, Hydrothermal petroleum; genesis, migration, and deposition in Guaymas Basin, Gulf of California: Canadian Journal of Earth Sciences 22 (3), 1919-1929.

Simoneit, B.R.T., Aboul-Kassim, T.A.T., Tiercelin, J.J., 2000. Hydrothermal petroleum from lacustrine sedimentary organic matter in the East African Rift. Applied Geochemistry 15, 355-368.

Smernik, R.J., Schwark, L., Schmidt, M.W.I., 2006. Assessing the quantitative reliability of solid-state ${ }^{13} \mathrm{C}$ NMR spectra of kerogens across a gradient of thermal maturity. Solid State Nuclear Magnetic Resonance 29, 312-321.

Soares, P.C., Landim, P.M.B., Fúlfaro, V.J., 1978. Tectonic cycles and sedimentary sequences in the Brazilian intracratonic basins. Geological Society of America Bulletin 89, 181-191.

Soares P.C., 1991. Tectônica sin-sedimentar cíclica na Bacia do Paraná. Tese de Titular, UFPR, Curitiba, PR, 148p.

Stach, E., Mackowsky, M.T., Teichmüller, M., Chandra, T.D., Teichmüller, R., 1982. Stach's Textbook of Coal Petrology, Gebrüder Borntraeger, Berlin, 535p.

Sturrock, C.P., Catlos, E.J., Miller, N.R., Akgun, A., Fall, A., Gabitov, R.I., Yilmaz, I.O., Larson, T., Black, K.N., 2017. Fluids along the North Anatolian Fault, Niksar basin, north central Turkey: Insight from stable isotopic and geochemical analysis of calcite veins. Journal of Structural Geology 101, 58-79.

Solum, M.S., Mayne, C.L., Orendt, A.M., Pugmire, R.J., Adams, J., Fletcher, T.H., 2014. Characterization of Macromolecular Structure Elements from a Green River Oil Shale, I. Extracts. Energy Fuels 28, 453-465.

Souza, I.V.A.F., Mendonça Filho, J.G., Menezes, T.R., 2008. Avaliação do efeito térmico das intrusivas ígneas em um horizonte potencialmente gerador da Bacia do Paraná: Formação Irati. Revista Brasileira de Geociências 38, 138-148.

Stasiuk, L.D., Snowdon, L.R., 1997. Fluorescence micro-spectrometry of synthetic and natural hydrocarbon fluid inclusions: crude oil chemistry, density and application to petroleum migration. Organic Geochemistry 12, 229-241.

Stewart K., Turner S., Kelley S., Hawkesworth C., Kirsten L., Mantovani M. 1996. 3-d, 40Ar-39 Ar geochronology in the Paraná continental flood basalt province. Earth and Planetary Science Letters 143, 95-109.

Stewart, A. K., Massey, M., Padgett, P. L., Rimmer, S. M., Hower, J. C., 2005. Influence of a basic intrusion on the vitrinite reflectance and chemistry of the Springfield (No. 5) coal, Harrisburg, Illinois. International Journal of Coal Geology $63,58-67$. 
Strugale, M., Rostirolla, S.P., Bartoszeck, M.K., Mancini, F., 2003. Deformação penecontemporânea na Formação Rio do Rasto (Permiano Superior a Triássico Inferior da Bacia do Paraná) na Serra do cadeado, Paraná. In: IX Simpósio Nacional de Estudo Tectônicos (SNET) Búzios, Rio de Janeiro. Anais 1: 14.

Strugale, M., Rostirolla S.P., Mancini F., Portela Filho C.V., Ferreira F.J.F., Freitas R.C., 2007. Structural framework and Mesozoic-Cenozoic evolution of Ponta Grossa Arch, Paraná Basin, southern Brazil. Journal of South American Earth Sciences 24, 203-227.

Suchý, V., Dobeš, P., Sýkorová, I., Machovič, V., Stejskal, M., Kroufek, J., Chudoba, J., Matějovský, L., Havelcová, M., Matusová, P., 2010. Oil-bearing inclusions in vein quartz and calcite and, bitumens in veins: Testament to multiple phases of hydrocarbon migration in the Barrandian Basin (lower Palaeozoic), Czech Republic. Marine and Petroleum Geology 27, 285-297.

Svensen, H., Jamtveit, B., Planke, S., Chevallier, L., 2006. Structure and evolution of hydrothermal vent complexes in the Karoo Basin, South Africa. Journal of Geological Society 163, 671-682.

Svensen, H., Planke, S., Polozov, A.G., Schmidbauer, N., Corfu, F., Podladchikov, Y.Y., Jamtveit, B., 2009. Siberian gas venting and the endPermian environmental crisis. Earth Planetary Science Letters 277, 490-500.

Teixeira, C.A.S., 2014. Evolução térmica e paleofluidos da Formação Serra Alta borda leste da Bacia do Paraná. Tese de Mestrado. Instituto de Geociências, Universidade de São Paulo, 80p.

Teixeira, C.A.S., Sawakuchi, A.O., Bello, R.M.S., Nomura, S.F., Bertassoli, D.J., Chamani, M.A.C., 2018. Fluid inclusions in calcite filled opening fractures of the Serra Alta Formation reveal paleotemperatures and composition of diagenetic fluids percolating Permian shales of the Paraná Basin. Journal of South American Earth Sciences 84, 242-251.

Thiede, D.S., Vasconcelos P.M., 2010. Paraná flood basalts: Rapid extrusion hypothesis confirmed by new ${ }^{40} \mathrm{Ar} /{ }^{39} \mathrm{Ar}$ results. Geology 38, 747-750.

Thiéry, R., Pironon, J., Walgenwitz, F., Montel, F., 2000b. PIT (Petroleum inclusion Thermodynamic): a new modeling tool for the characterization of hydrocarbon fluid inclusions from volumetric and microthermometric measurements. Journal of Geochemical Exploration 69-70, 701-704.

Thiéry, R., Pironon, P., Walgenwitz, F., Montel, F., 2002. Individual characterization of petroleum fluid inclusions (composition and P-T trapping conditions) by microthermometry and confocal laser scanning microscopy: inferences from applied thermodynamics of oils. Marine and Petroleum Geology $19,847-859$. 
Thomaz-Filho, A., Mizusaki, A.M.P., Antonioli, L., 2008. Magmatism and petroleum exploration in the Brazilian Paleozoic Basins. Marine and Petroleum Geology 25, 143-151.

Tissot, B.P., Welte, D.H., 1984. Petroleum Formation and Occurrence, $2^{\text {nd }}$ Edition. Berlin, Springer-Verlag, 699p.

Turra, B.B., Riccomini, C., Almeida, R.P., 2006. Significado tectônico dos sismitos permotriássicos da Bacia do Paraná. In: Congresso Brasileiro de Geologia 43, Aracaju, Anais: 111p.

United States Geological Survey (USGS)., 2013. National Oil and Gas Assessment, March, Shale Gas Assessment.

Vail, P.R., Mitchum, R.M., Thompson, S., 1977. Seismic stratigraphy and global changes of sea level, part 3: relative changes of sea level from coastal onlap. In: AAPG. Memoir, 26. Payton, C.E. (Eds.). Seismic stratigraphy: applications to hydrocarbon exploration. Tulsa: American Association of Petroleum Geologists, 63-81.

Vandenbroucke, M., Largeau, C., 2007. Kerogen origin, evolution and structure. Organic Geochemistry 38, 719-833.

Verna, D., Jadhav, G.N., Biswal, T.K., Jena, S.K., Sharma, N., 2012. Characterization of Hydrocarbon-bearing Fluid Inclusion in Sandstones of Jaisalmer Basin, Rajasthan: A Preliminary Approach. Journal Geological Society of India 80, 505-514.

Visscher, H., Looy, C.V., Collinson, M.E., Brinkhuis, H., Cittert, J., Kurschner, W.M., Sephton, M.A., 2004. Environmental mutagenesis during the end-Permian ecological crisis. Proceedings of the National Academy of Sciences of the United States of America 101, 12952-12956.

Wan, C.L., Jin, Q., Fan, B.J., 2001. Current Research Situation on HydrocarbonGenerating Evolution of Volcanic Minerals upon Hydrocarbon Source Rocks. Petroleum Geology and Recovery Efficiency.

Wang, Z.Y., Fan, P., Cheng, K.M., 1995. The thermal evolution indicator of carbonete rocks. Science in China Series B-Chemistry. Life Sciences and Earth Sciences 38, 733-740.

Wei, Z., Gao, X., Zhang, D., Da, J., 2005. Assessment of Thermal Evolution of Kerogen Geopolymers with Their Structural Parameters Measured by Solid-State ${ }^{13} \mathrm{C}$ NMR Spectroscopy. Energy Fuels 19, 240-250.

Wenger, L.M., Baker, D.R., 1987. Variations in vitrinite reflectance with organic facies - Examples from Pennsylvanian cyclothems of the MidContinent, USA. Organic Geochemistry 11, 411-416. 
Werner-Zwanziger, U., Lis, G., Mastalerz, M., Schimmelmann, A., 2005. Thermal maturity of type II kerogen from the New Albany Shale assessed by C-13 CP/MAS NMR. Solid state nuclear magnetic resonance 27, 140-148.

Witte, E.G., Shenk, H.J., Muller, P.J., Schwochau, K., 1988. Structural modifications of kerogen during natural evolution as derived from 13-C CP/MAS NMR, IR spectroscopy and Rock-Eval pyrolysis of Toarcian shales. Organic Geochemistry 13, 1039-1044.

Zalán P.V., Wolff S., Conceição J.C.J., Astolfi M.A.M.; Vieira I.S., Appi V.T., Zanotto, O.A., 1987. Tectônica e sedimentação da Bacia do Paraná. Curitiba PR. In: Simpósio Sul-Brasileiro de Geologia 3, 441-477.

Zalán, P.V., Wolff, S., Astolfi, M.A.M., Vieira, I.S., Conceição, J.C.J., Neto, E.V. S., Cerqueira, J.R., Marques, A., 1990. The Paraná Basin, Brazil. In: Leighton, M.W., Kolata, D.R., Olts, D.F., Eidel, J.J. (Eds.). Interior Cratonic Basins 51, 681708.

Zhang, Y.G., Frantz, J.D., 1987. Determination of the homogenization temperatures and densities of supercritical fluids in the system $\mathrm{NaCl}-\mathrm{KCl}-\mathrm{CaCl}_{2-}$ $\mathrm{H}_{2} \mathrm{O}$ using synthetic fluid inclusions, Chemical Geololy 64, 335-350.

Zhou, Q. H., Feng, Z. H., Men, G. T., 2007. Present Geothermal Features and Relationship with Gas in Xujiaweizi Fault Depression, Songliao Basin. Science in China. Series D: Earth Sciences, SII: 177-188.

Zhu, C., Xu, M., Yuan, Y., Zhao, Y., Shan, J., He, Z., Tian, Y., Hu, S., 2010. Palaegeothermal response and record of the effusing of Emeishan basalts in the Sichuan basin. Chinese Science Bulletin 55 (10), 949-956. 


\section{APÊNDICE I}

MATERIAL CONCEITUAL E DE APOIO 


\section{SISTEMAS PETROLÍFEROS}

\subsection{Convencionais versus não convencionais}

Em sistemas petrolíferos convencionais as denominadas rochas reservatório são em sua maioria arenitos e carbonatos fraturados porque apresentam valores de porosidade e permeabilidade consideráveis, sendo capazes de armazenar hidrocarbonetos e proporcionar a sua produção em taxas economicamente viáveis (Ribeiro, 2015). Estudos geológicos apontam que hidrocarbonetos se acumulam em pacotes de rocha sedimentar do Mesozóico ao Triássico, e comumente em trapas anticlinais (armadilhas estruturais) do que em qualquer outro tipo de trapeamento (armadilhas estratigráficas, Chapman, 1976). Contudo, várias acumulações de hidrocarbonetos distribuídas globalmente não seguem este padrão sendo possível encontrar acumulações em circunstâncias distintas do tradicional, ou seja, acumulações de hidrocarbonetos em contexto não convencional. Desta forma, a definição de sistema petrolífero contempla duas vertentes: os reservatórios convencionais e os reservatórios não convencionais. Do ponto de vista geológico, a principal diferença consiste no fato de que no reservatório não convencional a própria rocha geradora será a rocha reservatório, e devido à baixa permeabilidade será também a rocha selante (Chapman, 1976).

As rochas que formam os reservatórios convencionais possuem valor de porosidade superior a $10 \%$ e permeabilidade superior a $0,1 \mathrm{mD}$, enquanto que os reservatórios não convencionais compreendem rochas de porosidade inferior a $10 \% \mathrm{e}$ permeabilidade inferior a $0,1 \mathrm{mD}$ (Suárez, 2012). Assim, uma rocha reservatório de um sistema petrolífero convencional possui valores de porosidade e permeabilidade que permitem o armazenamento de hidrocarbonetos aliadas a situações estruturais de subsuperfície favoráveis para o aprisionamento e migração dos hidrocarbonetos em seu interior (presença de trapas e rochas selantes). As rochas reservatório de um sistema petrolífero não convencional, geralmente denominadas de folhelhos, consistem de rochas de baixos valores de permeabilidade e porosidade, mas devido à sua grande extensão geográfica e diferentes técnicas usadas para produção, são capazes de produzir consideráveis volumes de hidrocarbonetos (shale gas ou shale oil). 


\section{SISTEMA PETROLÍFERO CONVENCIONAL}

\subsection{Conceitos e definições}

Modelos de migração de paleofluidos e estudo diagenético são importantes para o reconhecimento e entendimento dos elementos e processos de um sistema petrolífero. Nesse sentido, os próximos parágrafos descrevem de forma sucinta os principais elementos e processos presentes em um sistema petrolífero (convencional e não convencional).

Sistema petrolífero é um modelo físico-químico dinâmico que controla a geração, migração e acumulação de hidrocarbonetos em um determinado tempo e espaço geológico (Nijhuis \& Baak, 1990; Demaison \& Huizinga, 1994; Magoon \& Dow, 2000). O conceito de sistema petrolífero foi definido como um sistema natural que inclui todos os elementos geológicos e processos necessários para a acumulação de hidrocarbonetos. Esses elementos geológicos correspondem ao conjunto: rocha geradora, rocha reservatório e rocha selante (capeadora), que devem ser coexistentes e síncronos aos processos de geração, migração e acumulação de petróleo, associados à formação de armadilhas geológicas estratigráficas ou estruturais (Magoon \& Dow, 2000).

\subsubsection{Rocha geradora}

O principal elemento para a ocorrência de hidrocarbonetos é a matéria orgânica acumulada durante a sedimentação e litificação dos sedimentos, em especial siliciclásticos de granulação fina (folhelhos) denominadas rochas geradoras. As rochas geradoras quando submetidas em condições específicas de pressão e temperatura durante a diagênese podem gerar acumulações de hidrocarbonetos em subsuperfície (Hunt, 1996). Rochas geradoras são predominantemente constituídas por materiais detríticos de granulação muito fina (fração argila), sendo geralmente representadas por folhelhos e/ou rochas carbonáticas. Quanto maior a quantidade de matéria orgânica, maior o potencial da rocha para a geração de hidrocarbonetos (Hunt, 1996). O principal controlador para geração de hidrocarbonetos em sistemas petrolíferos é a proporção hidrogênio-carbono (H/C) presente na rocha fonte (Hunt, 1996). Essa proporção está diretamente associada à origem do material orgânico depositado na bacia, sendo que o material de origem lacustre e marinha apresenta maior proporção $\mathrm{H} / \mathrm{C}$ do que o material proveniente de vegetais superiores (Hunt, 1996). Durante a deposição da matéria orgânica é vital a preservação do seu conteúdo original, rico em compostos de carbono (C) e hidrogênio $(H)$. Desta forma, o ambiente deve ser muito empobrecido ou livre de 
oxigênio, elemento de propriedade oxidante, destruidor das concentrações de $\mathrm{C}$ e $\mathrm{H}$ em partículas orgânicas originais. Assim, paleoambientes anóxicos favorecem a preservação da matéria orgânica e, consequentemente, a geração de hidrocarbonetos.

Geralmente, rochas sedimentares comuns apresentam teores de carbono orgânico total (COT) inferiores a 1 \%. Os valores mínimos de COT para uma rocha ser avaliada como potencialmente geradora são de 0,5 a $1 \%$, aproximadamente, ao longo de toda a unidade geológica (Hunt, 1996).

O tipo de hidrocarboneto produzido depende do tipo de matéria orgânica preservada na rocha geradora; assim materiais orgânicos derivados de vegetais superiores tendem a gerar hidrocarbonetos gasosos, enquanto materiais derivados de fitoplâncton e zooplâncton, marinho ou lacustre, tendem a gerar hidrocarbonetos líquidos (Hunt, 1996).

As principais condições para que os sedimentos se tornem rochas geradoras, são: 1) presença de matéria orgânica adequada e suficiente; 2) tipo de matéria orgânica adequada que tenha potencial para gerar óleo ou gás; 3 ) nível de maturação necessário para a geração de hidrocarbonetos.

\subsubsection{Matéria Orgânica}

Os principais representantes da matéria orgânica apropriada para a geração de hidrocarbonetos são o plâncton (marinho e fluvial) e as bactérias, sendo estas relacionadas tanto à preservação de matéria orgânica nos sedimentos como à biodegradação da mesma. A matéria orgânica ideal para a geração de hidrocarbonetos é representada pelo fito plâncton marinho e lacustre, devido sua composição rica em lípidos (gorduras - Hunt, 1996).

Aproximadamente $98 \%$ da matéria orgânica presente nos sedimentos corresponde a material amorfo e de natureza insolúvel, denominado querogênio. $O$ termo querogênio é aplicado para a fração de matéria orgânica sedimentar que é insolúvel na presença de solventes orgânicos (Hunt, 1996). O querogênio é um composto polímero de elevado peso molecular que compreende cerca de $90 \%$ da matéria orgânica dos folhelhos. Os restantes $10 \%$ são betumes de composições variadas que podem corresponder a querogênio termicamente alterado (Hunt,1996). 


\subsubsection{Rocha Reservatório}

Rochas carbonáticas biogênicas não detríticas são importantes reservatórios (recifes e estromatólitos), contudo, as rochas reservatório de composição detrítica e de granulometria fração areia a seixo (arenitos), são preponderantes na medida em que, posteriormente, hidrocarbonetos podem ser armazenados e extraídos à escala comercial (Link, 1982). Genericamente pode se assumir que quanto maior a porosidade maior a permeabilidade efetiva da rocha reservatório, porém, é necessário ter em conta a atuação de outros fatores como a capilaridade, tamanho e forma dos grãos. Reservatório de hidrocarbonetos, para ser eficiente, deve ser relativamente poroso e permeável, além de conter algum tipo de selo ou armadilha que contenha a migração de fluidos. A pressão dos fluidos, sustentada pela carga das camadas estratigraficamente superiores (pressão de soterramento), gás em solução e fluidos de origem meteórica, é fundamental para o desenvolvimento da pressão em reservatórios, onde a pressão interna do sistema é reduzida e as fases do fluido são modificadas (Rocha, 2016). À medida que a pressão do reservatório é reduzida, o gás em solução se separa da fase liquida (óleo). A pressão em que este fenômeno ocorre é denominada ponto de gaseificação. O processo de compactação dos sedimentos resulta na redução de porosidade e permeabilidade da rocha durante a diagênese. Contudo, quando os sedimentos se apresentam saturados em fluidos (como água, óleo ou gás), a porosidade será reduzida por cimentação. Compactação e condutividade hidráulica são fatores relacionados entre si e às propriedades de porosidade e permeabilidade de rochas, sendo importantes para o melhor entendimento de reservatórios de petróleo convencionais ou não convencionais (Rocha, 2016).

\subsubsection{Rocha Selante}

As rochas selantes ou capeadoras são as responsáveis pela retenção de hidrocarbonetos nas armadilhas. Devem apresentar baixa permeabilidade associada com alta pressão capilar, de modo a impedir a migração vertical do petróleo (Rocha, 2016). Os evaporitos (especialmente a halita) são os capeadores mais eficientes, embora os folhelhos sejam os mais comuns nas acumulações de petróleo (oil shale e shale gas). Os folhelhos podem, nos casos em que a pressão capilar não é suficientemente alta, atuar como capeadores seletivos, impedindo a passagem do óleo e permitindo a perda de gás da armadilha. Cabe ressaltar que a capacidade selante de uma rocha é dinâmica. Um folhelho capeador pode, com o aumento da compactação durante a diagênese e alguma atividade tectônica, fraturar-se e perder sua capacidade 
selante (Rocha, 2016). A presença ou ausência de rocha selante não exclui a importância de propriedades físicas, como capilaridade (pressão mínima que suporta a força de flutuação do fluido), continuidade lateral (geometria e arquitetura de fácies sedimentares), litologia (ocorrência de calcita, halita, anidrita, carbonatos ou chert), ductilidade (tendência da rocha fluir em resposta à deformação), e espessura (manutenção das características deposicionais ao longo do tempo e taxa de sedimentação) presentes em sistemas petrolíferos (Hunt, 1996).

\subsubsection{Processos}

\subsubsection{Maturação}

O estágio de maturação térmica de uma rocha geradora, isto é, a temperatura na qual deve ser submetida para que ocorra a geração, também influencia no tipo de hidrocarboneto gerado (Hunt, 1996). Genericamente em sistemas petrolíferos convencionais, uma rocha geradora inicia a transformação de querogênio em petróleo em torno de $60^{\circ} \mathrm{C}$. Inicialmente forma-se um óleo de baixa maturidade e caráter viscoso. À medida que a temperatura aumenta, o óleo gerado vai ficando mais fluido e a quantidade de gás vai aumentando. Por volta de $90 \stackrel{\circ}{ } \mathrm{C}$, as rochas geradoras atingem seu pico de geração, expelindo grandes quantidades de óleo. Com o aumento da temperatura em torno de $120 \stackrel{\circ}{ } \mathrm{C}$, o óleo fica cada vez mais fluído e mais rico em gás dissolvido. Nesta faixa de temperatura, a quantidade de gás predomina sobre a de óleo gerado, e o produto é considerado um condensado. A partir de $150^{\circ} \mathrm{C}$, apenas gás é gerado pela rocha geradora (Hunt, 1996).

\subsubsection{Geração}

Hidrocarbonetos são gerados a partir da quebra de moléculas de querogênio na rocha geradora, em função do aumento de temperatura durante o tempo geológico. Temperaturas entre $110-150{ }^{\circ} \mathrm{C}$ para óleo e $180{ }^{\circ} \mathrm{C}$ para gás induzem maturação e expulsão dos hidrocarbonetos, que posteriormente sofrem movimentação ascendente por empuxo, em condições hidrostáticas ou por flutuação associada ao fluxo de fluidos em condições hidrodinâmicas, representando o estágio de migração primária (Hunt, 1996). Quando a saturação em óleo residual varia entre 0,5 a $4 \%$, as forças de empuxo e a pressão interna condicionam a movimentação de hidrocarbonetos. A saturação é maior no topo do que na base da camada e depende do angulo de mergulho, viscosidade, taxa de suprimento de hidrocarbonetos e permeabilidade. A ausência de geração indica uma restrição no funcionamento de um sistema petrolífero. No entanto, 
mesmo que uma rocha contenha matéria orgânica, não significa que ocorrerá geração. A expulsão de hidrocarbonetos da rocha geradora ocorre quando a saturação (fração de microporosidade ocupada por hidrocarbonetos) em folhelhos excede 10-20\%. Geralmente, a eficiência de expulsão aumenta com o aumento de maturidade, alcançando 80-90 \% para rochas ricas e maturas (Rostirolla, 1999).

\subsubsection{Migração}

Depois da geração de hidrocarbonetos (líquidos e gasosos), eles passam a ocupar maior espaço/volume que o querogênio original da rocha. A rocha torna-se supersaturada em hidrocarbonetos e a pressão excessiva dos mesmos faz com que a rocha geradora se frature, permitindo a expulsão dos paleofluidos para zonas de pressão menor (Rostirolla, 1999). A percolação de paleofluidos através de rotas subsuperficiais ou profundas, até à chegada em uma formação porosa, selada e apta para armazená-los, é designada como migração. As rotas de migração em uma bacia sedimentar podem ser fraturas, em diversas escalas, falhas e rochas porosas variáveis (Rostirolla, 1999).

A migração corresponde à circulação de hidrocarbonetos que ocorre quando a pressão de fluidos excede a pressão capilar do mesmo fluxo. As rotas de migração se comportam como um conduto, com diferentes gradientes de pressão, permitindo a movimentação do fluido. A migração ao longo de falhas e fraturas é menor do que ao longo de camadas (Rostirolla, 1999). O autor afirma que a permeabilidade tectónica é menos eficaz que a permeabilidade sedimentar e assim, o principal fator que influencia na migração é o gradiente de pressão.

Segundo Link (1982), o conceito de migração é amplamente aceita, porém existe discordância quanto aos mecanismos envolvidos e distancias percorridas; desta forma propôs três diferentes conceitos de migração: a) Migração primária: quando o petróleo se desloca da rocha geradora (fonte) para a rocha reservatório; b) Migração secundária: quando o petróleo se movimenta no interior da rocha reservatório após sua acumulação; c) Migração terciária: quando o petróleo não fica armazenado e continua em busca de zonas de menor pressão, terminando como exudação, oxidado ou biodegradado.

\subsubsection{Acumulação}

Configurações geométricas estruturais ou rochas sedimentares que permitem a captação e acumulação de paleofluidos são designadas como trapas ou armadilhas (Link, 1982). Estas estruturas podem ser simples, como o flanco ou o topo de uma dobra 
anticlinal, arcos e domos salinos, ou complexas quando ocorre superposição de dobras ou falhas de natureza diversa. Quando ocorre acumulação nestas condições são denominadas armadilhas estruturais; contudo, nem sempre o petróleo é aprisionado desta forma, podendo ser acumulado no final da camada transportadora, por bloqueio da mesma ou por barreira diagenética de diferente permeabilidade, neste caso denominam-se armadilhas estratigráficas (Link, 1982).

\subsubsection{Caracterização e estrutura de hidrocarbonetos}

Hidrocarbonetos são vitais à vida moderna, sendo o componente básico de milhares de produtos, desde gasolina, óleo diesel, querosene, gás de cozinha, solventes, lubrificantes, borrachas, plásticos, tecidos sintéticos e até mesmo energia elétrica (Munz et al., 2001). Os principais componentes de hidrocarbonetos são o carbono, hidrogênio, enxofre, gases inorgânicos como $\mathrm{N}_{2}, \mathrm{H}_{2} \mathrm{~S}, \mathrm{CO}_{2}$, metais como $\mathrm{Fe}$, $\mathrm{Cu}, \mathrm{Pb}, \mathrm{Mn}, \mathrm{Ni}, \mathrm{V}$, etc, e também impurezas como água e sais (Munz, 2001). Os hidrocarbonetos, de acordo com a sua estrutura, podem ser divididos em três categorias: aromáticos, alifáticos e parafínicos. Aromáticos são representados pelo benzeno (anéis de benzeno), naftaleno, xileno e tolueno $\left(\mathrm{CH}_{3}\right)$. Alifáticos correspondem a hidrocarbonetos de cadeias abertas e cíclicas como os alcenos e alcinos (insaturados). Parafínicos: destacam-se os alcanos (saturados) como o metano, etano, propano, butano, pentano etc. $\mathrm{O}$ metano $\left(\mathrm{CH}_{4}\right)$ é o constituinte mais simples de hidrocarbonetos, cuja geração pode ser dominada por dois processos: 1) metano gerado por bactérias metanogênicas - archaea, conhecido como metano biogénico; e 2) metano gerado durante a decomposição térmica de moléculas orgânicas maiores - 0 metano termogênico (Wuebbles and Hayhoe, 2002) durante a diagênese. A produção de hidrocarbonetos de origem termogênica, geralmente ocorre em profundidades superiores a $1000 \mathrm{~m}$ e são produzidos sob condições de alta pressão e temperatura, quer pelo soterramento ou através do contato com corpos ígneos, sendo gerados por degradação térmica ou craqueamento (Hunt, 1996). 


\section{O ESTUDO DE INCLUSÕES FLUIDAS (IF'S) EM BACIAS SEDIMENTARES}

\subsection{Síntese evolutiva}

A presença de fluidos como inclusões em minerais foi observada desde o século IV, porém, o estudo de inclusões fluidas em geologia é comum desde o início do século XIX. A partir da segunda metade do século XX começaram a surgir, mais frequentemente, experimentos microtermométricos para a caracterização e composição de inclusões fluidas (Roedder, 1984).

Inclusões fluidas são pequenos volumes de fluidos aprisionados nas cavidades dos minerais ou em suas imperfeições estruturais (Figura 1.1) constituindo verdadeiras fontes de informação sobre as soluções presentes durante um determinado tipo de evento geológico. Depois de formadas, as inclusões tendem a permanecer como sistemas isolados que permitem apenas a troca de energia na forma de calor (Roedder, 1984). Esses fluidos, que podem ter origens e composições diferentes, ficam retidos como inclusões durante os processos de cristalização ou recristalização dos minerais hospedeiros e de cicatrização de fraturas (Roedder, 1984; Shepherd et al., 1985).

A aplicabilidade do estudo de inclusões fluidas é sustentada por um amplo conjunto de métodos analíticos qualitativos e semi-quantitativos irrefutáveis. Exemplos de métodos qualitativos incluem a petrografia convencional (Roedder, 1984; Goldstein \& Reynolds, 1994; Bello, 1996) e o uso de catodoluminescência (Boiron et al., 1992). No campo dos métodos semi-quantitativos também existem ensaios destrutivos e não destrutivos. Ensaios não destrutivos correspondem a microtermometria (Goldstein, 2001), a espectrofotometria de fluorescência através de exposição de luz ultravioleta (UV), que permite a caraterização da composição de inclusões compostas por hidrocarbonetos (Stasiuk \& Snowdon, 1997), e análises de inclusões fluidas aquosas de múltiplas fases, tanto pela presença de voláteis $\left(\mathrm{CH}_{4}, \mathrm{CO}_{2}\right.$ e $\left.\mathrm{N}_{2}\right)$ como de minerais de saturação (carbonatos, sulfatos e fosfatos), por espectroscopia Raman (Burke, 2001). Exemplos de ensaios destrutivos integram análises químicas totais (bulk analysis) para determinação de composição de inclusões aquocarbônicas (Roedder, 1984; Goldstein \& Reynolds, 1994), e análise química da composição molecular e de voláteis de inclusões aquosas e compostas por hidrocarbonetos, a partir de cromatografia gasosa acoplada a espectrómetro de massas (Munz, 2001; Munz et al., 2004).

O estudo de IF's por meio de observações petrográficas e análises microtermométricas permite a determinação de suas características físico-químicas, tais como, composições, densidades, salinidades, temperatura e pressão de aprisionamento, e a compreensão de aspectos de sua interação com as rochas 
encaixantes e de alteração das mesmas, como discutido em Roedder (1984); Goldstein \& Reynolds (1994) e Bello (1996).

No contexto de bacias sedimentares, IF's podem ser aprisionadas em diferentes ambientes sedimentares, formam-se durante a diagênese (Roedder, 1984; Goldstein \& Reynolds, 1994; Munz, 2001; Goldstein, 2001) e são eficazes para o estudo térmico em sistemas petrolíferos, agindo como paleotermômetro, pois preservam fluidos bacinais ancestrais (fluidos de formação) e hidrocarbonetos (óleo e/ou gás), mantendo suas propriedades químicas e físico-químicas inalteradas ao longo do tempo (Roedder, 1984; Goldstein \& Reynolds, 1994). O estudo de IF's em bacias sedimentares tem adquirido importância desde a década de 1980 (Burruss, 1981; Burruss et al., 1983), em especial na indústria petrolífera, pois guarda valiosa informação desde os primeiros pulsos de geração e migração de hidrocarbonetos em unidades geradoras, reservatório e/ou estruturas de transporte (Munz, 2001; Coelho, 2005).

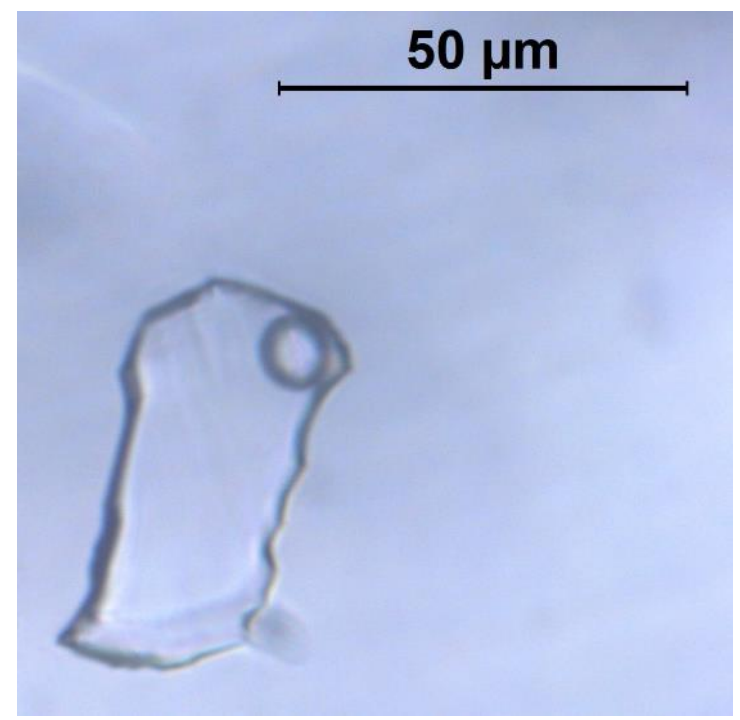

Figura 1.1. Exemplo de inclusão fluida aquosa bifásica à temperatura ambiente $\left(23^{\circ} \mathrm{C}\right)$. Retirado de amostra didática de topázio.

\subsection{Interpretações e considerações gerais}

Os minerais cristalizam a partir de um fluido, seja ele um fluido aquoso, com ou sem componentes voláteis, ou um fundido silicático (Roedder, 1984). Esses fluidos, que podem ter origens e composições diferentes, ficam retidos como inclusões durante os processos de cristalização ou recristalização dos minerais hospedeiros e de cicatrização de fraturas (Roedder, 1984; Shepherd et al., 1985), e armazenam informações sobre as características das soluções envolvidas em determinado processo.

O aprisionamento de inclusões fluidas pode ocorrer de diversas formas, muitas delas nem sempre passíveis de identificação. Durante a cristalização ou recristalização 
de um mineral a partir de um ou mais fluidos, estes podem ficar retidos nas irregularidades existentes na superfície do cristal, e qualquer fenômeno que interfira com o crescimento ideal de um mineral, que cause defeitos e imperfeições na sua rede cristalina, pode e deve causar o aprisionamento de parte do fluido envolvido.

Existem muitos mecanismos que podem causar imperfeições num cristal em crescimento, os quais seriam responsáveis pelo aprisionamento de inclusões fluidas durante a cristalização de um mineral, destacando-se entre eles, 1) a cristalização rápida, que pode causar a formação de cristais dendríticos, os quais são posteriormente recobertos por crescimento posterior; 2) a dissolução parcial de um cristal preexistente, formando reentrâncias e superfícies curvas, posteriormente recoberto por novo crescimento; 3) fraturamento do cristal em desenvolvimento com crescimento posterior; 4) presença de um outro sólido já cristalizado na superfície do mineral em crescimento - esse sólido pode ser aprisionado como inclusão cristalina, acompanhada por algum fluido. Em todos esses casos, o crescimento posterior pode causar o aprisionamento de inclusões (Roedder, 1984; Shepherd et al., 1985).

A base interpretativa para o estudo de IF's e início dos ensaios microtermométricos deve seguir um conjunto de premissas sobre a natureza do fluido aprisionado e o modo de formação das inclusões, para que possam ser elaboradas conclusões e modelos de evolução térmica sobre determinado contexto geológico (Roedder, 1984). Esses princípios, tanto indicados para contextos de depósitos minerais (Roedder, 1984) como para processos diagenéticos (Goldstein \& Reynolds, 1994), são: 1) uma inclusão deve ser formada a partir de um fluido hidrotermal ou diagenético durante o crescimento de um cristal (hospedeiro); 2) o cristal hospedeiro da inclusão deve manter suas características químicas inalteradas; 3) a inclusão deve permanecer em um sistema fechado desde a sua formação; e 4) o volume ou a densidade da inclusão deve manter-se constante após o seu aprisionamento.

De modo geral, a formação de IF's em profundidade pode ocorrer a partir de fluidos homogêneos, fluidos hidrotermais ou diagenéticos, onde as inclusões tendem a permanecer como sistemas isolados, permitindo apenas a troca de energia sob a forma de calor (Roedder, 1984; Goldstein \& Reynolds, 1994). Posteriormente, com o soerguimento e consequente resfriamento ocorre o aparecimento de uma bolha de gás ou vapor nas inclusões. Esse processo deve-se a contração diferencial entre o fluido e o mineral hospedeiro (o fluido se contrai mais) e ao decréscimo de solubilidade entre um componente volátil (ex: $\mathrm{CO}_{2}$ ), e a fase aquosa, com o decréscimo das condições de temperatura e pressão, seguindo o caminho indicado pelas respetivas isócoras (linhas de igual volume ou densidade, figura 1.2). Porém, em alguns casos o aprisionamento homogêneo não se verifica e pode ocorrer o aprisionamento heterogêneo de IF's. 
O aprisionamento heterogêneo ocorre, quando as inclusões já são formadas a partir de fluidos originalmente imiscíveis, por exemplo compostos por soluções aquosas e óleo (Munz, 2001). Além destes fenômenos, também podem ocorrer modificações pós-aprisionamento que causam reequilíbrio das inclusões pelos processos de estiramento (stretching), escape de fluidos (leakage), crepitação e até mesmo o estrangulamento das inclusões (necking down) (Roedder, 1984).

Feições de escape são comumente visualizadas ao microscópio como finos prolongamentos dispostos nas bordas ou ao redor da inclusão. O escape de fluidos (leakage) e a crepitação ocorrem devido às diferenças entre a pressão interna da inclusão e a pressão externa do ambiente que vai diminuindo. Essa diferença entre as pressões pode causar o aparecimento de microfraturas ao redor da inclusão provocando a fuga do próprio fluido ou no caso de essa diferença atingir valores extremos, pode ocorrer a crepitação (explosão) das inclusões (Roedder, 1984).

O estrangulamento (necking down) advém dos processos de dissolução e recristalização atuantes no mineral hospedeiro quando este é minimamente solúvel na solução aprisionada. Assim, inclusões com formas irregulares e de grandes dimensões, durante o aprisionamento, podem sofrer subdivisões em inclusões menores de morfologia mais regular. Se o estrangulamento for desenvolvido após o aparecimento da bolha de vapor serão formadas novas inclusões com diferentes proporções volumétricas entre as fases e composições distintas entre si, portanto, apresentam diferentes densidades que não correspondem às do fluido original (Roedder, 1984).

De qualquer forma, inclusões que apresentem ao microscópio características de terem sofrido modificações pós-aprisionamento, tais como, leakage e necking down, devem ser evitadas durante os estudos por não serem representativas dos fluidos originais. 


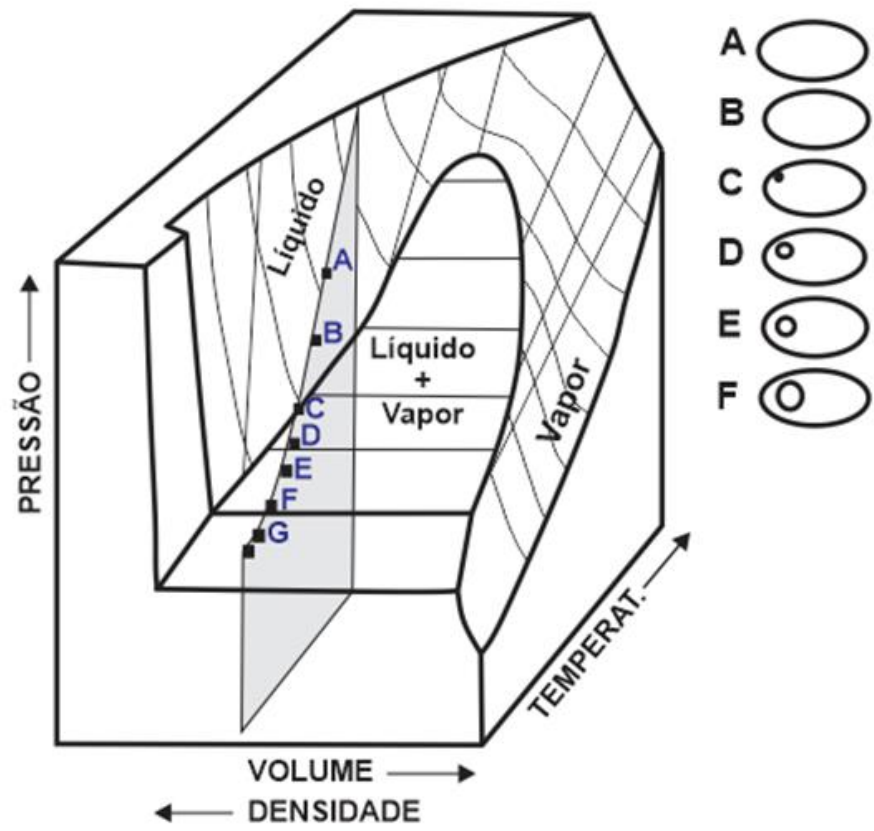

Figura 1.2. Diagrama de temperatura versus volume molar versus pressão (P-V-T), que mostra os limites das fases existentes, vapor, líquido + vapor e líquido, além dos campos de coexistência de fases para um sistema simples composto por $\mathrm{H}_{2} \mathrm{O}$ puro. O ponto A ilustra uma inclusão de fase líquida aprisionada em profundidade; o ponto G ilustra as condições de $P$ e $T$ de IF's bifásicas após soerguimento. Modificado de Goldstein \& Reynolds (1994).

\subsection{Classificação segundo origem e modo de ocorrência}

Inclusões fluidas são classificadas em três famílias distintas: primárias, secundárias e pseudo-secundárias (Roedder, 1984; Hollister, 1981), de acordo com sua origem e modo de ocorrência (Figura 1.3).

Inclusões fluidas primárias são aquelas aprisionadas durante a cristalização do mineral hospedeiro. Neste caso, constituem amostras originais dos fluidos presentes durante a formação dos minerais e podem ocorrer segundo arranjos planares, paralelos às faces de crescimento dos cristais, e, também, como inclusões isoladas ou grupos de inclusões não orientadas, dispostas de modo aleatório no interior dos grãos.

As inclusões fluidas secundárias são aquelas aprisionadas posteriormente à formação do mineral hospedeiro, principalmente, através de processos de cicatrização de microfraturas, permitindo a circulação de fluidos e a recristalização. Desse modo, representam fluidos posteriores, que podem apresentar características e idades totalmente distintas das soluções originais. Ocorrem, normalmente, delineando microfraturas cicatrizadas que atingem a superfície do cristal.

Inclusões pseudo-secundárias são formadas quando ocorre um fraturamento e sua cicatrização ainda durante o crescimento do mineral hospedeiro. Neste caso, os 
fluidos constituem amostras das soluções originais e as inclusões ocorrem ao longo de planos de fraturas cicatrizadas que, no entanto, não atingem a superfície do cristal (Roedder, 1984; Shepherd et al., 1985).

O estudo e a observação ao microscópio destes tipos de inclusões, considerandose a distribuição e modo de ocorrência, pode permitir a individualização de grupos distintos, bem como, o aperfeiçoamento de modelos cronológicos relativos, importantes para estudos posteriores (Touret \& Dietvorst, 1983).

Touret $(1977,1981)$ mostra uma cronologia relativa que pode ser estabelecida segundo várias premissas sendo elas, a) a partir do número de inclusões fluidas, isto é, inclusões isoladas seriam mais antigas em relação às que se dispõem segundo grandes alinhamentos; b) a partir do grau de cicatrização das fraturas, ou seja, algumas inclusões, principalmente aquosas, distribuem-se ao longo de fraturas levemente cicatrizadas (mais claras), sendo mais tardias; c) a partir da extensão do alinhamento e de suas relações com os limites dos grãos; as inclusões dispostas em alinhamentos localizados no interior de um cristal são mais antigas do que aqueles que cruzam os seus limites; d) a intersecção entre alinhamentos indica, frequentemente, suas idades relativas.

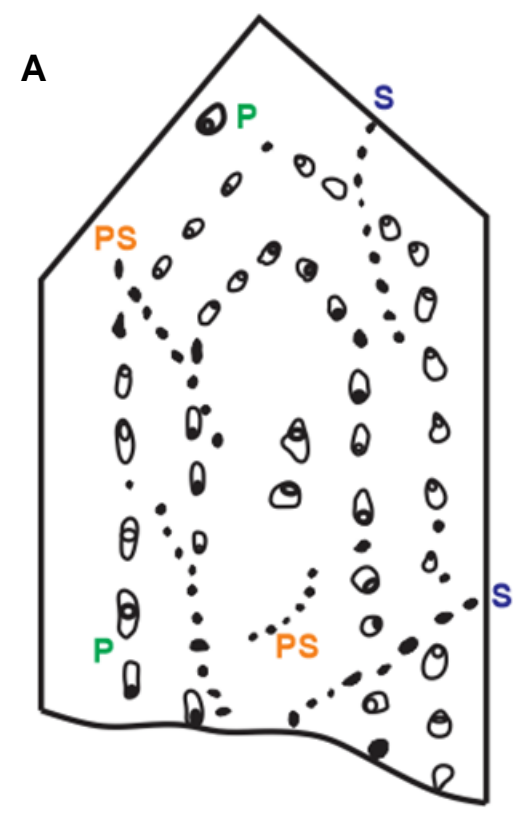

B

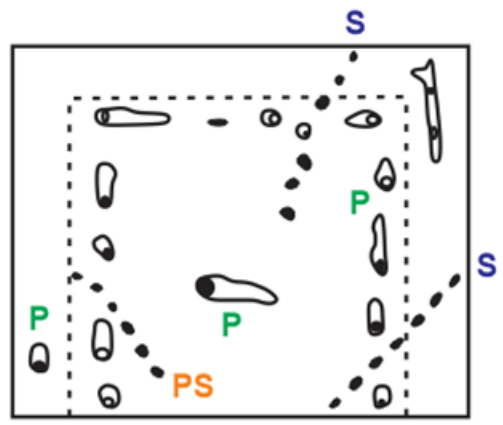

Figura 1.3. Esquema ilustrativo da distribuição de inclusões fluidas primárias, secundárias e pseudo-secundárias no quartzo e fluorita. (A) Quartzo, seção paralela ao eixo c; (B) Fluorita, seção paralela à face do cubo. Modificado de Goldstein \& Reynolds (1994). 


\subsection{Classificação segundo composição e número de fases à temperatura ambiente $\left(\sim 22{ }^{\circ} \mathrm{C}\right)$}

Os estudos petrográficos iniciais também permitem observações sobre a morfologia e o número de fases presentes nas inclusões, as quais podem ser monofásicas, bifásicas, trifásicas ou multifásicas.

A grande maioria das inclusões fluidas consiste de um líquido de baixa viscosidade e uma bolha de gás ou vapor. O líquido de baixa viscosidade, geralmente é composto por uma solução aquosa que contém várias quantidades de soluto. Esse soluto pode ser constituído por $\mathrm{Na}, \mathrm{K}, \mathrm{Ca}, \mathrm{Mg}, \mathrm{Cl}, \mathrm{SO}_{4}$, podendo também, conter menores quantidades de outros íons, sendo que o $\mathrm{Na}$ e o $\mathrm{Cl}$ são predominantes.

A bolha pode ser constituída por vapor de água ou por gás altamente comprimido, $\left(\mathrm{CO}_{2}, \mathrm{CH}_{4}\right)$ que estava originalmente dissolvido no fluido aprisionado. $\mathrm{O} \mathrm{CO}_{2}$ pode aparecer na forma líquida e/ou gasosa e predominar em relação a solução aquosa. $O$ $\mathrm{CH}_{4}$, no ambiente diagenético, ocorre como fluido supercrítico, ou seja, um fluido que tem algumas características da fase líquida e outras da fase gasosa.

Quanto ao número de fases as inclusões fluidas podem ser classificadas como, a) monofásicas quando apresentam apenas uma fase, seja ela líquida ou gasosa; b) bifásicas quando contém duas fases sejam elas líquida + gasosa, líquida + sólida, líquida + líquida ou sólida + gasosa; c) trifásicas quando apresentam um conjunto de três fases, sendo as mais comuns as de líquido + líquido + gás e de líquido + gás + sólido; d) polifásicas ou multifásicas (Figura 1.4) quando são constituídas por quatro ou mais fases, por exemplo, líquido 1 + líquido 2 + gás + sólidos (Roedder, 1984, Shepherd et al., 1985).

Após o aprisionamento de uma inclusão, a partir de um sistema homogêneo, esta pode sofrer algumas modificações, como, o aparecimento de uma fase vapor, resultante da maior contração do líquido em relação ao mineral hospedeiro com o resfriamento. $A$ partir do resfriamento até chegar à temperatura ambiente, também podem ocorrer outras modificações, assim como, a formação de sólidos de saturação, quando as soluções originais possuem altas salinidades. Além destas modificações, também podem ocorrer processos que causam o escape de fluidos (leakage), a crepitação e até mesmo o estrangulamento das inclusões (necking down) (Roedder, 1984). Contudo, inclusões que apresentam ao microscópio características de modificações posteriores ao aprisionamento devem ser evitadas durante os estudos, por apresentarem, proporções volumétricas distintas das originais, assim como, composições e diferentes densidades que não correspondem às do fluido original (Roedder, 1984; Goldstein \& Reynolds, 1994). 


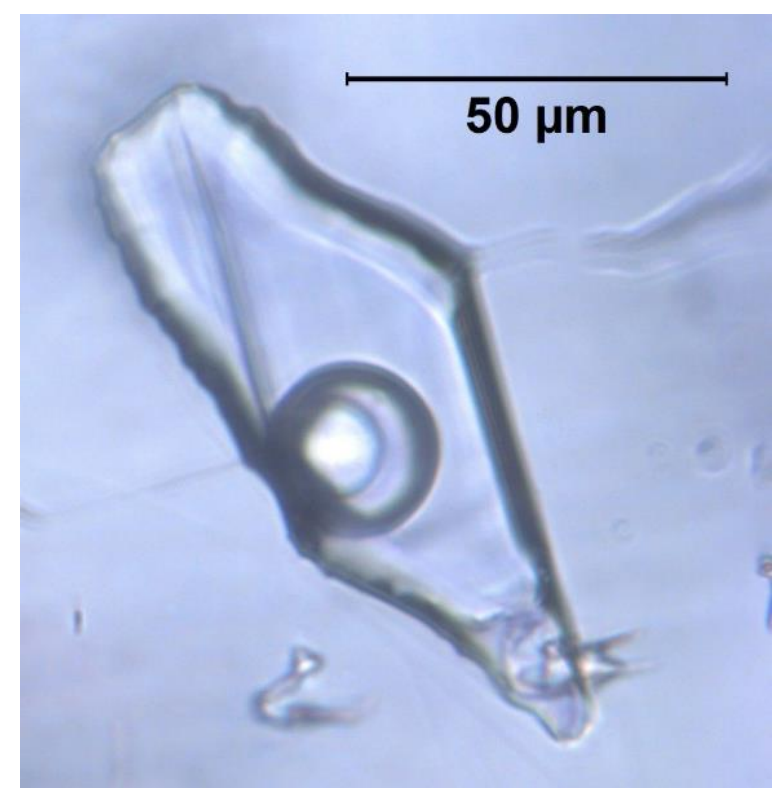

Figura 1.4. Exemplo de inclusão fluida multifásica à temperatura ambiente. Retirado de amostra didática de topázio.

\subsection{Microtermometria e temperaturas importantes}

A microtermometria é uma técnica não destrutiva que consiste na determinação das temperaturas de mudanças de fases que ocorrem em todos os componentes das inclusões fluidas, sob condições controladas de aquecimento e/ou resfriamento das amostras. Para o uso desse método, é fundamental seguir a premissa de que os fluidos aprisionados devem ser representativos da solução presente durante a formação do mineral hospedeiro, e as suas caraterísticas físico-químicas, tais como, densidade, volume e composição, devem permanecer constantes, e caso ocorram variações, estas têm de ser passíveis de identificação petrográfica (Roedder, 1984).

O equipamento utilizado para realização de estudos microtermométricos consiste de uma platina acoplada a um microscópio petrográfico que permite o aquecimento (até $600^{\circ} \mathrm{C}$ ) e o resfriamento da amostra (até $-180^{\circ} \mathrm{C}$ ); um cilindro (container) de nitrogênio líquido e de um sistema registrador/controlador das temperaturas durante os ensaios ( vide capitulo 3, figura 3.2). O aquecimento é obtido por meio de uma resistência interna disposta na região central da platina, próxima à amostra, enquanto o resfriamento é realizado pela circulação do nitrogênio líquido em uma canaleta interna do corpo da platina. Todos os processos e as modificações geradas nas inclusões ao longo dos ensaios são acompanhados em microscópio petrográfico.

As temperaturas importantes para o estudo de inclusões fluidas são, por isso, divididas em dois grupos: temperaturas de aquecimento e temperaturas de 
resfriamento. As temperaturas de aquecimento incluem a temperatura de homogeneização (Th) e de dissolução de sólidos de saturação (Tds) quando estes se encontram presentes; as temperaturas de resfriamento incluem a temperatura do ponto eutético (Te) e a temperatura de fusão do gelo ( $\mathrm{Tg}$ ).

Temperatura de homogeneização (Th) é definida como a temperatura na qual um fluido composto por diferentes fases torna-se homogêneo (Goldstein \& Reynolds, 1994) (Figura 1.5E-H). Em microtermometria este fenômeno, indica as temperaturas mínimas de aprisionamento, se este ocorreu a partir de um sistema de fluidos homogêneos, as quais, por meio de equações termodinâmicas referentes ao sistema presente, permite a determinação das pressões mínimas. A homogeneização total de uma inclusão pode ocorrer de três modos distintos: a) pela diminuição da bolha devido à contração da fase vapor (homogeneização para o líquido); b) pelo aumento da bolha devido à expansão da fase vapor (homogeneização para o vapor); c) pelo desaparecimento da bolha sem mudanças de volume (homogeneização crítica).

Temperatura do ponto eutético (Te) representa o início da fusão da solução aquosa salina congelada (Figura $1.5 \mathrm{~A}-\mathrm{C}$ ). Corresponde à temperatura mínima de estabilidade líquida em um sistema químico e indica a composição do sistema aprisionado, por meio da identificação dos principais íons dissolvidos na solução. A fase fluida de uma inclusão aquosa totalmente congelada, quando aquecida irá começar a fundir quando atingir o valor de Te (Roedder, 1984; Goldstein \& Reynolds, 1994). Assim, essa temperatura deve ser registrada quando ocorre o aparecimento da primeira gota de líquido, o que muitas vezes, é evidenciado por uma variação na textura da fase congelada. Porém, devido aos efeitos de metaestabilidade e a dificuldade de observação de Te, especialmente para as inclusões $<5 \mu \mathrm{m}$, muitas vezes é medido o primeiro valor de temperatura de fusão do gelo evidenciado pela mudança de textura, e depois é feita uma correlação com os vários valores de Te que constam na literatura (Roedder, 1984; Goldstein \& Reynolds, 1994). Alguns procedimentos microtermométricos como o uso de ciclos de aquecimento e resfriamento) podem reduzir a ocorrência desse fenômeno durante o aquecimento, porém, sem o evitar por completo (Roedder, 1984; Goldstein \& Reynolds, 1994). A avaliação de temperaturas de mudança de fase ocorridas em condição de equilíbrio metaestável, principalmente em baixa temperatura, constitui um fenômeno normal e que pode ser utilizado na interpretação dos dados microtermométricos. Problemas adicionais com a temperatura do ponto eutético advém quando valores muito próximos, a exemplo do sistema $\mathrm{KCl}$ $\mathrm{NaCl}-\mathrm{H}_{2} \mathrm{O}$, cujo o eutético ocorre a $-22,9^{\circ} \mathrm{C}$, e o sistema $\mathrm{NaCl}-\mathrm{H}_{2} \mathrm{O}$, cujo eutético ocorre em $-21,2^{\circ} \mathrm{C}$, torna inverossímil sua distinção microtermométrica em inclusões fluidas de baixa salinidade, compostas apenas da fase líquida e vapor à temperatura ambiente 
(Goldstein \& Reynolds, 1994; Bodnar, 2003). Nestes casos, a determinação da composição dos sistemas apenas é possível quando há a presença de um ou mais sólidos filhos (daughter minerals), como a halita e/ou silvita, que possam ser identificados tanto pelo seu comportamento microtermométrico, como descrito em Bodnar (2003), ou por métodos alternativos como a espectroscopia a laser Raman (Frezzotti et al., 2012). No caso do sistema $\mathrm{CaCl}_{2}-\mathrm{NaCl}-\mathrm{H}_{2} \mathrm{O}$ a temperatura do ponto eutético situa-se em $-52{ }^{\circ} \mathrm{C}$, além de ser composto pelos subsistemas $\mathrm{CaCl}_{2}-\mathrm{H}_{2} \mathrm{O}$, cujo eutético é $-49,9^{\circ} \mathrm{C}$ (Bodnar, 2003). Contudo, é importante referir que as temperaturas eutéticas do sistema $\mathrm{CaCl}_{2}-\mathrm{NaCl}-\mathrm{H}_{2} \mathrm{O}$ podem atingir valores bem inferiores (podendo chegar a $-75^{\circ} \mathrm{C}$ ) devido à metaestabilidade (Davis et al., 1990).

Similar à determinação da composição do sistema químico das inclusões fluidas aquosas (Te), a estimativa da salinidade é realizada a partir do diagrama que relaciona a temperatura final de fusão do gelo com a salinidade (Roedder, 1984; Bodnar, 2003). A partir da temperatura final de fusão do gelo (Tfg) é possível estimar a salinidade do fluido aprisionado, normalmente expressa em equivalente à porcentagem em peso de $\mathrm{NaCl}$. Sabe-se, por exemplo, que o ponto de fusão de um sistema constituído por água pura ocorre em temperaturas próximas a $0{ }^{\circ} \mathrm{C}$ (ponto triplo), sendo o seu rebaixamento indicativo da presença de sais dissolvidos no sistema (Roedder 1984; Shepherd et al., 1985; Fuzikawa 1985). Os três sistemas químicos citados acima são os mais comumente identificados na natureza (Bodnar, 2003). Seus comportamentos e relações com estimativas de salinidades podem ser consultados com detalhe em Bodnar (2003). Uma breve introdução sobre o sistema unitário simples $\mathrm{H}_{2} \mathrm{O}$ e o sistema binário $\mathrm{NaCl}$ $\mathrm{H}_{2} \mathrm{O}$ é descrita no tópico seguinte. Desta forma, os dados de salinidade, de temperatura de homogeneização total e das relações volumétricas entre as fases permitem determinar a densidade dos fluidos presentes nas inclusões. A determinação da salinidade, densidade e frações molares de $\mathrm{H}_{2} \mathrm{O}$ e $\mathrm{NaCl}$ é calculada através do software BULK FLUIDS (Bakker, 2003), que usa equações de estado, de acordo com a composição do sistema e valores das temperaturas (Th) e (Tfg) ou da proporção da fase líquida.

A interpretação dos dados microtermométricos é feita comparando-os com os dados Pressão-Volume-Temperatura-Composição (P-V-T-X), obtidos através de sistemas estudados experimentalmente, por meio de diagramas de fase e equações termodinâmicas onde são considerados os parâmetros de não idealidade de soluções e condições de gases não perfeitos. 

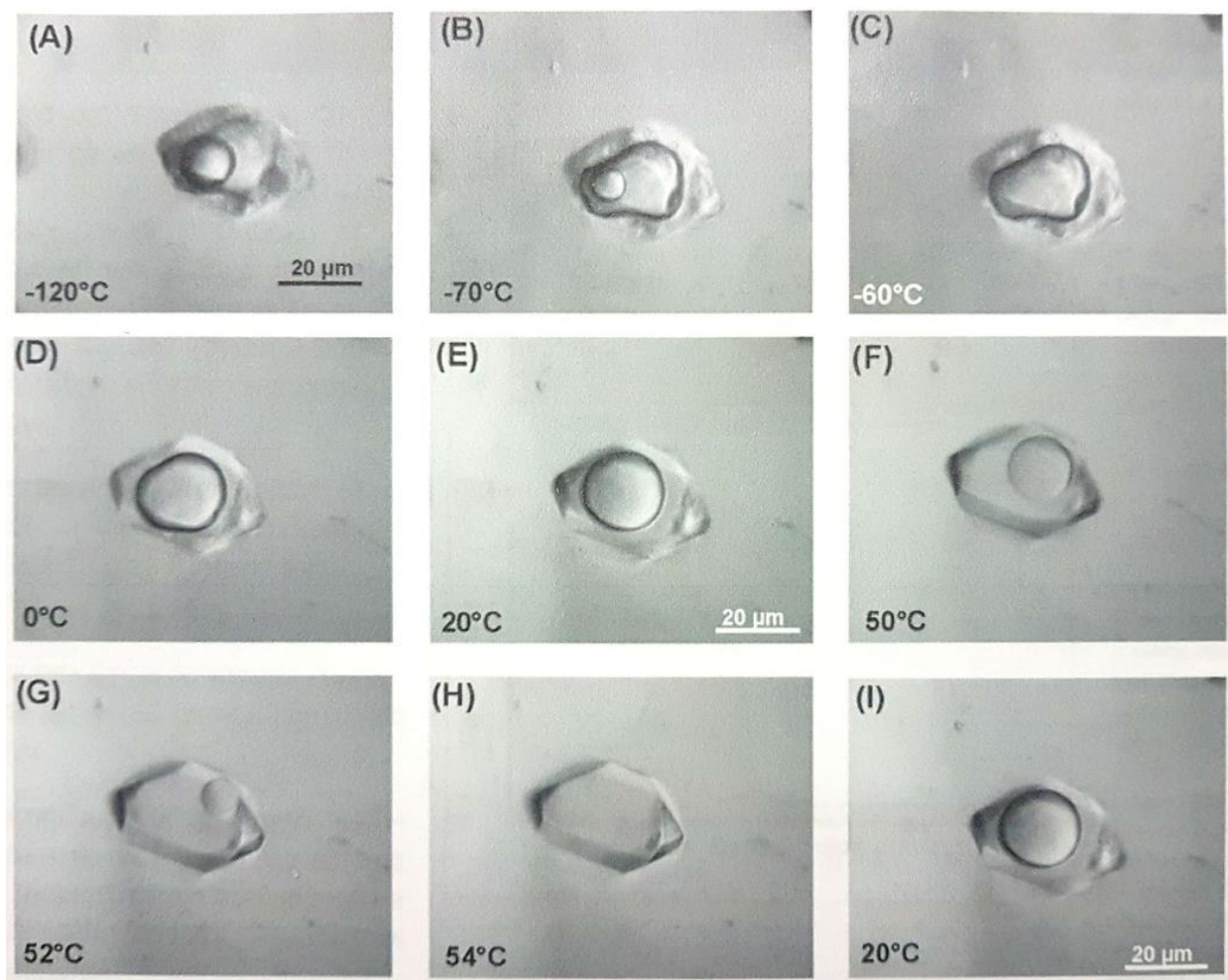

Figura 1.5. Sequência de resfriamento-aquecimento de uma inclusão fluida aquosa. (E-A) etapa de resfriamento; (A) congelamento total contem gelo e vapor; (C) temperatura do ponto eutético; (D) a caminho da temperatura ambiente a fusão do gelo está próxima; (E-H) etapa de aquecimento e $(\mathbf{H})$ temperatura de homogeneização para o estado líquido; (I) após o aquecimento, retornando-se à temperatura ambiente, a inclusão volta ao normal. Modificado de Coelho (2005).

\subsection{Exemplos de sistemas químicos e mudanças de fase}

Os dados experimentais obtidos através de microtermometria nos intervalos apropriados de pressão e temperatura, nos sistemas unitários $\left(\mathrm{H}_{2} \mathrm{O}, \mathrm{CH}_{4}\right)$, podem ser interpretados usando o espaço tridimensional Pressão-Volume-Temperatura (P-V-T) (Figura 1.6A).

Para fins ilustrativos, assume-se um sistema unitário simples constituído por $\mathrm{H}_{2} \mathrm{O}$, onde as inclusões fluidas são modeladas como sistema isocórico (sem mudanças de volume) e isoplético (sem mudança de composição química), ou seja, mantendo suas propriedades iniciais. À medida que a inclusão é sujeita a um decréscimo de temperatura, as suas condições de P-T estarão limitadas aos pontos pertencentes a isócora A-C (reta de volume constante e consequentemente de densidade constante) no espaço P-V-T.

Se ocorrer o aprisionamento de uma inclusão fluida, a partir da precipitação de um determinado mineral diagenético, a uma temperatura de $197{ }^{\circ} \mathrm{C}$ e pressão aproximadamente de 475 bar, situada no ponto A (Figura 1.6B), à medida que as 
condições se aproximam da temperatura ambiente, o caminho P-T percorrido pela inclusão vai ficar restrito à isócora de densidade $0,90 \mathrm{~g} / \mathrm{cm}^{3}$. Assim à temperatura de $190{ }^{\circ} \mathrm{C}$, ponto $\mathrm{B}$, a inclusão possui uma pressão interna de 300 bar, e o seu espaço P$\mathrm{T}$ corresponde à fase líquida. À medida que a temperatura desce até o ponto $\mathrm{C}, 167^{\circ} \mathrm{C}$ a 7 bar, a curva líquido (L) - vapor (V) é interceptada e deveria se formar uma bolha minúscula de vapor na inclusão (Figura 1.6B). Porém, tal cenário pode não acontecer devido a metaestabilidade, isto é, a bolha precisaria ter um volume mínimo para poder reduzir o efeito da tensão superficial e evitar o colapso da própria; assim, muitas vezes, a fase líquida pode persistir até temperaturas mais baixas. Muitas inclusões apresentam um comportamento metaestável, especialmente em baixa temperatura, devido ao fenómeno de histerese. A histerese ocorre sempre durante o congelamento das inclusões fluidas, razão pela qual a temperatura de nucleação das fases nunca se equivale ao ponto de mudança da própria fase (Roedder, 1984; Goldstein \& Reynolds, 1994). À medida que a inclusão é resfriada do ponto $C$ para o ponto $F$ o volume da bolha de vapor, quando esta é formada, cresce e a pressão interna decresce de forma gradual. Entre o ponto $\mathrm{D}$ e $\mathrm{E}$ a inclusão apresenta uma pressão de 1 bar (semelhante à pressão da superfície terrestre) e menos de $100{ }^{\circ} \mathrm{C}$ de temperatura, e no ponto $\mathrm{F}$ terá uma pressão interna ainda menor semelhante ao vácuo (Figura 1.6B). O mesmo diagrama também indica que durante a maior parte da história do resfriamento, a pressão interna das inclusões é mais baixa que a pressão dos fluidos dos poros circundantes, cujas condições se deslocam ao longo do gradiente termobárico considerado, enquanto nas inclusões o deslocamento ocorre segundo sua isócora. 

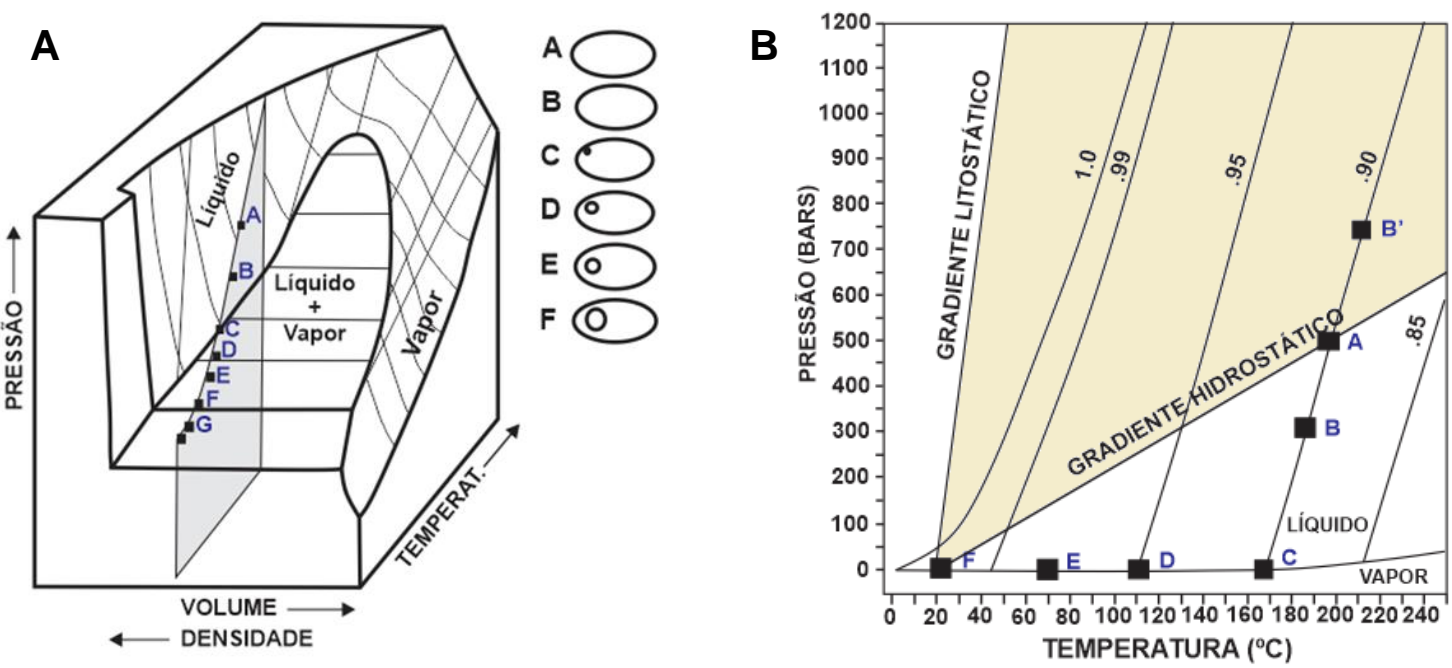

Figura 1.6. (A) Diagrama esquemático $\mathrm{P}-\mathrm{V}-\mathrm{T}$ para sistema unitário $\mathrm{H}_{2} \mathrm{O}$ (superfícies metaestáveis omitidas). As linhas tracejadas são linhas de volume e densidade constante chamadas isócoras; (B) Projeção P-T de um sistema puro composto por $\mathrm{H}_{2} \mathrm{O}$ para condições diagenéticas. Visualiza-se o comportamento de uma inclusão aprisionada em $A$, no interior de um cristal diagenético, sob condições de resfriamento e soerguimento progressivos, com passagem pela curva de equilíbrio líquido $(\mathrm{L})$ - vapor $(\mathrm{V})$, até chegar à temperatura ambiente. Modificado de Goldstein \& Reynolds (1994).

Para um sistema unitário simples constituído por $\mathbf{C H}_{4}$ (Figura 1.7) o processo é análogo ao constituído por $\mathrm{H}_{2} \mathrm{O}$, diferindo apenas pelo fato da curva L-V estar situada em menores temperaturas sendo que o ponto crítico (limite máximo para que o sistema se comporte como duas fases) ocorre nas condições P-T a $-82,1^{\circ} \mathrm{C}$ e 46,3 bar. No entanto, existem alguns aspetos importantes a considerar neste tipo de projeções P-T. Primeiro, as inclusões fluidas de $\mathrm{CH}_{4}$ puro contém apenas uma fase simples homogênea sob condições naturais. Condições diagenéticas naturais existem a pressões e temperaturas maiores do que aquelas onde é possível distinguir entre $\mathrm{CH}_{4}$ gasoso e líquido, uma vez que se encontram acima do ponto crítico. Assim, nestas condições o $\mathrm{CH}_{4}$ é assumido como um fluido e não como gás ou líquido. Segundo Goldstein \& Reynolds (1994), a maioria das inclusões de $\mathrm{CH}_{4}$ puro apresentam densidades em torno de 0,05 a $0,25 \mathrm{~g} / \mathrm{cm}^{3}$ (Figura 1.7), portanto, sofrem homogeneização, no laboratório, entre -97 e $-82^{\circ} \mathrm{C}$, onde as isócoras interceptam a curva L-V do sistema (Figura 1.7). Assim, diferentemente do sistema constituído por $\mathrm{H}_{2} \mathrm{O}$ pura, uma inclusão de $\mathrm{CH}_{4} \mathrm{em}$ temperaturas de superfície terá pressões internas maiores que 200 bar, enquanto a pressão à superfície é de apenas 1 bar. Na figura 2.8 observa-se que com 0 resfriamento, a inclusão $A$ atinge a curva $L-V$ em $B$, onde deve ser nucleada uma bolha de $\mathrm{CH}_{4}$ gasoso. Com o posterior resfriamento essa bolha aumenta de tamanho e com o procedimento inverso, isto é, aquecendo-se a inclusão a partir dessas temperaturas ela 
sofrerá homogeneização para o líquido no ponto B. A inclusão A' terá comportamento semelhante, embora sua homogeneização ocorrerá para o gás, uma vez que ela foi aprisionada em condições situadas abaixo da isócora crítica. Com um resfriamento ainda maior, o $\mathrm{CH}_{4}$ deveria sofrer congelamento em $-182,5^{\circ} \mathrm{C}$. Contudo, de modo semelhante ao sistema composto por água pura, é necessário um forte congelamento, até temperaturas situadas abaixo do ponto triplo para que seja nucleado $0 \mathrm{CH}_{4}$ sólido, o que normalmente ocorre abaixo de $-190^{\circ} \mathrm{C}$. Essas temperaturas estão fora dos limites atingidos pelos equipamentos microtermométricos e, portanto, a presença de $\mathrm{CH}_{4}$ apenas pode ser obtida com a utilização de outros métodos, como por exemplo a microespectroscopia Raman. 
A

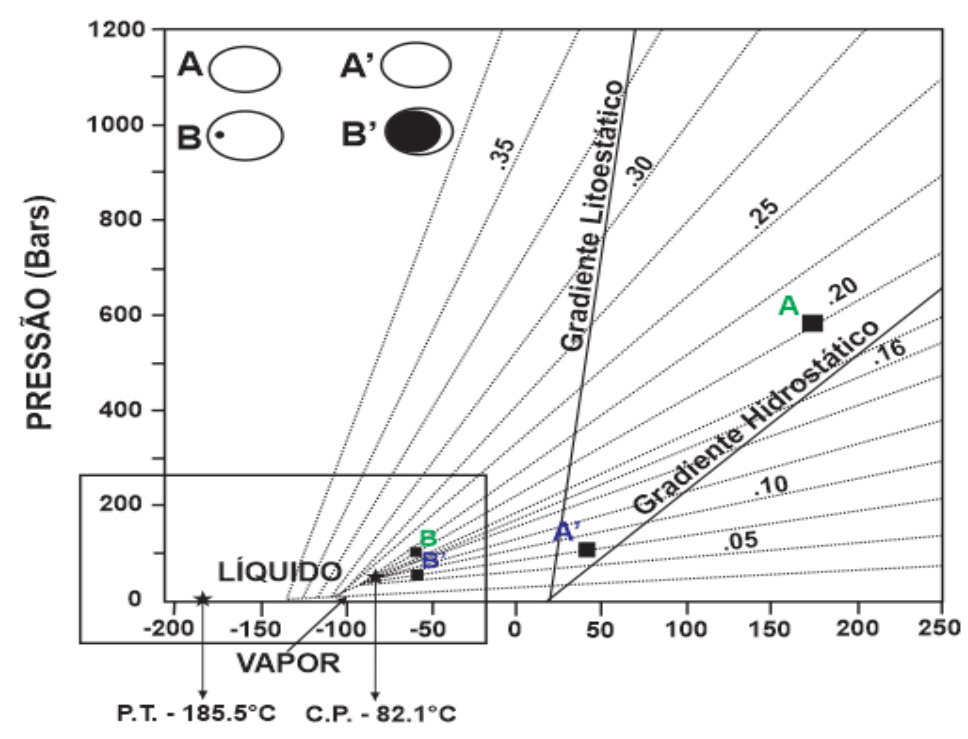

TEMPERATURA $\left({ }^{\circ} \mathrm{C}\right)$

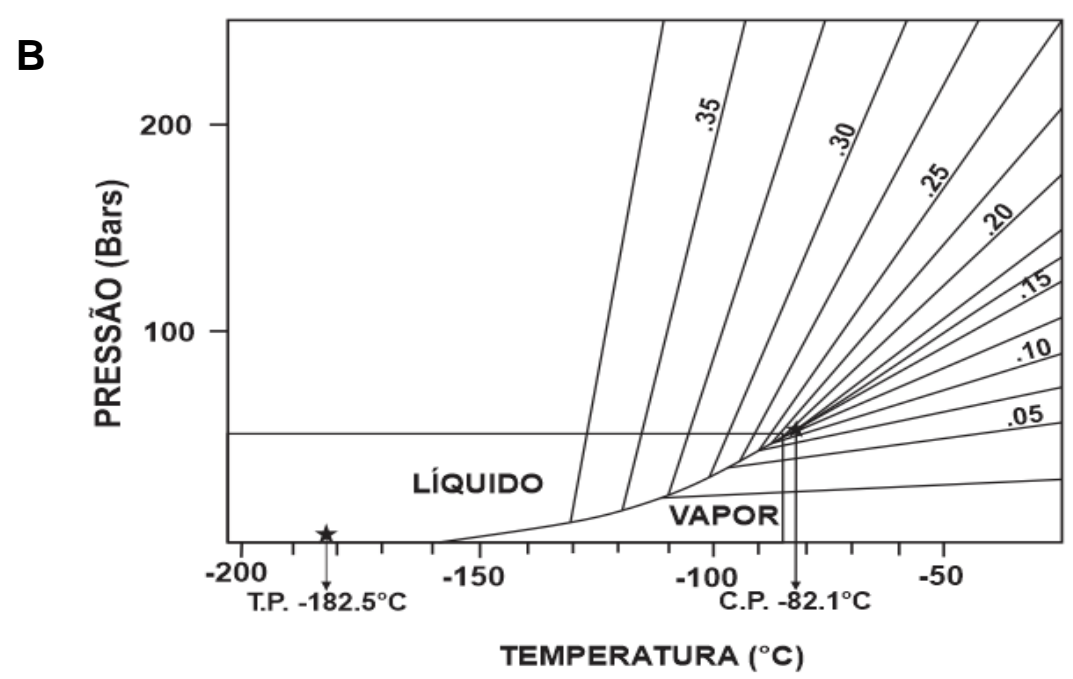

Figura 1.7. (A) Projeção P-T do sistema composto por $\mathrm{CH}_{4}$ e linhas de constante densidade (isócoras) $\mathrm{g} / \mathrm{cm}^{3}$; (B) Ampliação da área contornada por retângulo em A. Ponto Crítico a $-82,1 \stackrel{\circ}{\circ} \mathrm{C}$ e 46,3bars e ponto triplo a $-182,5 \stackrel{\circ}{ }{ }^{\circ}$. Modificado de Goldstein \& Reynolds (1994).

Para um sistema binário constituído, por exemplo, por $\mathbf{H}_{2} \mathrm{O}-\mathbf{N a C l}$, as projeções de P-T do limite das fases líquido L-V são semelhantes às do sistema unitário constituído por $\mathrm{H}_{2} \mathrm{O}$ pura, embora ocorram deslocamentos em função da quantidade de sal adicionado ao sistema (Figura 1.8). A presença de $\mathrm{NaCl}$ causa um aumento no ponto crítico da água pura, e a curva $L+V$ é estendida para maiores temperaturas. Também ocorrem mudanças nas inclinações das isócoras devido às modificações nas densidades, causadas pela presença de sais no sistema. Nesse sistema, a temperatura de fusão final do gelo ( $\mathrm{Tfg}$ ) está relacionada à quantidade de $\mathrm{NaCl}$ presente e este fato permite-nos determinar a salinidade para a inclusão fluida. Durante o congelamento, e através do diagrama da figura 1.9 que relaciona a temperatura $(T)$ com a porcentagem 
em peso de sal $(X)$, é possível observar as mudanças de fase de quatro inclusões fluidas. Quando a inclusão A1 é resfriada em laboratório o gelo deveria começar a se formar em uma temperatura negativa situada no ponto $E 1$; no entanto, tal fato não ocorre devido à metaestabilidade, como referido anteriormente, e o gelo irá se formar apenas no ponto $\mathrm{B} 1$, já no campo vapor $(\mathrm{V})+$ gelo $(\mathrm{I})+$ hidrohalita $\left(\mathrm{NaCl} .2 \mathrm{H}_{2} \mathrm{O}\right)$. Nessa temperatura, a inclusão estará preenchida por vapor, gelo e hidrohalita, mas como o gelo tem menor densidade que o líquido, vai ocupar a maior parte do volume total da inclusão, sendo que a fase vapor se apresentará reduzida. As inclusões A2 e A3 apresentam comportamento semelhante. Ao aquecer essas três inclusões estas irão nuclear o primeiro líquido nos pontos $C$ à temperatura eutética (TE) de $-21,2{ }^{\circ} \mathrm{C}$ característica desse sistema e terão composição de 23,2 \% de $\mathrm{NaCl}$ (Figura 1.9).

A inclusão A1 de menor salinidade, com o aquecimento subsequente a partir do Te, apresentará inicialmente a dissolução de toda hidrohalita, e desloca-se na curva gelo + líquido + vapor. Com uma elevação de temperatura ainda maior, se deslocará sobre essa curva até que o gelo funde totalmente na temperatura correspondente ao ponto E1. Essa temperatura ( $\mathrm{Tfg}$ ) possibilita a obtenção direta da salinidade da solução que é lida diretamente no diagrama.

A inclusão $A 3$, com o aquecimento a partir de TE, apresentará inicialmente a dissolução de todo o gelo, restando hidrohalita + líquido + vapor. Com a posterior elevação da temperatura essa inclusão vai se deslocando sobre a curva hidrohalita + líquido + vapor, até que toda hidrohalita sofra fusão no ponto E3. Também neste caso, a salinidade é lida diretamente no diagrama, considerando-se a temperatura de fusão da hidrohalita.

A inclusão A2 possui a própria composição do eutético do sistema $(23,2 \%$ em peso de $\mathrm{NaCl}$ ) e passa diretamente para o campo líquido + vapor, com a dissolução concomitante de hidrohalita e gelo. Sua salinidade representa a composição do próprio eutético.

A inclusão A4 é tratada separadamente, por representar uma solução com alta salinidade, com cristais de $\mathbf{N a C l}$ estáveis à temperatura ambiente. Para a determinação da salinidade dessa inclusão deve ser feito um aquecimento para temperaturas superiores à do ponto A4. Num ponto intermediário B4, observa-se um arredondamento dos cristais de halita devido à sua dissolução parcial, estando presente ainda uma bolha de vapor de menor volume. O cristal de halita, no exemplo da figura 1.9 irá atingir a curva halita + líquido + vapor no ponto $\mathrm{C} 4$, onde o sal dissolve totalmente e a solução passa para o campo líquido + vapor. Nesse caso, a salinidade obtida diretamente a partir da temperatura de dissolução de halita sobre a curva halita + líquido + vapor, fornecerá um valor bastante impreciso devido à alta inclinação da mesma. Assim, um 
valor mais preciso da composição do fluido deve ser obtido por meio da curva de solubilidade de halita (Figura 1.10). Se em vez de halita a fase estável à temperatura ambiente for constituída por cristais de silvita $(\mathbf{K C l})$, a salinidade da solução será obtida a partir da curva de solubilidade desse mineral (Figura 1.10).

Assim, a determinação da composição dos sistemas será mais simples na presença de halita ou silvita que possam ser interpretadas pelo seu comportamento microtermométrico ou por métodos alternativos como microespectroscopia Raman (Goldstein \& Reynolds, 1994).

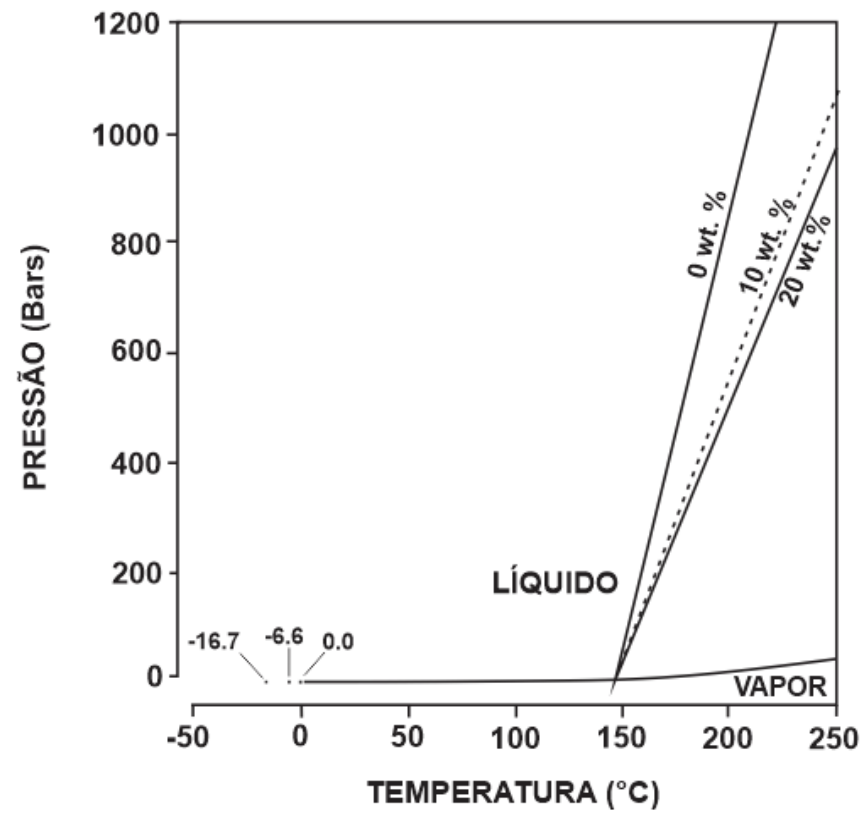

Figura 1.8. Diagrama P-T de um sistema composto por $\mathrm{H}_{2} \mathrm{O}$ e $\mathrm{NaCl}$, mostrando a diferença nas posições das curvas de equilíbrio de fase L-V e também das isócoras, com adição de sal no sistema. Modificado de Goldstein \& Reynolds (1994). 


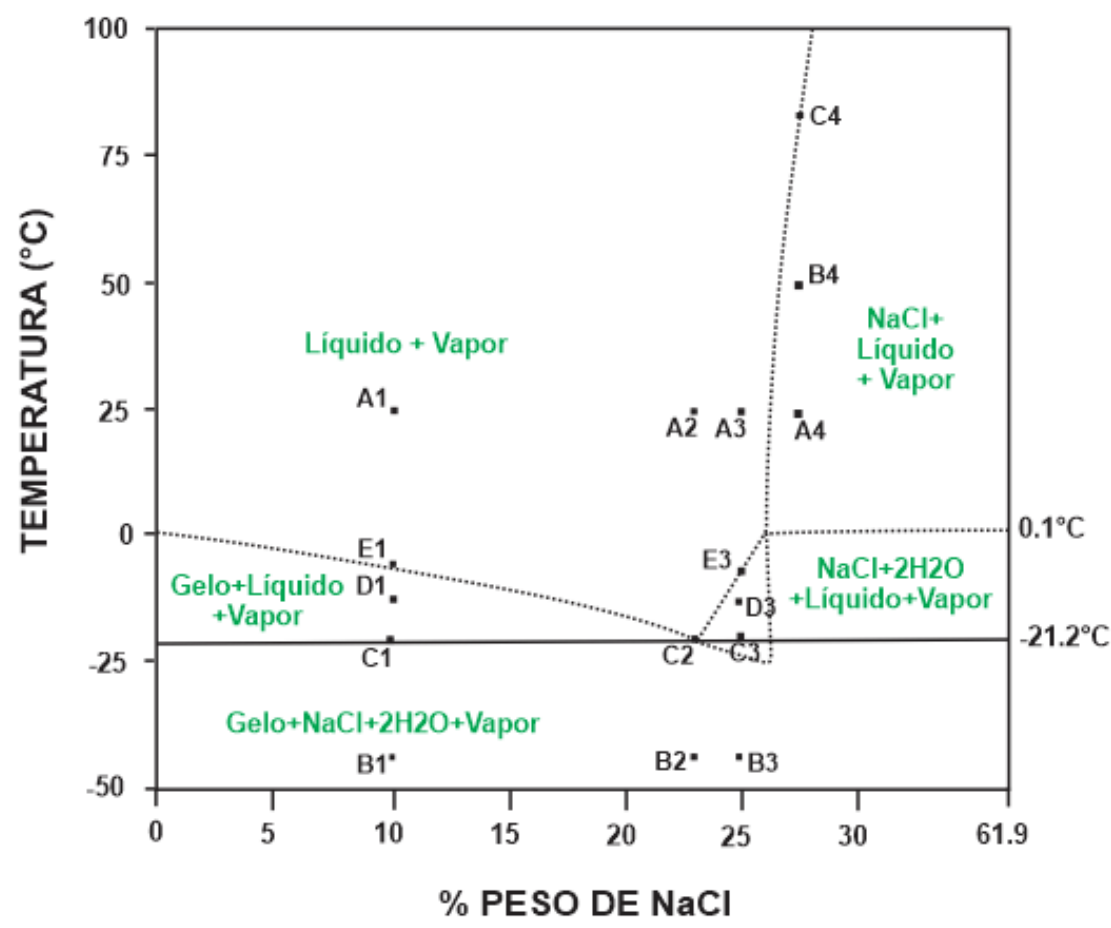

Figura 1.9. Diagrama T-X para baixa temperatura e baixa salinidade, de um sistema composto por $\mathrm{H}_{2} \mathrm{O}$ e NaCl. Modificado de Goldstein \& Reynolds (1994).

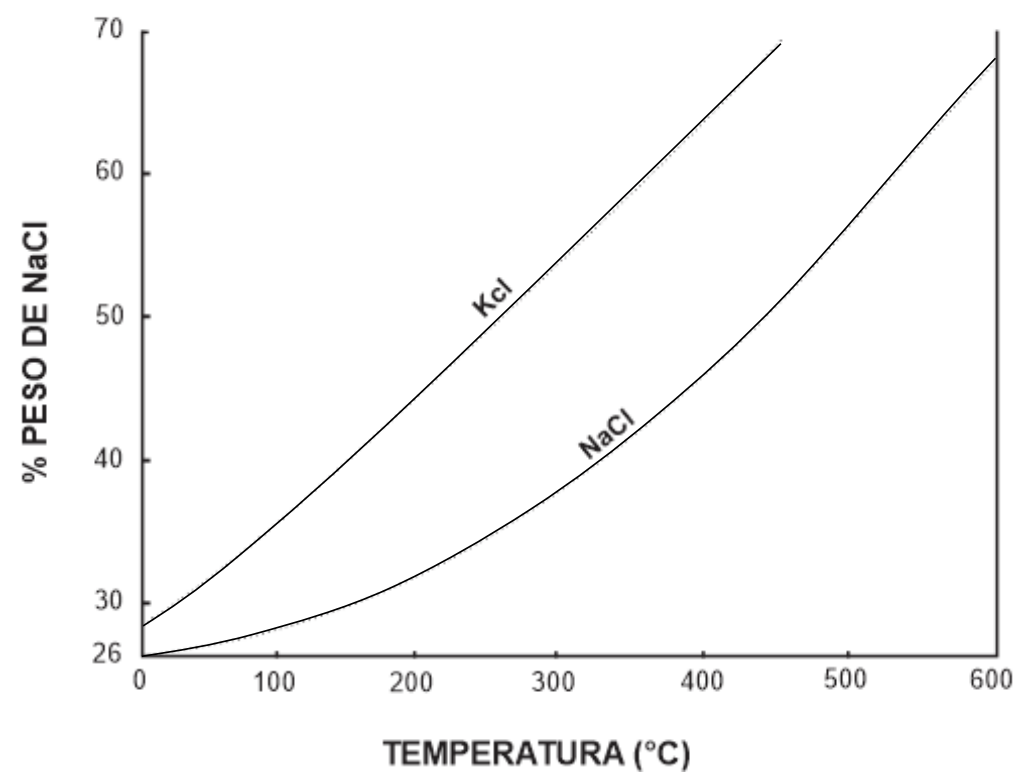

Figura 1.10. Curvas de solubilidade para $\mathrm{NaCl}$ e $\mathrm{KCl}$ em solução aquosa. Modificado de Shepherd et al. (1985). 


\subsection{Modo de ocorrência em ambiente diagenético de baixa temperatura e o efeito de reequilíbrio térmico}

Apenas com o uso de petrografia é possível estudar as condições de aprisionamento e subsequente história térmica de assembleias de inclusões fluidas (assumindo que estas possuem formas e tamanhos diferentes), em contextos diagenéticos distintos. No âmbito deste trabalho são discutidas as caraterísticas de inclusões fluidas aprisionadas em zona freática de baixa temperatura $\left(<50^{\circ} \mathrm{C}\right)$, sendo que, no contexto de bacia sedimentar e fluidos diagenéticos existe ainda a possibilidade de aprisionamento de assembleias de inclusões fluidas em ambientes diagenéticos distintos, como zona vadosa, e zona freática de elevada temperatura $\left(>50^{\circ} \mathrm{C}\right.$ ), cujas características poderão ser consultadas com detalhe em Goldstein \& Reynolds, (1994). A zona freática de baixa temperatura $\left(<50^{\circ} \mathrm{C}\right)$ existe abaixo do nível freático e as inclusões fluidas são caracterizadas por soluções aquosas com uma única fase líquida (Figura 1.11A), no entanto, também podem conter pequenas quantidades de gases como $\mathrm{CO}_{2}$ e $\mathrm{CH}_{4}$. Se não ocorrer soterramento nem reequilíbrios térmicos as inclusões fluidas aquosas se apresentarão monofásicas (diagnóstico de aprisionamento em zona freática de baixa temperatura, figura 1.11A). Com o soterramento e/ou aquecimento natural, algumas ou todas as inclusões fluidas poderão sofrer reequilíbrios térmicos por stretching e o resultado será a coexistência de inclusões fluidas monofásicas e bifásicas (Figura 1.11B). Para as inclusões bifásicas, as proporções entre as fases líquida ( $L$ ) e vapor (V) não variam muito; contudo, a fase vapor poderá variar desde bem pequena até cerca de $15 \%$ do volume da inclusão, devido aos reequilíbrios posteriores. Porém, se o aquecimento continuar para temperaturas mais elevadas, todas as inclusões fluidas sofrerão reequilíbrio e à temperatura ambiente serão bifásicas, também com razões das fases $L-V$ pouco variáveis (Figura 1.11C). A pressão interna das inclusões será próxima ao vácuo, no caso das constituídas apenas por soluções aquosas, ou mais elevada, quando também estiverem presentes voláteis como, por exemplo o $\mathrm{CO}_{2}$ ou o $\mathrm{CH}_{4}$. 


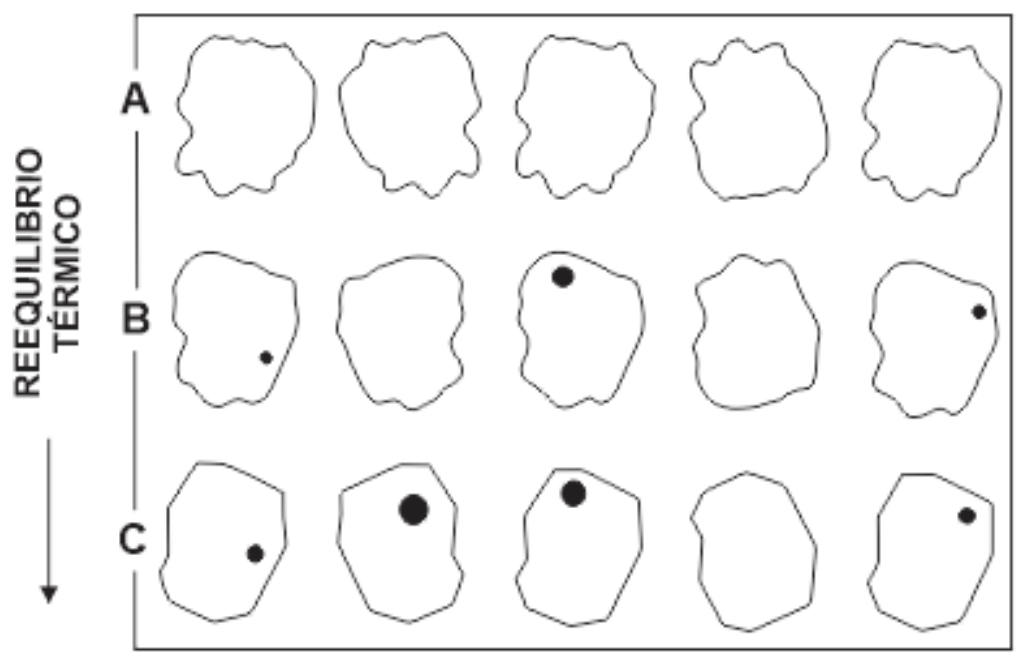

Figura 1.11. Assembleia de Inclusões fluidas em zona freática de baixa temperatura e respetivos comportamentos por reequilíbrio posterior. Modificado de Goldstein \& Reynolds (1994).

Durante o soterramento de um pacote sedimentar, as rochas, os minerais e as inclusões fluidas aprisionadas nesses minerais vão sofrer um aumento de pressão e temperatura ao longo do tempo. No caso das rochas, dos minerais constituintes e da pressão nos fluidos dos poros, as mudanças na pressão e na temperatura ocorrem dentro dos limites dos gradientes hidrostático e litostático típicos dos ambientes sedimentares/diagenéticos, enquanto nas inclusões fluidas, essas mudanças seguem caminhos diferentes, ou seja, segundo a isócora representativa do volume molar ou densidade do fluido original (Goldstein \& Reynolds, 1994). Com o soterramento ou evento térmico hidrotermal a pressão interna de uma inclusão torna-se maior que a externa, o que pode causar a expansão irreversível das inclusões aprisionadas em minerais de menor dureza por meio de deformações inelásticas (stretching). Consequentemente ocorre um decréscimo nas densidades das inclusões e aquelas que deveriam ser monofásicas em temperatura ambiente tornam-se bifásicas, e nas que já eram bifásicas ocorre um aumento dos volumes da fase vapor devido aos reequilíbrios por stretching. A sobrepressão interna da própria inclusão também pode provocar a crepitação (explosão) ou o reequilíbrio por escape de fluidos originais (leakage) se existirem zonas de fraqueza (clivagem; fissuras) situadas próximas às inclusões, com ou sem ocorrer o preenchimento com soluções presentes no novo ambiente. Aumentando a temperatura no sistema, a pressão interna continuará a subir, causando um maior aumento no volume da inclusão e, em termos práticos, o resultado ditará um aumento de Th (Figura 1.12). Uma inclusão fluida aprisionada no ponto $\mathrm{A}$ a $75^{\circ} \mathrm{C}$, no campo do líquido, quando sofre resfriamento natural, atinge a curva L-V em $65^{\circ} \mathrm{C}$. Contudo, se for sujeita a um aquecimento até os $135^{\circ} \mathrm{C}$, a pressão interna aumentará consideravelmente em comparação com a pressão hidrostática circundante. Se a inclusão sofrer estiramento devido a este aumento de pressão interna, seu volume aumentará e a densidade vai diminuir, o que é representado por uma queda para o ponto $\mathrm{C}$, 
ou seja, o deslocamento para uma isócora nova de menor densidade. Com o soerguimento até a superfície e respetivo resfriamento, a inclusão fluida interceptará a curva L-V no ponto $\mathrm{D}$ à temperatura de $100{ }^{\circ} \mathrm{C}$, onde se irá obter a medição da nova temperatura de homogeneização (Figura 1.12). Caso a inclusão fluida não tivesse sofrido reequilíbrio por estiramento sua temperatura de homogeneização seria de $65^{\circ} \mathrm{C}$ (Goldstein \& Reynolds, 1994).

Não só a dureza do mineral hospedeiro, nem o soterramento ou alterações térmicas, controlam os reequilíbrios; outras variáveis estão envolvidas (forma, tamanho, orientação das inclusões), mas o importante é que cada inclusão se comporta de modo diferente perante os processos de reequilíbrio, o que causa uma variação nas temperaturas de homogeneização (Goldstein \& Reynolds, 1994). O mesmo autor discute duas tendências distintas observadas em um diagrama que relaciona as Tfg com Th: uma indicativa de stretching e outra de troca de fluidos causados por reequilíbrio térmico (Figura 1.13). As inclusões fluidas que sofreram reequilíbrio por troca de fluidos irão apresentar salinidades distintas e diferentes Th que são representativas dos distintos níveis de soterramento e da composição dos fluidos envolvidos durante o processo. Esses parâmetros também podem refletir a ocorrência de escape parcial de fluidos e misturas em diversas proporções com as novas soluções. Essas características podem ser vistas na tendência assinalada como escape e repreenchimento no diagrama da figura 1.13. Também pode ser observado o comportamento de inclusões reequilibradas por stretching, que apresentam diferentes Th, representativas das diferentes etapas de aquecimento, para fluidos com a mesma salinidade, uma vez que o sistema se manteve fechado quanto à composição. Na presença destas duas formas de reequilíbrio, o encontro das tendências, região circundada, significa as condições originais dos fluidos aprisionados antes do reequilíbrio (Figura 1.13).

Desse modo, observa-se que os processos de reequilíbrio provocam uma ampla variação nas temperaturas de homogeneização e os máximos valores de Th obtidos no laboratório correspondem às mínimas temperaturas atingidas durante os processos de reequilíbrio (Prezbindowski \& Larese, 1987). 


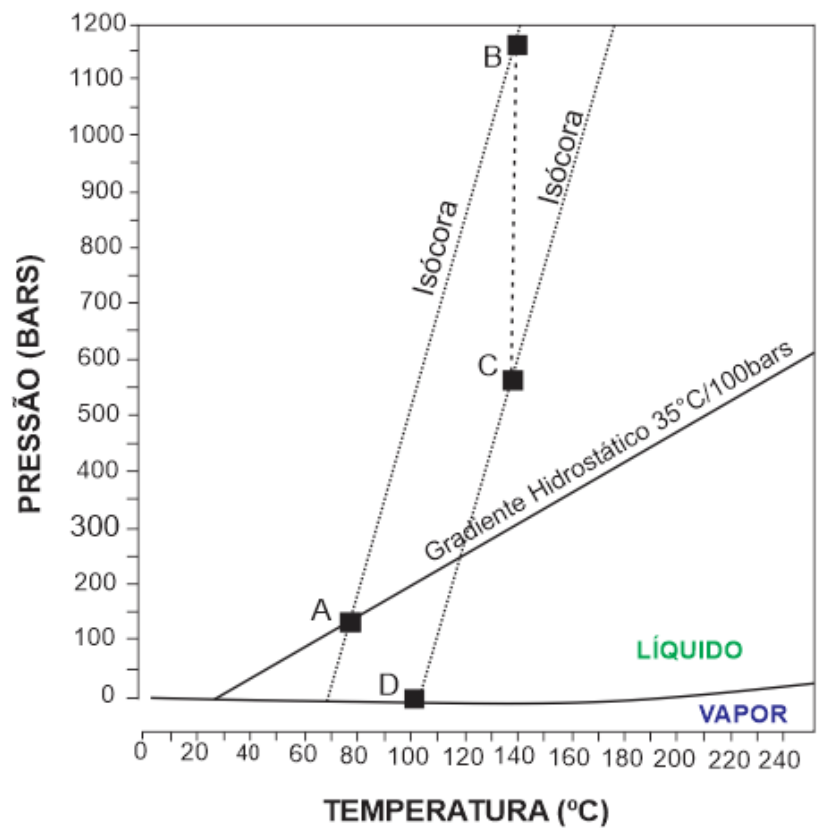

Figura 1.12. Diagrama de fase P-T ilustrando o stretching de uma inclusão fluida líquida durante o aquecimento provocado pelo soterramento progressivo ou ação de corpos igneos. Modificado de Goldstein \& Reynolds (1994).

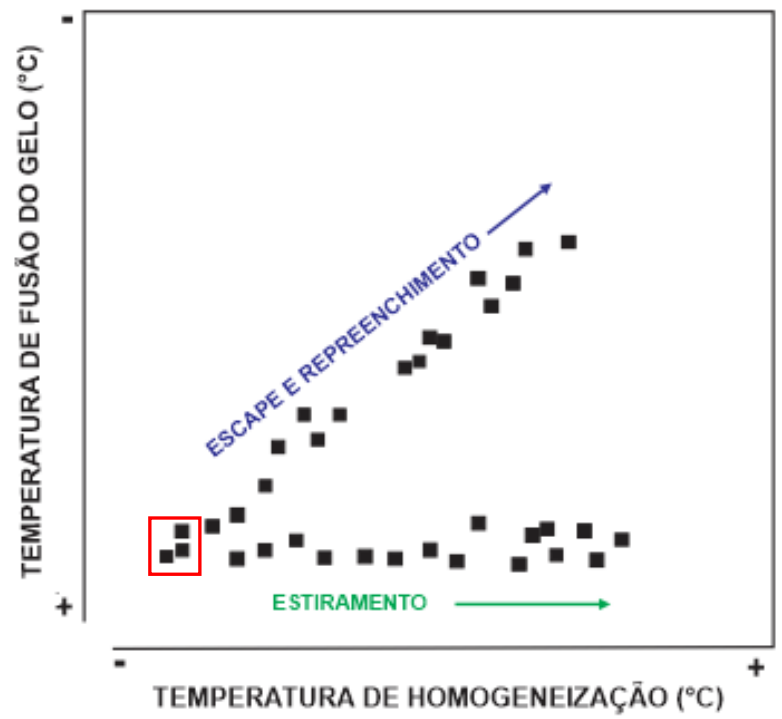

Figura 1.13. Diagrama esquemático ilustrando o comportamento de inclusões fluidas que foram submetidas a estiramento (stretching) e a escape e repreenchimento (leakage), causados por reequilíbrio térmico. Modificado de Goldstein \& Reynolds (1994). 


\subsection{Características de inclusões fluidas compostas por hidrocarbonetos (HCFl's)}

A aplicação do estudo de inclusões fluidas em sistemas petrolíferos tem sido uma ferramenta muito importante na exploração de petróleo. Inclusões fluidas compostas por hidrocarbonetos ou inclusões fluidas de petróleo (Munz, 2001), incluindo inclusões fluidas de óleo e/ou de gás, são comuns em ambientes sedimentares associados a sistemas petrolíferos (Burruss, 2003).

A presença de inclusões fluidas compostas por hidrocarbonetos (óleo e/ou gás) em cimento diagenético ou em fraturas cicatrizadas demonstra que os hidrocarbonetos foram aprisionados na época da cimentação e cicatrização de fraturas. Desta forma, é patente o sincronismo entre a geração e migração de hidrocarbonetos, assim como, a história tectônica e diagenética da bacia (Burruss, 2003).

Em ambiente sedimentar associado a sistemas petrolíferos, a sistemática de inclusões fluidas compreende uma vasta área de atuação focada na exploração de novas reservas de hidrocarbonetos (Coelho, 2005). Desta forma, existem algumas técnicas desenvolvidas e testadas com objetivo de melhorar o conhecimento desses recursos como: 1) termodinâmica de inclusões fluidas (TIF), a estratigrafia de inclusões fluidas (FIS) e a composição molecular de inclusões fluidas (GOI/MCl), cujas características e aplicações podem ser consultadas em detalhe no trabalho de Coelho (2005).

O estudo de IF's compostas por hidrocarbonetos, incluindo a petrografia, microtermometria, análises de microespectroscopia Raman, microscopia confocal de varredura a laser, entre outras, permite a reconstrução termobarométrica do aprisionamento de hidrocarbonetos (Burruss, 2003), além de fornecer parâmetros para elaboração de modelos de evolução térmica em bacias sedimentares (Coelho, 2005).

Dados geoquímicos (somente hidrocarbonetos de baixo peso molecular - até $\mathrm{C}_{15}$ ) têm sido utilizados para a localização de intervalos portadores de hidrocarbonetos que não tenham sido detectados por métodos convencionais. A composição molecular de hidrocarbonetos presente em IF's permite fazer correlações óleo - óleo ou óleo - rocha geradora, bem como determinação da maturação térmica (Coelho, 2005). Inclusões fluidas compostas por hidrocarbonetos possuem uma complexa mistura de componentes orgânicos o que impossibilita uma estimativa composicional completa por métodos não destrutivos. Por conseguinte, para uma caracterização composicional completa é, frequentemente, empregado o uso de técnicas analíticas como gas chromatography (GC), gas chromatography mass spectometry (GC - MS) e gas 
chromatography initial ratio mass spectometry (GC - IRMS) dependendo do objetivo (Munz, 2001).

Inclusões fluidas compostas por hidrocarbonetos são incolores, mas em muitos casos podem apresentar tons acastanhados. A cor é em função da composição e da dimensão da própria inclusão (Munz, 2001). As inclusões fluidas compostas por hidrocarbonetos podem ser facilmente confundidas por inclusões fluidas aquosas ou aquocarbônicas. A maneira mais rápida e eficaz de distingui-las é através de microscopia óptica sob luz ultravioleta (UV). Quando expostas à luz UV as inclusões compostas por hidrocarbonetos fluorescem emitindo luz no intervalo visível (Figura 1.14), enquanto as inclusões fluidas aquosas ou aquocarbônicas não são fluorescentes (Munz, 2001). Geralmente, a cor de fluorescência reflete informações sobre a composição e densidade de hidrocarbonetos, se a amostra contém uma ou mais gerações de inclusões de petróleo, e pode ser controlada por múltiplas variáveis, desde a natureza do óleo aprisionado e do mineral hospedeiro e condições físico-químicas do ambiente (P, T, ph, etc) (Pironon \& Pradier, 1992). A cor de fluorescência pode ser usada como índice de maturidade, como identificação de tipos de matéria orgânica e pode ser relacionada à densidade do óleo (Figura 1.15) ou coeficiente de gravidade do óleo:

$$
\text { [사 }=(141,5 / d-131,5)],
$$

onde $d$ representa a densidade em $\mathrm{g} / \mathrm{cm}^{3}$ a $60 \stackrel{\circ}{\circ} \mathrm{F}$ (Pironon \& Pradier, 1992). Como 0 grau API ( $\mathrm{API})$ é inversamente proporcional à densidade relativa os hidrocarbonetos podem ser classificados em: 1) hidrocarbonetos leves ( ${ }^{\mathrm{API}}>31$ ), 2) hidrocarbonetos médios ( ${ }^{\circ} \mathrm{API}$ de 21 a 31), 3) hidrocarbonetos pesados ( ${ }^{\circ} \mathrm{API}<21$ ) e 4) hidrocarbonetos extrapesados ( $\left.{ }^{\circ} \mathrm{API}<10\right)$.

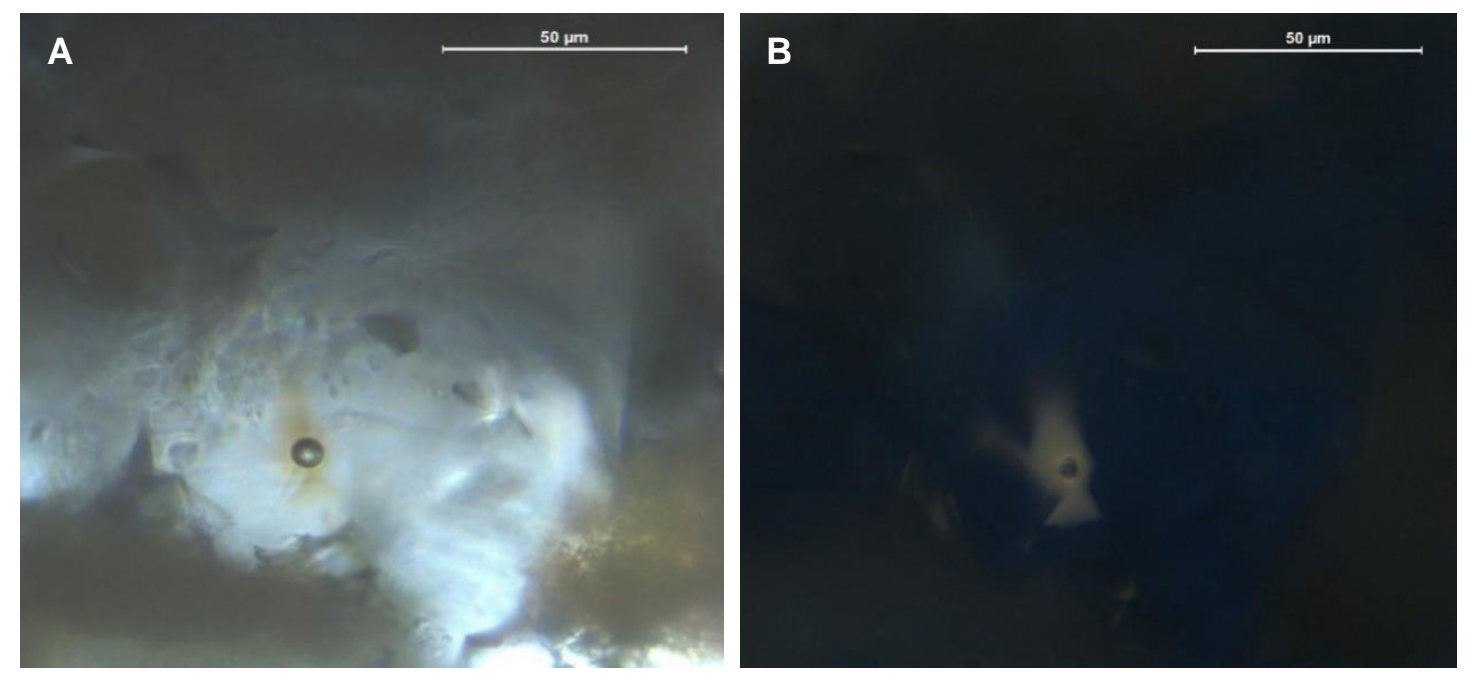

Figura 1.14. Fotomicrografia de inclusão fluida composta por hidrocarbonetos à temperatura ambiente $\left(22^{\circ} \mathrm{C}\right)$. (A) Luz transmitida; (B) Luz ultravioleta. 


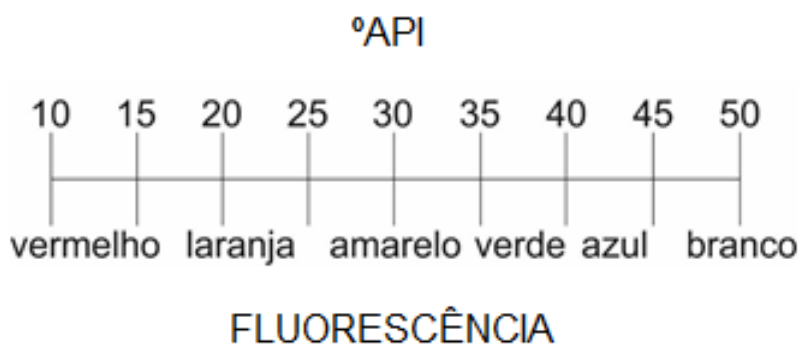

Figura 1.15. Grau API de hidrocarbonetos e relação com cor de fluorescência. Modificado de Goldstein \& Reynolds (1994).

\subsubsection{Microtermometria e termodinâmica}

Inclusões fluidas podem aprisionar múltiplas fases de hidrocarbonetos (líquida e vapor), soluções aquosas na fase líquida e sólidos de hidrocarbonetos (Munz, 2001). Sólidos de hidrocarbonetos podem se originar a partir de precipitação durante 0 resfriamento, precipitação durante adição de gás no sistema ou durante o craqueamento através da maturação térmica (Burruss, 2003). Através de petrografia, a partir do volume da fase vapor e da fase líquida presente na própria inclusão, é possível distinguir inclusões fluidas de óleo ou inclusões fluidas de gás, porém na presença de sólidos de hidrocarbonetos, interpretações termodinâmicas requerem 0 uso de métodos destrutivos (Munz, 2001; Burruss, 2003).

A interpretação de microtermometria de IF's compostas por hidrocarbonetos é diferente de inclusões fluidas aquosas (Bodnar, 2003) ou aquocarbônicas (Diamond, 2003b) devido ao fato do petróleo aprisionado ser uma mistura complexa de compostos químicos orgânicos e não existirem fases suficientes para integrar e explicar os comportamentos termobarométricos (condições P-V-T-X). Quando essas misturas contemplam moléculas curtas estamos na presença de um reservatório de gás à pressão e temperatura ambiente. Se a mistura contempla moléculas longas o reservatório é constituído por paleofluidos, à pressão e temperatura ambiente, com diversas frações químicas presentes (McCain, 1990). A composição química e densidade dos componentes existentes nos hidrocarbonetos e a variação da proporção de moléculas pesadas a leves, possibilitou a McCain (1990) definir, pela mesma ordem, uma classificação de paleofluidos em reservatório: black oil (óleo comum), óleo volátil, óleo de densidade crítica e gás condensado. O gás condensado ou gás natural pode ainda ser classificado como gás seco ou gás úmido, sendo o gás seco constituído principalmente por metano $\left(\mathrm{CH}_{4}\right)$ com traços de dióxido de carbono $\left(\mathrm{CO}_{2}\right)$, e gás úmido constituído tanto por moléculas leves $\left(C_{1}-C_{5}\right)$, pesadas $\left(C_{6}-C_{7+}\right)$ e também moléculas inorgânicas (McCain, 1990). 
A microtermometria de IF's compostas por hidrocarbonetos tem como parâmetro fundamental a temperatura de homogeneização (Th), ou seja, a temperatura obtida durante o aquecimento da amostra, na qual duas ou mais fases constituintes das inclusões tornam-se uma única fase $(L+V=L$ ou $V)$ (Coelho, 2005). Homogeneização para a fase líquida revela um fluido de densidade elevada e isócora de maior ângulo no espaço P-T, enquanto a homogeneização para a fase vapor indica um fluido menos denso com isócora de menor ângulo no espaço P-T (Burruss, 2003).

Os resultados mais acurados para os cálculos de simulação do comportamento termodinâmico de hidrocarbonetos são obtidos a partir do uso de equações de estado tridimensionais (McCain, 1990), como as equações de Soave-Redlich-Kwong (Soave, 1972) e Peng-Robinson (Peng \& Robinson, 1976), de forma a determinar as isócoras e isopletas representativas de cada classe de hidrocarbonetos aprisionados (Figura 1.16).

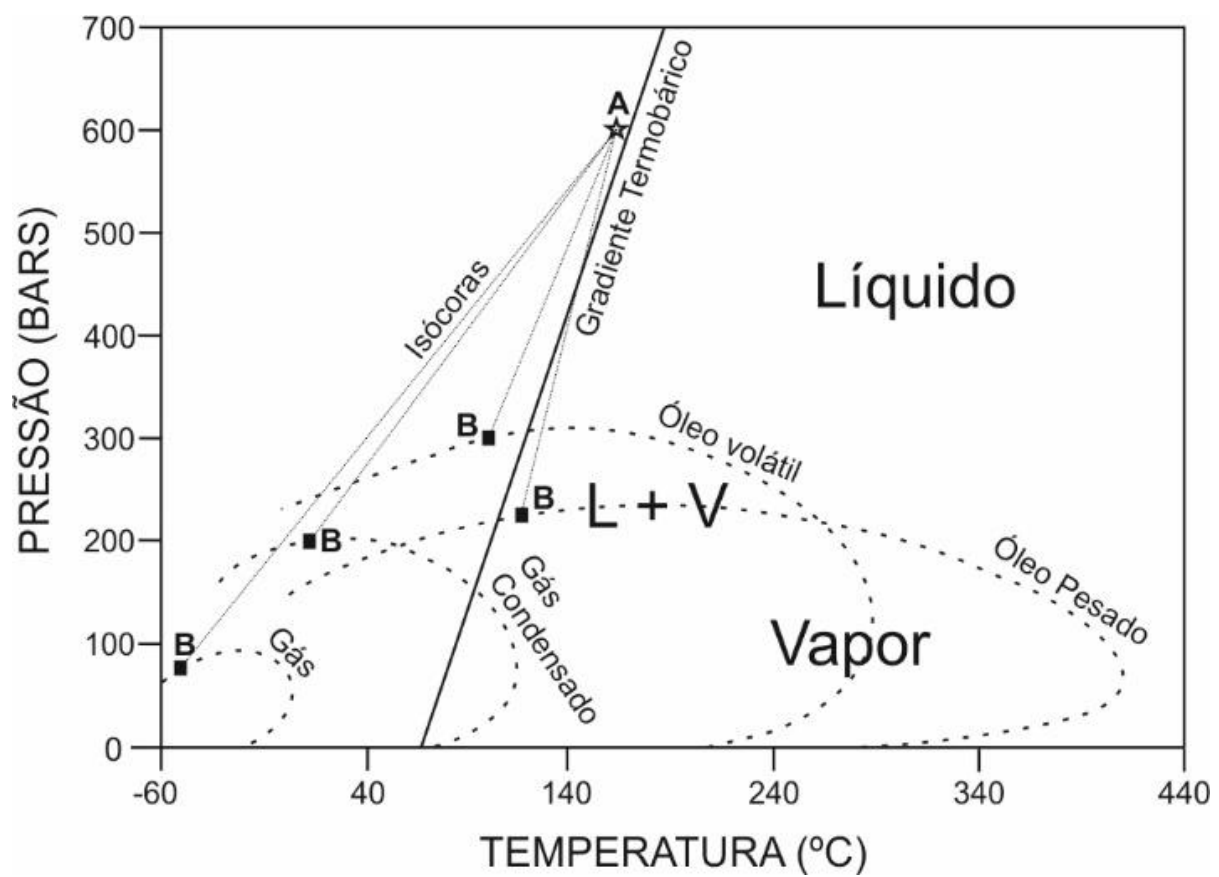

Figura 1.16. Diagrama de $P-T$ de fases exibindo isócoras e envelopes de quatro óleos genéricos com base em equações de estado de Peng \& Robinson (1976). Modificado de Goldstein \& Reynolds (1994).

Por conseguinte, é importante notar a diferença de intervalo P-T entre os limites das curvas L-V para os diferentes tipos de hidrocarbonetos. Uma inclusão composta por diferentes tipos de hidrocarbonetos, aprisionada em condições de pressão de 600 bars e temperatura de $165^{\circ} \mathrm{C}$ (ponto $\mathrm{A}$ ), demonstra grande variação de temperaturas de homogeneização entre -60 a $80^{\circ} \mathrm{C}$ aproximadamente (pontos B - Figura 1.16). Como os declives das isócoras da maioria das inclusões fluidas compostas por 
hidrocarbonetos são menores que os das inclusões fluidas aquosas as Th das inclusões compostas por hidrocarbonetos não são tão precisas (reais) como as Th das inclusões aquosas (exceto se forem aprisionadas em equilíbrio com fase gasosa). Geralmente, como as isócoras das IF's compostas por hidrocarbonetos tem igual ou menor declividade que o gradiente termobarométrico presente em ambiente diagenético, se uma inclusão composta por hidrocarbonetos sofrer elevado soterramento após aprisionamento, a pressão interna da inclusão não será maior que a pressão externa no poro, que é o oposto do processo que ocorre com inclusões fluidas aquosas. Assim, também se torna importante referir que os pontos de formação de bolha (pontos B) de cada classe de hidrocarbonetos ocorrem sempre em condições de pressão maiores quando se compara com sistemas unitários simples compostos apenas por $\mathrm{H}_{2} \mathrm{O}$ (Goldstein \& Reynolds, 1994).

Várias equações de estado já foram testadas experimentalmente para simulação de comportamentos termodinâmicos de inclusões fluidas compostas por hidrocarbonetos, mas a estimativa composicional dos seus componentes apresenta sempre dificuldades acrescidas (Aplin et al., 1999; Thiery et al., 2002). Apesar das limitações experimentais, é possível inferir a composição total do hidrocarboneto cruzando os dados de volume da fase vapor $\left(F_{v}\right)$, obtidos a partir de microscopia confocal de varredura a laser (Pironon et al., 1998; Aplin et al., 1999; Thiery et al., 2002), com as temperaturas de homogeneização (Th) das inclusões fluidas compostas por hidrocarbonetos (Bourdet et al., 2008 - Fig. 1.17), obtidas através de microtermometria. Consequentemente, se torna fidedigna a construção de modelos de história térmica em sistemas petrolíferos durante a diagênese, com relação às condições reais de aprisionamento (pressão e temperatura) dos hidrocarbonetos ou na identificação e caracterização de fenômenos de modificações pós-aprisionamento (Fig. 1.18). Todavia e contabilizando as devidas condições experimentais, este método deve ser utilizado como indicativo composicional para as diversas classes de paleofluidos e na identificação de reequilíbrios posteriores das inclusões fluidas após o seu aprisionamento (Bourdet et al., 2008). 


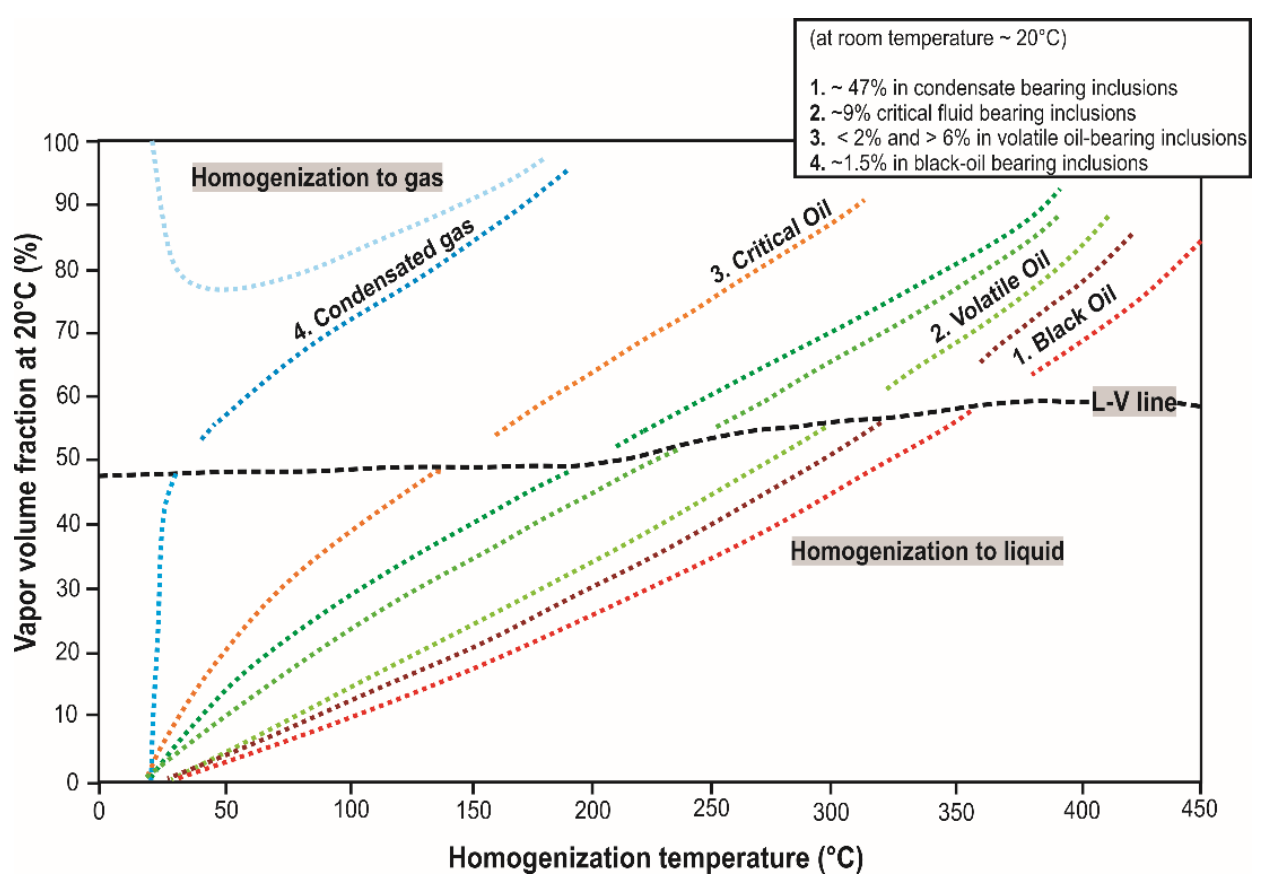

Figura 1.17. Diagrama $F_{v}$ versus Th a $20^{\circ} \mathrm{C}$, mostrando os campos de ocorrência para as principais classes de petróleo, de acordo com a classificação de McCain (1980), em inclusões fluidas testadas experimentalmente (Bourdet et al., 2008). Adaptado de Bourdet et al. (2008) e modificado de Pestilho \& Monteiro, 2017. 


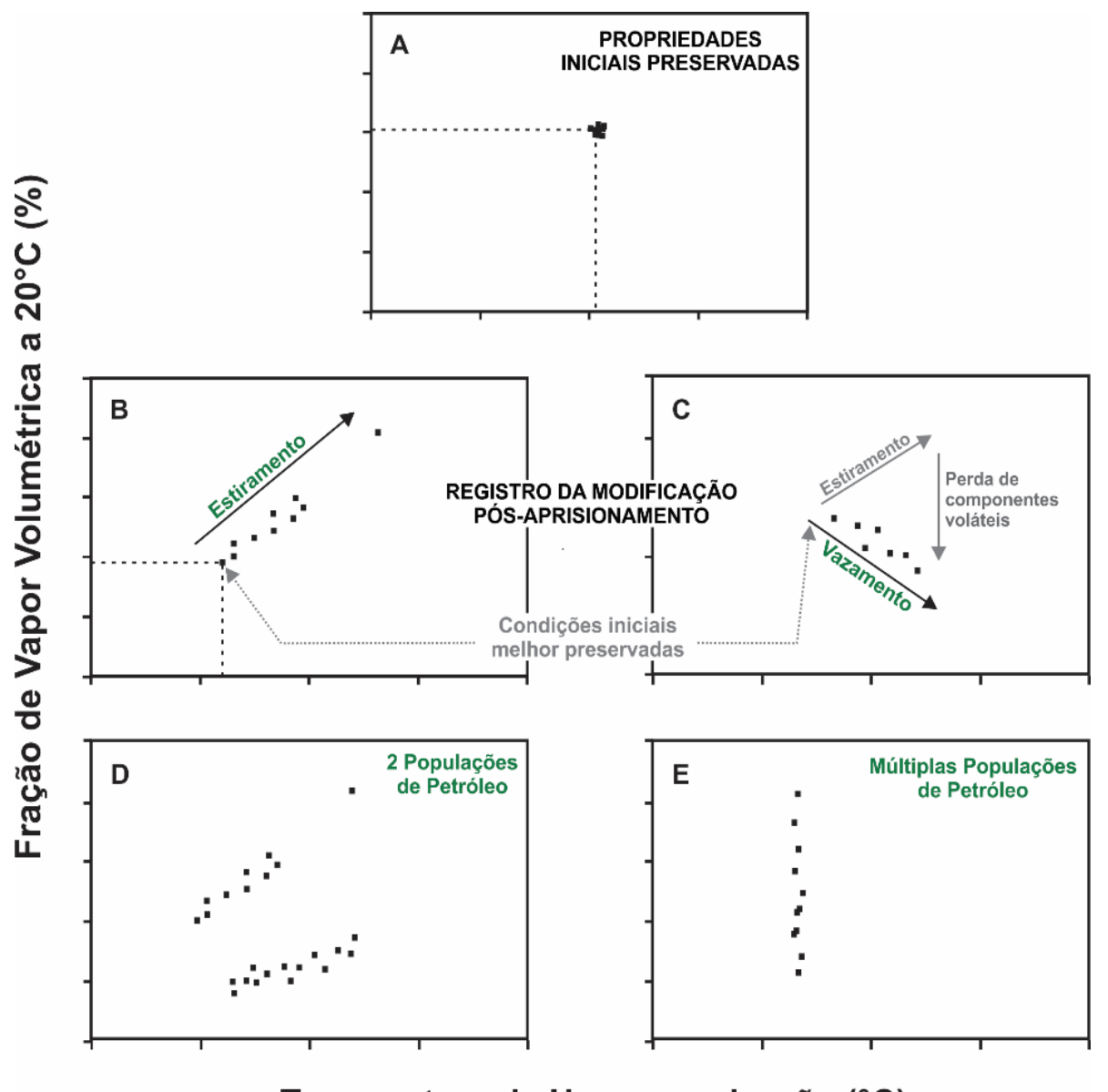

Temperatura de Homogeneização $\left({ }^{\circ} \mathrm{C}\right)$

Figura 1.18. Diagrama de $F_{v}$ versus Th, exibindo as tendências de conjuntos de valores de inclusões fluidas compostas por hidrocarbonetos que sofreram processos de aprisionamento posterior ou aprisionamento de diferentes populações de hidrocarbonetos. Modificado de Bourdet et al. (2008).

Nas últimas décadas, com o propósito de ultrapassar as dificuldades encontradas na estimativa composicional de hidrocarbonetos em sistemas petrolíferos, McLimans (1987) e Bodnar (1990), assumem a composição das inclusões fluidas de hidrocarbonetos equivalente à do petróleo original presente no reservatório. Posteriormente, Aplin et al. (1999) e Thiéry et al. (2002), estimam a composição de hidrocarbonetos com base em parâmetros composicionais físico-químicos bem definidos e representativos, que possam modelar adequadamente o comportamento de hidrocarbonetos naturais. No primeiro caso, essa premissa é limitada visto que vários reservatórios apresentam modificações posteriores ao aprisionamento de hidrocarbonetos (Aplin et al., 1999; Thiéry et al., 2002), como processos químicos de biodegradação, alteração por influxo de água (water-washing) ou gás (gas-washing) e mistura de hidrocarbonetos de origem distinta (Tissot \& Welte, 1984). A segunda premissa é baseada em um modelo composicional matemático que possibilita a 
inferência da composição de hidrocarbonetos em contexto geológico similar (Aplin et al., 1999), ou com base em composições de hidrocarbonetos conhecidos (Thiéry et al., 2002).

A rotina de Aplin et al. (1999) consiste no uso da composição do hidrocarboneto presente no reservatório como parâmetro de entrada em um modelo composicional matemático focado em modelagem P-V-T (Pressão-Volume-Temperatura), que se rege, essencialmente, por duas variáveis: 1) volume molar do hidrocarboneto aprisionado na inclusão a $20^{\circ} \mathrm{C}$ e sua temperatura de homogeneização; 2) a razão entre as fases liquida e vapor $\left(F_{v}\right)$ da inclusão a $20^{\circ} \mathrm{C}$. Contudo, um obstáculo à construção final do diagrama de fases reside na forte dependência do hidrocarboneto inicial escolhido (Aplin et al., 1999).

A rotina de Thiéry et al. (2002) apresenta um modelo composicional matemático mais eficiente, devido ao desenvolvimento das equações de estado baseadas no modelo de Montel (1993) e nas equações de estado de Peng \& Robinson (1976), sendo, posteriormente, integradas no software FIT-OIL@) (Thiéry et al., 2011 apud Pestilho \& Monteiro, 2017). O modelo de Montel (1993) assegura maior eficiência pelo fato de integrar nas suas equações de estado toda a gama de pesos moleculares dos componentes de hidrocarbonetos, desde os mais leves até aos pesados, baseando-se em um teorema matemático de dois parâmetros fundamentais ( $\alpha$ e $\boldsymbol{\beta}$ ). O parâmetro " $\alpha$ " descreve a distribuição de frações não voláteis (" $n$ " maior que 10) como função de "n", com valores típicos entre 0,6 e 0,91 (Ping et al., 2011). O parâmetro " $\beta$ " descreve a variação na composição da fração volátil $\left(C_{1}-C_{6}\right)$, indicando o seu enriquecimento para valores positivos ou o seu empobrecimento em voláteis para valores negativos, sendo que valores típicos ocorrem entre -0,2 e 1 (Ping et al., 2011). Por outro lado, a equação de estado de Peng \& Robinson (1976), possibilita a construção do diagrama de fases do hidrocarboneto calculando todas as suas propriedades físico-químicas (densidade, fugacidade etc.). Não obstante, ambas as rotinas de Aplin et al. (1999) e Thiéry et al. (2002), apresentam vantagens e desvantagens, sendo limitadas na estimativa precisa da fração leve dos hidrocarbonetos, composta principalmente de metano. Contudo, as estimativas permitem prever a pressão de saturação com erro de menos de $10 \%$ de desvio absoluto médio (Ping et al., 2011). 


\section{REFERÊNCIAS}

Aplin, A.C., Mcleod, G., Larter, S.R., Pedersen, K.S., Sorensen, H., Booth, T., 1999. Combined use of confocal laser microscopy and PVT simulation for estimating the composition and physical properties of petroleum in fluid inclusions. Marine and Petroleum Geology 16, 97-110.

Bakker, R.J., 2003. Package fluids 1. Computer programs for analysis of fluid inclusion data and for modeling bulk fluid properties. Chemical Geology 194, 323.

Bello, R.M.S., 1996. Apostila do curso sobre inclusões fluidas, Instituto de Geociências - USP.

Bodnar, R.J., 1990. Petroleum migration in the Miocene Monterey Formation, California, U.S.A.: Constraints from fluid-inclusion studies. Mineralogical Magazine 54, 295-304.

Bodnar, R.J., 2003. Reequilibration of fluid inclusions. In I. Samson, A. Anderson, D. Marshall. (Eds.). Fluid Inclusions: Analysis and Interpretation. Mineral. Assoc. Canada, Short Course 32, 213-230.

Boiron, M.C, Essarraj, S., Sellier, E., Cathelineau, M., Lespinasse, M., Poty, B., 1992. Identification of fluid inclusions in relation to their host microstructural domains in quartz by cathodoluminescence. Geochimica et Cosmochimica Acta 56, 115-185.

Bourdet, J., Pironon, J., Levresse, G., Trittla, J., 2008. Petroleum type determination through homogenization temperature and vapour volume fraction measurements in fluid inclusions. Geofluids 8, 46-59.

Burke, E.A.J., 2001. Raman microspectrometry of fluid inclusions. Lithos 55, 139158.

Burruss, R.C., 1981. Hydrocarbon fluid inclusions in studies of sedimentary diagenesis. In: Hollister, L.S., Crawford, M.L. (Eds.). Short Course in Fluid Inclusions: Applications to Petrology. Mineral. Assoc. Canada 6, 138-156.

Burruss, R.C., Cerone, K.R., Harris, P.M., 1983. Fluid inclusion petrography and tectonic-burial of the Al Ali No 2 well: Evidence for the timing of diagenesis and oil migration, northern Oman Foredeep. Geology 11, 567-570.

Burruss, R.C., 2003. Petroleum fluid inclusions: An Introduction. In: Samson, I., Anderson, A., Marshall, D. (Eds.). Fluid Inclusions: Analisys and interpretation. Canadá, Ottawa: Mineralogical Association of Canada, (Short Course series, 32), 6, 159-174.

Chapman, R.E., 1976. Petroleum geology: A concise study. Elsevier Scientific Publishing Company. Amsterdam, Oxford, New York. 
Coelho, C.E., 2005. O estudo de inclusões fluidas na exploração de petróleo. Boletim de Geociências da Petrobras, Rio de Janeiro, Boletim de Geociências da Petrobras 13, 61-80.

Davis, D. W., Lowenstein, T. K., Spencer, R. J. 1990. Melting Behavior of fluid inclusions in laboratory - Grown halite crystals in the systems $\mathrm{NaCl}-\mathrm{H}_{2} \mathrm{O}, \mathrm{NaCl}-$ $\mathrm{KCl}-\mathrm{H}_{2} \mathrm{O}, \mathrm{NaCl}-\mathrm{MgCl}_{2}-\mathrm{H}_{2} \mathrm{O}$, and $\mathrm{NaCl}-\mathrm{CaCl}_{2}-\mathrm{H}_{2} \mathrm{O}$. Geochimica et Cosmochimica Acta 54, 591-601.

Demaison, G., Huizinga, B.J., 1994. Genetic classification of petroleum systems. AAPG Bulletin 75, 1626-1643.

EIA/ARI, 2013. EIA/ARI World Shale Gas and Shale Oil Assessment.

Frezzotti, M.L., Tecce, F., Casagli, A., 2012. Raman spectroscopy for fluid inclusion analysis. Journal of Geochemical Exploration 112, 1-20.

Fuzikawa, K., 1985. Inclusões fluidas: métodos usuais de estudo e aplicações. Contribuições à geologia e à petrologia. SBGM, 29-44.

Goldstein, R.H., Reynolds, T.J., 1994. Systematics of fluid inclusions in diagenetic minerals. Estados Unidos da América, Tulsa: SEPM (Society for Sedimentary Geology), short courses 31, 199p.

Goldstein, R.H., 2001. Fluid inclusions in sedimentary and diagenetic systems. Lithos 55, 159-192.

Hollister, L.S., 1981. Information Intrinsically available from fluid inclusion, In: Hollister, L.S., Crawford, M.L. (Eds.). Fluid inclusions: Applications to Petrology, Calgary, Mineralogical Association of Canada, 1-12 (Short Course, handbook, v. $6)$.

Hunt, J.M., 1996. Petroleum Geochemistry and Geology. H. Freeman and Company, $2^{\text {nd }}$ Edition. New York. USA.

Link, P.K., 1982. Basic Petroleum Geology. Oil and Gas Consultants International (OGCl). United Sates. Tulsa, $3^{\text {rd }}$ Edition, 232p.

Magoon, L.B., Dow, W.G., 2000. Mapping the petroleum system - An Investigative technique to explore the hydrocarbon fluid system. In: Mello M.R., Kats B.J. (Eds.). Petroleum systems of South Atlantic Margins. AAPG Memoir 73, 53-68.

McLimans, R.K., 1987. The application of fluid inclusions to migration of oil and diagenesis in petroleum reservoirs. Applied Geochemistry 2, 585-603.

Montel, F., 1993. Phase equilibria needs for petroleum exploration and production industry. Fluid Phase Equilibria 84, 343-367. 
Munz, I.A., 2001. Petroleum inclusions in sedimentar basins: systematics, analytical methods and applications. Lithos 55, 195-212.

Munz, I., Wangen, M., Girard, J.P., Lacharpagne, J.C., Johansen, H., 2004. Pressure, temperature, time, composition (P-T-t-X) constraints of multiple petroleum charges in the Hid field, Norwegian North Sea. Marine and Petroleum Geology 21, 1043-1060.

Nijhuis, H.J., Baak, A.B., 1990. A calibrated prospect appraisal system: Procedings of the Indonesian Petroleum Association, 19th Annual convention, 69-83.

Peng, D.Y., Robinson, D.B., 1976. A new two-constant equation of state. Industrial Engineering Chemicals Fundamentals 15, 59-64.

Pestilho, A.L.S., Monteiro, L.V.S., 2017. Uma revisão dos fundamentos do estudo de inclusões fluidas aquosas e de petróleo. Terræ Didática 13, 42-63.

Ping, H., Thiéry, R., Chen, H., 2011. Thermodynamic modeling of petroleum inclusions: the prediction of the saturation pressure of crude oils. Geofluids 11, 328-340.

Pironon J., Pradier B., 1992. Ultraviolet-fluorescence alteration of hydrocarbon fluid inclusions. Organic Geochemistry 18, 501-509.

Pironon, J., Canals, M., Dubessy, J., Walgenwitz, F., Laplace-Builhe, C., 1998. Volumetric reconstruction of individual oil inclusions by confocal scanning laser microscopy. European Journal of Mineralogy 10, 1143-1150.

Prezbindowski D.R., Larese R.E., 1987. Experimental stretching of fluid inclusions in calcite - implications for diagenetic studies. Geology 15, 333-336.

Ribeiro da Silva, T.J., 2015. Estudo de reservatórios não convencionais de shale gas no Brasil. Trabalho de conclusão de curso. Engenharia do Petróleo, Centro de Tecnologia, UFRN. 84pp.

Rocha, H.V., 2016. Estudo geológico do potencial de exploração e produção de gás natural não convencional na Bacia do Paraná: avaliação da viabilidade no abastecimento da usina termoeléctrica de Uruguaiana (RS). Tese de Mestrado, Programa de Pós-Graduação em Energia da Universidade de São Paulo.

Roedder, E., 1984. Fluid inclusions. In: Ribbe, P.H. (Eds.). Reviews in Mineralogy, Mineralogical Society of America 12, 646p.

Rostirolla, S.P., 1999. Análise de Incertezas de Sistemas Petrolíferos. Revista Brasileira de Geociências 29, 261-270.

Shepherd, T.J., Ranking, A.H., Alderton, D.H., 1985. A practical guide to fluid inclusions studies. Blackie and Son Ltd, New York, 239p. 
Soave, G., 1972. Equilibrium constants from a modified Redlich - Kwong equation of state. Chemical Engineering Science 27, 1197-1203.

Suárez, A.A., 2012. The expansion of unconventional Production of Natural Gas (Tight gas, Gas Shale and Coalbed Methane). Advances in Natural Gas Technology. Spain Commission. In Tech. 123-146.

Stasiuk, L.D., Snowdon, L.R., 1997. Fluorescence micro-spectrometry of synthetic and natural hydrocarbon fluid inclusions: crude oil chemistry, density and application to petroleum migration. Organic Geochemistry 12, 229-241.

Thiéry, R., Pironon, P., Walgenwitz, F., Montel, F., 2002. Individual characterization of petroleum fluid inclusions (composition and P-T trapping conditions) by microthermometry and confocal laser scanning microscopy: inferences from applied thermodynamics of oils. Marine and Petroleum Geology $19,847-859$.

Tissot, B.P., Welte, D.H., 1984. Petroleum Formation and Occurrence, $2^{\text {nd }}$ Edition. Berlin, Springer-Verlag, 699p.

Touret, J.L.R., 1977. The significance of fluid inclusions in metamorphic rocks. In: Nato Advanced Study Institute Series, D. G. Fraser (Eds.). Thermodynamics in Geology, 203-227.

Touret, J.L.R., 1981. Fluid Inclusions in high grade metamorphic rocks. In: Short Course in Fluid Inclusions: Applications to Petrology. L.S. Hollister and M.L. Crawford (Eds.). Min. Ass. Canada, Calgary, 182-208.

Touret, J.L.R., Dietvorst, P., 1983. Fluid inclusions in high-grade anatetic metamorphites. Journal of Geological Society of London 140, 635-649.

Wuebbles, D.J., Hayhoe, K., 2002; "Atmospheric methane and global change". EarthScience Reviews 57, 11-210. 


\section{ANEXO I}

Artigo 1. "Fluid inclusions in calcite filled opening fractures of the Serra Alta Formation reveal paleotemperatures and composition of diagenetic fluids percolating Permian shales of the Paraná Basin"

\section{PUBLICADO}

Abril 2018

Journal of South American Earth Sciences

https://doi.org/10.1016/j.jsames.2018.04.004 


\title{
Fluid inclusions in calcite filled opening fractures of the Serra Alta Formation reveal paleotemperatures and composition of diagenetic fluids percolating Permian shales of the Paraná Basin
}

\author{
C.A.S. Teixeira ${ }^{a}$, , A.O. Sawakuchi ${ }^{a}$, R.M.S. Bello ${ }^{a}$, S.F. Nomura ${ }^{b}$, D.J. Bertassoli ${ }^{a}$, \\ M.A.C. Chamani ${ }^{\mathrm{a}}$ \\ ${ }^{a}$ Universidade de São Paulo, Instituto de Geociências, Departamento de Geologia Sedimentar e Ambiental, Rua do Lago, 562, São Paulo, SP, 05508-080, Brazil \\ ${ }^{\mathrm{b}}$ Petróleo Brasileiro S.A. (Petrobrás), Unidade de Operações de E\&P da Bacia de Santos - Rua Marques de Herval, 90, Valongo, Santos, SP, Brazil
}

\section{A R T I C L E I N F O}

\section{Keywords:}

Paraná Basin

Magmatism

Aqueous fluids

Calcite filled opening fractures

Thermal evolution

Fluid inclusion assemblages

Stable isotopes

\begin{abstract}
A B S T R A C T
The thermal and diagenetic evolution of shale units has received renewed focus because of their emergence as unconventional hydrocarbon reservoirs. The Serra Alta Formation (SAF) is a Permian shale unit of the Paraná Basin, which is the largest South American cratonic basin. The SAF stands out as a pathway for aqueous fluids and hydrocarbon migration from the Irati organic-rich shales to the Pirambóia fluvial-eolian sandstone reservoirs. Vertical NNW and NNE opening fractures would be the main pathways for the migration of buried pore waters and aqueous fluids, besides the input of meteoric water. These fractures would be associated to the reactivation of basement discontinuities such as the Jacutinga (NE) and Guapiara (NW) faults. Thus, vertical NNE and NNW associated fractures would represent the main pathways for fluid migration in the studied area. The vertical calcite filled opening fractures from SAF record moderately low salinity (0-4.5 wt \% of $\mathrm{NaCl}$ eq.) aqueous fluids, suggesting the input of meteoric water in the buried fracture system. Eutectic melting temperatures at $-52 \pm 5{ }^{\circ} \mathrm{C}$ indicate an $\mathrm{H}_{2} \mathrm{O}+\mathrm{NaCl}+\mathrm{CaCl}_{2}$ system with $\mathrm{CaCl}_{2}$ or $\mathrm{MgCl}_{2}$ in solution. Homogenization temperatures recorded in fluid inclusion assemblages (FIAs) of calcite filled opening fractures indicate that the SAF in the studied area reached temperatures above $200{ }^{\circ} \mathrm{C}$, suitable for generation of gaseous hydrocarbons. The recorded paleotemperatures point to a thermal peak associated with Serra Geral volcanic event during the Early Cretaceous, with the thermal effect of volcanic rock cap possibly overcoming the effect of intrusive igneous bodies. The detection of methane in SAF shale pores indicates conditions for hydrocarbon generation. However, additionally studies are necessary to confirm the thermogenic and/or biogenic origin of the methane within the SAF.
\end{abstract}

\section{Introduction}

Cratonic basins affected by magmatic episodes have complex thermal and diagenetic evolution. The widespread thermal effect of magmatism that influences the characteristics of diagenetic aqueous paleofluids and hydrocarbons, is reported in worldwide cratonic basins such as the Solimões Basin (Milani et al., 2007a), Amazonas Basin and the Parnaíba Basin (Thomaz-Filho et al., 2008) in Brazil, the Neuquén Basin in Argentina (Monreal et al., 2009) the Illinois Basin (Stewart et al., 2005; Mastalerz et al., 2009) in USA, the Tunguska Basin (Kontorovich et al., 1997) in Russia, the Sichuan Basin (Zhu et al., 2010) in China, the Gunnedah Basin (Salmachi et al., 2016) in Australia and the Karoo Basin (Brown et al., 1998; Smithard et al., 2015) in Africa.
The Paraná Basin is located on the South American Platform and evolved in Western Gondwana during the Paleozoic and Mesozoic (Milani et al., 2007a). It comprises Devonian and Permian organic-rich shale units, which were affected by an intraplate volcanic event during the Early Cretaceous. This volcanic event has been considered a key factor for the thermal history of the Paraná Basin rocks and their paleofluids (Araújo et al., 2000; Nomura et al., 2014; Thiede and Vasconcelos, 2010). It had great impact on the thermal evolution of the Paraná Basin shale units and consequent importance for the generation and migration of aqueous diagenetic fluids and hydrocarbons (Nomura et al., 2014).

The Serra Alta Formation (SAF) is a shale unit predominantly composed of dark grey pelitic facies and integrates the Permian succession of the Paraná Basin (Fig. 1A). It represents offshore

\footnotetext{
* Corresponding author.

E-mail address: carlitoz.teixeira@gmail.com (C.A.S. Teixeira).
} 


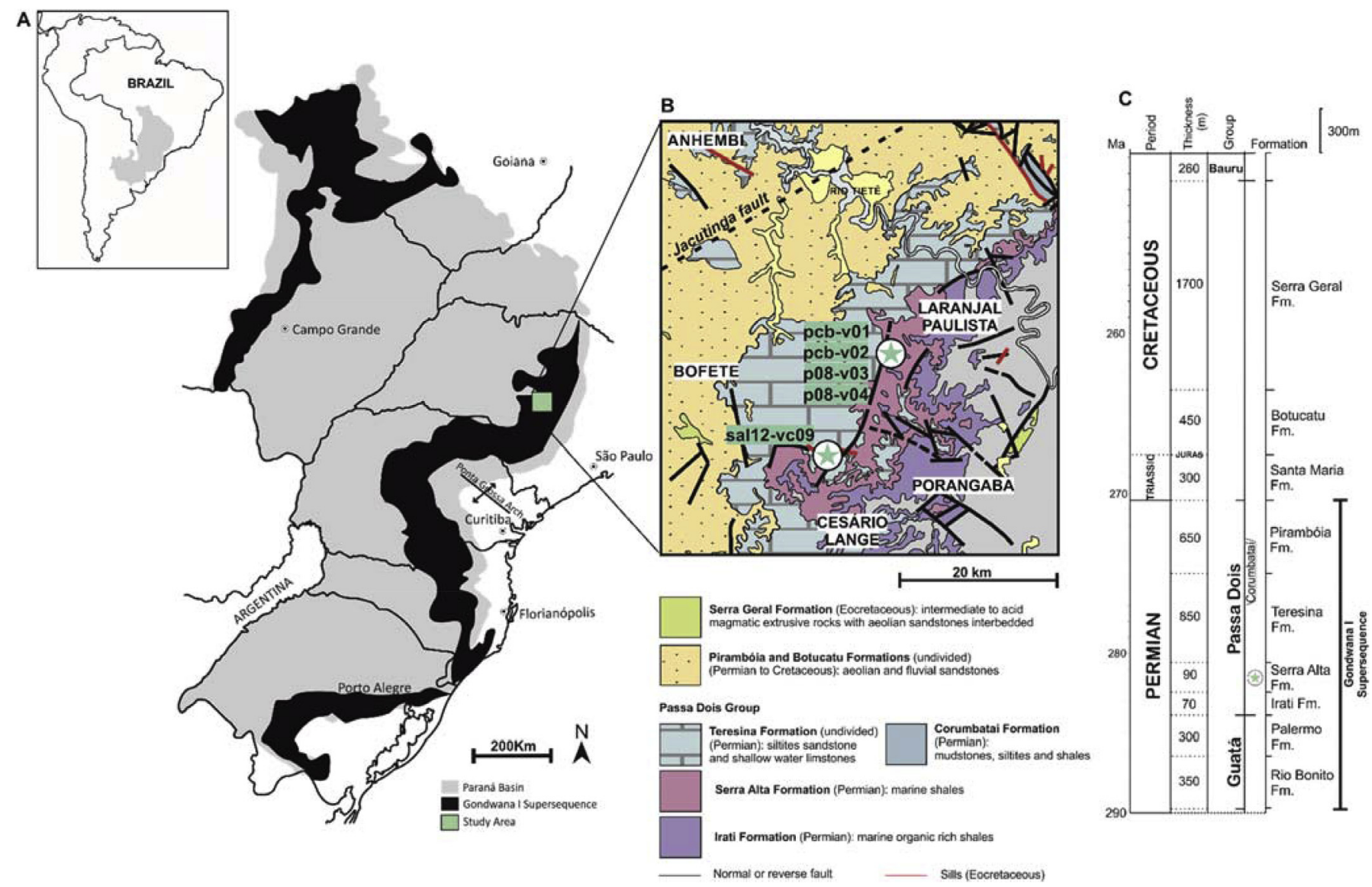

Fig. 1. (A) Location of the study area in the eastern border of the Paraná Basin (Modified from Calça, 2016). (B) Detail of the geological map in the study area. The stars indicate the location of the studied samples (Modified from Nomura et al., 2014). (C) Stratigraphy of the Permian and Cretaceous units of the Paraná Basin (maximum formation thickness and groups based on Milani et al., 2007b).

sedimentation in a shallow interior sea under mainly dysoxic conditions (Holz et al., 2010). The SAF lies above oil shales of the Irati Formation and below the Teresina Formation, which is overlain by the fluvialeolian sandstones of the Pirambóia Formation. The shales of the Irati Formation and sandstones of the Pirambóia Formation define the IratiPirambóia Petroleum System (IPPS) (Zalán et al., 1990; Araújo et al., 2005; Milani et al., 2007a). Diagenetic minerals from the SAF are valuable materials that recorded the paleofluids and thermal history of the Permian succession of the Paraná Basin, including geologic elements (source rocks and reservoirs) and processes (hydrocarbon generation; migration and entrapment) in the IPPS.

Shale formations are geographically widely distributed in almost every region of the world (Swann and Munns, 2003; Zhu et al., 2010; Huang et al., 2012; Selley, 2012). The growing importance of unconventional shale gas resources and associated environment issues motivate a better understanding about the evolution of fine-grained rocks. In spite of no shale gas exploration activity has been reported in the Brazilian sedimentary basins, the potential of onshore world sedimentary basins for shale gas production has been debated worldwide (Chalmers et al., 2012; USGS, 2013; EIA/ARI, 2013; Xin-gang and Yahui, 2015). In Brazil, the Paraná, Solimões, Parnaíba, and Parecis basins have a total shale resources estimate of about $414 \mathrm{Tcf}$ (EIA/ARI, 2013). In this context, the Serra Alta Formation shales stand out as a potential hydrocarbon source rock as well as cap rock unit of the Irati oil shale.

The main goal of this study was to reconstruct the thermal history and paleofluids of the Serra Alta Formation through the characterization of diagenetic calcite filled opening fractures. We used the analysis of fluid inclusions and oxygen $\left(\delta^{18} \mathrm{O}\right)$ and carbon $\left(\delta^{13} \mathrm{C}\right)$ stable isotopes in diagenetic calcite crystals combined with TOC (total organic carbon) and methane $\left(\mathrm{CH}_{4}\right)$ concentration analysis in shale samples. Measurements of methane concentrations in shales samples were made to highlight the possibility of previous hydrocarbon generation within the SAF. These data are discussed in context of the diagenetic evolution of the Permian succession and fluids migration in the IPPS. Petrographic and microthermometry studies of aqueous fluid inclusions and $\delta^{18} \mathrm{O}$ and $\delta^{13} \mathrm{C}$ stable isotopes data allowed to estimate the paleotemperatures reached by the Serra Alta Formation shale as well as to obtain information about fluid composition and fluid origin during the crystallization of calcite in vertical open fractures.

\section{Geological setting}

The Paraná Basin is an Ordovician to Cretaceous cratonic basin with an NE-SW elongated shape occupying an area of approximately $1,700,000 \mathrm{~km}^{2}$ in central-southeastern South America.

In the east-central portion of the basin in the São Paulo State, the Serra Alta Formation overlies the Irati Formation and it is mapped from the southern boundary of the São Paulo State to the Gibóia Dome, located north of Laranjal Paulista county (Warren et al., 2015) (Fig. 1A-B).

The Serra Alta Formation represents the last major marine incursion recorded in the Paraná Basin (Milani et al., 2007a). It consists of a sequence of dark to light grey shales and siltites, with heterolithic lamination, sparse carbonate concretions and clastic sand dykes and vertical fractures. Its fossil assemblage is mainly represented by fish remains (bones and teeth), mollusks shells and palinomorphs which suggest a late Permian age (Meglhioratti et al., 2005). The thickness of the SAF on the eastern edge of the Paraná Basin is between 60 and $90 \mathrm{~m}$ 
(Meglhioratti et al., 2005), decreasing in the northeastern region of the basin.

The circulation and migration of aqueous fluids in the eastern border of the Paraná Basin would be favored during the periods of generation or reactivation of late Permian faults (Rostirolla et al., 2000; Riccomini et al., 2005; Strugale et al., 2007). Vertical calcite filled opening fractures with NNW to NW and NNE to NE directions are common features observed in outcrops of the SAF. According to Zalán et al. (1990) and Strugale et al. (2007), the fracture trends resulted from extension stress responsible for the intraplate Serra Geral magmatism during the Early Cretaceous. In the eastern border of the Paraná Basin, clay mineral authigenesis was induced in the Permian units by migrating hydrothermal fluids related to the Early Cretaceous Serra Geral magmatism, probably from 140 to $130 \mathrm{Ma}$ (Sant'Anna et al., 2006). Low to high salinity aqueous fluids are recorded in reequilibrated fluid inclusions with homogeneization temperatures above $200{ }^{\circ} \mathrm{C}$ from calcite veins of the Teresina Formation lying above the SAF (Nomura et al., 2014). This relatively high temperatures are interpreted as a result of the influence of the Serra Geral volcanic event on the Permian sequence of the Paraná Basin (Nomura et al., 2014).

\section{Materials and methods}

\subsection{Sampling and outcrop descriptions}

Shale and calcite samples were collected from surface in outcrops. Thus, some measured characteristics like total organic carbon and methane concentration can not exactly reflect subsurface conditions. The studied SAF outcrops were described in terms of their sedimentary facies and calcite filled opening fractures. The orientations of these fractures were compared with the regional structural framework of the Paraná Basin. Igneous bodies were absent in the studied outcrops. Nonetheless, a large sill intruded in the Irati Formation occurs around $60 \mathrm{Km}$ northeastward the studied area (Fig. 1B). In the studied area, flood basalts of the Serra Geral Formation were separated from the SAF by siliciclastic rocks of the Teresina, Pirambóia and Botucatu formations (Milani et al., 2007b). The sedimentary facies of the SAF were described through columnar section and the directions of the calcite filled fractures were represented in stereograms.

Twenty-nine samples of calcite filled opening fractures and shales were collected in outcrops of SAF in the eastern border of the Paraná Basin. The samples of calcite were used for fluid inclusion analysis. The shale samples were submitted to analyses of total organic carbon (TOC), hydrogen concentration in organic matter and methane $\left(\mathrm{CH}_{4}\right)$ concentration. Carbon and oxygen stable isotopes analyses were also carried out on calcite from fractures and matrix of shale bulk samples.

\subsection{Total organic carbon (TOC) and hydrogen $(H)$ concentration}

Approximately $250 \mathrm{~g}$ of each shale samples were crushed using a hydraulic press and ground in the ring mill and mortar to obtain particle size of approximately $4 \mu \mathrm{m}$ (200 mesh). The samples were dried at $60^{\circ} \mathrm{C}$ for $24 \mathrm{~h}$ in an oven. Afterwards, $10 \mathrm{~g}$ of each sample were disposed in $100 \mathrm{ml}$ of hydrochloric acid $10 \%$ at $70{ }^{\circ} \mathrm{C}$ for $24 \mathrm{~h}$ for dissolution of carbonates. Dry samples were weighted for calculation of carbonate concentration. From the insoluble residues, $1.5 \mathrm{~g}$ was separated to perform TOC and $\mathrm{H}$ concentration analyses in the Institute of Chemistry of the University of São Paulo, using a Perkin Elmer 2400 CHN element analyzer equipment. This equipment has an analytical error of $\pm 0.3 \%$.

\subsection{Fluid inclusion analysis}

Thin sections of five calcite samples were prepared for fluid inclusion analysis. Thin sections polished (thickness of 70-100 $\mu \mathrm{m}$ ) on both sides were studied in a polarized Leitz Wetzlar petrographic microscope to map fluid inclusion assemblages (FIAs) based on features indicative of trapping conditions (primary, pseudosecondary and secondary) and distribution within the anlysed calcite crystals according definition by Goldstein and Reynolds (1994). Fluid inclusion petrography and microthermometry were performed in the Fluid Inclusion Laboratory of Geoanalítica-USP Core Facility in the Institute of Geosciences at the University of São Paulo. Microthermometry data were acquired and grouped considering FIAs previously defined through fluid inclusions petrography as described by Goldstein and Reynolds (1994), and focusing on host crystals containing the largest number of fluid inclusions suitable for microthermometry. Fluid inclusions dimensions should allow for both the observation of inclusions phases and the record of temperature phase changes during heating and cooling. Fluid inclusions presenting features of leakage, necking down or deformation after trapping were not considered for microthermometric analysis. The fluid inclusion microthermometry was carried out in a microscope equipped with CHAIXMECA model MTM 85 stage calibrated with MERCK 320 signotherm for low temperatures and standards MERK MSP for high temperatures $\left(>40{ }^{\circ} \mathrm{C}\right)$.

For lower temperatures, calibrations were made using Calanda quartz sample (Switzerland), containing pure $\mathrm{CO}_{2}$ inclusions, with triple point at $-56.6^{\circ} \mathrm{C}$, mercury with melting point at $-38.86^{\circ} \mathrm{C}$ and pure water with melting point at $0^{\circ} \mathrm{C}$.

It was also made through the calibration standards SYN FLINC (Synthetic Fluid Inclusions) for aqueous, aqueous saline $\left(\mathrm{H}_{2} \mathrm{O}+\mathrm{NaCl}\right.$; $\mathrm{H}_{2} \mathrm{O}+\mathrm{KCL}$ ) and aqueous carbonic synthetic inclusions.

The measurements of homogenization temperatures (Th) were acquired at heating rate of $2{ }^{\circ} \mathrm{C} / \mathrm{min}$. Heating for measurements of homogenization temperatures were taken before the freezing tests necessary to measure eutectic temperatures (TE) and ice melting temperatures ( $\mathrm{Tm}$ ice). This procedure was performed to avoid an increase in the volume of the fluid inclusion cavity (stretching) due to ice crystallization producing meaningless Th values, especially in minerals such as calcite which has a low hardness and major cleavage in several directions. Tm ice measurements allowed the determination of salinity in weight $\%$ of $\mathrm{NaCl}$ equivalent (wt $\% \mathrm{NaCl}$ eq.). Eutectic temperatures indicate the composition of aqueous fluids in terms of types of solution ions. The salinities and densities of the trapped fluids were calculated using thermodynamic equations (Archer, 1992; Zhang and Frantz, 1987) considering the variables $\mathrm{Tm}$ ice and Th or the volume proportion of the liquid phase. These equations are included in the BULK software from the Fluids package of computer programs for fluid inclusion studies (Bakker, 2003).

\subsection{Carbon and oxygen stable isotope analysis in calcite filled opening fractures}

Analysis of carbon $\left(\delta^{13} \mathrm{C}\right)$ and oxygen $\left(\delta^{18} \mathrm{O}\right)$ stable isotopes was performed in calcite filled fractures and calcite from the matrix of shale bulk samples. Calcite filled opening fractures were crushed for hand picking of clean crystals under a stereoscopic microscope. Bulk samples were grinded in a mortar. Measurements of $\delta^{13} \mathrm{C}$ and $\delta^{18} \mathrm{O}$ were performed in the Stable Isotope Laboratory of the Institute of Geosciences at the University of São Paulo.

Isotope measurements were carried out in an Isotope Ratio Mass spectrometer (IRMS) Delta V Advantage Model, coupled to Gas-Bench II (Thermo Finnigan Model and GC-PAL automatic sampler). $\delta^{13} \mathrm{C}$ and $\delta^{18} \mathrm{O}$ were measured by continuous flow method through the reaction with phosphoric acid $\left(\mathrm{H}_{3} \mathrm{PO}_{4}\right)$. The internal accuracy (instrumental deviation) specified by the manufacturer is $0.006 \%$ for $\delta^{13} \mathrm{C}$ and $0.008 \%$ for $\delta^{18} \mathrm{O}$. In this study, $\delta^{13} \mathrm{C}$ and $\delta^{18} \mathrm{O}$ values were standardized according the international Pee Dee Belemnite (PDB) standard.

\subsection{Methane detection in shale samples}

Methane $\left(\mathrm{CH}_{4}\right)$ measurements were performed for 11 sahle samples. 
Shale fragments were disaggregated and sieved, with collection of the fraction between $0.28 \mathrm{~mm}$ and $0.20 \mathrm{~mm}$. Fractions were then split in triplicates with $15 \mathrm{~g}$ each and placed inside $100 \mathrm{ml}$ serum vials. Those where filled with $20 \mathrm{ml}$ of $\mathrm{NaOH}(4 \%)$ to expel methane from pores (Fonseca et al., 2004; Birgel et al., 2015) and sealed with butyl rubber stoppers and aluminum crimps. Air samples were also collected to discount background values of atmospheric methane. The vials were then put in ultrasonic bath for $1 \mathrm{~h}$ in $60^{\circ} \mathrm{C}$ to guarantee the release of retained gases. Headspace samples $(20 \mathrm{ml})$ were then collected with syringes and analyzed in a Gas chromatograph equipped with FID (SHIMADZU GC-17A). Methane concentration data were presented as statistics among the triplicates.

\section{Results}

\subsection{Sedimentary facies}

The facies analysis of the studied SAF outcrops was based on the description of mineralogical composition, grain size, primary sedimentary structures and fossiliferous content. In the studied outcrops, five sedimentary facies were recognized for the SAF. The characteristics of the sedimentary facies and their interpreted depositional conditions are described in Table 1.

The studied sedimentary successions are dominated by laminated argillaceous and sandy siltites (facies ASi and SSi) and shales with fish remains (bone beds) (facies $\mathrm{Sh}$ ) intercalated with fine-grained sandstones with parallel lamination (facies FgS). Facies FgS is more frequent in the bottom part of the studied succession, near the boundary with the Irati Formation. Shale facies (Sh) dominate the whole succession, with higher thickness in the middle and upper portions of the succession (Fig. 2). Limestone facies (Lm) with bivalve fossils appear as thin layers.

\subsection{Direction of calcite filled opening fractures}

The studied outcrops show a conjugate fractures system. Fractures are filled with calcite and have two preferential directions, NE-SW and NW-SE (Fig. 3). However, cross-cutting relation was not observed in outcrops. The calcite filled opening fractures are 1-4 cm thick (Fig. 4) with dip angles from $87^{\circ}$ to $90^{\circ}$, occurring both in NE and NW trending fractures, although the NE trend appears to be the most frequent. The calcite filled opening fractures, as exemplified by samples pcb-v01 and pcb-v02, with 2 and $3 \mathrm{~cm}$ thickness, can be classified as syntaxial veins because they consist of crystals precipitation on the wall rock with growth inwards, an elongate blocky texture and diagenetic dissolution features. The studied syntaxial calcite filling fractures are generally composed of euhedral to anedral crystals. Most crystals have a dusty appearance showing twinning planes (Fig. 5A).

The calcite filled opening fractures represented by sample P08-v03 and P08-v04 have 4 and $2 \mathrm{~cm}$ thickness and consists of equant crystals with diameter ranging from 150 to $350 \mu \mathrm{m}$ and a blocky texture. The crystals have often a dusty appearance due to extremely small solid dark inclusions, with possible organic matter inclusions and high abundance of aqueous inclusions, which are randomly distributed within the host crystal (Fig. 5B). Twinning calcite crystal plans are less common in this sample type.

Sample sal12-v09 is $2 \mathrm{~cm}$ thick and it is formed by predominantly large calcite crystals (from 300 to $400 \mu \mathrm{m}$ ) with frequent patchy thin twins, usually an indicator of low deformation in low temperature conditions (Burkhard, 1993), and elongate blocky texture due to the growth of both sides of the vein towards the center. The crystals also have a dusty appearance due to small solid inclusions and aqueous fluid inclusions randomly distributed or oriented over the twinning plans (Fig. 5C).

\subsection{Petrography of thin sections}

As shown in Fig. 2, the most frequent sedimentary facies observed in the studied outcrops are shale ( $\mathrm{Sh}$ ), argillaceous siltite (ASi) and sandy siltite (SSi). Thin sections from ASi (sample Sal12-08) and SSi (sample Sal12-23) facies were described under the microscope to characterize depositional and diagenetic components and features.

Observation of thin sections of siltite shows very fine matrix fragments and eogenetic cement textures with crystal size variations between $<5$ and $100 \mu \mathrm{m}$.

The argillaceous siltite facies (ASi) correspond to fine and very fine siltite without clear lamination. Euhedral to subhedral calcite crystals with commonly sharp and straight contacts, despite sutured contacts are also observed, obliterate the detritic framework. ASi also contains opaque authigenic sub rounded crystals disseminated within the matrix or forming irregular dendritic shapes (Fig. 8A).

The sandy siltite facies (SSi) represents medium to coarse-grained laminated siltstone, with the lamination defined by grain size variations (Fig. 8B). The calcite cement partially replaces some detrital grains and bioclasts. Most bioclasts occurs typically as long narrow phosphate fragments (fish remains). Some of these fragments are deformed and compacted due to burial. Remains of bioclasts are often observed (Fig. 8C).

\subsection{TOC and hydrogen concentration}

The TOC and $\mathrm{H}$ analyses were performed on twenty-nine shale samples (Table 2). Fig. 6 shows TOC values between 0.10 and $0.50 \%$, with average of $0.16 \%$. H concentration ranged from 0.24 to $3.20 \%$, with average of $1.03 \%$. The H/TOC ratio is higher than 2 , with an average of 8.68 , suggesting kerogen type I or II (lacustrine or marine organic matter).

\subsection{Stable isotope geochemistry}

$\delta^{13} \mathrm{C}$ and $\delta^{18} \mathrm{O}(\mathrm{PDB})$ values of bulk shale samples range from -8.7 to $-2.3 \%$ and from -8.5 to $+1.4 \%$, respectively. The calcite filling fractures exhibit values of $\delta^{18} \mathrm{O}$ from -6.2 to $-4.5 \%$, with an average

Table 1

Sedimentary facies described in the studied outcrops of the Serra Alta Formation in eastern flank of the Paraná Basin.

\begin{tabular}{|c|c|c|}
\hline FACIES & DESCRIPTION & DEPOSITIONAL ENVIRONMENT \\
\hline $\begin{array}{l}\text { Fine grained sandstone } \\
\qquad(\mathrm{FgS})\end{array}$ & $\begin{array}{l}\text { Reddish well sorted fine to very fine sandstone beds }(50 \mathrm{~cm} \text { thick) with } \\
\text { plan-parallel or cross lamination and intraclasts. Beds have a fining } \\
\text { upward pattern. }\end{array}$ & Deposition under unidirectional water flow with decreasing velocity. \\
\hline Argillaceous siltite (ASi) & $\begin{array}{l}\text { Tabular argillaceous siltite beds }(15 \mathrm{~cm} \text { thick) with calcite cement and } \\
\text { plan-parallel lamination. }\end{array}$ & Deposition by decantation in calm waters. \\
\hline Shale (Sh) & $\begin{array}{l}\text { Dark grey clayey shale beds ( } 4 \mathrm{~m} \text { thick) with fish fossil remains (scales, } \\
\text { bones and teeth). }\end{array}$ & $\begin{array}{l}\text { Deposition by decantation in still water setting. Dark staining suggests low } \\
\text { oxygen conditions at water sediment interface suitable for organic matter } \\
\text { preservation. }\end{array}$ \\
\hline Sandy siltite (SSi) & $\begin{array}{l}\text { Tabular grey to beige sandy siltite beds ( } 2 \mathrm{~m} \text { thick) with heterolithic } \\
\text { lamination. }\end{array}$ & $\begin{array}{l}\text { Deposition under conditions of intermittent water flow (short duration } \\
\text { currents). }\end{array}$ \\
\hline Limestone (Lm) & Massive fine-grained limestone sets $(8-10 \mathrm{~cm}$ thick $)$ & Carbonate sedimentation during phases of low terrigenous sediment supply. \\
\hline
\end{tabular}




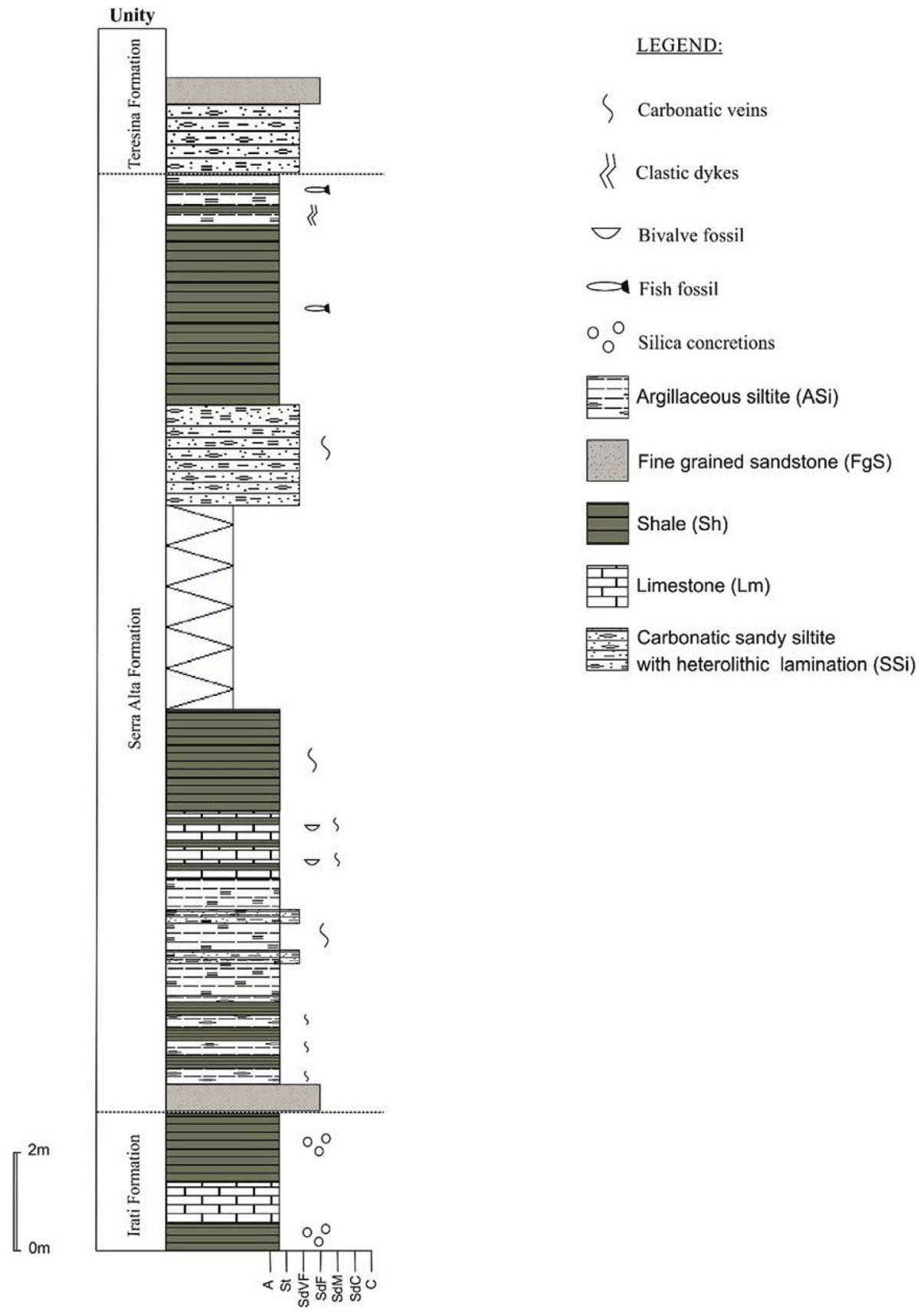

Fig. 2. Sedimentary facies succession of the Serra Alta Formation in the study area.

of $-5.5 \%$, and $\delta^{13} \mathrm{C}_{\mathrm{PDB}}$ values between -5.1 and $-3.7 \%$, with average of $-4.6 \%$. Table 3 summarizes the $\delta^{13} \mathrm{C}$ and $\delta^{18} \mathrm{O}$ data. Three main clusters of authigenic calcite are evident when $\delta^{13} \mathrm{C}$ versus $\delta^{18} \mathrm{O}$ values are plotted (Fig. 7). Bulk shale samples are grouped into two clusters, suggesting two different generations of calcite cement precipitation. Cluster 1 has $\delta^{13} \mathrm{C}$ values between -4.6 and $-2.3 \%$ and $\delta^{18} \mathrm{O}$ values between -7.6 and $-1.1 \%$. Cluster 2 has $\delta^{13} \mathrm{C}_{\mathrm{PDB}}$ and $\delta^{18} \mathrm{O}_{\mathrm{PDB}}$ values ranging from -8.6 to -6.2 and from -8.4 to $-4.1 \%$ respectively. Cluster 3 represents the calcite filled opening fractures, with $\delta^{13} \mathrm{C}_{\mathrm{PDB}}$ and $\delta^{18} \mathrm{O}_{\mathrm{PDB}}$ values from -5.1 to -3.6 and from -4.4 to $-6.1 \%$, respectively.

\subsection{Fluid inclusions data}

Five thin sections of calcite filled opening fractures (samples pCBv01, pCB-v02, p08-v03, p08-v04 and sal12-v09) were used for fluid inclusion analysis. Table 4 shows the microthermometric data obtained for the studied fluid inclusion assemblages (FIAs). Host calcite crystals present one-phase and two-phase clear aqueous inclusions with irregular (mainly one-phase) to approximately regular shape in the same FIA (Fig. 9). Fluid inclusions occur as randomly distributed groups within calcite crystals, pointing out to a primary origin. They also occur as healed internal fractures within crystals which had taken place before crystal growth terminated, suggesting a pseudo-secondary origin as discussed by Roedder (1984), Shepherd et al. (1985) and Goldstein and Reynolds (1994). The primary and pseudo-secondary inclusions mostly from regular shape are the aim of the microthermometric data because they preserve physical-chemical characteristics (pressure, composition, density) of paleofluids circulating during crystal growth in the studied fractures.

The two-phase inclusions have a diameter ranging from 4 to $16 \mu \mathrm{m}$ with vapor phase volume predominantly between 2 and $13 \%$, 


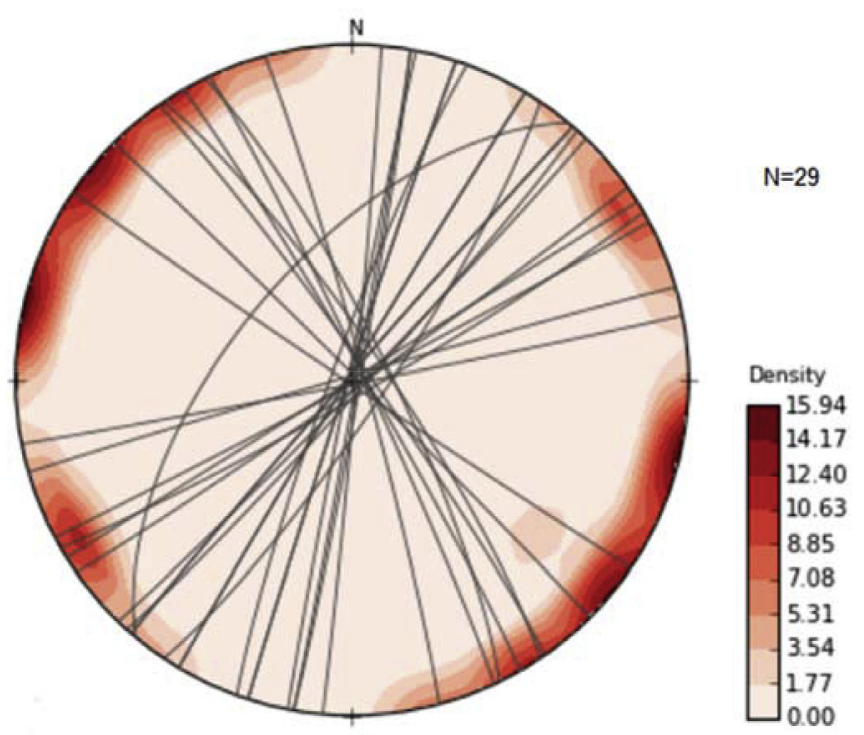

Fig. 3. Stereo plot of strike directions and dip angles of calcite filled opening fractures in outcrops of the Serra Alta Formation in the study area.

determined through Archer (1992) and Zhang and Frantz (1987) from the Bulk software (Bakker, 2003). These two-phase inclusions, are often associated with single-phase inclusions with similar diameter. The twophase fluid inclusions show homogenization temperatures (Th) ranging from 60 to $200^{\circ} \mathrm{C}$, but values up to $300^{\circ} \mathrm{C}$ were also observed (Fig. 10). Temperatures of the eutectic point (TE) for fluid inclusions range from -56 to $-48{ }^{\circ} \mathrm{C}$, approximately. The variation of the vapor phase volume in two-phase inclusions and its association with single-phase inclusions indicate fluid inclusion entrapment at low temperature phreatic zone (Goldstein and Reynolds, 1994). Ice melting temperatures (Tm ice) mainly vary from -3 to $0{ }^{\circ} \mathrm{C}$ (Fig. 10). It was also obtained Tm ice values above $0{ }^{\circ} \mathrm{C}$, indicative of metastability resulting from fluids trapped at low temperatures (Roedder, 1984). Thus, these values were not considered in the dispersion diagram (Fig. 11) due to their inaccuracy related to metastability. Tm ice values mainly situated between -3 and $0{ }^{\circ} \mathrm{C}$ correspond to salinities ranging from 0 to $4.5 \mathrm{wt} \%$ of $\mathrm{NaCl}$ equivalent. The calculated densities of the aqueous fluids range from 0.91 to $0.95 \mathrm{~g} / \mathrm{cm}^{3}$. Fig. 10 shows homogenization, ice melting, eutectic point temperatures and vapor volume percentage. The high variation of Th with small variations of Tm ice suggests post-trapping modification of fluid inclusions (Goldstein and Reynolds, 1994) (Fig. 11).

\subsection{Methane in shale samples}

Concentration of methane in atmospheric air samples was $2.55 \pm 0.47 \mathrm{ppm}$. All eleven headspace experiments demonstrated significant increase in methane concentrations associated to samples degassing, varying from $4.43 \pm 0.57 \mathrm{ppm}$ to $14.17 \pm 0.77 \mathrm{ppm}$, with $7.17 \pm 0.64 \mathrm{ppm}$ as a mean value (Table 2). No significant correlation was observed between TOC and methane content.

\section{Discussion}

\subsection{Characteristics and origin of diagenetic aqueous fluids of the SAF} shales

The composition of the aqueous paleofluids is given by the eutectic point temperature (TE) of the solutions. Studied calcite filled opening fractures showed TE from -56 to $-48^{\circ} \mathrm{C}$. Eutectic melting at $-52 \pm 5{ }^{\circ} \mathrm{C}$ indicate an $\mathrm{H}_{2} \mathrm{O}+\mathrm{NaCl}+\mathrm{CaCl}_{2}$ system, which is a common composition for aqueous diagenetic fluids (Goldstein and
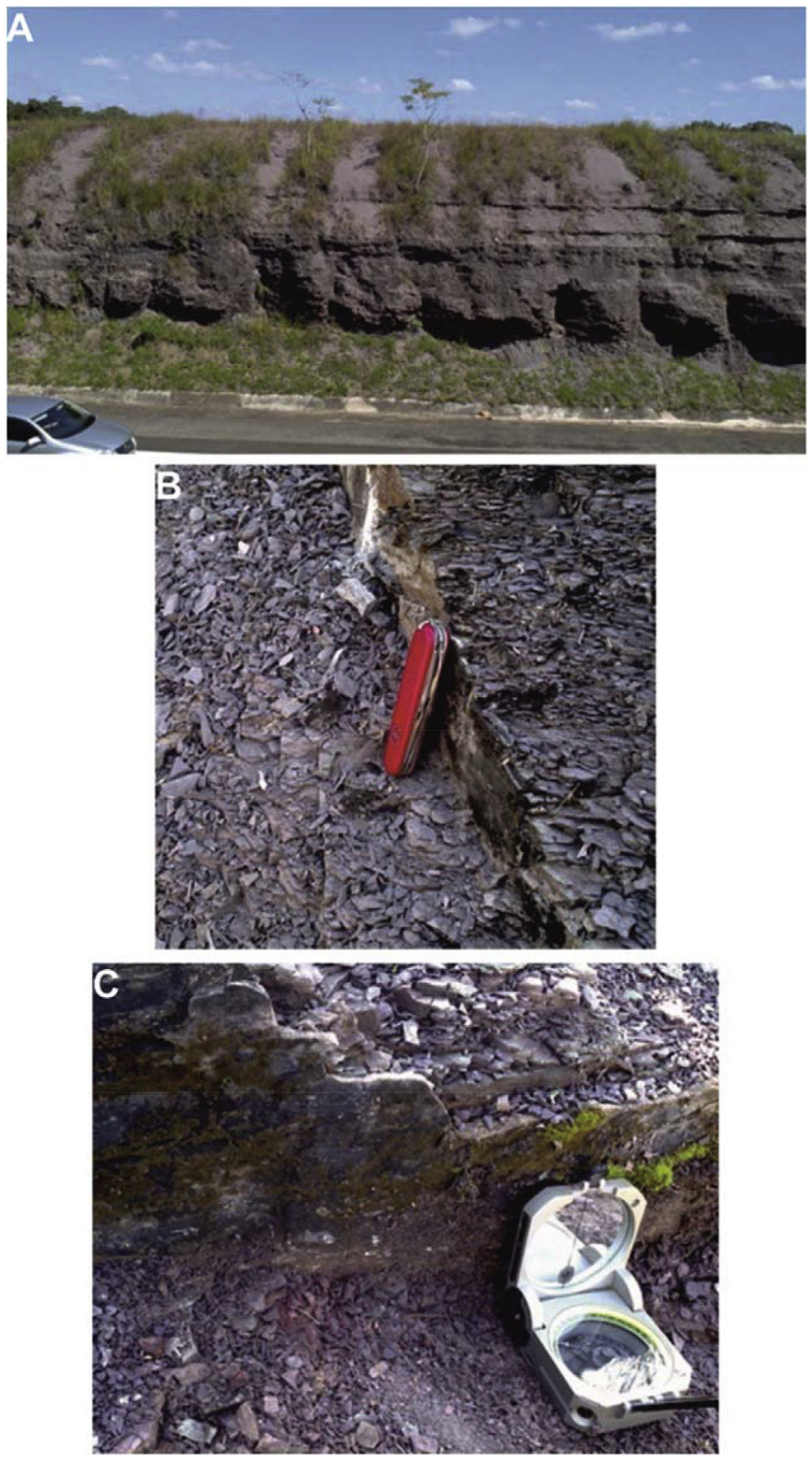

Fig. 4. (A) Serra Alta Formation outcrop. (B, C) Fractures filled with calcite in shales of the Serra Alta Formation.

Reynolds, 1994). Roedder (1984) and Goldstein and Reynolds (1994) indicate that eutectic temperatures below $-40{ }^{\circ} \mathrm{C}$ point out aqueous solutions with divalent cations $\left(\mathrm{Ca}^{2+}\right.$ and/or $\left.\mathrm{Mg}^{2+}\right)$. Therefore, the fluid would be composed of $\mathrm{NaCl}$ and $\mathrm{H}_{2} \mathrm{O}$ while the $\mathrm{CaCl}_{2}$ and the $\mathrm{MgCl}_{2}$ could come from the original solution or derived from ionic exchange between the fluid and the host calcite as discussed by Crawford and Hollister (1992). Nomura et al. (2014) observed TE values ranging from -25 to $-35^{\circ} \mathrm{C}$ in horizontal calcite veins from the overlying Teresina Formation, indicating the presence of $\mathrm{NaCl}$ in solution (Goldstein and Reynolds, 1994), and between -40 and $-57^{\circ} \mathrm{C}$, suggesting the presence of $\mathrm{H}_{2} \mathrm{O}+\mathrm{NaCl}$ with $\mathrm{CaCl}_{2}$ or $\mathrm{MgCl}_{2}$ in solution.

In this study, to obtain the salinity system in weight of percentage of $\mathrm{NaCl}$ equivalent (wt \% $\mathrm{NaCl}$ eq.), we only consider the $\mathrm{H}_{2} \mathrm{O}+\mathrm{NaCl}$ model, which was obtained through computer analytical methods by the software fluids (Bakker, 2003). Tm ice between -3 and $0{ }^{\circ} \mathrm{C}$ point to salinities between 0 and $4.5 \mathrm{wt} \% \mathrm{NaCl}$ eq. for the fluid inclusions from calcite filled fractures in the SAF (Fig. 10).

The salinity obtained for the paleofluids percolating fractures of the SAF is moderately low when compared to the salinity of paleofluids 

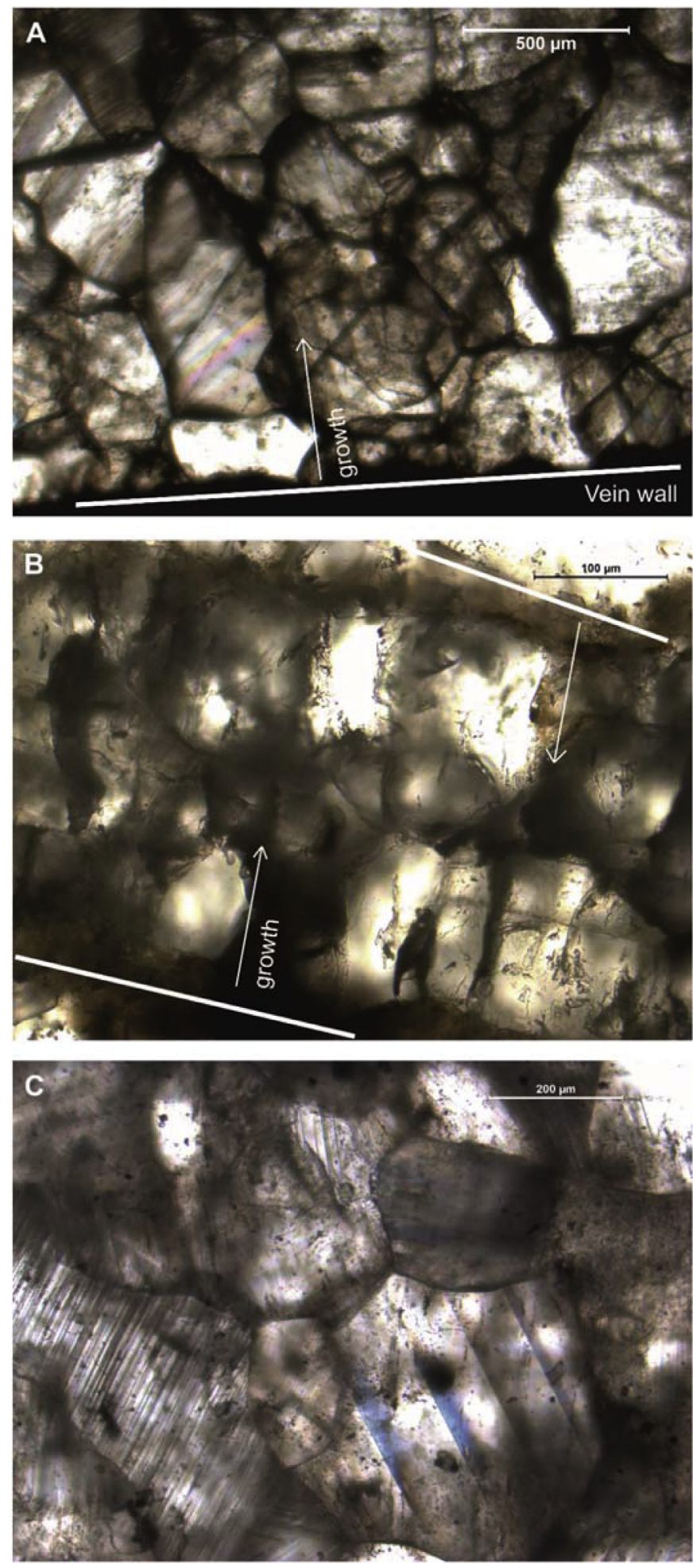

Fig. 5. (A) Calcite crystals with cloudy appearance, patchy twins, concaveconvex boundaries and elongate blocky crystal texture (pcb-v01; pcb-v02). (B) Vertical calcite vein with blocky crystal texture (p08-v03; p08-v04). (C) Patchy twins in calcite crystals with concave-convex boundaries. Pictures under parallel-polarized transmitted light (sal12-v09).

recorded in the underlying Irati Formation (Oliveira, 2012) and to the salinity determined by Nomura et al. (2014) in horizontal calcite veins of the Teresina Formation (overlying). In the Irati Formation, aqueous paleofluids with salinities from 0 to $7.5 \mathrm{wt} \%$ of $\mathrm{NaCl}$ eq. are recorded in calcite veins (Oliveira, 2012) while Nomura et al. (2014) observed
Table 2

Total organic carbon (TOC), hydrogen $(\mathrm{H})$ and methane $\left(\mathrm{CH}_{4}\right)$ content statistics.

\begin{tabular}{lllll}
\hline & TOC $\%$ & H $\%$ & H/TOC & CH $_{4} \%$ \\
\hline Minimum & 0.00 & 0.00 & 0.00 & 4.41 \\
Maximum & 0.50 & 3.20 & 40.00 & 14.17 \\
Average & 0.16 & 1.03 & 8.68 & 7.17 \\
Median & 0.14 & 0.94 & 6.00 & 5.21 \\
Standard deviation & 0.10 & 0.61 & 8.53 & 3.67 \\
Number of samples & 29 & 29 & 29 & 11 \\
\hline
\end{tabular}
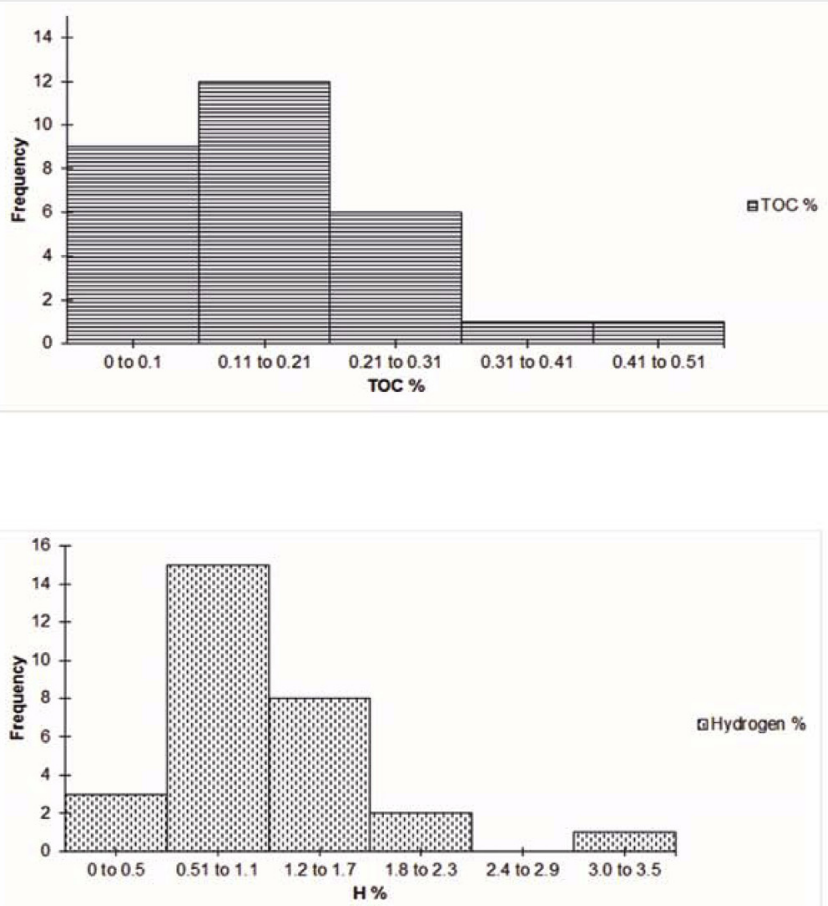

aHydrogen $\%$

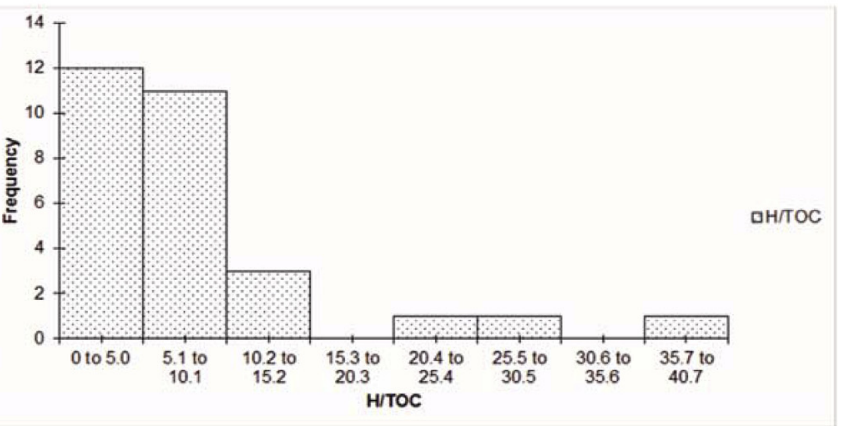

Fig. 6. Histograms of total organic carbon (TOC), hydrogen concentration and H/TOC ratios values. TOC and hydrogen concentration data are presented in weight percentage.

inclusions reaching salinities of about $26 \mathrm{wt} \%$ of $\mathrm{NaCl}$ eq. in calcite veins of the Teresina Formation. Nomura et al. (2014) also reveal low salinity values (1-4.5 wt \% of $\mathrm{NaCl}$ eq.) in pseudosecondary fluid inclusions hosted in vertical calcite veins in the Teresina Formation outcropping in the eastern border of the Paraná Basin. Thus, this scenario indicates pervasive movement of diagenetic fluids along faults and fractures of the Paraná Basin in the studied area. This circulation of aqueous fluids with variable salinities is concomitant with crystallization and recrystallization of diagenetic calcite within fractures and 
Table 3

$\delta^{13} \mathrm{C}$ and $\delta^{18} \mathrm{O}$ statistics from samples of the Serra Alta Formation.

$$
\text { Minimum Maximum Average } \begin{aligned}
& \text { Standard } \\
& \text { deviation }
\end{aligned} \quad \begin{aligned}
& \text { Number of } \\
& \text { samples }
\end{aligned}
$$

\begin{tabular}{|c|c|c|c|c|c|}
\hline \multicolumn{6}{|c|}{$\delta^{13} \mathrm{C}(\mathrm{PDB}) \%$} \\
\hline Bulk shale & -8.7 & -2.3 & -4.1 & +1.8 & 29 \\
\hline $\begin{array}{l}\text { Calcite from } \\
\text { fractures }\end{array}$ & -5.1 & -3.7 & -4.6 & +0.4 & 27 \\
\hline \multicolumn{6}{|c|}{$\delta^{18} \mathrm{O}(\mathrm{PDB}) \% 0$} \\
\hline Bulk shale & $-8,5$ & +1.4 & -4.3 & 2.2 & 29 \\
\hline $\begin{array}{l}\text { Calcite from } \\
\text { fractures }\end{array}$ & -6.2 & -4.5 & -5.5 & +0.4 & 27 \\
\hline
\end{tabular}

subsequent growth and healing of micro fractures during mineral growth. Moderately low salinity diagenetic fluids suggest contribution of meteoric waters circulating within fractures of the SAF shales without discarding the possibility of refilling and mixing with hydrothermal fluids associated to Cretaceous magmatism as shown by the reequilibration $\mathrm{Th}$ versus $\mathrm{Tm}$ ice diagram (Fig. 11).

Carbon and oxygen stable isotopes can shed light on the sources of calcite parent fluids. The $\delta^{13} \mathrm{C}$ values of carbonate rocks of marine origin from Cambrian to Tertiary age have relatively low range of variation and have values close to zero (range about -1 to $+3 \%$ PDB). On the other hand, freshwater carbonates, are usually more variable and more enriched in ${ }^{12} \mathrm{C}\left(\delta^{13} \mathrm{C}\right.$ values typically range between -15 and $-1 \%$ ) compared with marine carbonates (Keith and Weber, 1964).

Carbon and oxygen isotopes values for the calcite filled opening fractures (cluster 3) show low variation, with $\delta^{13} \mathrm{C}$ from 5.1 to $-3.7 \%$ o and $\delta^{18} \mathrm{O}$ from -6.2 to $-4.5 \%$, suggesting their formation by fluids from a single source (Fig. 7).

The $\delta^{13} \mathrm{C}$ composition of precipitated carbonates primarily indicates the sources of bicarbonate dissolved in water, which can include sea water $\left(\delta^{13} \mathrm{C}\right.$ near $0 \%$ ), soil weathering processes $\left(\delta^{13} \mathrm{C}\right.$ near $\left.-10 \%\right)$ or abiotic reactions associated with thermal cracking and decarboxylation of organic matter $\left(\delta^{13} \mathrm{C}\right.$ from -10 to $-25 \%$ ) (Campbell and Abigail, 1996). The light $\delta^{13} \mathrm{C}$ values of nearly all the studied calcite samples attest to the incorporation of organic carbon $\left({ }^{12} \mathrm{C}\right.$-enriched) during oxidation-diagenesis of the organic material in sediments (Fig. 7). These values may correspond to fluids derived from soil weathering or dissolution of marine sediments, and carbonate minerals that have been subsequently precipitated in shallow phreatic or vadose zones (Allen and Mathews, 1982; Moore, 1989). The SAF calcite filled fractures show moderately low values of $\delta^{13} \mathrm{C}$ (from -5.1 to $-3.7 \%$ ), which suggest precipitation in shallow phreatic zones. This agrees with fluid inclusion petrography that revealed entrapment in the low temperature phreatic zone ( $\leq 50^{\circ} \mathrm{C}$ ) (Fig. 9).

The $\delta^{18} \mathrm{O}$ of carbonate minerals precipitated from water depends chiefly on the $\delta^{18} \mathrm{O}$ composition and temperature of the water. Lighter $\delta^{18} \mathrm{O}$ values tend to be associated with decreasing salinity and with increasing fluid temperatures (Campbell and Abigail, 1996). The origin of SAF calcite filled opening fractures was probably related to meteoric water due to the relatively low salinity fluids as demonstrated in fluid inclusion analysis (Fig. 10). Meteoric water presents high variation of $\delta^{18} \mathrm{O}$ (between -40 and 10\%) if compared to marine water, which exhibits positive $\delta^{18} \mathrm{O}$ values ranging between 0 and $\pm 2 \%$ (Hoefs, 2004).

The $\delta^{13} \mathrm{C}_{\mathrm{PDB}}$ and $\delta^{18} \mathrm{O}_{\mathrm{PDB}}$ plot separates the carbonate extracted from bulk shale samples into two clusters (clusters 1 and 2), suggesting two different diagenetic fluids giving origin to distinct phases of carbonate precipitation or two heterogeneous cement types (Fig. 7). Cluster $1\left(\delta^{13} \mathrm{C}\right.$ from -2.3 to $-4.6 \%$ and $\delta^{18} \mathrm{O}$ from -7.6 to $-1.1 \%$ ) suggests $\mathrm{CO}_{2}$ contribution from a mixture of different mineral phases, which could include inorganic and organic components of the bulk samples (Fig. 8). A similar interpretation for cluster 2, where lighter $\delta^{13} \mathrm{C}_{\mathrm{PDB}}$ and $\delta^{18} \mathrm{O}_{\mathrm{PDB}}\left(\delta^{13} \mathrm{C}\right.$ from -6.2 to $-8.6 \%$ and $\delta^{18} \mathrm{O}$ from -8.4 to $-4.1 \%$ ) may result both from deep burial diagenesis or influx of abundant meteoric fluids into shallow-marine areas (Campbell and Abigail, 1996). In lacustrine or marine environments, oxidation due to biological degradation of organic matter results in the return of ${ }^{12} \mathrm{C}$ to the water column and lighter $\delta^{13} \mathrm{C}$ values in carbonates. Water recirculation and mixing, which carries ${ }^{13} \mathrm{C}$ to the surface, and diagenetic processes are responsible for $\delta^{13} \mathrm{C}$ fractionation where interstitial fluids tend to capture ${ }^{12} \mathrm{C}$, resulting in slightly negative $\delta^{13} \mathrm{C}$ values (Armstrong and Brasier, 2005). The light $\delta^{13} \mathrm{C}$ values in diagenetic calcite from the SAF shales suggest that carbon for carbonate precipitation was derived from a source with slightly depleted ${ }^{13} \mathrm{C}$, which seems to be partially related to microbial degradation of organic matter (Faure and Coule, 1999).

The high variation of Th from 60 to $200{ }^{\circ} \mathrm{C}$, but reaching $320^{\circ} \mathrm{C}$ in some cases, observed in fluid inclusions of the studied calcite could be due to thermal reequilibration (stretching) or leakage. Despite the low deformation of the diagenetic calcite, microthermometric data show narrower variation of Th from specific FIAs within calcite crystals hosted in the different sets of fractures. Pronounced dispersion in Th with small variations of Tm ice observed in the studied FIAs (Table 4) indicates the existence of inclusions reequilibrated by inelastic dilation

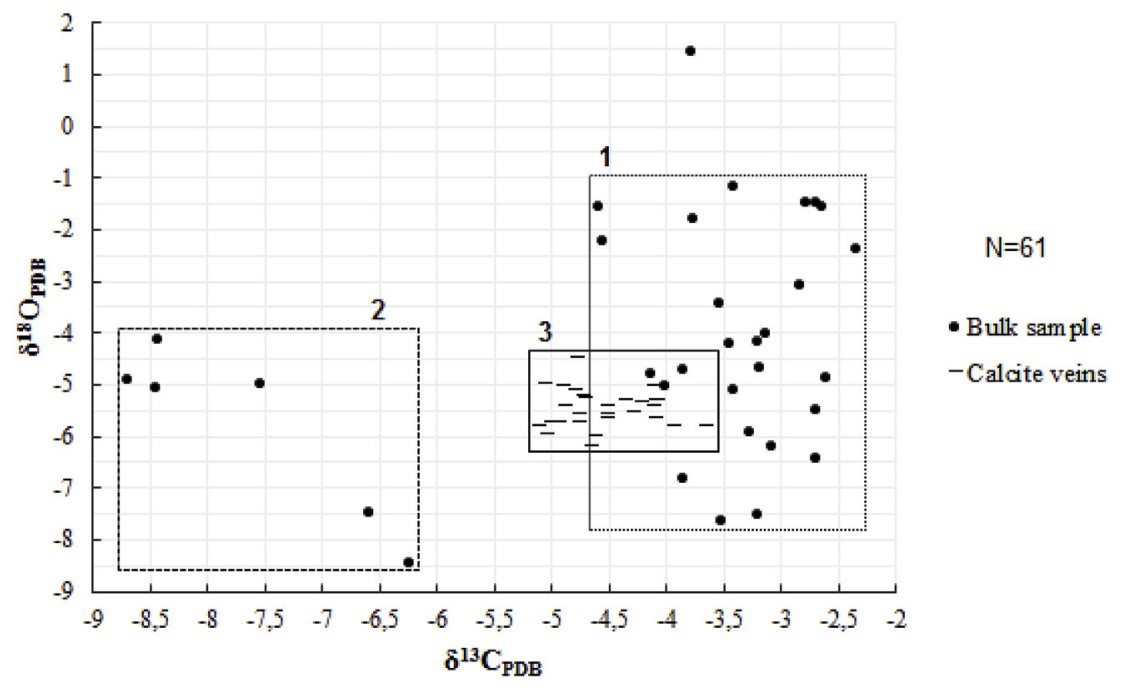

Fig. 7. Cross-plot of $\delta^{13} \mathrm{C}$ versus $\delta^{18} \mathrm{O}$ (PDB) for bulk shale samples and calcite from fractures of the Serra Alta Formation. 

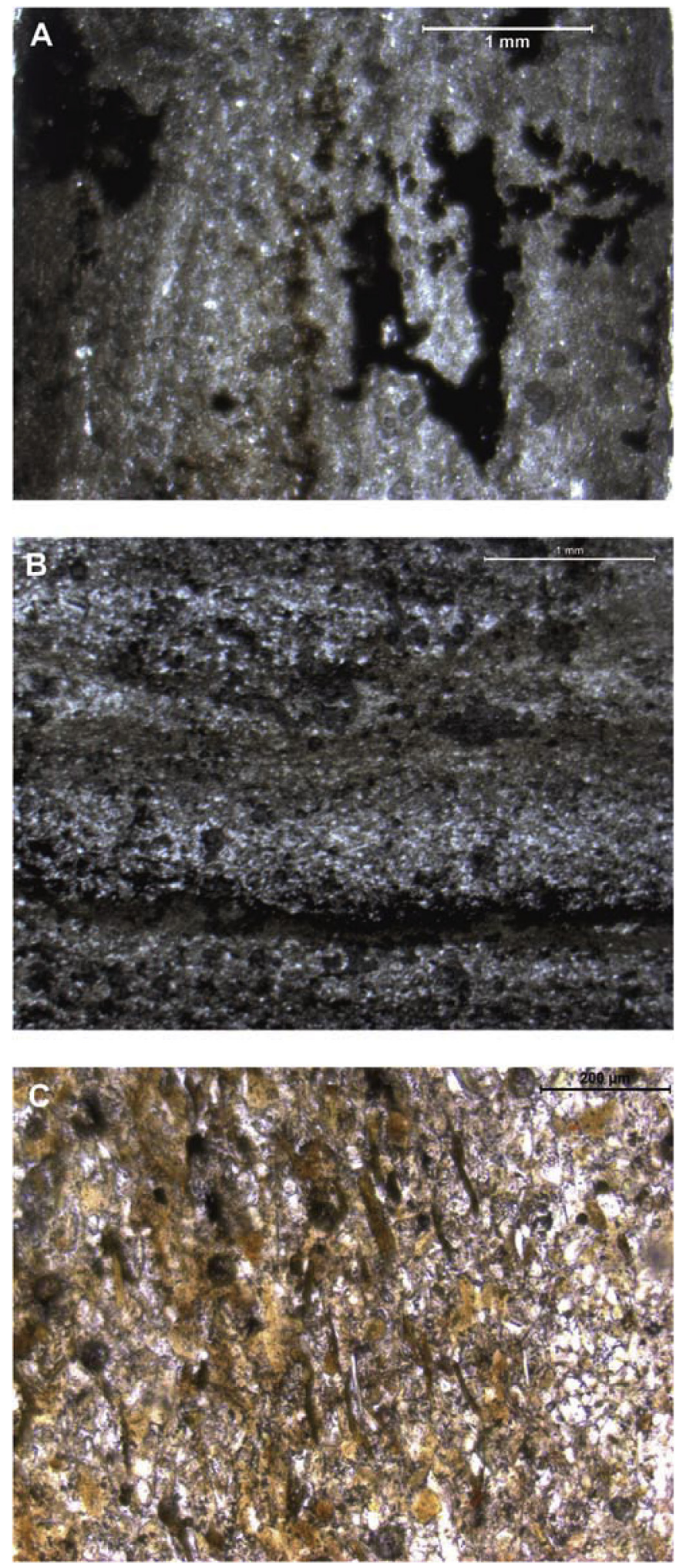

Fig. 8. (A) Opaque authigenic minerals in argilaceous siltite facies. (B) Laminated siltite. (C) Disseminated microsparry calcite cement and bioclasts in sandy siltite facies.

processes (stretching) originated by temperature increase during burial or emplacement of igneous bodies. Stretching reequilibration results in significant variations of Th for relatively constant fluids composition (Prezbindowski and Larese, 1987; Goldstein and Reynolds, 1994). The maximum $\mathrm{Th}$ is the minimum temperature of reequilibration by stretching (Prezbindowski and Larese, 1987). Significant number of fluid inclusions presented $\mathrm{Tm}$ ice from -3 to $0{ }^{\circ} \mathrm{C}$ and $\mathrm{Th}$ values up to $200{ }^{\circ} \mathrm{C}$ (Fig. 11), which could be considered as a minimum estimate for the heating temperature responsible for fluid inclusion reequilibration. The higher values of homogenization temperatures $\left(>250^{\circ} \mathrm{C}\right.$ ) could be associated to post-trapping modification (possibly leakage) which corresponds mostly to irregular inclusions with larger vapor phase volumes (Figs. 10 and 11). The variation in the vapor phase volume (2-13\%) and densities indicates different behavior of the inclusions during reequilibration (Fig. 10) (Goldstein and Reynolds, 1994). Also, the existence of one-phase inclusions associated with two-phase inclusions (Fig. 9) suggests fluid trapping in the low temperature phreatic zone $\left(\leq 50^{\circ} \mathrm{C}\right)$ before subsequent reequilibration (Goldstein and Reynolds, 1994).

\subsection{Diagenetic fluids in the tectonic context of the Paraná Basin}

Meteoric water in sedimentary basins is generally recharged at higher elevations along the margins of the basin and its presence or circulation can be influenced by tectonic events. The Araguainha crater impact that reached the northern portion of the Paraná Basin in Permian-Triassic transition (Tohver et al., 2013) and the Serra Geral volcanic event during the Early Cretaceous (Zalán et al., 1990; Araújo et al., 2000) would play an important role for the thermal evolution and tectonic deformation of the Paraná basin sediments. These two events influenced the development of hydrothermal systems (Nomura et al., 2014) and petroleum systems (Artur and Soares, 2002). These thermal activities positively influenced the petroleum system by providing thermal energy for organic matter maturation and diagenetic fluids circulation due to fractured reservoirs and the formations of trap structures. However, simultaneously, this activity caused the fracture of sealing rocks and trap structures which allowed the percolation of aqueous surface paleofluids into the basin and hydrocarbons secondary migration due to the trap structures loss (Artur and Soares, 2002).

In the Paraná Basin, the circulation and migration of paleofluids would be favored during periods of tectonic activity, with generation and reactivation of faults (Rostirolla et al., 2000; Riccomini et al., 2005; Strugale et al., 2007). The Paraná Basin tectonic framework is characterized by the presence of large structural lineaments, with NW-NE and E directions (Rostirolla et al., 2003; Milani et al., 2007a). The SAF corroborates the influence of those structures in the circulation of diagenetic fluids, besides being the route for surface water input, for presenting a network of two sets of connecting fractures with two preferential direction trends (Fig. 3). These conjugate sets of connecting fractures have important role for subsurface fluid flow and can be represent by a paleocleat system, since they are partially sealed by diagenetic calcite. Other parameters like fracture size, spacing and aperture (width) determine the fluid flow potential with the fracture system (Yarmohammadtooski et al., 2017). The diagenetic calcite fills opened fractures in syntaxial array of crystals. The crystal growth is from both sides of the fracture walls towards the center, but occasionally, some crystals can grow from one side towards the other (Fig. 5A and B). Syntaxial crystals can form from a single cracking event, which created the space for minerals to grow into (Bons et al., 2012). Space can also be generated by processes such as dissolution, which is common in eodiagenesis stage. In the studied region, aqueous fluids have percolated along fractures of the SAF where they were trapped as primary and pseudosecondary fluid inclusions during the crystallization of calcite (Fig. 8).

In this context, the Jacutinga NNE fault and subordinated structures associated to NNW direction, such as Guapiara fault, would be the regional structures capable to promote the pathways for the circulation and migration of diagenetic fluids in low permeability units like SAF, on the eastern edge of the Paraná Basin (Fig. 1). 
Table 4

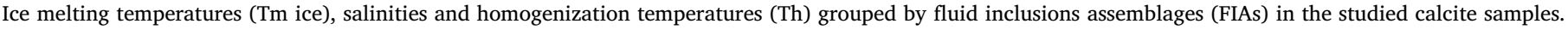
Positive Tm ice temperatures (*) indicate metastability.

\begin{tabular}{|c|c|c|c|c|c|}
\hline Sample & FIA & Number of fluid inclusion & Tm ice $\left({ }^{\circ} \mathrm{C}\right)$ & Salinity (wt \% of $\mathrm{NaCl}$ eq.) & Th $\left({ }^{\circ} \mathrm{C}\right)$ \\
\hline \multirow[t]{3}{*}{ pCB-v01 } & 1 & 16 & -1.6 to -2.9 & 4.9 to 0 & 175 to 261 \\
\hline & 2 & 6 & 0 to $0.3 *$ & $\sim 0$ & 147 to 222 \\
\hline & 3 & 8 & -2 to $4.5 *$ & 3.42 to 0.23 & 124 to 164 \\
\hline \multirow[t]{3}{*}{ pCB-v02 } & 1 & 12 & -2.6 to $3 *$ & 4.39 to 0.23 & 90 to 197 \\
\hline & 2 & 9 & -2.7 to $4.4 *$ & 3.10 to 0.23 & 91 to 167 \\
\hline & 3 & 4 & $\sim 0$ & $\sim 0$ & 138 to 149 \\
\hline \multirow[t]{8}{*}{ p08-v03 } & 1 & 11 & -1.7 to $4.9 *$ & 2.93 to 0.23 & 117 to 190 \\
\hline & 2 & 9 & -2.3 to -1.2 & 3.91 to 2.10 & 133 to 324 \\
\hline & 3 & 6 & -1.5 to $0.3 *$ & 2.60 to 0.57 & 111 to 179 \\
\hline & 4 & 18 & -1 to $0.6 *$ & 1.76 to 0.23 & 111 to 330 \\
\hline & 5 & 5 & 0.8 to $5.6 *$ & $\sim 0$ & 92 to 159 \\
\hline & 6 & 10 & -2.2 to -0.2 & 3.75 to 0.40 & 102 to 290 \\
\hline & 7 & 16 & -1.5 to $4.2 *$ & 2.60 to 0.23 & 116 to 199 \\
\hline & 8 & 18 & 2.7 to $5.1 *$ & 4.55 to 0.23 & 98 to 183 \\
\hline \multirow[t]{3}{*}{ p08-v04 } & 1 & 15 & -2.4 to $5.3 *$ & 4.07 to 0.23 & 88 to 179 \\
\hline & 2 & 14 & -1.6 to $3.5 *$ & 2.77 to 0.23 & 98 to 161 \\
\hline & 3 & 38 & -2.2 to $4.7 *$ & 3.75 to 0.23 & 90 to 186 \\
\hline \multirow[t]{8}{*}{ Sal 12-vc09 } & 1 & 21 & -1.7 to $1 *$ & 2.93 to 0.23 & 81 to 191 \\
\hline & 2 & 12 & -2.2 to -1.7 & 3.75 to 2.93 & 149 to 173 \\
\hline & 3 & 8 & -2.4 to -1.6 & 4.07 to 2.77 & 122 to 186 \\
\hline & 4 & 14 & -0.9 to $4.3 *$ & 1.59 to 0.23 & 67 to 200 \\
\hline & 5 & 13 & -2.4 to -0.7 & 4.07 to 1.26 & 61 to 170 \\
\hline & 6 & 20 & -1.9 to $2.1 *$ & 3.26 to 0.23 & 87 to 265 \\
\hline & 7 & 24 & -2.4 to $2.6 *$ & 4.07 to 0.23 & 79 to 180 \\
\hline & 8 & 21 & 2.5 to $3.9 *$ & $\sim 0$ & 73 to 115 \\
\hline
\end{tabular}

\subsection{Hydrocarbon generation and migration}

The shale samples of SAF have TOC between 0.04 and $0.5 \%$, indicating low potential for oil and gas generation (Peters and Cassa, 1994). However, these values may not be representative of the original organic carbon concentrations considering the relatively high paleotemperatures $\left(200^{\circ} \mathrm{C}\right)$ recorded for the SAF and possibility of carbon loss due to weathering since the studied samples were collected in outcrops. In the studied area, the volcanic rock cap, sills and dykes of the Serra Geral magmatism may be contributed to thermal alteration of organic matter within the SAF shales, reducing the organic carbon content. Nevertheless, organic-rich sediments are still preserved in the underlaying Irati Formation, even in intervals highly affected by the emplacement of magmatic bodies (Araújo et al., 2000; Souza et al., 2008). Despite hydrocarbons fluid inclusions were not observed in the calcite filled opening fractures of the SAF, Nomura et al. (2014) observed light oil inclusions in horizontal calcite veins of the overlying Teresina Formation. The absence of organic facies in the Teresina Formation points to the possible generation of hydrocarbons in the underlying Irati and Serra Alta formations, but in periods before the generation of the NW and NE trending fractures. Homogenization temperatures recorded in fluid inclusions of calcite filled fractures indicate that the SAF in the studied area reached temperatures $\left(>200{ }^{\circ} \mathrm{C}\right)$ suitable for generation of gaseous hydrocarbons. However, hydrocarbon biodegradation would be favored by the input of meteoric water since the Early Cretaceous, as indicated by low salinity fluid inclusions in calcite filling fractures, contributing to reduce organic carbon concentration in this unit (Jones et al., 2013).

The detection of methane in SAF shale pores indicates that hydrocarbon generation is a viable hypothesis. However, the methane detected in SAF has an uncertain origin, as it can be biogenic, the product of methanogenic metabolism, or thermogenic.
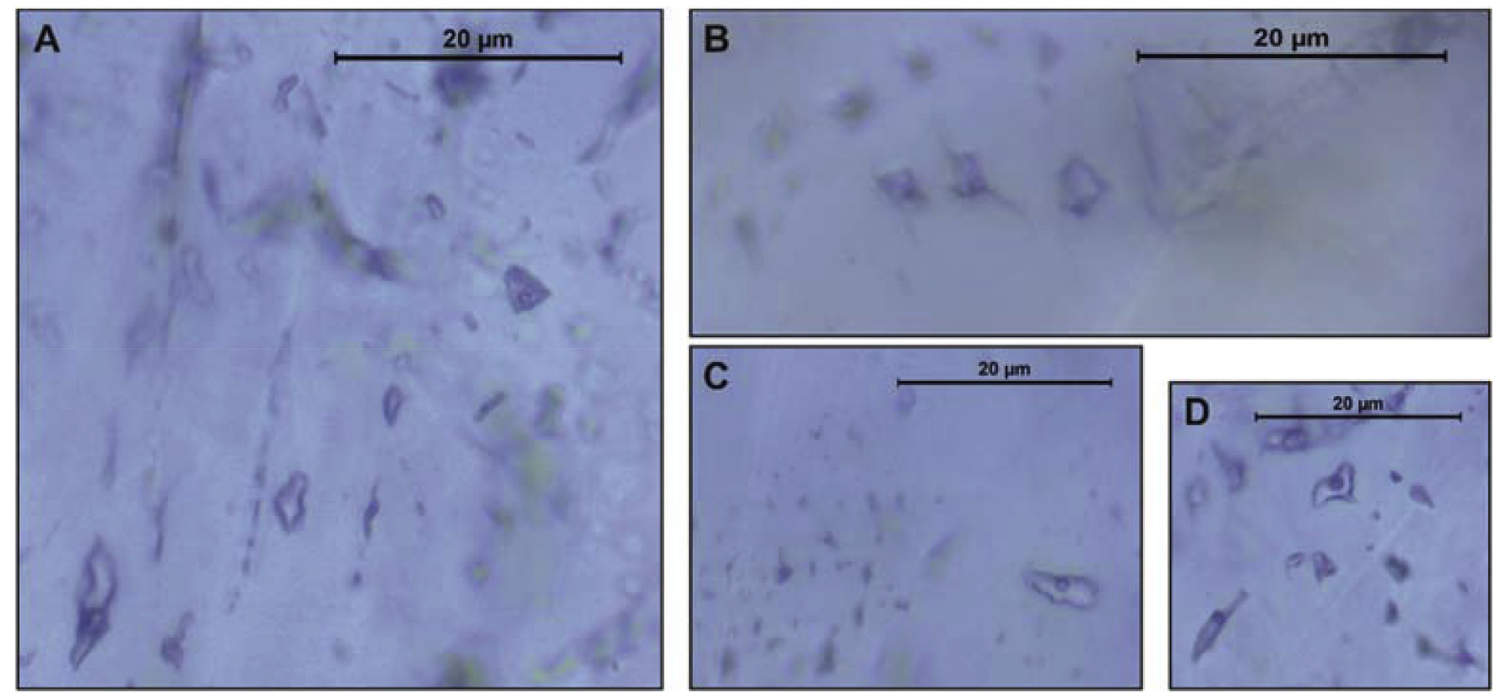

Fig. 9. (A) Aligned or randomly distributed fluid inclusions in calcite crystal. (B) Assemblage of two-phase primary fluid inclusions with negative crystal shape. (C, D) Assemblage of one-phase and two-phase inclusions with irregular shape and variable dimensions (sample Sal12-v09). 

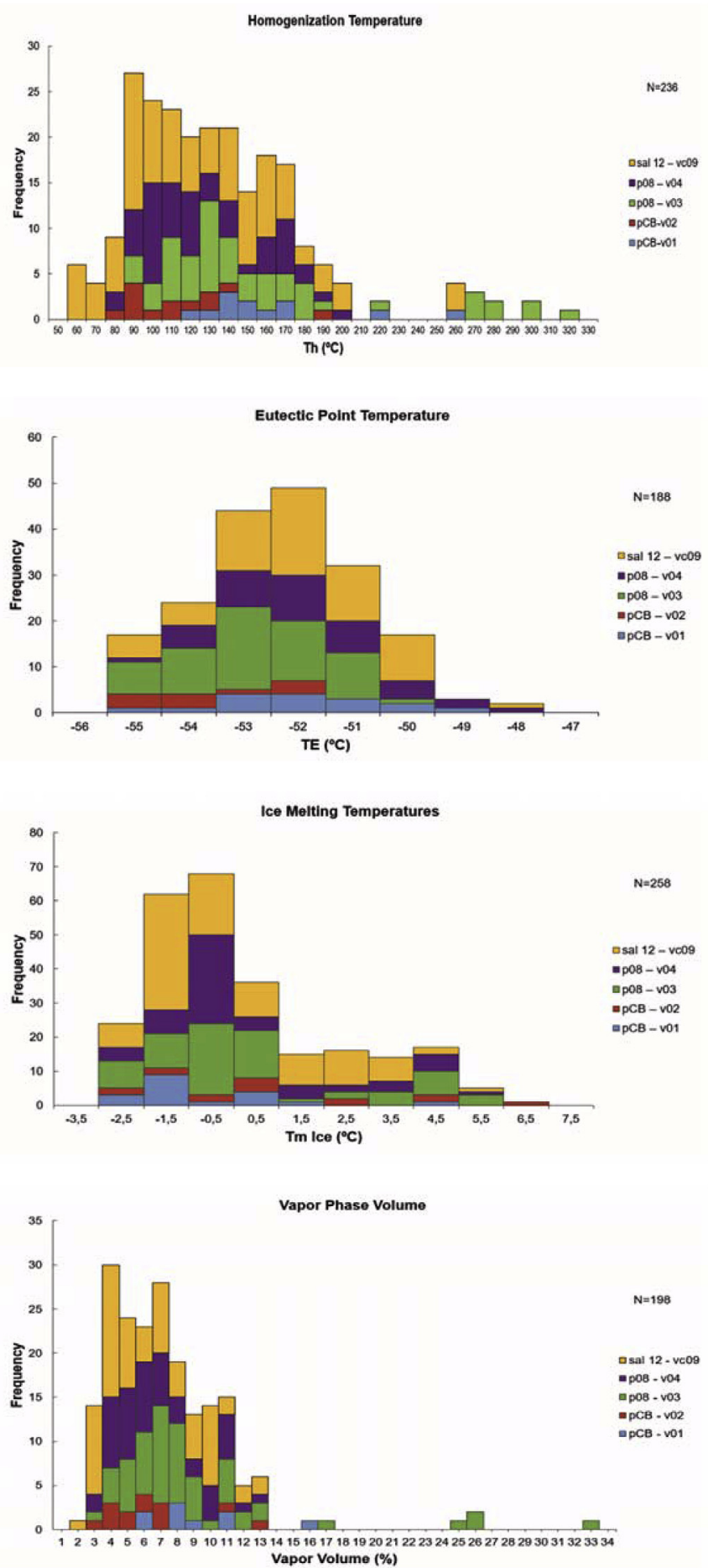

Fig. 10. Frequency distributions of homogenization temperatures (Th), eutectic point temperatures (TE), ice melting temperatures (Tm ice) and vapor volume phases. All temperatures measured in fluid inclusions from calcite veins of SAF in the studied area. As the behavior of the fluid inclusion assemblage (FIA) was similar they were not individualized on the diagrams.

Most homogenization temperatures (Th) of the aqueous fluid inclusions with similar composition hosted in the calcite filled opening fractures lie in a range between 60 and $200{ }^{\circ} \mathrm{C}$, suggesting inclusion reequilibration due to subsequent heating to fluid entrapment (stretching). This temperature would be compatible with the generation window of dry gas $\left(\mathrm{CH}_{4}\right)$. Milani et al. (2007a) suggest that the estimated maximum depth for the Permian units is about $1500 \mathrm{~m}$ in the eastern edge of Paraná Basin. At the Late Permian and Early Triassic, the area of Gondwana comprising the Paraná Basin had a maximum surface temperature of $50{ }^{\circ} \mathrm{C}$ (Sun et al., 2012). Thus, the highest Th recorded in the SAF could not be explained only by heating due to burial. When considering geothermal gradient of $24^{\circ} \mathrm{C} / \mathrm{km}$ for cratonic basins (Allen and Allen, 2005) and maximum depth of $1500 \mathrm{~m}$, it is expected trapping temperatures lower than $100^{\circ} \mathrm{C}$ for the eastern border of the Paraná Basin. Th obtained for SAF are similar to those obtained by the overlying Teresina Formation (Nomura et al., 2014). Thus, the heating caused by the Serra Geral magmatism would have affected in a relatively similar way the Permian sequence in the eastern edge of the Paraná Basin. Some authors (Milani et al., 1994; Araújo et al., 2000; Thomaz Filho et al., 2008) propose that the thermal maturity of the Irati shales would be controlled by the presence of intrusive igneous bodies (sills and dykes) associated with the Serra Geral magmatism. Notwithstanding, the relatively similar temperatures obtained by microthermometry in Permian units suggest regional pervasive heating and not only heating linked to occasional presence of sills and dykes.

The entrapment of low salinity fluids in calcite filled fractures occurred in low temperature phreatic zone (around $50{ }^{\circ} \mathrm{C}$ ) as pointed out by fluid inclusions results (Figs. 9 and 10), just before the thermal peak during Early Cretaceous. This would explain the absence of hydrocarbon primary fluid inclusions in these calcite crystals. Furthermore, the dominant NE fractures and subordinated NW structures could have been reactivated during the Permian-Triassic seismic events occurred in the Paraná Basin. These events are possibly related to the far-field propagation of the compressional stresses of N-S direction originated in the southern border of Gondwana during the Late Paleozoic, recorded in the Cape Belt of South Africa and Sierra Las Ventanas in Argentina (Riccomini et al., 2005; Turra et al., 2006).

Considering the fluid inclusion microthermometry results (Fig. 10), we can infer that the SAF achieved high thermal maturity under temperature above $200{ }^{\circ} \mathrm{C}$ as well as reached the gas generation window, after the crystallization of calcite filled opening fractures.

\section{Conclusions}

The SAF in the eastern border of the Paraná Basin was percolated along fractures by aqueous fluids which were trapped as primary and pseudosecondary fluid inclusions during the formation of calcite filled opening fractures. This study characterized the composition and temperature of paleofluids that migrated through fractures of paleocleat system.

The $\delta^{18} \mathrm{O}_{\mathrm{PDB}}$ values for the calcite from fractures show low variation in isotopic composition, suggesting a single fluid source dominated by meteoric waters. This agrees with the fluid inclusions hosted in the studied authigenic calcite, which also shows low salinity aqueous fluids characteristics of meteoric waters. The composition of the aqueous paleofluids indicates an $\mathrm{H}_{2} \mathrm{O}+\mathrm{NaCl}+\mathrm{CaCl}_{2}$ system with $\mathrm{MgCl}_{2}$ in solution. The NE and NW hosting fractures could have been reactivated as a result of the development of fold belts in southern Gondwana during the Permian-Triassic or associated to the Araguainha crater impact, although, the calcite that fills the studied fractures system shows low deformation in low temperature condition as demonstrated by crystals textures and fluid inclusions data.

The $\delta^{13} \mathrm{C}_{\mathrm{PDB}}$ values for calcite from the matrix of shale bulk samples suggest $\mathrm{CO}_{2}$ contribution from mixture of different sources. This could include primary carbonates and organic matter within sediments that had been altered by near surface meteoric or deep burial diagenesis. Carbonate cements within sedimentary facies suggest pervasive percolation of diagenetic fluids. The $\delta^{13} \mathrm{C}$ values of diagenetic calcite in the SAF shales point out that carbon for carbonate precipitation was derived from a source with slightly depleted ${ }^{13} \mathrm{C}$, which seems to be partially related to microbial degradation of organic matter. Fluid inclusions and carbon and oxygen stable isotopes in the authigenic 


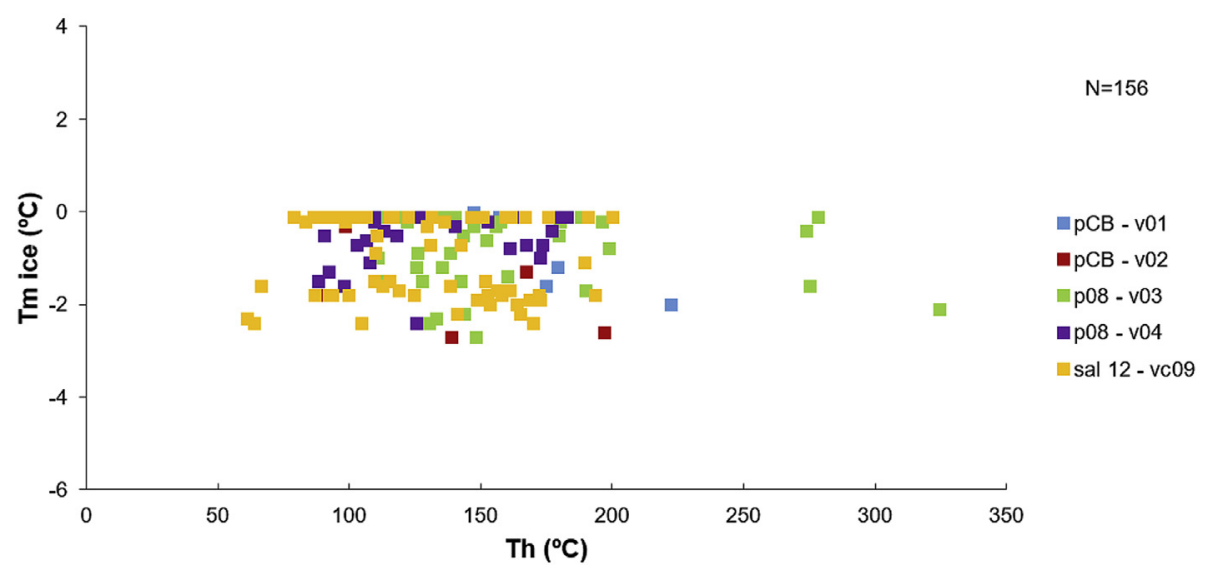

Fig. 11. Homogenization temperatures (Th) in relation to ice melting temperatures (Tm ice) measured in fluid inclusions from calcite in fractures of the SAF. Metastable inclusions were not considered due to inaccuracy of obtained values.

carbonates reveal two cementation phases possibly related to burial pore fluids and circulation of meteoric fluids.

Paleotemperatures recorded by aqueous fluid inclusions hosted in the calcite filled opening fractures were higher than $200{ }^{\circ} \mathrm{C}$, indicating high thermal maturity for SAF shales despite the studied outcrops are out of the direct effect of igneous sills and dykes. These higher temperatures were achieved during Early Cretaceous due to the Serra Geral magmatism and after calcite precipitation within fractures as indicated by fluid inclusion reequilibration phenomena (stretching). Similar temperatures achieved in the adjacent Teresina Formation reinforce the regional heating hypothesis and not only the local heating due to presence of intrusive igneous bodies of the Serra Geral magmatism. Thus, the recorded paleotemperatures suggest that the thermal effect of the volcanic rock cap would surpass the effect of intrusive igneous bodies. The Serra Geral magmatism may have contributed to thermal alteration of organic matter within the SAF shales and reduction of organic carbon content. Significant concentration of methane was detected in pores of the SAF shales, but the origin of the methane (biogenic or thermogenic) is still unknown.

\section{Acknowledgements}

CAST was supported by Conselho Nacional de Desenvolvimento Científico e Tecnológico and Programa de Formação de Recursos Humanos em Geologia do Petróleo e Meio Ambiente (PFRH-241Petrobras). AOS is supported by CNPq (grant 3009223/2014-8). This project was funded by Fundação de Amparo à Pesquisa do Estado de São Paulo (FAPESP grant 09/52270-6) and CNPq (grant 454362/2014$5)$.

\section{References}

Allen, P.A., Allen, J.R., 2005. Basin Analysis. Principles and Applications. Blackwell, Oxford.

Allen, J.R., Mathews, R.K., 1982. Isotopes signatures associated with early meteoric diagenesis. Sedimentology 29, 797-817.

Araújo, L.M., Trigüis, J.A., Cerqueira, J.R., Freitas, L.C.S., 2000. The atypical Permian petroleum system of the Paraná Basin, Brazil. In: In: Mello, M.R., Katz, B.J. (Eds.), Petroleum Systems of South Atlantic Margins, vol. 73. AAPG Memoir, pp. 377-402.

Araújo, C.C., Yamamoto, J.K., Rostirolla, S.P., Madrucci, V., Tankard, A., 2005. Tar sandstones in the Paraná Basin of Brazil: structural and magmatic controls of hydrocarbon charge. Mar. Petrol. Geol. 22, 671-685.

Armstrong, H.A., Brasier, M.D., 2005. Microfossil, Stable Isotopes and Ocean-atmosphere History. Microfossils, second ed. Blackwell Publishing, Malden, USA, pp. 25-34.

Archer, 1992. D.G. ArcherThermodynamic properties of the $\mathrm{NaCl}+\mathrm{H}_{2} \mathrm{O}$ system: II. Thermodynamic properties of $\mathrm{NaCl}(\mathrm{aq}), \mathrm{NaCl} \cdot 2 \mathrm{H}_{2} \mathrm{O}(\mathrm{cr})$, and phase equilibria. J. Phys. Chem. 28, 1-17 Ref. Data.

Artur, P.C., Soares, P.C., 2002. Paleoestruturas e petróleo na Bacia do Paraná. Brasil. Revista Brasileira de Geociências 32, 433-448.

Bakker, R.J., 2003. Package fluids 1. Computer programs for analysis of fluid inclusion data and for modeling bulk fluid properties. Chem. Geol. 194, 3-23.

Birgel, D., Meister, P., Lundberg, R., Horath, T.D., Bontognali, T.R.R., Bahniuk, A.M., de Rezende, C.E., Vasconcelos, C., Mckenzie, J.A., 2015. Methanogenesis Produces Strong 13C Enrichment in Stromatolites of Lagoa Salgada, vol. 13. A modern analogue for Palaeo-/Neoproterozoic stromatolites. Geobiology, Brazil, pp. 245-266.

Bons, P.D., Elburg, M.A., Rivas, A.G., 2012. A review of the formation of tectonic veins and their microstructures. J. Struct. Geol. 43, 33-62.

Brown, R., Gallagher, K., Duane, M., 1998. Quantitative assessments of the effect of magmatismo on termal history of the Karoo sedimentary sequence. J. Afr. Earth Sci. $18,227-243$.

Burkhard, M., 1993. Calcite twins, their geometry, appearance and significance as stressstrain markers and indicators of tectonic regime: a review. J. Struct. Geol. 15, $351-368$.

Calça, C.P., 2016. Abordagem micropaleontológica e geoquímica da Formação Assistência (Subgrupo Irati, Permiano, Bacia do Paraná, Brasil). Tese de Doutorado. Instituto de Geociências, Universidade de São Paulo, São Paulo, pp. 180.

Campbell, S.N., Abigail, M.S., 1996. Stable oxygen and carbon isotope compositional fields for skeletal and diagenetic components in New Zealand Cenozoic nontropical carbonate sediments and limestones: a synthesis and review. New Zealand. J. Geol. Geophys. 39, 93-107.

Chalmers, G.R.L., Ross, D.J.K., Bustin, R.M., 2012. Geological controls on matrix permeability of Devonian gas shales in the Horn River and Liard basins, northeastern British Columbia. Canada. Int. J. Coal Geol. 103, 120-131.

Crawford, M.L., Hollister, L.S., 1992. Fluid-rock interactions during metamorphism. In: In: Walther, J.V., Wood, B.J. (Eds.), Advances in Physical Chemistry, vol. 4. pp. 1-35.

EIA/ARI, 2013. EIA/ARI World Shale Gas and Shale Oil Assessment.

Faure, K., Coule, D., 1999. Geochemical evidence for lacustrine microbial blooms in the vast Permian Main Karoo, Paraná, Falkland Islands and Huab basins of southwestern Gondwana. Palaeogeogr. Palaeoclimatol. Palaeoecol. 152, 189-213.

Fonseca, A.L.D.S., Minello, M., Marinho, C.C., Esteves, F.D.A., 2004. Methane concentration in water column and in pore water of a coastal lagoon (Cabiúnas lagoon, Macaé, RJ, Brazil). Braz. Arch. Biol. Technol. 47, 301-308.

Goldstein, R.H., Reynolds, T.J., 1994. Systematics of fluid inclusions in diagenetic minerals. In: Society for Sedimentary Geology, Short Course, 31. Society of Sedimentary Geology (SEPM), Tulsa, pp. 199.

Hoefs, J., 2004. Stable Isotope in Geochemistry, fifth ed. Springer-Verlag, Berlin, pp. 244.

Holz, M., França, A.B., Souza, P.A., Iannuzi, R., Rohn, R., 2010. A stratigraphic chart of the Late Carboniferous/Permian succession of the eastern border of the Paraná Basin, Brazil, South America. J. S. Am. Earth Sci. 29, 381-399.

Huang, J.L., Zou, C.N., Li, J.Z., Dong, D.Z., Wang, S.L., Wang, S.Q., Cheng, K.M., 2012. Shale gas generation and potential of the lower Cambrian Qiongzhusi formation in the southern Sichuan Basin, China. Petrol. Explor. Dev. 39, 75-81.

Jones, E.J.P., Harris, S.H., Barnhart, E.P., Orem, W.H., Clark, A.C., Corum, M.D., Kirshteins, J.D., Varonka, M.S., Voytek, M.A., 2013. The effect of coal bed dewatering and partial oxidation on biogenic methane potential. Int. J. Coal Geol. 115, 54-63.

Keith, M.L., Weber, J.N., 1964. Isotopic composition and environmental classification of selected limestones and fossils. Geochem. Cosmochim. Acta 28, 1787-1816.

Kontorovich, A.E., Khomenko, A.V., Burshtein, L.M., Likhanov, I.I., Pavlov, A.L., Staroseltsev, V.S., Ten, A.A., 1997. Intense basic magmatism in the Tunguska petroleum basin, eastern Siberia, Russia. Petrol. Geosci. 3, 359-369.

Mastalerz, M., Drobniak, A., Schimmelmann, A., 2009. Changes in optical properties, chemistry, and micropore and mesopore characteristics of bituminous coal at the contact with dikes in the Illinois Basin. Int. J. Coal Geol. 77, 310-319.

Meglhioratti, T., Rohn, R., Lourenço, A.T.A., 2005. Estratigrafia do grupo Passa Dois na região de Sapopema-Congoinhas/PR (Permiano, Bacia do Paraná). Simpósio de Geologia do Sudeste (Abstracts). .

Milani, E.J., França, A.B., Schneider, R., 1994. Bacia do Paraná. Boletim de Geociências Petrobrás. Rio Janeiro 8, 69-82.

Milani, E.J., França, A.B., Medeiros, R.A., 2007a. Rochas Geradoras e rochas reservatório da bacia do Paraná, faixa oriental de afloramentos, Estado de Paraná. In: Bacia do 
Paraná. Boletim de Geociências Petrobrás 15. pp. 135-162.

Milani, E.J., Melo, J.H.G., Souza, P.A., Fernandes, L.A., França, A.B., 2007b. Bacias sedimentares brasileiras: cartas estratigráficas. Bol. Geociencias Petrobras 15, 265-287.

Moore, C.H., 1989. Carbonate Diagenesis and Porosity. Elsevier, Amsterdam.

Monreal, F.R., Villar, H.J., Baudino, R., Delpino, D., Zencich, S., 2009. Modeling an atypical petroleum system: a case study of hydrocarbon generation, migration and accumulation related to igneous intrusions in the Neuquen Basin, Argentina. Mar. Petrol. Geol. 26, 590-605.

Nomura, S.F., Sawakuchi, A.O., Bello, R.M.S., Méndez-Duque, J., Fuzikawa, K., Giannini, P.C.F., Dantas, M.S.S., 2014. Paleotemperatures and paleofluids recorded in fluid inclusions from calcite veins from northern flank of the Ponta Grossa dyke swarm: implications for hydrocarbon generation and migration in the Paraná Basin. Mar. Petrol. Geol. 52, 107-124.

Oliveira, A.F., 2012. Paleotemperaturas e paleofluidos da Formação Irati na borda leste da Bacia do Paraná: Implicações para a geração e migração de hidrocarbonetos. Tese de Mestrado. Instituto de Geociências, Universidade de São Paulo, pp. 115.

Peters, K.E., Cassa, M.R., 1994. Applied Source rock geochemistry. AAPG Memoir 60, 93-120.

Prezbindowski, D.R., Larese, R.E., 1987. Experimental streching of fluid inclusions in calcite e implications for diagenetic studies. Geology 15, 333-336.

Riccomini, C., Almeida, R.P., Turra, B.B., Chamani, M.A.C., Fairchild, T.R., Hachiro, J., 2005. Reativação de falha do embasamento causa sismicidade no permotriássico da Bacia do Paraná. In: $12^{\circ}$ Simpósio Nacional de Estudos Tectônicos - IV International Symposium on Tectonics. Boletim de Resumos Expandidos, Curitiba, pp. 18-20.

Roedder, E., 1984. Fluid inclusions. In: In: Ribbe, P.H. (Ed.), Reviews in Mineralogy, vol. 12. Mineralogical Society of America, pp. 646.

Rostirolla, S.P., Assine, M.L., Fernandes, L.A., Artur, P.C., 2000. Reativação de paleolineamentos durante a evolução da bacia do Paraná - o exemplo do Alto Estrutural de Quatiguá. Rev. Bras. Geociencias 30, 639-648.

Rostirolla, S.P., Mancini, F., Rigoti, A., Kraft, R.P., 2003. Structural styles of intracratonic reativation of the perimbó fault zone, Paraná basin, Brazil. J. S. Am. Earth Sci. 16, 287-300.

Salmachi, A., Rajabi, M., Reynolds, P., Yarmohammadtooski, Z., Wainman, C., 2016. The effect of magmatic intrusions on coalbed methane reservoir characteristics: a case study from the Hoskissons coalbed, Gunnedah Basin, Australia. Int. J. Coal Geol. 165, 278-289.

Sant'Anna, L.G., Clauer, N., Cordani, U.G., Riccomini, C., Velázquez, V.F., Liewig, N., 2006. Origin and migration timing of hydrothermal fluids in sedimentary rocks of the Paraná Basin, South America. Chem. Geol. 230, 1-21.

Selley, R.C., 2012. UK shale gas: the story so far. Mar. Petrol. Geol. 31, 9-100.

Shepherd, T.J., Rankin, A.H., Alderton, D.H., 1985. A Practical Guide to Fluid Inclusions Studies. Blackie and Son Ltd, New York, pp. 239.

Smithard, T., Bordy, E.M., Reid, D., 2015. The effect of dolerite intrusions on the hydrocarbon potential of the lower permian WhiteHill Formation (Karoo Supergroup) in South Africa and Southern Namíbia: a preliminary study. S. Afr. J. Geol. 118, 489-510.
Souza, I.V.A.F., Mendonça Filho, J.G., Menezes, T.R., 2008. Avaliação do efeito térmico das intrusivas ígneas em um horizonte potencialmente gerador da Bacia do Paraná: formação Irati. Rev. Bras. Geociencias 38, 138-148.

Stewart, A.K., Massey, M., Padgett, P.L., Rimmer, S.M., Hower, J.C., 2005. Influence of a basic intrusion on the vitrinite reflectance and chemistry of the Springfield (No. 5) coal, Harrisburg, Illinois. Int. J. Coal Geol. 63, 58-67.

Strugale, M., Rostirolla, S.P., Mancini, F., Portela Filho, C.V., Ferreira, F.J.F., Freitas, R.C., 2007. Structural framework and mesozoic-cenozoic evolution of ponta grossa arch, Paraná basin, southern Brazil. J. S. Am. Earth Sci. 24, 203-227.

Sun, Y., Joachimski, M.M., Wignall, P.B., 2012. Lethally hot temperatures during the early Triassic greenhouse. Science 338, 366-370.

Swann, G., Munns, J., 2003. The Hydrocarbon Prospectivity of Britain's Onshore Basins. Department of Energy and Climate Change, London, pp. 78.

Thiede, D.S., Vasconcelos, P.M., 2010. Paraná flood basalts: rapid extrusion hypothesis confirmed by new ${ }^{40} \mathrm{Ar} /{ }^{39} \mathrm{Ar}$ results. Geology 38, 747-750.

Thomaz-Filho, A., Mizusaki, A.M.P., Antonioli, L., 2008. Magmatism and petroleum exploration in the Brazilian paleozoic basins. Mar. Petrol. Geol. 25, 143-151.

Tohver, E., Lana, C., Cawood, P.A., Fletcher, I.R., Jourdan, F., Sherlock, S., Rasmussen, R., Trindade, R.I.F., Yokoyama, E., Souza Filho, C.R., Marangoni, Y., 2013. Geochronological constraints on the age of Permo-Triassic impact event: U-Pb and ${ }^{40} \mathrm{Ar} /{ }^{39} \mathrm{Ar}$ results for the $40 \mathrm{~km}$ Araguainha structure of central Brazil. Geochem. Cosmochim. Acta 86, 214-227.

Turra, B.B., Riccomini, C., Almeida, R.P., 2006. Significado tectônico dos sismitos permotriássicos da Bacia do Paraná. In: Congresso Brasileiro de Geologia, vol. 43 Aracaju, Anais, 111pp.

USGS (U.S. Geological Survey), 2013. National Oil and Gas Assessment, March, Shale Gas Assessment.

Warren, L.V., Assine, M.L., Simões, M.G., Riccomini, C., Anelli, L.E., 2015. The Serra Alta formation, permian, in the central-eastern portion of São Paulo State, Paraná basin Brazil. Braz. J. Genet. 45, 109-126.

Yarmohammadtooski, Z., Salmachi, A., White, A., Rajabi, M., 2017. Fluid flow characteristics of Bandanna coal formation: a case study from the fairview field, Eastern Australia. Aust. J. Earth Sci. http://dx.doi.org/10.1080/08120099.2017.1292316.

Zalán, P.V., Wolff, S., Astolfi, M.A.M., Vieira, I.S., Conceição, J.C.J., Appi, V.T., Neto, E.V.S., Cerqueira, J.R., Marques, A., 1990. The Paraná basin, Brazil. In: In: Leighton, M.W., Kolata, D.R., Olts, D.F., Eidel, J.J. (Eds.), Interior Cratonic Basins, vol. 51. pp. 681-708.

Zhang, Y.G., Frantz, J.D., 1987. Determination of the homogenization temperatures and densities of supercritical fluids in the system $\mathrm{NaCl}-\mathrm{KCl}-\mathrm{CaCl}_{2}-\mathrm{H}_{2} \mathrm{O}$ using synthetic fluid inclusions. Chem. Geol. 64, 335-350.

Xin-gang, Zhao, Ya-hui, Yang, 2015. The current situation of shale gas in Sichuan, China. Renew. Sustain. Energy Rev. 50, 653-664.

Zhu, C., Xu, M., Yuan, Y., Zhao, Y., Shan, J., He, Z., Tian, Y., Hu, S., 2010. Palaeogeothermal response and record of the effusing of Emeishan basalts in the Sichuan basin. Chin. Sci. Bull. 55 (10), 949-956. 


\section{ANEXO II}

Manuscrito 1. "Hydrocarbons generation in the Permian Irati organic-rich shales under the influence of the Early Cretaceous Paraná Large Igneous Province"

Submetido

Março 2019 


\title{
Hydrocarbons generation in the Permian Irati organic-rich shales under the influence of the Early Cretaceous Paraná Large Igneous Province
}

\author{
C.A.S. Teixeira a, R.M.S. Bello a, N.S. Almeida a , A. Pestilho ${ }^{b}$, S. Brochsztain $^{c}$, \\ T. Branquinho d, L.S. Andrade d, D.F. Gregório Júnior d, A.O. Sawakuchi a . \\ a Institute of Geosciences, University of São Paulo, Rua do Lago, 562, São Paulo, SP 05508-080, \\ Brazil.
}

b Petrobras R\&D Center (CENPES), Av. Horácio Macedo, 950, Cidade Universitária, Rio de Janeiro, RJ, Brazil

c Federal University of $A B C$, Centro de Engenharia, Modelagem e Ciências Sociais Aplicadas, Av. dos Estados 5001, Santo André, SP 09210-580, Brazil.

d Federal University of ABC, Centro de Ciências Naturais e Humanas, Av. dos Estados 5001, Santo André, SP 09210-580, Brazil.

\section{ABSTRACT}

Due to the global interest and demand on natural gas and byproducts organicrich shales stand up as one of the most important future liquid or gas hydrocarbon unconventional play types. Our understanding of unconventional reservoirs, such as oil shale, is still evolving, especially in petroleum systems with hydrocarbons generation processes influenced by magmatism and considered atypical such as the Permian Irati Formation shales in the Paraná Basin, which hosts the Paraná Large Igneous Province (LIP). In this study, we analyzed fluid inclusions in authigenic calcite and quartz veins and organic components of shale samples to constrain the composition and thermal generation conditions of hydrocarbons and aqueous diagenetic fluids within the Irati Formation.

Samples of organic-rich shales from the southern part of the basin were analyzed by vitrinite reflectance (\% Ro) and solid-state carbon nuclear magnetic resonance with cross polarization at magic angle spinning $\left({ }^{13} \mathrm{C}\right.$ CP-MAS NMR) of the isolated 
kerogen extracts, in order to provide maturity assessments. The low aromaticity of the kerogen $\left(f_{\mathrm{ar}} \approx 30 \%\right)$ and the vitrinite reflectance results (\% Ro $\approx 0.6$ ) suggest a less mature organic-rich shale in this area. This data is in contrast with the temperatures achieved by fluid inclusions analysis (vary from 50 to $330{ }^{\circ} \mathrm{C}$ ) in authigenic veins cutting this unit at the northeastern part of the basin.

In the northeastern part of the Paraná Basin, the large intruded sill within the Irati Formation, with over $100 \mathrm{~m}$ thickness, might be responsible for the local thermal heat, generation and pervasive circulation of a meteoric/marine fluid flow concomitant with the migration of hydrocarbons (liquid hydrocarbons), trapped as fluid inclusions within the veins. Magmatism can influence the generation of hydrocarbons around intrusive igneous bodies in sedimentary rocks and along the pathways of diagenetic fluids migration in fault and fracture systems. The aqueous fluid has salinity varying mainly between $0-5 \%$ wt. of $\mathrm{NaCl}$ equivalent and reached temperatures above $250^{\circ} \mathrm{C}$ in the studied veins. The hydrocarbons trapped as fluid inclusions were classified as black oil through their vapor fraction volumes $\left(F_{v}\right)$ acquired through confocal scanner laser microscope (CSLM) and homogenization temperatures (Th) through micro-thermometry analysis. The PVT model estimated for this part of the basin suggests an active shallow hydrocarbon petroleum system $(\approx 2 \mathrm{~km}$ deep) during the development of the veins in the Early Cretaceous, which could have facilitated biodegradation processes. No gas-rich $\left(\mathrm{CH}_{4}\right)$ or carbonic-rich $\left(\mathrm{CO}_{2}\right)$ fluid inclusions were observed within the authigenic veins, which possibly means that a low volatile generation flux or a low degassing of the organic-rich shales of the Irati Formation.

Keywords: Paraná Basin; LIP Paraná; Aqueous fluid inclusions; Hydrocarbon fluid inclusions; Calcite and quartz veins; Stable isotopes; Vitrinite reflectance; Kerogen aromaticity

\section{INTRODUCTION}

The most of the documented occurrences of hydrocarbons and/or reconstructions of fluid dynamics in petroleum systems through the use of analytical methods (destructive and non-destructive) are described from 
reservoirs due to the increase of exploration activity (Munz, 2001). However, this study focus to provide new insights of an unconventional petroleum system (the organic-rich shales of the Irati Formation) with subaerial exposure that has been affected by an intense magmatism in the Early Cretaceous. Organic-rich shales are envisaged as one of the most important future liquid or gas hydrocarbon unconventional reservoirs (Montgomery et al., 2005; Ross and Bustin, 2008, 2009). Due to the increasing demand on hydrocarbons including natural gas and byproducts, besides the widespread worldwide distribution of shale deposits, oil shale (shale oil) and shale gas systems (shale gas) have become one of the major focus of the global energy industry as a target for hydrocarbon production (USGS, 2013; EIA/ARI, 2013). In this context, the oil shale of the Permian Irati Formation represents the greatest economic potential for scientific researches and industrial advancements because of its quality and extensive distribution over the Paraná Basin (Dyni, 2003). The Irati Formation is a Permian unit composed of very fine grained and laminated black shales, siltstone, dolomites and limestones (Milani et al., 2007a).

Some unconventional petroleum systems including shale gas systems, are product of the effect of igneous bodies on organic-rich shales (Othman et al., 2001; Baudino et al., 2004; Parnell, 2004; Monreal et al., 2009), which the hydrocarbons generation and migration processes associated to igneous intrusions are not well perceived. Due to the low natural occurrence of hydrocarbons generated by the effect of intrusive igneous bodies and also by the combined effects of magmatism and burial in unconventional petroleum systems, it is difficult to discriminate the thermal process involved (Monreal et al., 2009). In addition, large igneous provinces (LIP's) stand out because they can thermally affect thick sedimentary successions such as organic, carbonate and salt-rich sedimentary rocks (Heimdal, 2018). The South American Paraná Basin (Milani et al., 2007a) hosts one of the world's largest LIP's, the Early Cretaceous Paraná LIP (Santos et al., 2009). The Paraná LIP event is represented by a thick lava cover (Serra Geral Formation), a set of dykes cutting the entire sedimentary strata (Ordovician to Cretaceous) and several levels of intruded sills (Milani et al., 2007a). The area estimated for the flood basalt flows of the Paraná LIP is of the order of $10^{6} \mathrm{~km}^{2}$ (Hurter and Pollack, 1994). The thermal history of the Paraná Basin rocks and their associated paleofluids was deeply affected by the Paraná 
LIP (Araújo et al., 2000; Souza et al., 2008; Thomaz-Filho et al., 2008; Nomura et al., 2014; Teixeira et al., 2018). Aqueous fluids and hydrocarbons derived from the effect of LIP's on organic and carbonate-rich sedimentary rocks like the Irati Formation can be eventually trapped as fluid inclusions in authigenic minerals (Roedder, 1984; Goldstein and Reynolds, 1994). Fluid inclusions allow to constrain the past conditions of petroleum systems in sedimentary basins, since they often contain hydrocarbon fluids that have migrated and trapped in authigenic minerals (Burruss et al., 1983; McLimans, 1987; Munz, 2001; Parnell et al., 2001; Coelho, 2005) and can supply important information about paleotemperatures, fluid compositions, trapping conditions and post-entrapment modifications (Roedder, 1984; Goldstein and Reynolds, 1994; Goldstein, 2001). Since the Paraná LIP has been considered as a possible cause for the generation of liquid and gaseous hydrocarbons in the Irati Formation, this study aims to investigate the thermal history of the Irati Formation as an unconventional oil shale system and its associated paleofluids in representative outcrops. To achieve this goal, fluid inclusion studies including estimations on hydrocarbons classification and PVT modeling of hydrocarbon fluid inclusions are performed, with carbon and oxygen stable isotopes analyses in calcite veins hosted in the Irati Formation shales. Furthermore, aromaticity of the kerogen, as determined by nuclear magnetic resonance $\left({ }^{13} \mathrm{C}\right.$ CP-MAS NMR) and vitrinite reflectance (\% Ro) of the organic-rich shales are performed for evaluating of the thermal maturity of the Irati Formation.

\section{GEOLOGICAL SETTING}

The Irati Formation, one of the largest oil shale deposit in the world (EIA, 2013), is a Permian unit well distributed all over the Paraná Basin with thickness varying from a few meters to 70 meters ( $40 \mathrm{~m}$ average), which is composed of darkgrey/black shales, siltstones, limestones and dolomites (Milani et al., 2007a). The organic matter of the Irati Formation shales is characterized by Type 1 kerogen with high hydrogen contents and total organic carbon (TOC) varying between 8 $\%$ and $23 \%$ (Araújo et al., 2000; Milani et al., 2007a). The Irati Formation covers an area of $\sim 700.000 \mathrm{~km}^{2}$ and it is considered an atypical petroleum system characterized by complex thermal effect of heterogeneous distribution of hosted 
sills, cutting dykes and overlaying continental flood basalts emplaced during the Early Cretaceous (Araújo et al., 2000). In addition, this magmatic event affected the structural framework of the basin, causing the development of fractures affecting the entire sedimentary succession which served as pathways for input of surface waters into the Permian units (Teixeira et al., 2018) and hydrocarbon migration (Artur and Soares, 2002). The magmatic sills hosted in the Irati Formation, occur all over the Paraná Basin, with an average thickness of 10-20 $\mathrm{m}$, but exceeding hundreds of meters in some cases (Hurter and Pollack, 1994). The Paraná Basin is a cratonic basin located on the South American platform, including the central and southern Brazil and northwestern Uruguay, parts of Paraguay and Argentina (Fig. 1). The sedimentary fill of the Paraná Basin has over $7 \mathrm{~km}$ of thickness (Milani et al., 2007b) and was controlled by tectoniceustatic cycles linked to the evolution of Western Gondwana Supercontinent during the Paleozoic and Mesozoic (Holz et al., 2010). The Paraná Basin was affected by the Early Cretaceous magmatism with successive magmatic pulses (Peate et al., 1992; Peate, 1997). This magmatic event was responsible for the creation of the Paraná LIP, which includes the flooding basalts of the Serra Geral Formation and its origin is related to the breakup of the Western Gondwana and the opening of the southern section of the Atlantic Ocean (Pacheco et al. 2018). In central east border of the Paraná Basin, the preserved thickness of the volcanic rock cap of the Paraná LIP is approximately $400 \mathrm{~m}$ with the Irati Formation lying about $300 \mathrm{~m}$ below it (Janasi et al., 2007). Stewart et al. (1996) considered that the maximum duration of the Paraná LIP was 10 Ma. Ernesto et al. (2002) reported younger ages for the northern high-Ti basalt types (134.8-131.5 Ma) of the Serra Geral Formation suggesting a duration of $\sim 3 \mathrm{Ma}$. However, Renne et al. (1996) indicated a duration of less than $2 \mathrm{Ma}$ based on ${ }^{40} \mathrm{Ar} /{ }^{39} \mathrm{Ar}$ dating, while Thiede and Vasconcelos (2010) suggested duration less than 1 Ma based on ${ }^{40} \mathrm{Ar} /{ }^{39} \mathrm{Ar}$ dating for the same period (134.2-134.8 Ma). However, the onset of the Paraná LIP is indicated by a basal dacite $(134.3 \pm 0.8$ ), based on new U-Pb dating, found in the southeastern border of the Paraná Basin (Piraju-Ourinhos counties), which contrasts with the ages of the overlying high Ti-basalts (133.6-131.5 Ma) suggesting a period of $\sim 3$ Ma necessary to the build-up of the voluminous highTi lava sequence of the basin (Janasi et al., 2011). 


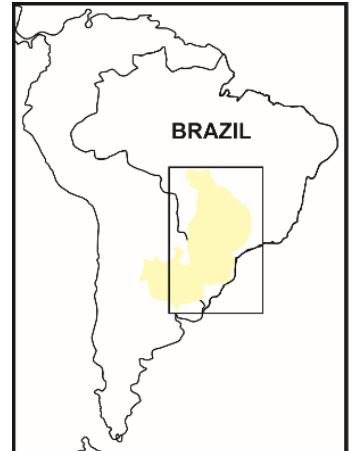

Paraná Basin

Permian units (Passa Dois Group)

Vitrinite reflectance points

$\star$ Microthermometric points

$\star$ SG-01: Continental flood basalt SLIP-02: Sill from the Paraná LIP

1 Jacutinga fault

2 Tiête lineament

3 Guapiara fault

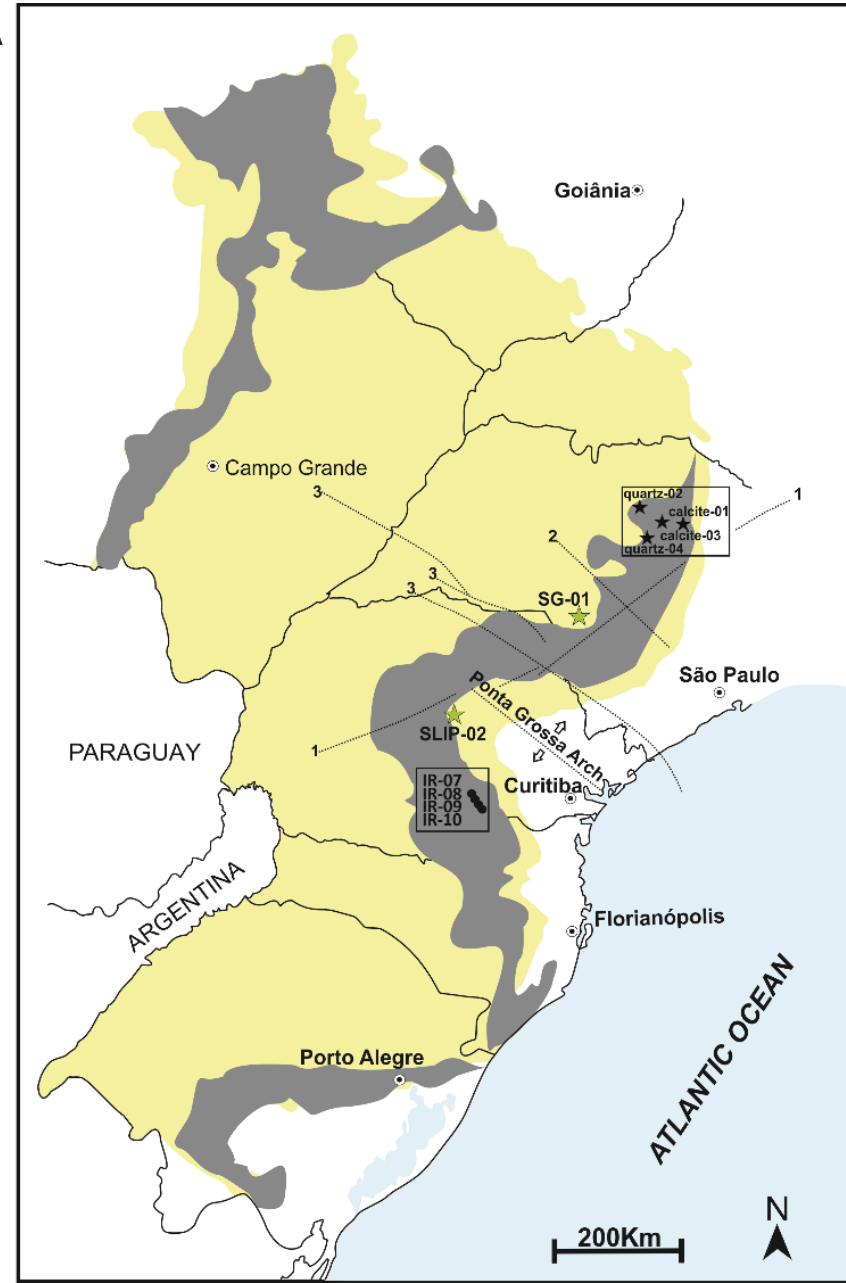

B

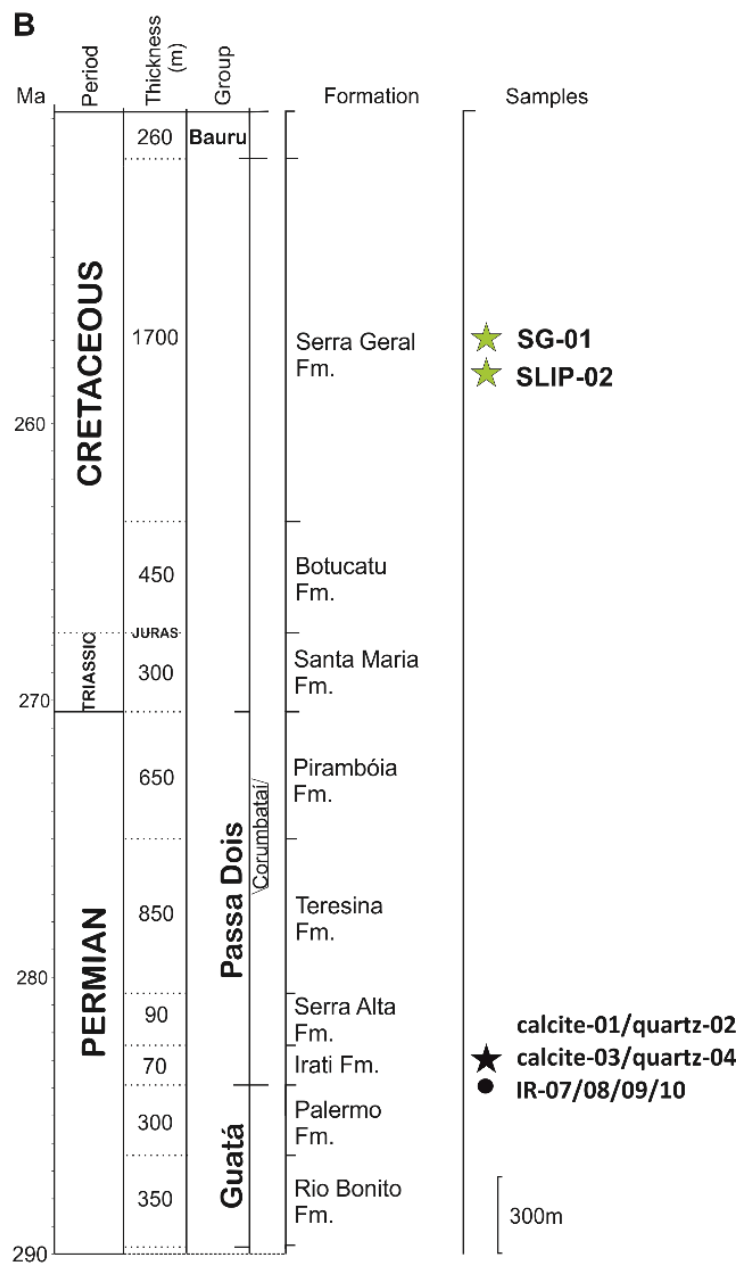

Fig. 1. (A) Paraná Basin in South America platform, Permian units based in Milani et al. (2007b) and sampling outcrops. (B) Lithostratigraphic chart with respective formations and sampling analyzes. 


\section{METHODS}

\subsection{Studied samples of calcite and quartz veins}

Samples of calcite and quartz veins were collected from outcrops along the northeastern border of the Paraná Basin (Fig. 1). Samples include calcite veins (samples calcite-01 and calcite-03) and quartz veins (sample quartz-02 and quartz-04) hosted in the Irati Formation (Permian) and calcite vein of the continental flood basalt (SG-01) of the Serra Geral Formation (Cretaceous) and in a sill (SLIP-02) of the Paraná LIP.

\subsection{Fluid inclusion analysis}

Samples of calcite and of quartz veins from the Irati Formation, continental flood basalt of the Serra Geral Formation and the sill from the Paraná LIP were prepared for fluid inclusion analysis using double polished thick sections (thickness of $100 \mu \mathrm{m}$ ). A total of ten double polished sections were studied to define the origin and the trapping conditions of the fluid inclusion (Table 1) according to the classification by Goldstein and Reynolds (1994). Fluid inclusion analysis were performed in the Sedimentary Petrography Laboratory of the University of São Paulo, using a polarized ZEISS petrographic microscope model AXIOPLAN 2 equipped with transmitted polarized white light and an ultraviolet light source. The microscope is equipped with Leica MC170HD camera and Qwin 550 software to take photomicrographs. Fluorescence microscopy was used to identify and characterize liquid hydrocarbon fluid inclusions. Fluid inclusion microthermometry (Table 2) was accomplish in the Fluid Inclusion Laboratory of Geoanalítica-USP Core Facility in the Institute of Geosciences at the University of São Paulo. Fluid inclusion presenting evident petrographic features of leakage, necking down or post-trapping deformation were not treated for microthermometry. The micro-thermometry analysis was performed using a CHAIXMECA MTM 85 heating-cooling stage. The calibrations followed the procedures from Teixeira et al. (2018). Eutectic temperatures indicate the composition of the aqueous fluids regarding the different types of solution ions. $\mathrm{Tm}$ ice measurements permitted the calculation of the salinity in weight percent 
of $\mathrm{NaCl}$ equivalent (wt. \% $\mathrm{NaCl}$ eq.). The properties of salinity and density of aqueous fluid inclusions hosted in calcite and quartz veins were calculated using thermodynamic equations (Archer, 1992; Zhang and Frantz, 1987) considering the volume proportion of the liquid phase and Tm ice and Th parameters. 
Table 1. Summary of the fluid inclusions types of the Paraná LIP, Serra Geral and the Irati formations.

\begin{tabular}{|c|c|c|c|c|c|c|c|c|c|c|c|c|c|}
\hline $\begin{array}{l}\text { Sample } \\
\text { code }\end{array}$ & Formation & $\begin{array}{c}\text { Location } \\
\text { (state) }\end{array}$ & $\begin{array}{c}\text { Inclusion } \\
\text { type }\end{array}$ & $\begin{array}{c}\text { Authigenic } \\
\text { mineral } / \\
\text { Host rock }\end{array}$ & Composition & Phases & Shape & $\begin{array}{l}\text { Mode of } \\
\text { occurrence }\end{array}$ & Origin & Diameter & $\begin{array}{c}\text { Volume } \\
\text { (petrography) }\end{array}$ & Fluorescence & Figure \\
\hline \multirow[t]{2}{*}{ Calcite-01 } & \multirow{8}{*}{ Irati Fm. } & \multirow{8}{*}{$\begin{array}{l}\text { São } \\
\text { Paulo }\end{array}$} & 1 & \multirow[t]{2}{*}{$\begin{array}{l}\text { Vertical } \\
\text { calcite vein / } \\
\text { Shale }\end{array}$} & Aqueous & $\begin{array}{l}\text { One- } \\
\text { phase } \\
\text { coexisting } \\
\text { with two- } \\
\text { phase }\end{array}$ & $\begin{array}{l}\text { Irregular } \\
\text { to } \\
\text { regular }\end{array}$ & $\begin{array}{l}\text { Random } \\
\text { distributed / } \\
\text { isolated / } \\
\text { microcracks }\end{array}$ & $\begin{array}{l}\text { Primary } \\
\text { and } \\
\text { Pseudo- } \\
\text { secondary }\end{array}$ & $\begin{array}{l}5 \text { to } 15 \\
\mu \mathrm{m}\end{array}$ & 5 to $20 \%$ & - & $\begin{array}{c}5 \mathrm{~A} \text {, and } \\
5 \mathrm{E}\end{array}$ \\
\hline & & & 2 & & Hydrocarbon & $\begin{array}{l}\text { Two- } \\
\text { phase }\end{array}$ & Irregular & $\begin{array}{c}\text { Random } \\
\text { distributed / } \\
\text { isolated }\end{array}$ & Primary & $\begin{array}{c}10 \text { to } 20 \\
\mu \mathrm{m}\end{array}$ & 5 to $15 \%$ & Bright Yellow & $\begin{array}{l}5 C^{\prime} \text { and } \\
5 \mathrm{D}\end{array}$ \\
\hline \multirow[t]{2}{*}{ Quartz-02 } & & & 1 & \multirow[t]{2}{*}{$\begin{array}{l}\text { Vertical } \\
\text { calcite vein / } \\
\text { Limestone }\end{array}$} & Aqueous & $\begin{array}{c}\text { One- } \\
\text { phase } \\
\text { coexisting } \\
\text { with two- } \\
\text { phase }\end{array}$ & $\begin{array}{l}\text { Irregular } \\
\text { to } \\
\text { regular }\end{array}$ & $\begin{array}{l}\text { Random } \\
\text { distributed / } \\
\text { isolated }\end{array}$ & Primary & $\begin{array}{l}5 \text { to } 15 \\
\mu \mathrm{m}\end{array}$ & 5 to $15 \%$ & - & $5 B$ \\
\hline & & & 3 & & Hydrocarbon & $\begin{array}{l}\text { Two- } \\
\text { phase }\end{array}$ & $\begin{array}{c}\text { Irregular } \\
\text { to } \\
\text { regular }\end{array}$ & $\begin{array}{l}\text { Random } \\
\text { distributed / } \\
\text { isolated }\end{array}$ & Primary & $\begin{array}{c}10 \text { to } 40 \\
\mu \mathrm{m}\end{array}$ & 5 to $20 \%$ & Orange/Brown & - \\
\hline \multirow[t]{2}{*}{ Calcite-03 } & & & 1 & \multirow{2}{*}{$\begin{array}{l}\text { Vertical } \\
\text { quartz vein / } \\
\text { Limestone }\end{array}$} & Aqueous & $\begin{array}{c}\text { One- } \\
\text { phase } \\
\text { coexisting } \\
\text { with two- } \\
\text { phase }\end{array}$ & $\begin{array}{l}\text { Irregular } \\
\text { to } \\
\text { regular }\end{array}$ & $\begin{array}{l}\text { Random } \\
\text { distributed / } \\
\text { microcracks }\end{array}$ & $\begin{array}{l}\text { Primary } \\
\text { and } \\
\text { pseudo- } \\
\text { secondary }\end{array}$ & $\begin{array}{l}3 \text { to } 30 \\
\mu \mathrm{m}\end{array}$ & 5 to $10 \%$ & - & - \\
\hline & & & 2 and 3 & & Hydrocarbon & $\begin{array}{l}\text { Two- } \\
\text { phase }\end{array}$ & Irregular & $\begin{array}{l}\text { Random } \\
\text { distributed / } \\
\text { microcracks }\end{array}$ & $\begin{array}{l}\text { Primary } \\
\text { and } \\
\text { pseudo- } \\
\text { secondary }\end{array}$ & $\begin{array}{l}5 \text { to } 25 \\
\mu \mathrm{m}\end{array}$ & 5 to $15 \%$ & Bright Yellow & $\begin{array}{c}5 \mathrm{E}^{\prime} \text { and } \\
5 \mathrm{~F}\end{array}$ \\
\hline \multirow[t]{2}{*}{ Quartz-04 } & & & 1 & \multirow{2}{*}{$\begin{array}{l}\text { Vertical } \\
\text { quartz vein / } \\
\text { Limestone }\end{array}$} & Aqueous & $\begin{array}{c}\text { One- } \\
\text { phase } \\
\text { coexisting } \\
\text { with two- } \\
\text { phase }\end{array}$ & $\begin{array}{l}\text { Irregular } \\
\text { to } \\
\text { regular }\end{array}$ & $\begin{array}{l}\text { Random } \\
\text { distributed / } \\
\text { healed } \\
\text { microcracks }\end{array}$ & $\begin{array}{l}\text { Primary } \\
\text { and } \\
\text { secondary }\end{array}$ & $\begin{array}{c}2 \text { to } 15 \\
\mu \mathrm{m}\end{array}$ & 5 to $15 \%$ & - & - \\
\hline & & & 2 & & Hydrocarbon & $\begin{array}{l}\text { Two- } \\
\text { phase }\end{array}$ & Irregular & $\begin{array}{c}\text { Random } \\
\text { distributed / } \\
\text { healed } \\
\text { microcracks }\end{array}$ & $\begin{array}{l}\text { Primary } \\
\text { and } \\
\text { Secondary }\end{array}$ & $\begin{array}{l}5 \text { to } 20 \\
\mu \mathrm{m}\end{array}$ & 5 to $15 \%$ & $\begin{array}{l}\text { Yellow / Bright } \\
\text { Yellow }\end{array}$ & $\begin{array}{c}5 \mathrm{G} \text { and } \\
5 \mathrm{H}\end{array}$ \\
\hline SG-01 & $\begin{array}{c}\text { Serra } \\
\text { Geral Fm. }\end{array}$ & & \multirow{2}{*}{1} & $\begin{array}{c}\text { Vertical } \\
\text { calcite vein / } \\
\text { Basalt }\end{array}$ & \multirow{2}{*}{ Aqueous } & \multirow{2}{*}{$\begin{array}{l}\text { One- } \\
\text { phase } \\
\text { coexisting } \\
\text { with two- } \\
\text { phase }\end{array}$} & \multirow{2}{*}{$\begin{array}{l}\text { Irregular } \\
\text { to } \\
\text { regular }\end{array}$} & \multirow{2}{*}{$\begin{array}{l}\text { Random } \\
\text { distributed / } \\
\text { isolated }\end{array}$} & \multirow{2}{*}{$\begin{array}{l}\text { Primary } \\
\text { and } \\
\text { Pseudo- } \\
\text { secondary }\end{array}$} & \multirow{2}{*}{$\begin{array}{l}5 \text { to } 20 \\
\mu \mathrm{m}\end{array}$} & \multirow{2}{*}{5 to $15 \%$} & - & \multirow{2}{*}{ - } \\
\hline SLIP-02 & $\begin{array}{l}\text { Paraná } \\
\text { LIP }\end{array}$ & Paraná & & $\begin{array}{c}\text { Vertical } \\
\text { calcite vein / } \\
\text { Sill }\end{array}$ & & & & & & & & - & \\
\hline
\end{tabular}


Table 2. Resume of the total microthermometry data.

\begin{tabular}{|c|c|c|c|c|c|c|c|c|c|c|c|}
\hline Formation & Sample & Type & Composition & Fluid System & Th (ㅇ) & TE (ํ) & Tm ice $\left({ }^{\circ} \mathrm{C}\right)$ & $\begin{array}{l}\text { Salinity (wt. } \\
\% \text { of } \mathrm{NaCl} \\
\text { eq.) }\end{array}$ & $\begin{array}{c}\text { Average } \\
\text { Volume (\%) }\end{array}$ & $\begin{array}{c}\text { Total } \\
\text { inclusions } \\
\text { analyzed }\end{array}$ & Figure \\
\hline \multirow{7}{*}{ Irati } & \multirow[t]{2}{*}{ calcite-01 } & 1 & Aqueous saline & $\begin{array}{c}\mathrm{H}_{2} \mathrm{O}+\mathrm{NaCl}+\mathrm{CaCl}_{2}+ \\
\left(\mathrm{MgCl}_{2}\right)\end{array}$ & $50-330$ & -48 to -44 & {$[-12]$ and $[-3$ to 0$]$} & $\begin{array}{c}{[1-5] \text { and }} \\
{[16-17]}\end{array}$ & $12.2^{*}$ & 84 & $\begin{array}{c}6 \mathrm{~A}, 6 \mathrm{~B}, 6 \mathrm{C} \\
\text { and } 6 \mathrm{E}\end{array}$ \\
\hline & & 2 & Oil & Fluid Imiscibility: $\mathrm{Oil}_{+} \mathrm{H}_{2} \mathrm{O}$ & $50-200$ & - & - & - & - & 10 & $6 \mathrm{H}$ \\
\hline & quartz-02 & 1 & Aqueous saline & $\begin{array}{c}\mathrm{H}_{2} \mathrm{O}+\mathrm{NaCl}+\mathrm{CaCl}_{2}+ \\
\left(\mathrm{MgCl}_{2}\right)\end{array}$ & $50-340$ & -55 to -46 & $\begin{array}{c}{[-15 \text { to }-10] \text { and }[-} \\
5 \text { to } 0]\end{array}$ & [0-21] & $9.4^{*}$ & 87 & $\begin{array}{c}6 \mathrm{~A}, 6 \mathrm{~B}, 6 \mathrm{C} \\
\text { and } 6 \mathrm{E}\end{array}$ \\
\hline & \multirow{2}{*}{ calcite-03 } & 1 & Aqueous saline & $\begin{array}{c}\mathrm{H}_{2} \mathrm{O}+\mathrm{NaCl}_{+} \mathrm{CaCl}_{2}+ \\
\left(\mathrm{MgCl}_{2}\right)\end{array}$ & $50-170$ & -53 to -42 & {$[-3$ to -1$]$} & {$[1-5]$} & $5.5^{*}$ & 31 & $\begin{array}{c}6 \mathrm{~A}, 6 \mathrm{~B}, 6 \mathrm{C} \\
\text { and } 6 \mathrm{E}\end{array}$ \\
\hline & & 2 and 3 & Oil & Fluid Imiscibility: $\mathrm{Oil}_{+} \mathrm{H}_{2} \mathrm{O}$ & $50-160$ & - & - & - & - & 31 & $6 \mathrm{H}$ \\
\hline & \multirow[t]{2}{*}{ quartz-04 } & 1 & Aqueous saline & $\begin{array}{c}\mathrm{H}_{2} \mathrm{O}+\mathrm{NaCl}+\mathrm{CaCl}_{2}+ \\
\left(\mathrm{MgCl}_{2}\right)\end{array}$ & $50-210$ & -57 to -49 & $\begin{array}{c}{[-18 \text { to }-9] \text { and }[-5} \\
\text { to }-0]\end{array}$ & $\begin{array}{c}{[0-4] \text { and }} \\
{[13-21]}\end{array}$ & $7.9^{*}$ & 43 & $6 \mathrm{H}$ \\
\hline & & 2 & Oil & Fluid Imiscibility: $\mathrm{Oil}_{+} \mathrm{H}_{2} \mathrm{O}$ & $50-250$ & - & - & - & $5.4^{\star \star}$ & 145 & $6 \mathrm{G}$ and $6 \mathrm{H}$ \\
\hline Serra Geral & SG-01 & 1 & Aqueous saline & $\mathrm{H}_{2} \mathrm{O}+\mathrm{NaCl}_{+} \mathrm{CaCl}_{2}+$ & $70-250$ & -54 to -47 & [-2 to 0$]$ & {$[0-4]$} & $5.9^{*}$ & 76 & \multirow[t]{2}{*}{7} \\
\hline Paraná LIP & SLIP-02 & 1 & & & $50-240$ & -56 to -48 & {$[-2$ to -1$]$} & [2-3] & $6.4^{*}$ & 49 & \\
\hline
\end{tabular}

*calculated with program included in the computer package FLUIDS (Bakker, 2003);

${ }^{\star *}$ calculated with 3D image modeling software through confocal scanning laser microscope analysis. 


\subsection{Confocal Scanning Laser Microscope (CSLM)}

Confocal scanning laser microscope was applied to determine the vapor volume fraction $\left(F_{v}\right)$ of natural two-phase hydrocarbon fluid inclusions (Table 3 ). The vapor volume fraction $\left(\mathrm{F}_{\mathrm{v}}\right)$ determination allows the possibility of knowledge of oil phases. The volumetric reproductions of fluorescent hydrocarbon fluid inclusions by confocal laser scanning microscopy (CLSM) to calculate $F_{v}$ in inclusions at room conditions have been studied by Pironon et al. (1998), Aplin et al. (1999) and Thiéry et al. (2002).

The confocal microscopy was carried out in the Analytical Center of the Chemical Institute at the University of São Paulo using a Confocal Scanning Laser Microscope from Zeiss, model LSM 510-Meta, with laser source at $488 \mathrm{~nm}$. The images were captured with an 100x objective immersed in oil (immersol $518 \mathrm{~F}$ ). The $x-y$ resolution and the resolution along the $z$-axis followed the routine of Bourdet et al. (2008). The 2D sequence image obtained can provide a 3D model inclusion which can be useful to precise cavity location and the real dimension of the inclusion. In case of hydrocarbon fluid inclusions bigger than $10 \mu \mathrm{m}$, the sections (slices) were spaced in constant intervals depth of $0.5 \mu \mathrm{m}$, while hydrocarbon fluid inclusions smaller than $10 \mu \mathrm{m}$ the slices were spaced in interval depth of $0.8 \mu \mathrm{m}$ for better accuracy to precise the bubble cavity and the real dimension of the inclusion. 
Table 3. Volume vapor fraction $\left(F_{v}\right)$ from primary Type 2 inclusions and respective homogenization temperature $(\mathrm{Th})$ for one specific FIA. Th average $=101.4{ }^{\circ} \mathrm{C} ; \mathrm{F}_{\mathrm{v}}$ average $=5.4$ $\%$.

\begin{tabular}{c|c|c|c|c}
\hline \multirow{2}{*}{ IF } & $\begin{array}{c}\text { Microthermometric } \\
\text { analysis }\end{array}$ & \multicolumn{3}{|c}{ Confocal analysis } \\
\cline { 2 - 5 } & Th $\left({ }^{\circ} \mathrm{C}\right)$ & $\begin{array}{c}\text { Volume liquid } \\
\text { phase }\left(\mu \mathrm{m}^{3}\right)\end{array}$ & $\begin{array}{c}\text { Volume vapor } \\
\text { phase }\left(\mu \mathrm{m}^{3}\right)\end{array}$ & $\begin{array}{c}\text { Vapor volume } \\
\text { fraction } \text { Fv }_{\mathrm{v}}(\%)\end{array}$ \\
\hline $\mathbf{1}$ & 63.1 & 715.33 & 24.92 & 3.5 \\
\hline $\mathbf{2}$ & 69.6 & 93.36 & 2.56 & 2.7 \\
\hline $\mathbf{3}$ & 63.8 & 24.12 & 1.15 & 4.8 \\
\hline $\mathbf{4}$ & 62.3 & 7.93 & 0.13 & 1.6 \\
\hline $\mathbf{5}$ & 69.9 & 251.5 & 14.75 & 5.9 \\
\hline $\mathbf{6}$ & 92.3 & 14.89 & 0.78 & 5.2 \\
\hline $\mathbf{7}$ & 137.4 & 24.73 & 1.50 & 6 \\
\hline $\mathbf{8}$ & 150 & 8.78 & 0.84 & 9.6 \\
\hline $\mathbf{9}$ & 83.9 & 41.99 & 2.41 & 5.7 \\
\hline $\mathbf{1 0}$ & 90 & 45.88 & 2.27 & 8.9 \\
\hline $\mathbf{1 1}$ & 139.7 & 17.42 & 1.43 & 6.3 \\
\hline $\mathbf{1 2}$ & 94.5 & 841.84 & 53.22 & 8 \\
\hline $\mathbf{1 3}$ & 150 & 24.85 & 1.99 & 2.2 \\
\hline $\mathbf{1 4}$ & 110.6 & 75.77 & 1.64 & 3.6 \\
\hline $\mathbf{1 5}$ & 113.2 & 27.65 & 0.99 & 2.7 \\
\hline $\mathbf{1 6}$ & 65.1 & 135.79 & 3.6 & 8.1 \\
\hline $\mathbf{1 7}$ & 139.5 & 6.76 & 0.54 & 5.4 \\
\hline $\mathbf{1 8}$ & 138.3 & 5.6 & 0.51 & 0.16 \\
\hline $\mathbf{1 9}$ & 93.5 & 2.98 & & \\
\hline
\end{tabular}

\subsection{Modeling of pressure-temperature (P-T) conditions}

We attempt to construct the two-phase envelope and P-T conditions of the hydrocarbon types trapped as inclusions in the studied calcite and quartz filling fractures. For this purpose, hydrocarbon fluid inclusions were modelled according to the assumptions based on Thiéry et al. (2002) with Peng-Robinson equation of state (Peng and Robinson, 1976) and the $\alpha-\beta$ compositional model developed by Montel (1993). This approach requires the Th and the $F_{v}$ parameters of the hydrocarbon fluid inclusion as input data represented by a $\beta(\alpha)$ curve in an $\alpha-\beta$ diagram (Thiéry et al., 2002). By constraining the $F_{v}$ data acquired in confocal microscopy analysis, the simulation package (PIT - Thiéry et al., 2000b apud Pestilho and Monteiro, 2017) calculates the hydrocarbon two-phase envelope, the respective bubble point curve and the isochore inclusion. Thus, our volumetric data from hydrocarbon fluid inclusions combined with the Th from coeval aqueous fluid inclusions (Table 3), will supply new P-T constraints for trapping conditions. This provides a graphically solution to reproduce the composition of all natural 
hydrocarbon inclusion and reconstructing the isochoric paths of coeval aqueous fluid inclusions (Pironon et al., 1998; Aplin et al., 1999; Bourdet et al., 2008).

\subsection{Carbon and oxygen stable isotope analysis in calcite veins}

Analysis of carbon $\left(\delta^{13} \mathrm{C}\right)$ and oxygen $\left(\delta^{18} \mathrm{O}\right)$ stable isotopes was performed in calcite veins from the Irati Formation, continental flood basalt and the sill from the Paraná LIP. The procedure of sampling preparation and the equipment used for the stable isotope analysis is the same used by Teixeira et al. (2018).

Measurements of $\delta^{13} \mathrm{C}$ and $\delta^{18} \mathrm{O}$ were performed in the Stable Isotope Laboratory of the Institute of Geosciences at the University of São Paulo. The $\delta^{13} \mathrm{C}$ and $\delta^{18} \mathrm{O}$ values were standardized in agreement to the international Vienna Pee Dee Belemnite (VPDB) standard. The internal accuracy specified by the manufacturer is $0.05 \%$ to $\delta^{13} \mathrm{C}$ and $0.07 \%$ to $\delta^{18} \mathrm{O}$ (instrumental deviation). The error for these analyses is $<0.1 \%$ as indicated by replicate analyses of internal standards.

\subsection{Vitrinite Reflectance (\%Ro)}

Samples IR-07; IR-08; IR-09 and IR-10 of Irati Formation shales were used to perform vitrinite reflectance analysis. All samples were collected in southern part of the Paraná Basin (Fig. 1). Vitrinite reflectance analyses are executed on crushed rock mounts (known as whole-rock mounts). Whole rock mounts include rock samples fixed in an epoxy resin pellet. The sample preparations followed the procedures of Stach et al. (1982). Our sampling process was based on the established routine of the Laboratory of Organic Geochemistry of the Geosciences Department, Environment and Regional Planning at the University of Porto, Portugal.

For qualitative characterization of the organic matter and determining the vitrinite reflectance, it was used an optical microscope LEICA DM 4000M reflection, equipped with a Hilgers FOSSIL MOT system for observation oil, and white and blue fluorescence light. Identification and characterization of organic matter were based on international accepted classification by ICCP - International Committee for Coal and Organic Petrology (ICCP 1998, 2001). The determination of the vitrinite reflectance, which allows to evaluate the degree of maturation of the 
organic material (Tissot and Welte, 1984) was performed based on procedures described in ASTM D7708 (2011).

\subsection{NMR data}

Solid state nuclear magnetic resonance spectroscopy with cross polarization at magic angle spinning $\left({ }^{13} \mathrm{C}\right.$ CP-MAS NMR) was performed in the Irati Formation shale to provide comprehensive structural information about the kerogen. Kerogen was isolated from shale samples IR- $07, \mathrm{IR}-08$ and IR-10 following a wellknown literature procedure (Vandenbroucke and Largeau, 2007). Grinded shale samples $(8-11 \mathrm{~g})$ were first extracted in a soxhlett extractor for 24 hours with dichloromethane-methanol solvent mixture $(9: 1 \mathrm{v} / \mathrm{v})$ to remove soluble bitumen. The extracted samples ( $5 \mathrm{~g}$ aliquots) were then demineralized by acid digestion, stirring for $24 \mathrm{~h}\left(60^{\circ} \mathrm{C}\right)$ with a mixture of $40 \mathrm{~mL} 6 \mathrm{M} \mathrm{HCl}+20 \mathrm{~mL} \mathrm{HF} 40 \%$. After this period, the mixture was diluted with water $(1 \mathrm{~L})$ and the solid residue was filtered off, rinsed copiously with water and finally dried in air. The dry kerogen samples were soxhlett-extracted once again for $24 \mathrm{~h}$ with dichloromethanemethanol $(9: 1 \mathrm{v} / \mathrm{v})$ in order to remove any remaining bitumen. The resulting kerogen samples were dried in air and grinded for NMR analysis.

Solid state cross polarization under magic angle spinning (CP-MAS) ${ }^{13} \mathrm{C}-\mathrm{NMR}$ experiments were conducted in a Varian Avance $500 \mathrm{MHz}$ spectrometer operating at the resonance frequency of $125.7 \mathrm{MHz}$, at magic angle spinning of $10 \mathrm{KHz}$. The grinded kerogen samples were packed into 4-mm diameter zirconia rotors. Typical acquisition parameters were ${ }^{1} \mathrm{H}-\pi / 2$ pulse length of $2.5 \mu \mathrm{s}$ and relaxation delay of $5 \mathrm{~s}$, with contact time of $1.5 \mathrm{~ms}$. Chemical shifts are reported relative to tetramethylsilane (TMS) at $0 \mathrm{ppm}$, using adamantane as secondary reference with the $\mathrm{CH}_{2}$ carbon at $38.5 \mathrm{ppm}$. A line broadening cutoff corresponding to $250 \mathrm{~Hz}$ were employed in the FID before Fourier-transformed. The spectra of the kerogens IR-10 and IR-08 were averaged by $22 k$ transients while IR-07 spectrum by $10 \mathrm{k}$ transients. 


\section{RESULTS}

\subsection{Macro and microscopic morphology of calcite and quartz veins}

In the studied area, the Permian Irati Formation, the flood basalt of the Serra Geral Formation and the sill of the Paraná LIP show a system of conjugate sub vertical dip fractures (88 dip average) with two trend directions at NNE-SW and NNW-SE, with some fractures filled with authigenic quartz and calcite (Fig. 2). In the Irati Formation the quartz and calcite veins are $0.5-3 \mathrm{~cm}$ thick and $10-200$ $\mathrm{cm}$ long, and they show tabular geometry (Fig. 3). Both quartz and calcite veins (samples calcite-01; quartz-02; calcite-03 and quartz-04) present blocky texture with subhedral individual shape crystals, interlobate boundary geometries and inequigranular distribution (Fig. 4A and 4B).

The calcite veins in the flood basalt of the Serra Geral Formation and the sill from the Paraná LIP are 0.3 to $1.5 \mathrm{~cm}$ thick and 10 to $100 \mathrm{~cm}$ long and display tabular geometry (Fig. 4C). These calcite veins (samples SG-01 and SLIP-02) present blocky texture composed of euhedral shape crystals showing polygonal boundary geometries, equigranular distribution, tabular twinning and perfect cleavage (Fig. $4 C)$. 


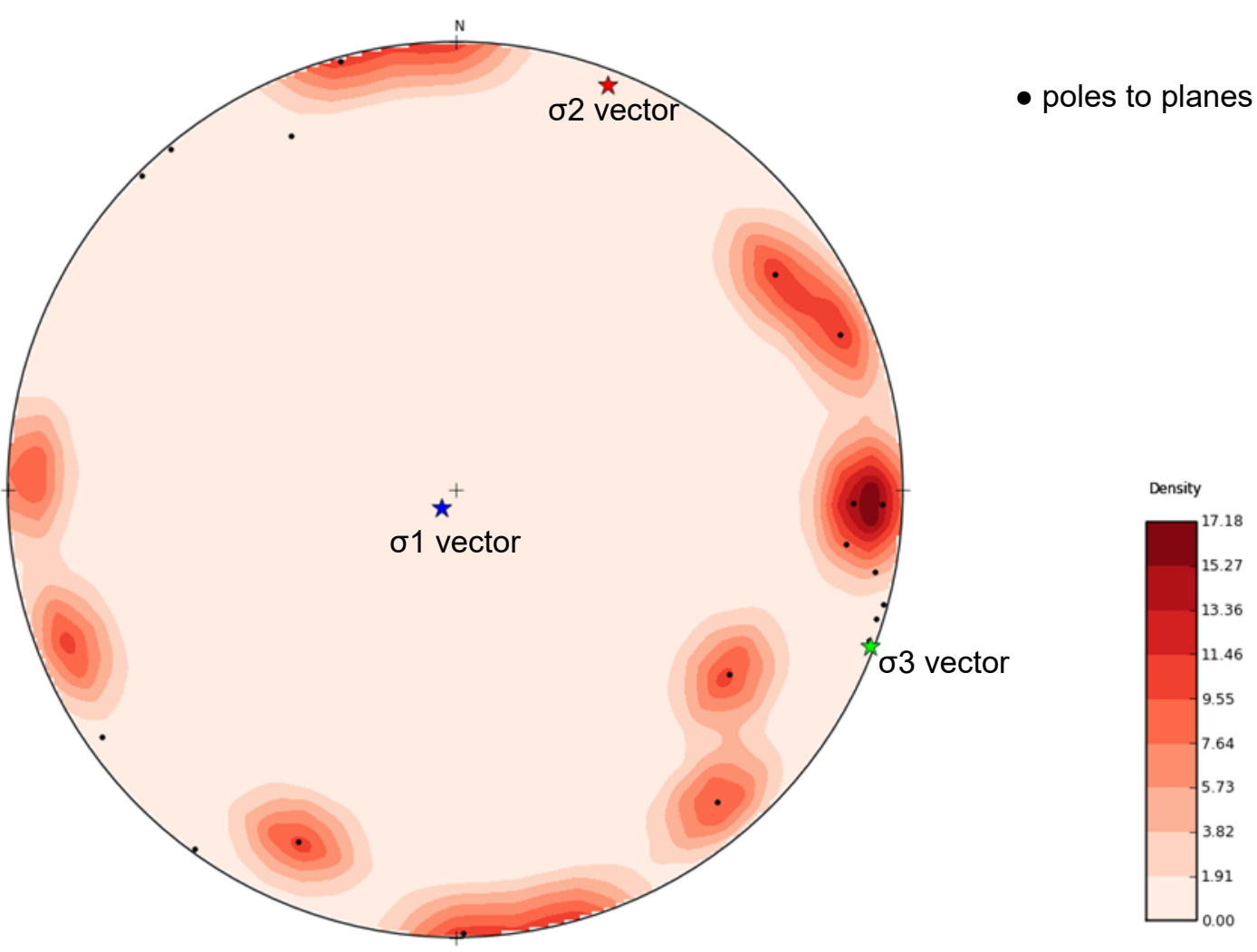

Fig. 2. Polar contour diagram of the density of poles to the authigenic filled opening fractures and the tectonic stress field vectors in the Irati Formation (Samples quartz-02; calcite-03 and quartz-04). 

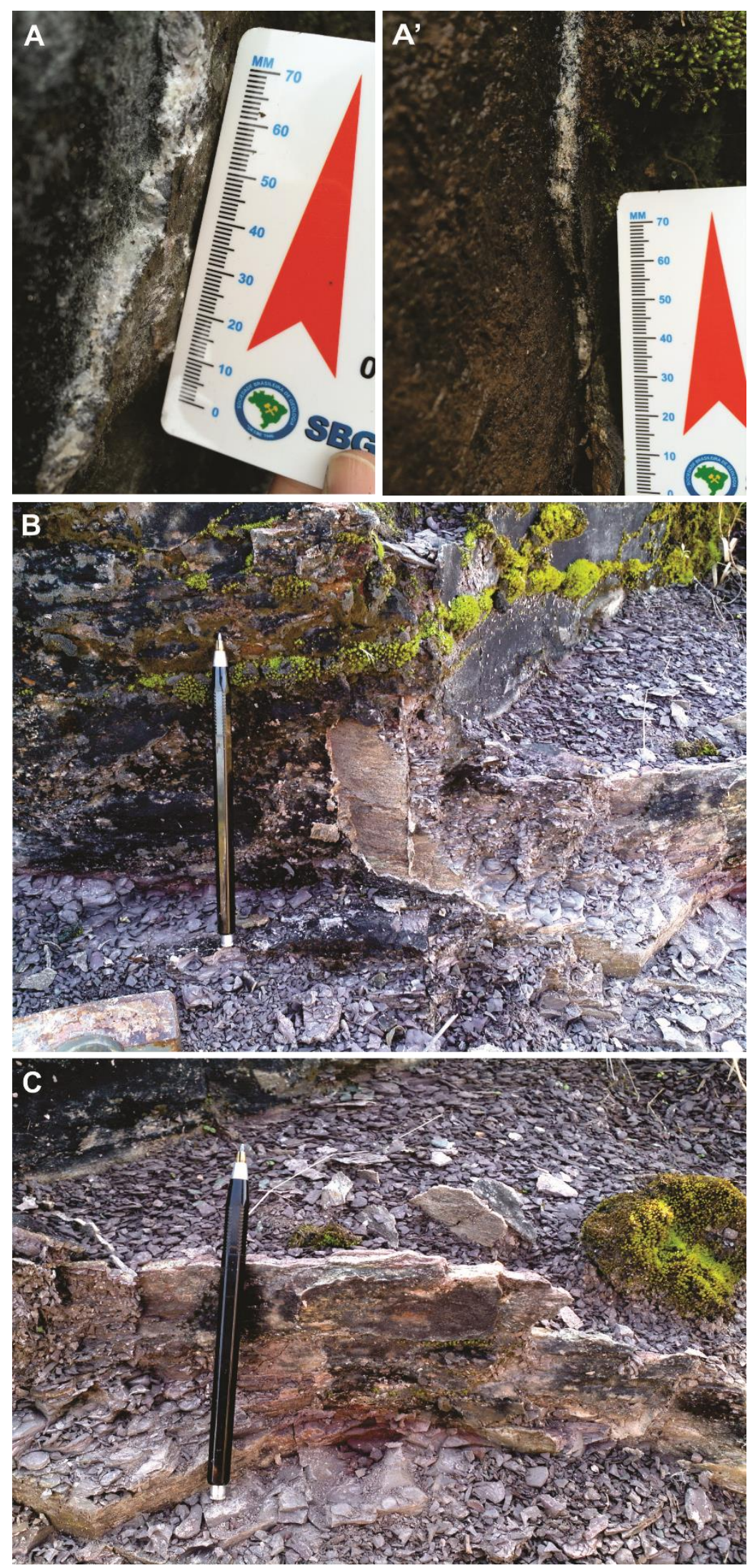

Fig. 3. Calcite-filling fractures from the Irati and Serra Geral formations. (A) Subvertical calcite veins of the Serra Geral Formation with thickness varying between 0.5 and $1.5 \mathrm{~cm}$ (samples SG01 and SLIP-02). (B) and (C) respectively show the top and bottom sections of a vertical calcite vein hosted in the Irati Formation, with thickness varying from $0.4 \mathrm{~cm}$ on the top to $1 \mathrm{~cm}$ at the base (sample calcite-01). 

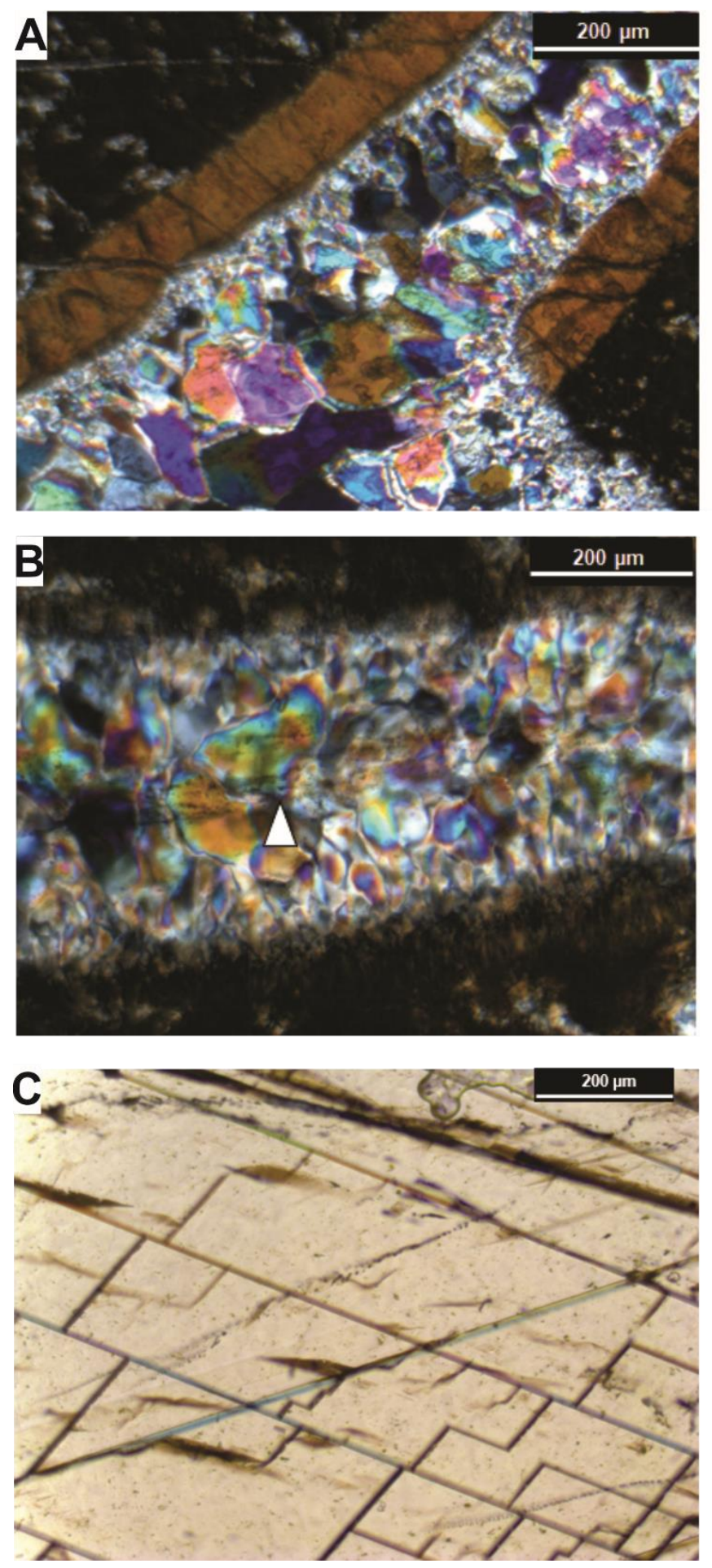

Fig. 4. Sub-vertical veining system as they occur in the Irati and Serra Geral formations. (A) Syntaxial sub-vertical quartz vein hosted in shale (Irati Formation) displaying three different cementation patterns from the wall-rock to the vein center: banded chalcedony, microcrystalline quartz, and the fluid inclusion-bearing fine mosaic quartz (PX); (B) Secondary hydrocarbon fluid inclusions from the Irati Formation aligned within healed black microcracks (white arrow) which cuts the quartz boundaries (PX) (C) Calcite vein from the continental flood basalt of the Serra Geral Formation with patchy twins and perfect cleavage hosting secondary aqueous fluid inclusions (white arrow) cross-cutting crystal boundaries (plane polarized transmitted light). 


\subsection{Fluid Inclusion petrography}

The fluid inclusions characteristics (types, modes of occurrence, fluorescence and sampling points) are detailed in Table 1. The petrography was performed according to the sampling units (Irati Formation, continental flood basalt of the Serra Geral Formation and in the sill associated to the Paraná LIP) and individually through every fluid inclusion assemblage (Table 4).

Type 1 inclusions from quartz and calcite veins consist in one-phase aqueous saline inclusions with irregular shape and two-phase aqueous saline inclusions with regular shape, which occurred randomly distributed or isolated (Fig. 5A). These inclusions can occur as random distributed groups or along internal fractures (microcracks which not cross the crystal boundaries), within quartz and calcite crystals pointing out a primary and pseudo-secondary origin (Fig. 5B). In terms of proportion of the vapor phase volume relative to the total inclusion volume $\left(\mathrm{V}_{\mathrm{V}} / \mathrm{V}_{\mathrm{IF}}\right)$ the veins of the Irati Formation reveal two-phase inclusions diameter ranges from 5 to $15 \mu \mathrm{m}$ with $\mathrm{V}_{\mathrm{V}} / \mathrm{V}_{\mathrm{IF}}$ varying from 0.05 to 0.15 with an average of 0.10 . Relatively to the continental flood basalt of the Serra Geral Formation and the sill associated to the Paraná LIP the two-phase inclusions diameter ranges from 5 to $10 \mu \mathrm{m}$ with VV/VIF varying from 0.05 to 0.07 with an average of 0.06 , and are often associated with single-phase inclusions with similar diameter (Fig. 5A).

Type 2 inclusions show bright yellow/white fluorescence (Table 1). Under the petrography it shows two-phase hydrocarbons fluid inclusions with small vaporliquid volume ratios, irregular shape, usually lighter brown body colored but it can show colorless body too, dark bubbles and diameter ranging from 5 to $20 \mu \mathrm{m}$ (Fig. 5C and 5C'). Type 2 inclusions occur as random distributed groups within calcite and quartz crystals and some orientated hydrocarbon inclusions are limited by the crystal boundaries suggesting primary and pseudo-secondary origin. However, microcracks with aligned HCFl's cutting authigenic quartz crystal boundaries are also common (Fig. 4 and $5 \mathrm{H}$; sample quartz-04). This point out a secondary origin indicating hydrocarbon inclusions trapped after crystal growth is complete.

Type 3 inclusions from calcite filled fractures, under UV-light exhibit orange fluorescence tones, random isolated or trapped in healed microcracks that are 
limited by crystal boundaries, suggesting a primary and pseudo-secondary origin, respectively (Fig. 5E and E'). It shows two-phase hydrocarbon fluid inclusions with irregular shape, most have darker brown body colored, dark bubbles and diameter varying from 10 to $20 \mu \mathrm{m}$. Despite their different fluorescence, the twophase inclusions have no large variable vapor/liquid ratios, suggesting a single event of oil entrapment during vein development. 
Table 4. Resume of fluid inclusion assemblage data.

\begin{tabular}{|c|c|c|c|c|c|c|c|c|}
\hline Sample & FIA & $\begin{array}{l}\text { № of } \\
\text { Total } \\
\text { Fl's }\end{array}$ & $\begin{array}{l}\text { № of } \\
\text { Total } \\
\text { HCFl's }\end{array}$ & $\begin{array}{l}\text { № of } \\
\text { Total } \\
\text { AqFl's }\end{array}$ & $\begin{array}{c}\text { Th of HCFl's } \\
\left({ }^{\circ} \mathrm{C}\right)\end{array}$ & Tm ice $\left({ }^{\circ} \mathrm{C}\right)$ & $\begin{array}{c}\text { Salinity (wt. } \\
\% \text { of } \mathrm{NaCl} \\
\text { eq.) }\end{array}$ & $\begin{array}{c}\text { Th of AqFl's } \\
\left({ }^{\circ} \mathrm{C}\right)\end{array}$ \\
\hline \multirow{8}{*}{$\begin{array}{c}\text { calcite- } \\
01\end{array}$} & 1 & 91 & 0 & 14 & - & - & - & 108 to 133.9 \\
\hline & 2 & 4 & 2 & 4 & 61.9 to 67.3 & - & - & 110.5 to 196.3 \\
\hline & 3 & 10 & 0 & 10 & - & - & - & 93.6 to 270 \\
\hline & 4 & 20 & 0 & 20 & - & - & - & 97.3 to 184.8 \\
\hline & 5 & 5 & 0 & 5 & - & - & - & 55.9 to 250 \\
\hline & 6 & 12 & 2 & 10 & 74 to 81.7 & -12.9 to -12.3 & 5 to 17.1 & 74 to 199.7 \\
\hline & 7 & 18 & 2 & 16 & 104.9 to 59.4 & -2 to -0.7 & 1.2 to 3.4 & 59.4 to 339.7 \\
\hline & 8 & 8 & 3 & 4 & 117.3 to 209.8 & -2.2 to -2.7 & 2.2 to 4.5 & 76.9 to 216.8 \\
\hline \multirow{9}{*}{$\begin{array}{c}\text { quartz- } \\
02\end{array}$} & 1 & 7 & 3 & 4 & - & - & - & 90.2 to 226.4 \\
\hline & 2 & 7 & 0 & 7 & - & - & - & 76.7 to 170 \\
\hline & 3 & 17 & 0 & 17 & - & -1.3 & 2.2 & 100.2 to 212.1 \\
\hline & 4 & 7 & 0 & 7 & - & - & - & 53.2 to 130.3 \\
\hline & 5 & 6 & 0 & 6 & - & -4.2 to -1.7 & 2.9 to 5.4 & 65.3 to 170 \\
\hline & 6 & 5 & 0 & 5 & - & - & - & 81.8 to 170 \\
\hline & 7 & 23 & 0 & 23 & - & -15.9 to -0.2 & 0.4 to 19.8 & 57 to 180.9 \\
\hline & 8 & 7 & 0 & 7 & - & -2 to -0.3 & 0.5 to 3.4 & 100.1 to 144.4 \\
\hline & 9 & 9 & 4 & 9 & - & -1.3 to -15 & 2.27 to 21.4 & 75.7 to 342.1 \\
\hline \multirow{9}{*}{$\begin{array}{l}\text { calcite- } \\
03\end{array}$} & 1 & 8 & 8 & 0 & 50.8 to 125.2 & - & - & - \\
\hline & 2 & 5 & 5 & 0 & 61.6 to 130.5 & - & - & - \\
\hline & 3 & 6 & 6 & 0 & 59 to 114.5 & - & - & - \\
\hline & 4 & 14 & 12 & 2 & 61.6 to 156.5 & - & - & - \\
\hline & 5 & 5 & 0 & 5 & - & -1.3 & 2.2 to 2.6 & 62.7 to 147.7 \\
\hline & 6 & 12 & 0 & 12 & - & -1.3 to -3 & 2.2 to 4.7 & 70.1 to 210.7 \\
\hline & 7 & 4 & 0 & 4 & - & - & 2.2 & 80 to 129.1 \\
\hline & 8 & 5 & 0 & 5 & - & - & 2.2 & 80.1 to 134.9 \\
\hline & 9 & 7 & 0 & 7 & - & -1.3 & 1.2 & 105 to 146.5 \\
\hline \multirow{16}{*}{$\begin{array}{c}\text { quartz- } \\
04\end{array}$} & 1 & 10 & 0 & 10 & - & -0.9 to -5.7 & 1.5 to 8.9 & 54 to 215.2 \\
\hline & 2 & 13 & 0 & 13 & - & -0.6 to -15.6 & 1.4 to 19.5 & 89.6 to 161.5 \\
\hline & 3 & 7 & 0 & 7 & - & -1 to -18.5 & 1.7 to 21.9 & 89.5 to 107.2 \\
\hline & 4 & 6 & 0 & 5 & - & -0.2 to -1.1 & 0.4 to 1.9 & 80.4 to 167.6 \\
\hline & 5 & 14 & 0 & 14 & - & -0.1 to -1.3 & 0.2 to 2.2 & 74.5 to 205.1 \\
\hline & 6 & 15 & 15 & 0 & 62.3 to 150 & - & - & - \\
\hline & 7 & 11 & 11 & 0 & 65.1 to 150 & - & - & - \\
\hline & 8 & 24 & 24 & 0 & 60.8 to 201.9 & - & - & - \\
\hline & 9 & 16 & 16 & 0 & 115.2 to 250 & - & - & - \\
\hline & 10 & 15 & 15 & 0 & 51.6 to 88.7 & - & - & - \\
\hline & 11 & 11 & 11 & 0 & 53 to 97.8 & - & - & - \\
\hline & 12 & 9 & 9 & 0 & 66.5 to 121.5 & - & - & - \\
\hline & 13 & 10 & 10 & 0 & 121.7 to 201.8 & - & - & - \\
\hline & 14 & 10 & 10 & 0 & 59.9 to 83.5 & - & - & - \\
\hline & 15 & 11 & 11 & 0 & 70 to 163.8 & - & - & - \\
\hline & 16 & 16 & 11 & 0 & 74 to 109.2 & - & - & - \\
\hline \multirow{7}{*}{ SG-01 } & 1 & 10 & 0 & 10 & - & -0.1 to -1.3 & 0.2 to 2.2 & 85.6 to 180 \\
\hline & 2 & 12 & 0 & 12 & - & -0.3 to -2.4 & 0.5 to 4 & 70.2 to 127.2 \\
\hline & 3 & 13 & 0 & 13 & - & -0.6 to -1.8 & 1 to 3 & 79.8 to131.6 \\
\hline & 4 & 8 & 0 & 8 & - & -0.9 to -2.9 & 1.5 to 4.8 & 86.8 to 240 \\
\hline & 5 & 17 & 0 & 17 & - & -1.1 to -2.4 & 1.9 to 4 & 88.8 to 200 \\
\hline & 6 & 8 & 0 & 8 & - & -0.7 to -1.5 & 1.2 to 2.6 & 80.1 to 157.8 \\
\hline & 7 & 8 & 0 & 8 & - & -0.3 to -1.9 & 0.5 to 3.2 & 72.2 to 131.4 \\
\hline \multirow{5}{*}{ SLIP-02 } & 1 & 17 & 0 & 18 & - & - & - & 90.2 to 240 \\
\hline & 2 & 10 & 0 & 11 & - & -1.4 to -2.3 & 2.4 to 3.9 & 53.1 to 240 \\
\hline & 3 & 9 & 0 & 10 & - & -1.5 to -1.9 & 2.6 to 3.4 & 72.8 to 240 \\
\hline & 4 & 4 & 0 & 5 & - & -1.4 to -2.1 & 2.4 to 3.5 & 80.9 to 140.6 \\
\hline & 5 & 9 & 0 & 5 & - & -1.3 to -1.6 & 2.2 to 2.7 & 78.4 to 130.4 \\
\hline
\end{tabular}

$\mathrm{FIA}=$ fluid inclusion assemblage; $\mathrm{Fl}$ 's=fluid inclusions; $\mathrm{HC}=$ hydrocarbon; $\mathrm{Aq}=$ aqueous. 


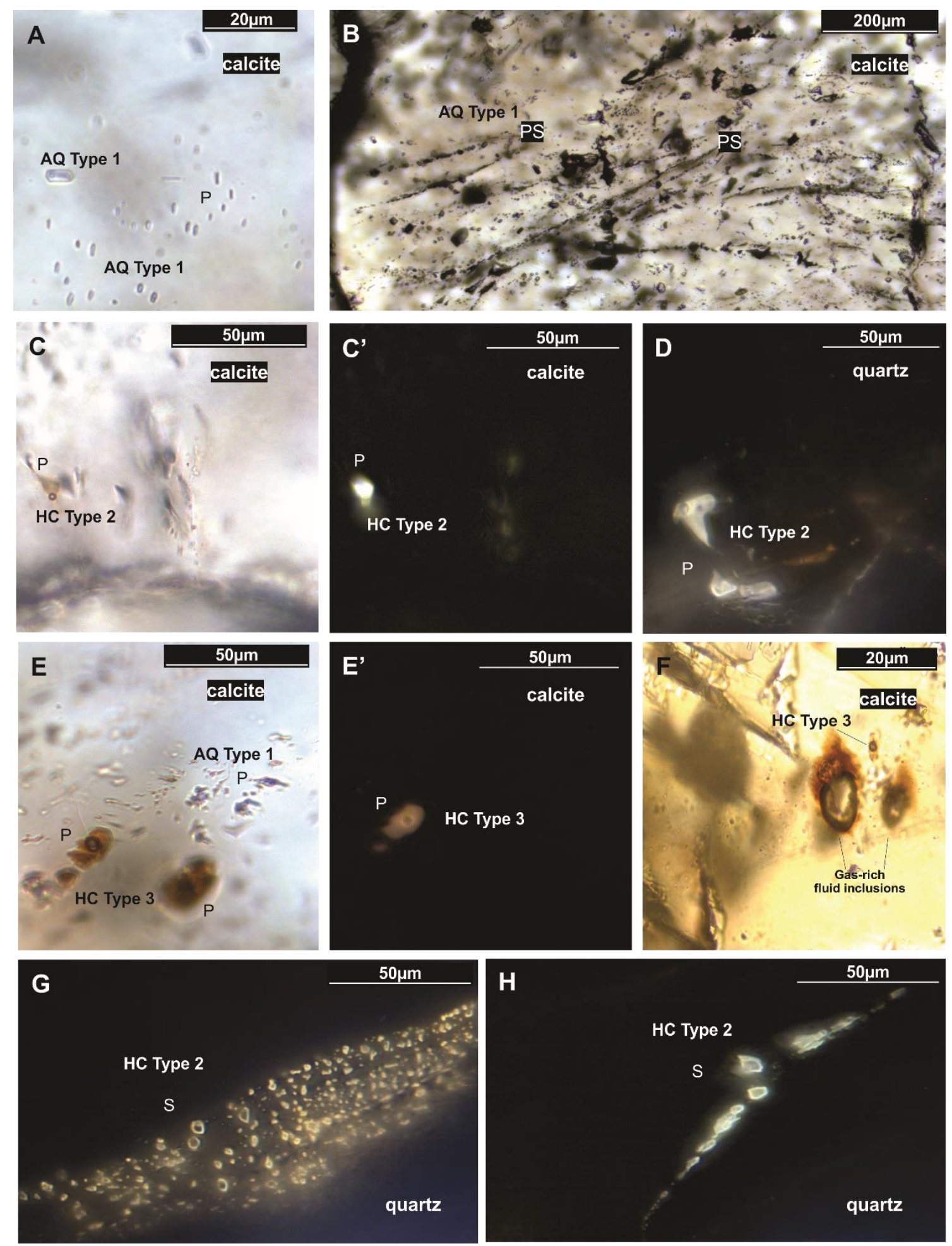

Fig. 5. Photomicrographs of aqueous and hydrocarbon fluid inclusion assemblages in quartz and calcite veins from the Irati Formation at room temperature $(\sim 20 \stackrel{\circ}{\circ})$. A; B; C; E; and F under transmitted light. C'; D; E'; G and H under ultraviolet light. (A) Assemblage of two-phase primary aqueous fluid inclusions associated to one-phase aqueous fluid inclusions in calcite (sample calcite-01) (B) Aligned pseudo-secondary fluid inclusions within healed microcracks which do not cut the authigenic calcite boundaries (sample quartz-02). (C and E) Assemblage of two-phase primary HCFl's coeval with AqFl's with irregular shape in calcite crystals (samples calcite-01 and calcite-03 respectively). (C') Two-phase primary hydrocarbon fluid inclusion with bright yellow fluorescence. (D) Quartz hosted two-phase primary hydrocarbon fluid inclusions with bright yellow/yellowish white fluorescence and irregular shapes (sample quartz-04). (E') A two-phase 
primary hydrocarbon fluid inclusion with orange fluorescence. (F) Gas-rich fluid inclusion with irregular shape (sample calcite-03). (G) Two-phase secondary HCFl's with irregular shapes and yellow fluorescence aligned within healed microcracks in quartz (sample quartz-04). (H) Twophase secondary HCFI's with irregular shapes and bright yellow fluorescence aligned within a healed microcrack (sample quartz-04). $\mathrm{P}=$ primary origin; $\mathrm{S}=$ secondary origin; $\mathrm{PS}=$ pseudosecondary origin. More details in Table 1.

\subsection{Fluid inclusion micro-thermometry}

4.3.1. Type 1 aqueous saline fluid inclusions (AqFl's)

The micro-thermometry data (Th, TE, Tm ice and salinity values) are resumed in the Table 2. The AqFl's from quartz and calcite veins of the Irati Formation (samples calcite-01; quartz-02; calcite-03 and quartz-04) have eutectic points (TE) between -57 and $-42{ }^{\circ} \mathrm{C}$ (Fig. 6B), ice melting temperatures (Tm ice) in intervals from -9.5 to $-18.5{ }^{\circ} \mathrm{C}$ and from -0 to $-5{ }^{\circ} \mathrm{C}$ (Fig. $6 \mathrm{C}$ ), and the homogenization temperatures (Th) vary from 50 to $330{ }^{\circ} \mathrm{C}$, with average of 133 ${ }^{\circ} \mathrm{C}$ (Fig. 6A). The Tm ice temperatures indicate two salinity groups, one with lower salinity varying from 0 to $5 \mathrm{wt}$. \% of $\mathrm{NaCl}$ equivalent, and the second with higher salinity varying mainly from 16 to 21 wt. \% of $\mathrm{NaCl}$ equivalent, with some intermediate values (Fig. 6D).

The AqFl's from calcite veins of the flood basalt of the Serra Geral Formation (sample SG-01) and the sill of the Paraná LIP (sample SLIP-02) have TE varying between -56 and $-47^{\circ} \mathrm{C}$ (Fig. 7B), Tm ice from 0 to $-2^{\circ} \mathrm{C}$ (Fig. 7C), and Th varying between 50 and $250^{\circ} \mathrm{C}$, with average of $143^{\circ} \mathrm{C}$ (Fig 7A). The Tm ice temperatures indicate fluid salinity varying from 0 to $4 \mathrm{wt}$. \% of $\mathrm{NaCl}$ equivalent. All Type 1 inclusions from both veins hosted in the Irati Formation and igneous bodies homogenize to the liquid phase. 
$\mathbf{A}$

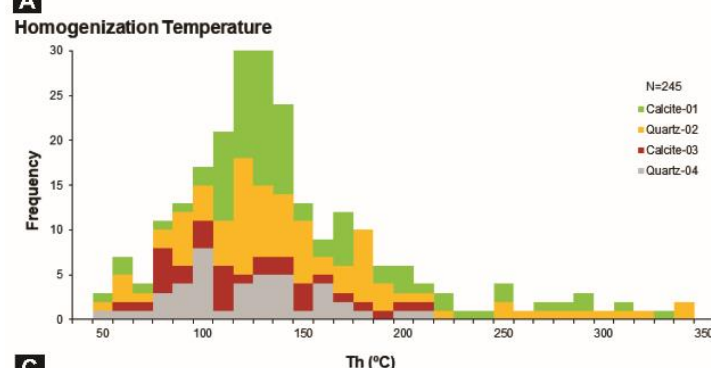

c Ice Melting Temperatures

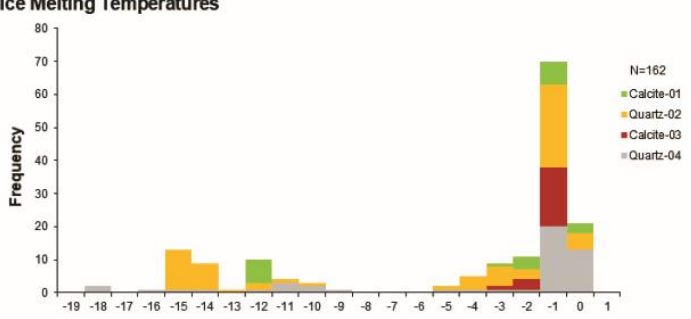

E

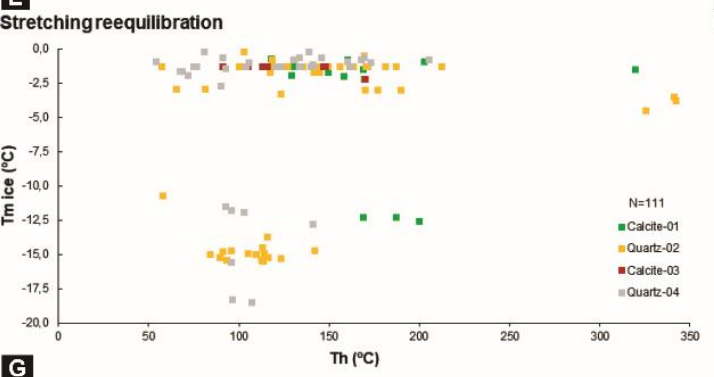

G

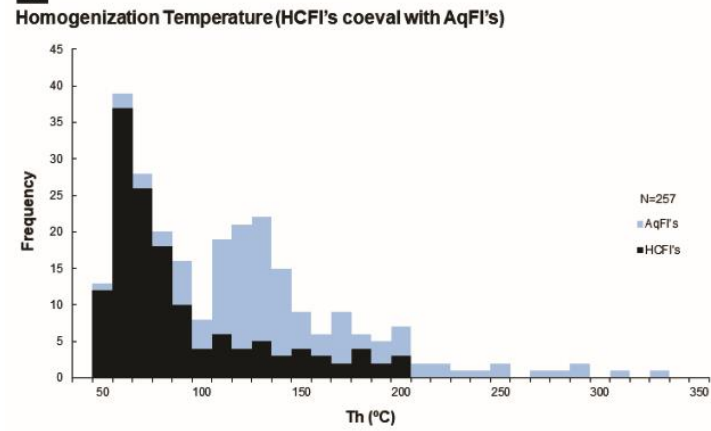

B

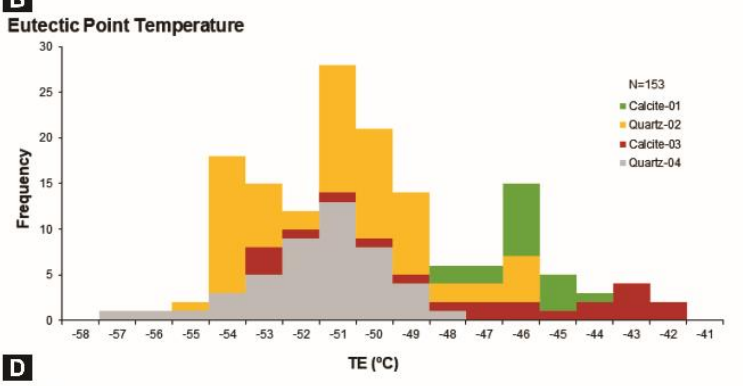

D

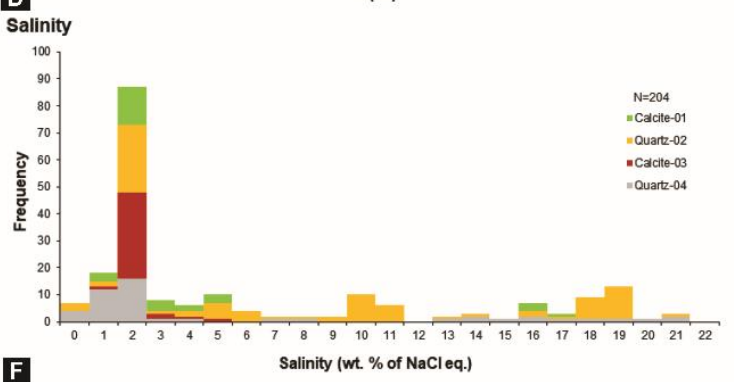

$\mathbf{F}$

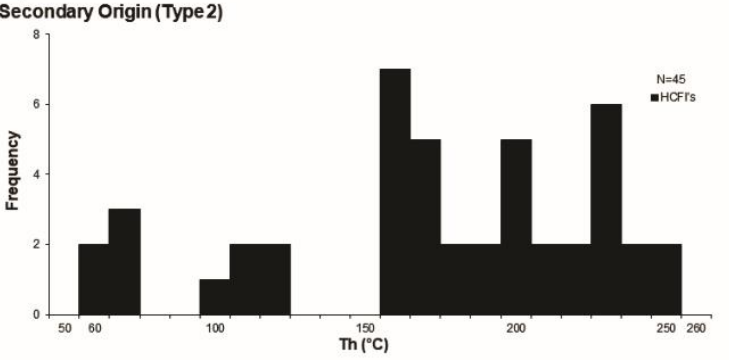

G'
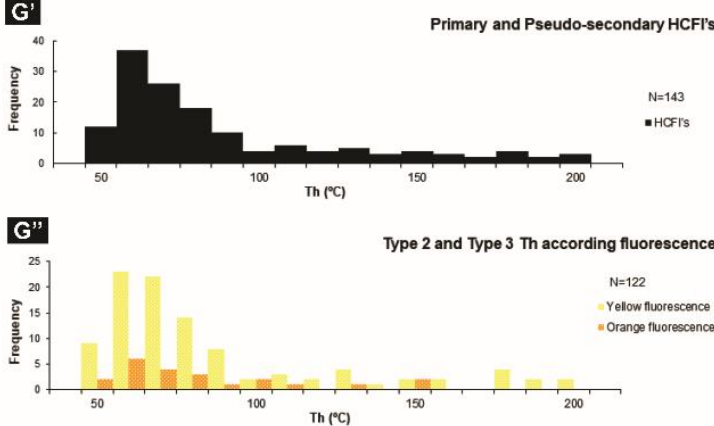

Fig. 6. Microthermometry results of the vein bearing of fluid inclusions from the Irati Formation. (A) Homogenization temperature (Th) from Type 1 inclusions. (B) Eutectic melting temperatures. (C) Ice Melting temperatures for Type 1 inclusions. (D) Salinity histogram showing two groups: one with moderately low salinity group ranging between $0-5 \mathrm{wt}$. \% of $\mathrm{NaCl}$ eq., and the other group ranging from 16-21 wt. \% $\mathrm{NaCl}$ eq. (E) Homogenization temperatures versus ice melting temperatures for Type 1 fluid inclusions. The data suggests the stretching reequilibration phenomena (see Bodnar, 2003). (F) Homogenization temperature (Th) from quartz veins hosted secondary hydrocarbon fluid inclusions (Type 2). (G) Homogenization temperature (Th) from primary and pseudo-secondary hydrocarbon fluid inclusions coeval with primary and pseudosecondary aqueous fluid inclusions. (G') Homogenization temperature (Th) from primary and pseudo-secondary hydrocarbon fluid inclusions. (G") Homogenization temperature (Th) from primary and pseudo-secondary hydrocarbon fluid inclusions according fluorescence. 

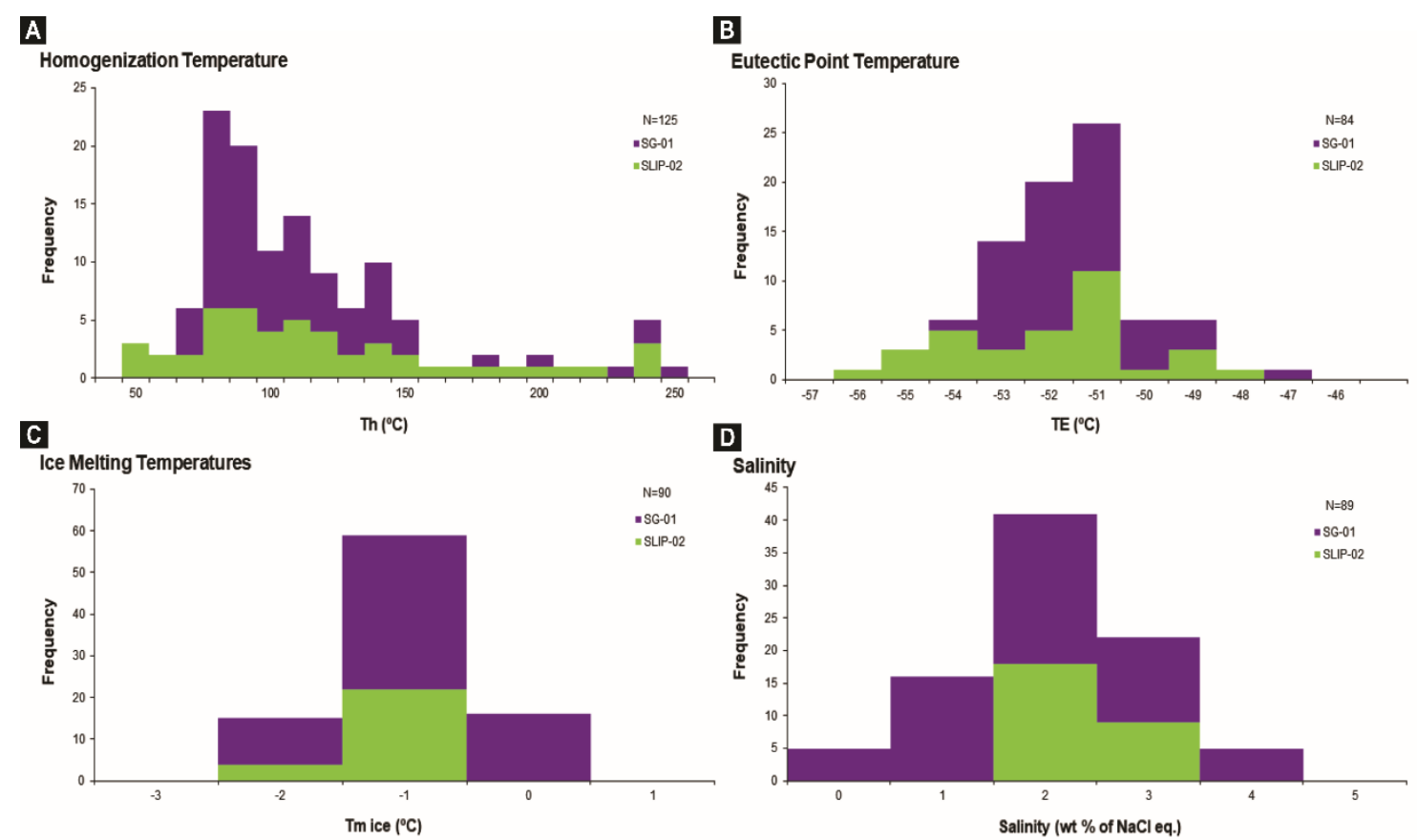

Fig. 7. Microthermometry results (Type 1 inclusions) from the veins in the flood basalt (sample SG-01) of the Serra Geral Formation and the veins hosted in the sill of the Paraná LIP (sample SLIP-02). (A) Eutectic temperature of the aqueous system. (B) Homogenization temperature from aqueous fluid inclusions. (C) Ice Melting temperatures for Type 1 inclusions suggests low salinity composition for the fluid flux. (D) Salinity (minimum salinity) histogram showing a moderate low values.

\subsubsection{Type 2 and Type 3 hydrocarbon fluid inclusions (HCFl's)}

The micro-thermometry data for all the HCFl's (primary and secondary origin) show variation of homogenization temperature (Th) from 50 to $250^{\circ} \mathrm{C}$. Primary origin of Type 2 and Type 3 inclusions, documented in the Irati Formation, can occur as random distributed (isolated) within both authigenic calcite (calcite-01 and calcite-03) and quartz crystals (quartz-04), coexisting with AqFl's. The Th data for the primary origin of HCFl's vary between 50 to $200{ }^{\circ} \mathrm{C}$, with a higher concentration between 60 and $80{ }^{\circ} \mathrm{C}$, with a few measures at 150 and $200{ }^{\circ} \mathrm{C}$ (Fig. 6G). Homogenization temperatures (contraction of vapor rich phase) from primary and pseudo-secondary origin of HCFl's (Type 2 and Type 3) vary from 50 to $200{ }^{\circ} \mathrm{C}$ (average of $96{ }^{\circ} \mathrm{C}$ ) and 50 to $330^{\circ} \mathrm{C}$ (average of $135^{\circ} \mathrm{C}$ ) for coeval AqFl's (primary origin). No relationship was observed between Th of Type 2 and Type 3 inclusions and their fluorescence color (Fig. 6G"). Secondary origin of Type 2 inclusions has Th variation between 160 to $250{ }^{\circ} \mathrm{C}$, with average of 173 ${ }^{\circ} \mathrm{C}$ and with some lower values between 60 and $120^{\circ} \mathrm{C}$ (Fig. 6F). 


\subsection{Confocal analysis of hydrocarbon fluid inclusions}

The sample quartz-04 from the Irati Formation was selected for confocal microscopy analysis of Type 2 HCFl's (primary origin). In total, it was analyzed 34 HCFl's by in situ confocal microscopy although the phase volume was determined in only 19 inclusions. The HCFl's present a small vapor volume fraction $\left(F_{v}\right)$ varying between 1.6 and $9.6 \%$ with average of $5.4 \%$ in relation of the total size of the inclusion and homogenization temperature varying between 62.3 and $139.7^{\circ} \mathrm{C}$ (Table 4). The analyzed inclusions appear to be spherical in shape (Fig. 8C).
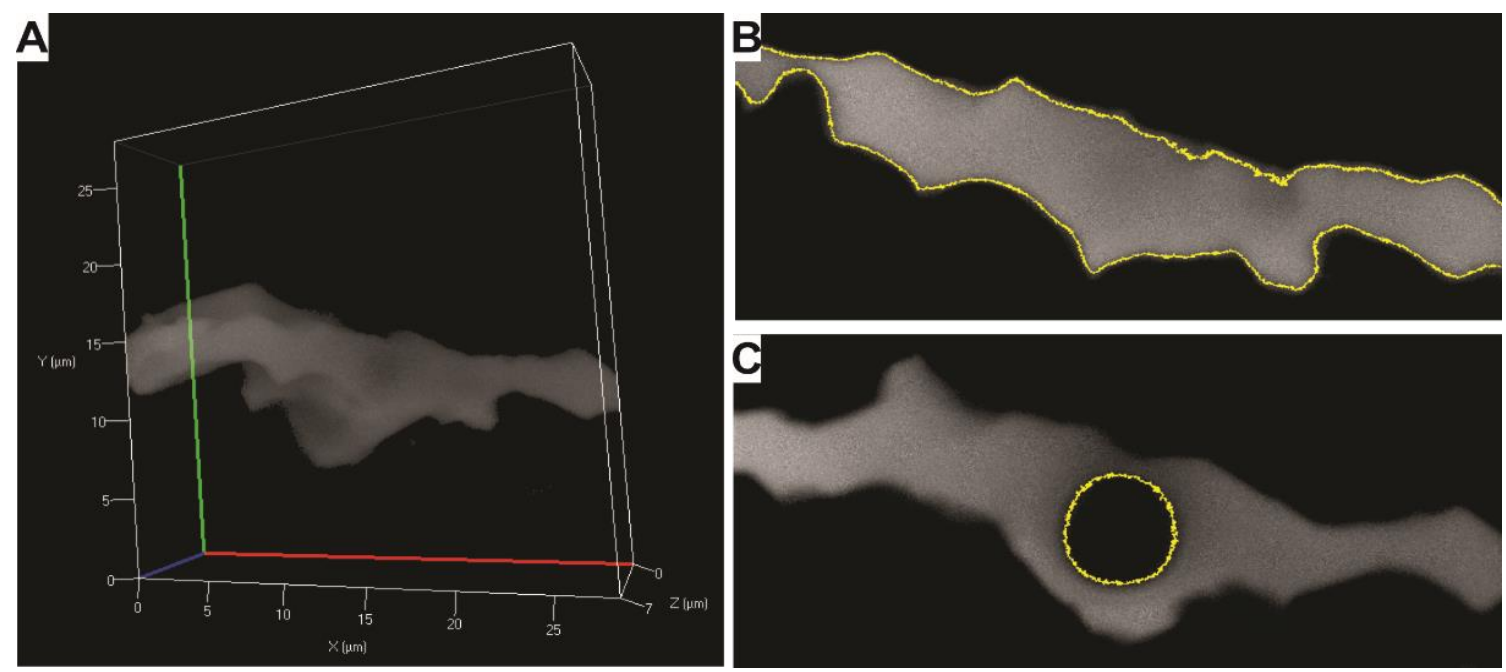

Fig. 8. Confocal scanning laser microscope analysis. (A) Example of a 3D volume rendering of a Type 2 inclusion hosted in the Irati Formation veins. (B, C) 2D confocal images modeled by specific software program to obtain the $F_{v}(C)$ and the liquid phase volume (B).

\subsection{Estimations of hydrocarbon trapping pressure}

Before the reconstruction of the PVT phase diagram of the hydrocarbon fluid inclusions from the Irati Formation (isopleths, isochores and real trapping conditions), it is necessary to illustrate $(\alpha-\beta)$ diagrams and plot the $\beta(\alpha)$ curve. This curve represents the best approximation to the nature of the original hydrocarbon fluid by selecting at least one point within the $\beta(\alpha)$ curve, which is the best way to obtain and describe the P-T properties of the trapped hydrocarbon (Thiéry et al., 2002). This curve can be modelled using micro-thermometry (Th) 
combined with phase volumes determined by confocal analysis $\left(F_{v}\right)$ as input parameters for the estimation (Table 4). Liquid petroleum, from low to high densities have $\alpha$ values ranging between 0.8 and 0.9 , while $\beta$ values are more variable, around 0.3 for heavy oils and 0.7 for light oils (Thiéry et al., 2002). Thus, as the results pointing out to black oil evidences (Fig. 9), it was considered a range of $(\alpha-\beta)$ between $(\alpha=0.916$ and $\beta=0.011)$ and $(\alpha=0.935$ and $\beta=0.306)$ for set $A$ and $B$, respectively, in order to attempt a reliable estimation. Thus, it was created two possible models, called A and B sets respectively (Fig. 10). The hydrocarbon P-T path was acquired based on the lower $\left(50^{\circ} \mathrm{C}\right)$ and higher $(80$ ${ }^{\circ} \mathrm{C}$ ) homogenization temperatures obtained from Type 2 inclusions. For set $A$, the P-T diagram shows a hydrocarbon large phase envelope and a coeval aqueous fluid inclusion homogenization temperature line (average of $135^{\circ} \mathrm{C}$ ) intersecting the hydrocarbon fluid inclusion isochore in a pressure about 496 bar for the 50 ${ }^{\circ} \mathrm{C}$ hydrocarbon isochore and 296 bar for the $80{ }^{\circ} \mathrm{C}$ hydrocarbon isochore (Fig. 10). For set $B$, the AqFl's Th line intersects the $50^{\circ} \mathrm{C} \mathrm{HCFl's} \mathrm{isochore} \mathrm{in} \mathrm{a}$ pressure of 548 bar and about 348 bar for the $80^{\circ} \mathrm{C}$ hydrocarbon isochore (Fig. 10). 


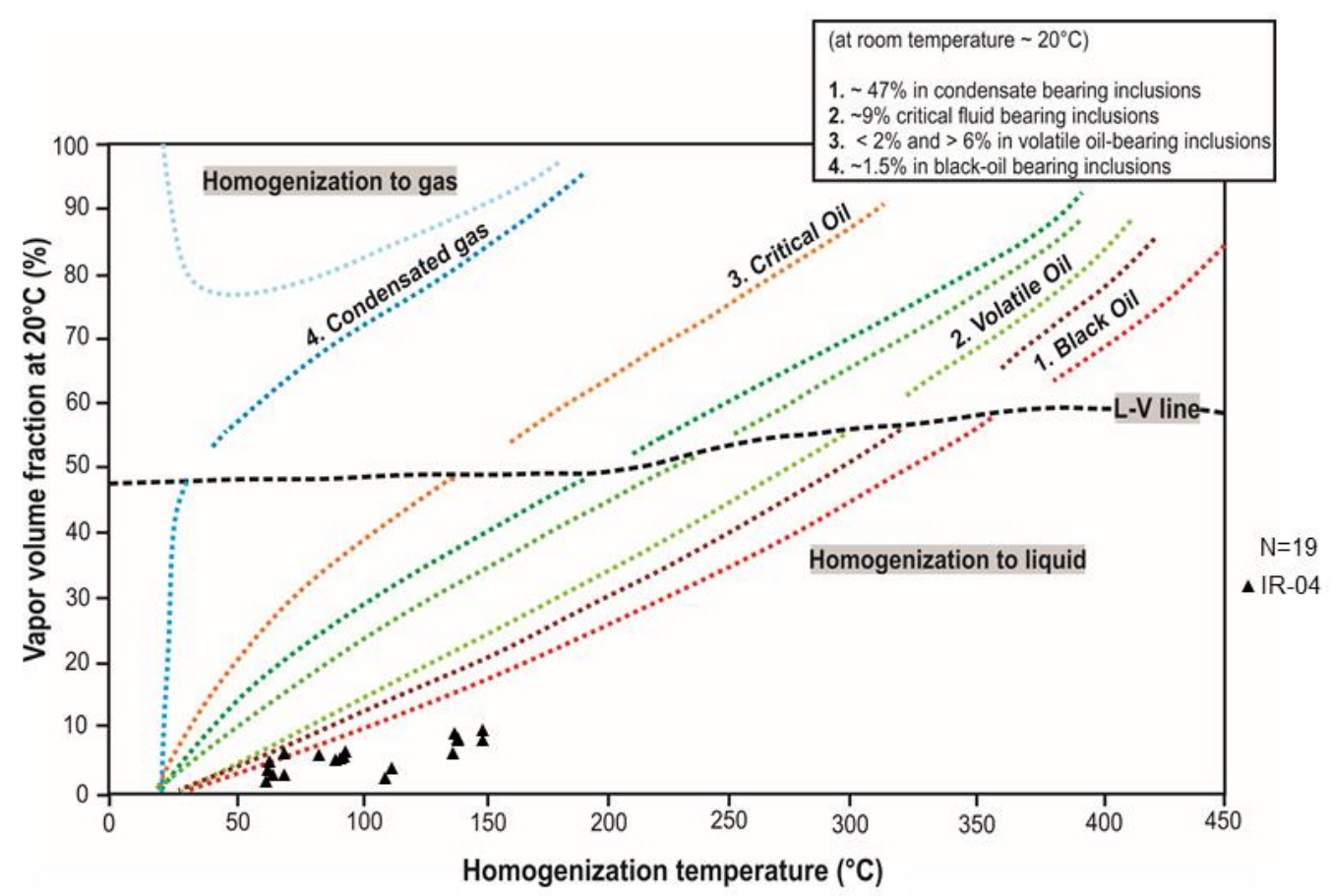

Fig. 9. Homogenization temperature versus vapor fraction. Black arrows represent $F_{v}$ versus $T h$ projections from hydrocarbon bearing fluid inclusions trapped in the veins of the Irati Formation, obtained from confocal scanning laser microscopy and microthermometry. The dashed lines indicate the variation of Th and Fv for several petroleum types (adapted from Bourdet et al., 2008 and modified from Pestilho and Monteiro 2017). 


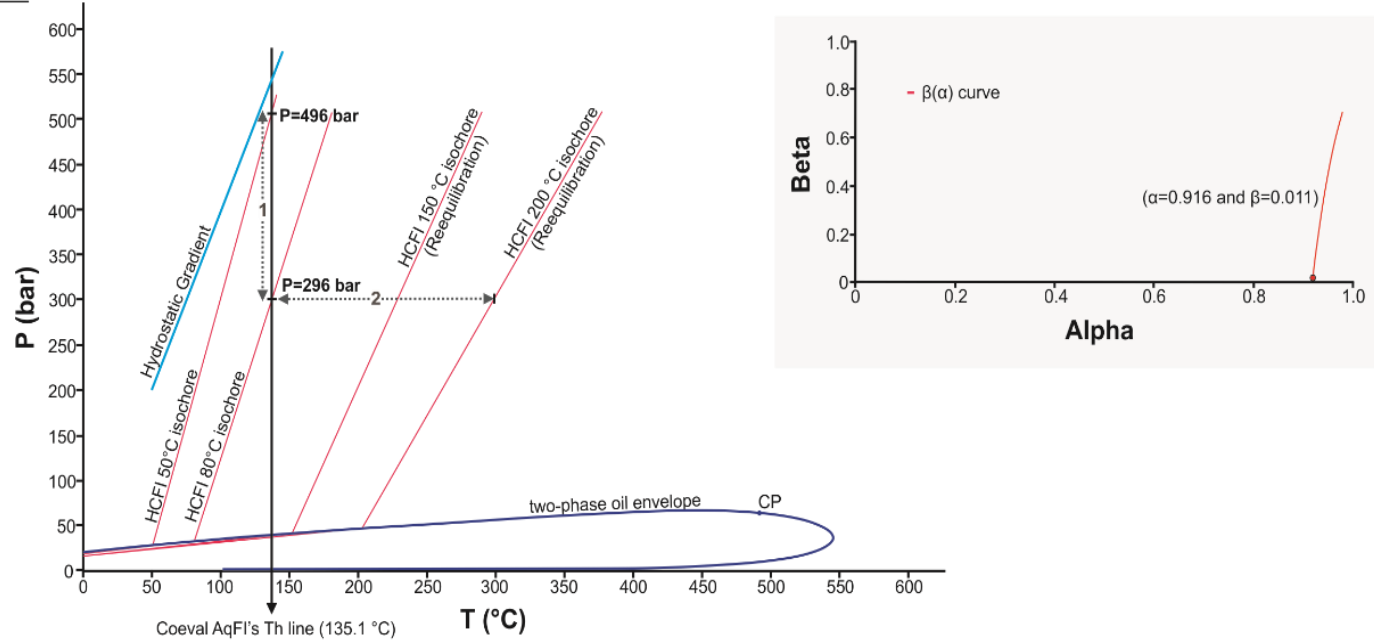

SET B

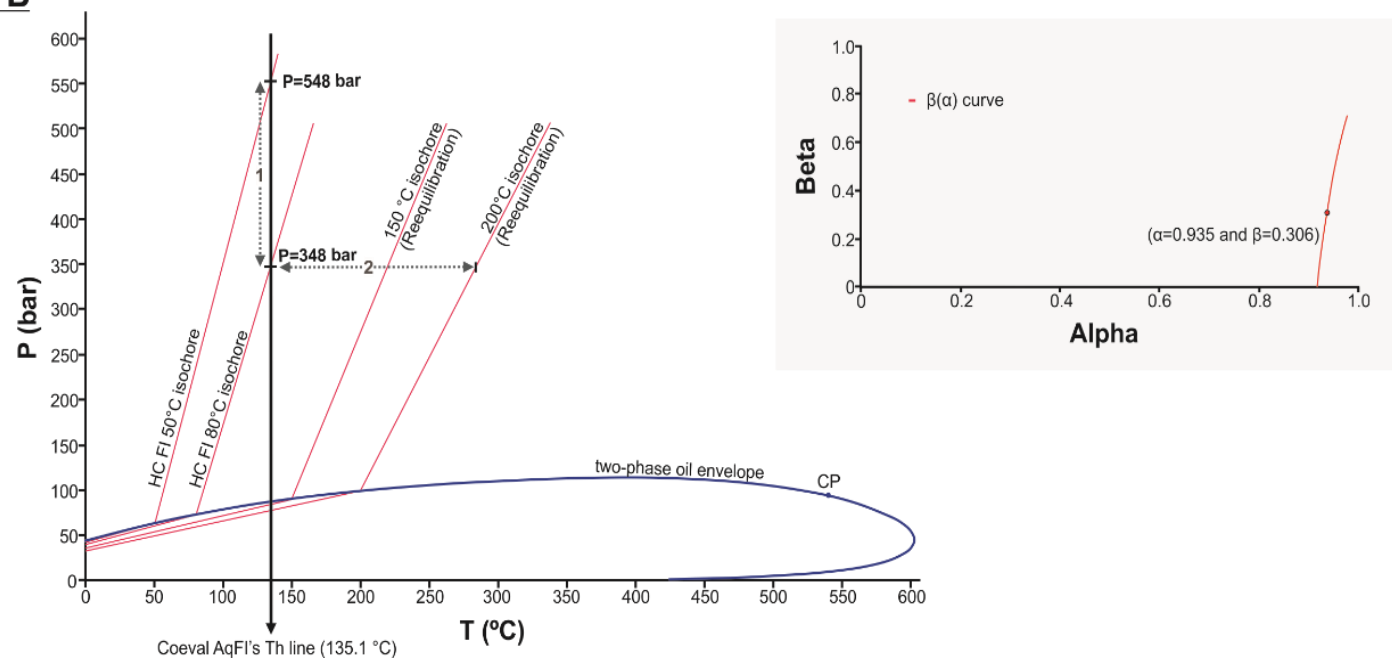

Fig. 10. PVT model and respective $\beta(\alpha)$ curve for hydrocarbon fluid inclusions trapped in subvertical quartz veins (extensional veins) in the Irati Formation. SET A: (1) Isothermal decompression which occurs with decreasing pressure at constant temperature. (2) Isobaric heating that occurs with increasing temperature for constant pressure. SET B is tested to prove pressure fluctuation (50bar) during the PVT modeling of the entrapped fluids.

\subsection{Stable carbon and oxygen isotopes in calcite veins}

Table 5 summarizes the $\delta^{13} \mathrm{C}$ and $\delta^{18} \mathrm{O}$ data obtained in the studied calcite veins. All samples tend towards negative (lower) $\delta^{13} \mathrm{C}$ and $\delta^{18} \mathrm{O}$ (PDB) values of calcite filled fractures from the Irati Formation, the flood basalt of the Serra Geral Formation and the sill associated to the Paraná LIP, thus they are enriched in ${ }^{12} \mathrm{C}$ and ${ }^{16} \mathrm{O}$ respectively. $\delta^{13} \mathrm{C}$ and $\delta^{18} \mathrm{O}$ values of calcite veins of the Irati Formation 
range from -5.97 to $1.36 \%$ (average of $-2.92 \%$ ) and from -6.79 to $-3.24 \%$ (average of $-2.85 \%$ ), respectively. The veins of the flood basalt (sample SG-01) of the Serra Geral Formation and the sill of the Paraná LIP (sample SLIP-02) have $\delta^{13} \mathrm{C}$ varying from -11.52 to $-7.93 \%$ with $-9.72 \%$ as average and $\delta^{18} \mathrm{O}$ from -9.47 to $-7.66 \%$ with average of $-8.57 \%$, respectively (Fig. 11 ).

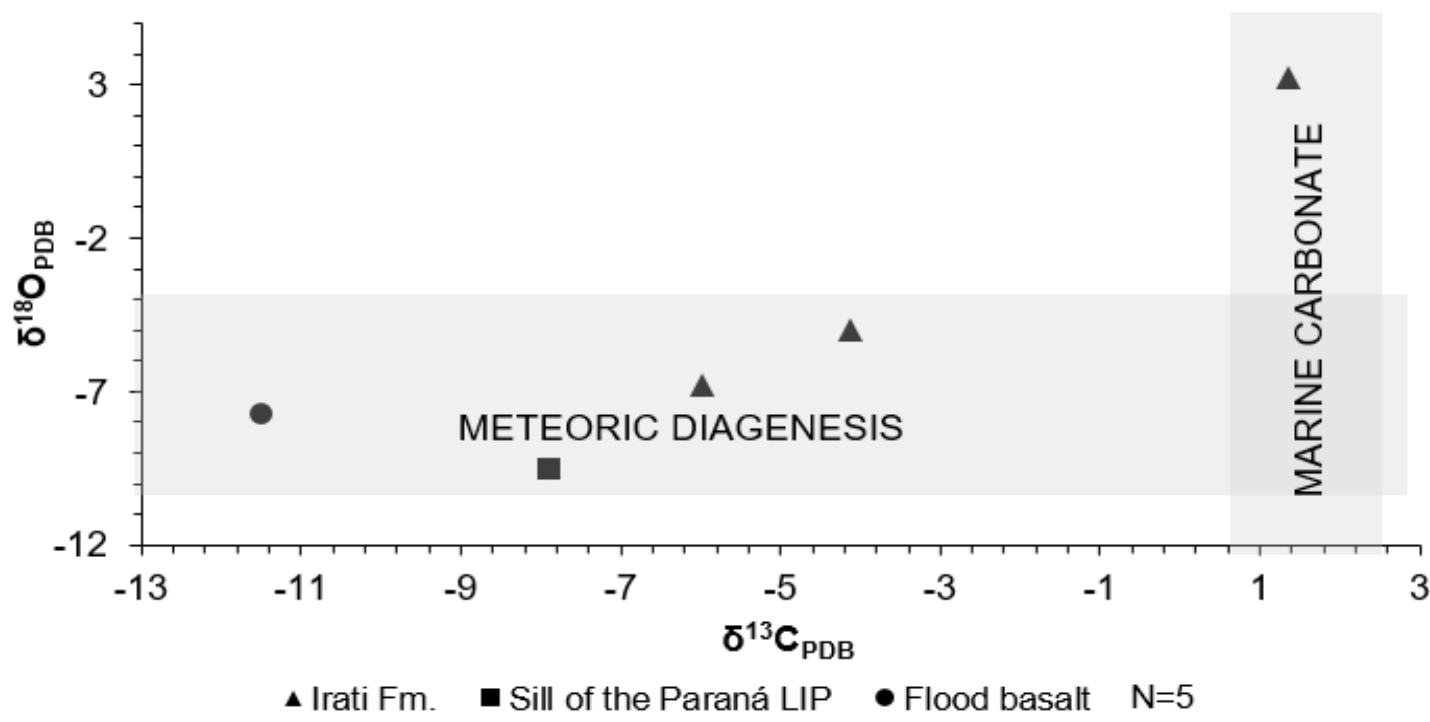

Fig. 11. Stable carbon and oxygen isotopes from the veins of the Irati Formation, the vein hosted in the flood basalt of the Serra Geral Formation and the vein hosted in the sill of the Paraná LIP. Meteoric diagenesis range based on Oehlert and Swart (2014).

\subsection{Vitrinite reflectance $(\% \mathrm{Ro})$ and thermal maturity}

All samples show concordant values of vitrinite reflectance (\% Ro), ranging between 0.2 and $0.9 \%$, with higher frequency measurement of between 0.6 and $0.7 \%$ (Fig. 12). All samples (IR-07; IR-08; IR-09; IR-10) show similar composition with great amount of mineral matrix and vitrinite maceral. The presence of vitrinite maceral is restricted to small fragments that occurred dispersed in the matrix. All samples show \% Ro average values of 0.6 varying from 0.2 to 0.8 (Fig. 12). Higher reflectance values of vitrinite fragments were observed in the sample IR$07(\%$ Ro $=0.9)$, however, they are not representative due to their low occurrence. The samples IR-09 and IR-10 contain vitrinite fragments with lowest reflectance values, between 0.2 and $0.3 \%$, with low occurrence as well (Fig. 12). 

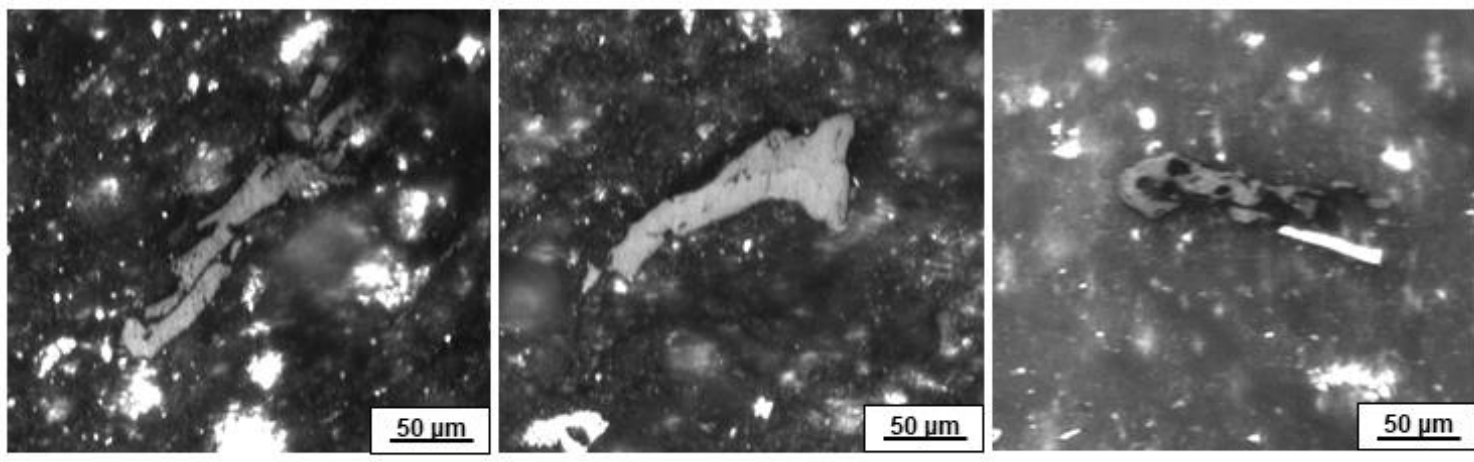

$\underset{\substack{\text { IR-07 } \\(\mathrm{n}=78)}}{ }$

IR-08

$(n=42)$
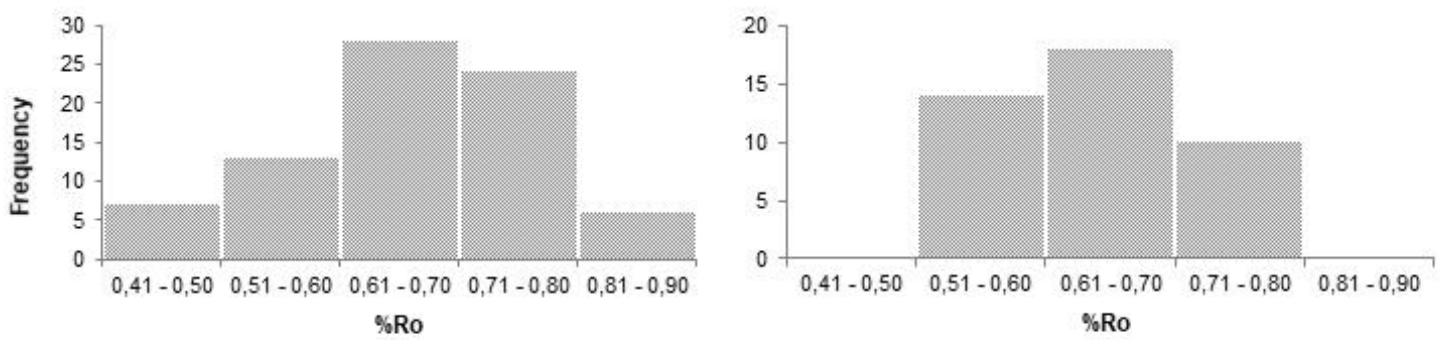

$\underset{\substack{\text { IR-09 } \\(n=38)}}{ }$

$\underset{\substack{\text { IR-10 } \\(\mathrm{n}=49)}}{ }$
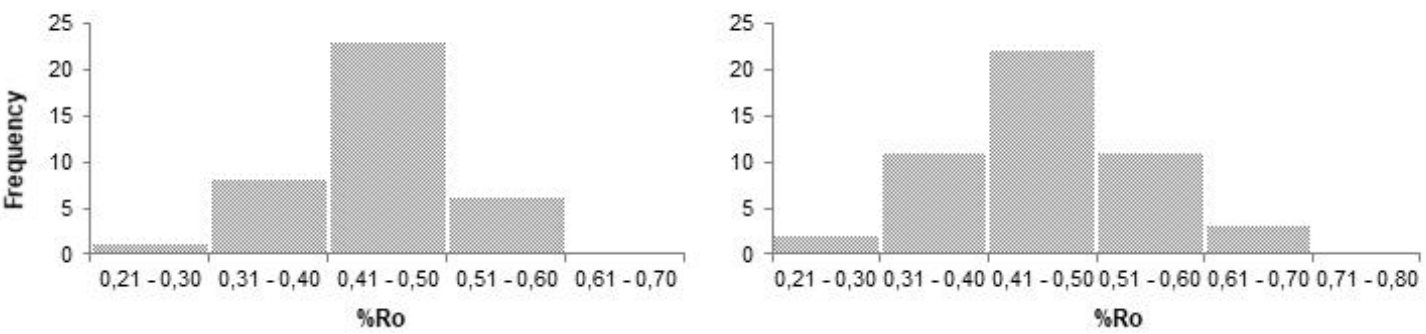

Fig. 12. Vitrinite reflectance data from the Irati Formation at southern flank of the Paraná Basin (Paraná State).

\subsection{NMR kerogen characterization}

The structural characteristics of kerogens isolated from the Irati Formation shale oil were studied by ${ }^{13} \mathrm{C}$ CP-MAS NMR. The ${ }^{13} \mathrm{C}$ CP-MAS NMR spectra of the solid kerogen samples, shown in Figure 14, are similar to other kerogen spectra described in the literature (Smernik et al., 2006; Kelemen et al., 2007), displaying two broad bands that can be assigned to aliphatic ( 0 to $70 \mathrm{ppm})$ and aromatic carbons (100 to $180 \mathrm{ppm}$ ). The aliphatic to aromatic or alkene ratios obtained for the kerogen samples are given in Table 5. 
Table 5. Resume of the organic geochemistry data and kerogen characterization of the Irati Formation shales.

\begin{tabular}{c|c|c|c|c|c}
\hline Sample & TOC & $\%$ Ro & $\begin{array}{c}\text { Kerogen } \\
\text { yield (\%) }\end{array}$ & $\begin{array}{c}\text { Aromatic C } \\
(\%)\end{array}$ & $\begin{array}{c}\text { Aliphatic C } \\
(\%)\end{array}$ \\
\hline IR-07 & 6.16 & 0.65 & 10.7 & 25 & 75 \\
\hline IR-08 & 4.69 & 0.65 & 8.3 & 44 & 56 \\
\hline IR-10 & 2.05 & 0.45 & 6.2 & 23 & 77 \\
\hline
\end{tabular}

\section{DISCUSSION}

\subsection{Thermal maturity of the Irati Formation shales and kerogen characterization}

Vitrinite reflectance is a trustworthy indicator of thermal maturity of organic components within sedimentary rocks (Hood et al., 1975; Hutton and Cook, 1980; Tissot and Welte, 1984) and for evaluating temperatures required for oil and gas generation (Potter et al., 1998; Jarvie et al., 2007), although, there are still major limitations inherent. The critical problem regarding the use of Ro is the vitrinite reflectance suppression and enhancement (Fang and Jinayu, 1992). Vitrinite suppression could be associated to the presence of vitrinite macerals with a dominant population of liptinite group macerals (alginate; resinite, etc) and the Ro values enhancement could be related to aerobic depositional conditions (Wenger and Baker, 1987).

Though Araújo et al. (2000) have shown that vitrinite reflectance values in the Irati Formation increased from 0.6 to $2 \%$ Ro within $1.5 \mathrm{~m}$ of the contact with an igneous body, it is common to find abnormally low \% Ro values in source rocks that have been heated above $150^{\circ} \mathrm{C}$ and contain liquid hydrocarbons (Price and Barker, 1985). In the southeastern part of the Paraná Basin, vitrinite measured in the studied shale samples yield Ro average of $0.6 \%$ (Fig. 12), suggesting a low maturity kerogen for the Permian organic-rich shales and a temperature window between 60 and $80{ }^{\circ} \mathrm{C}$, in an area with absence of magmatic intrusive bodies. Thus, this maturity data suggest that the thermal evolution of the organic-rich shales was controlled essentially by burial, including the thick continental flood basalt cap, but with minor effect of dykes or sills intruded in the adjacent units. 
These vitrinite reflectance values correspond to oil-window maturities in which liquid hydrocarbon is generated (Dembicki, 2013). Such evidences are in contrast with our Th values from AqFl's coeval with HCFl's (varying between 50 and 330 ${ }^{\circ} \mathrm{C}$ ), pointing out to differences in thermal maturity between the Irati Formation shales and the veins cutting this unit in the northeastern part of the basin. The Ro and the ${ }^{13} \mathrm{C}$ CP-MAS NMR results of the solid kerogen samples (Table 5) indicate convergence between the aromaticity $\left(f_{\mathrm{ar}}\right)$ of the kerogen and the vitrinite reflectance maturity. Aromaticity (ratio of aromatic to aliphatic carbons) is accepted as reliable parameter for determine thermal maturity of the kerogen (Wang et al., 1995; Werner-Zwanziger et al., 2005). Our studied samples (IR-07; IR-08 and IR-10) show ${ }^{13} \mathrm{C}$ CP-MAS NMR spectra including aliphatic and aromatic carbon structures (Fig. 13). Indeed, the carbons with unsaturated bonds, not necessary cyclic, are observed around $130 \mathrm{ppm}$. Thus, the broad signal at higher frequencies can be associated to a mixture of aromatic and alkene carbons. However, considering the long contact time (1.5 ms) is supported by several reported studies within an error of roughly $20 \%$ with a tendency of underestimation of unsaturated carbons (Wei et al., 2005; Smernik et al., 2006; Kelemen et al., 2007; Solum et al., 2014). The signal noise ratio of the $B$ and $C$ spectra (samples IR-08 and IR-10) is lower than the A spectrum (sample IR-07) due to the lower contents of protons in the kerogens from the IR-08 and IR-10 samples in comparison with kerogen from the IR-07 sample. The signal due to the aliphatic carbons for samples IR-07 and IR-08 are much broader than for the sample IR-10, with their signals extending to higher frequencies (up to $50 \mathrm{ppm}$ ). The signals near $50 \mathrm{ppm}$ can be attributed to carbon atoms bonded to oxygen, nitrogen and sulfur functionalities, which are commonly present in kerogens. These results indicate a higher content of $\mathrm{O}, \mathrm{N}$ and $\mathrm{S}$ functionalities in IR-07 and IR-08 as compared to IR-10. Also, the signals close to $50 \mathrm{ppm}$ might indicate NSO compounds (C-O, C-N and C-S), which normally are present in the kerogen in small quantities. When plotting \% Ro versus $f_{\text {ar }}$ data, it is identified a non-linear relationship between the samples IR-07 and IR-10 and other macerals from

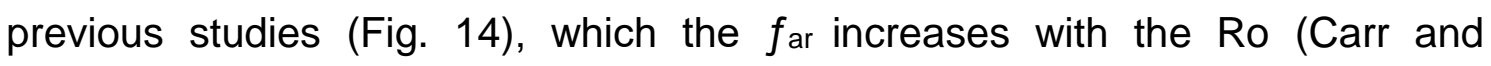
Williamson, 1990), during natural heat caused by the presence of igneous bodies or by burial (Witte et al., 1988). In addition, previous studies endorsed that increase of aromaticity combined with increasing of maturity is followed by the 
loss of aliphatic fraction (Witte et al., 1988; Miknis et al., 1993; Cao et al., 2013), which is not this case. These thermal indicators data based on kerogen analysis suggest a low maturity level achieved by the Irati Formation shales over the southeastern part of the Paraná Basin while fluid inclusions data can have significant influence of hydrothermal fluids induced by magmatic intrusive bodies (Liu et al., 2017).

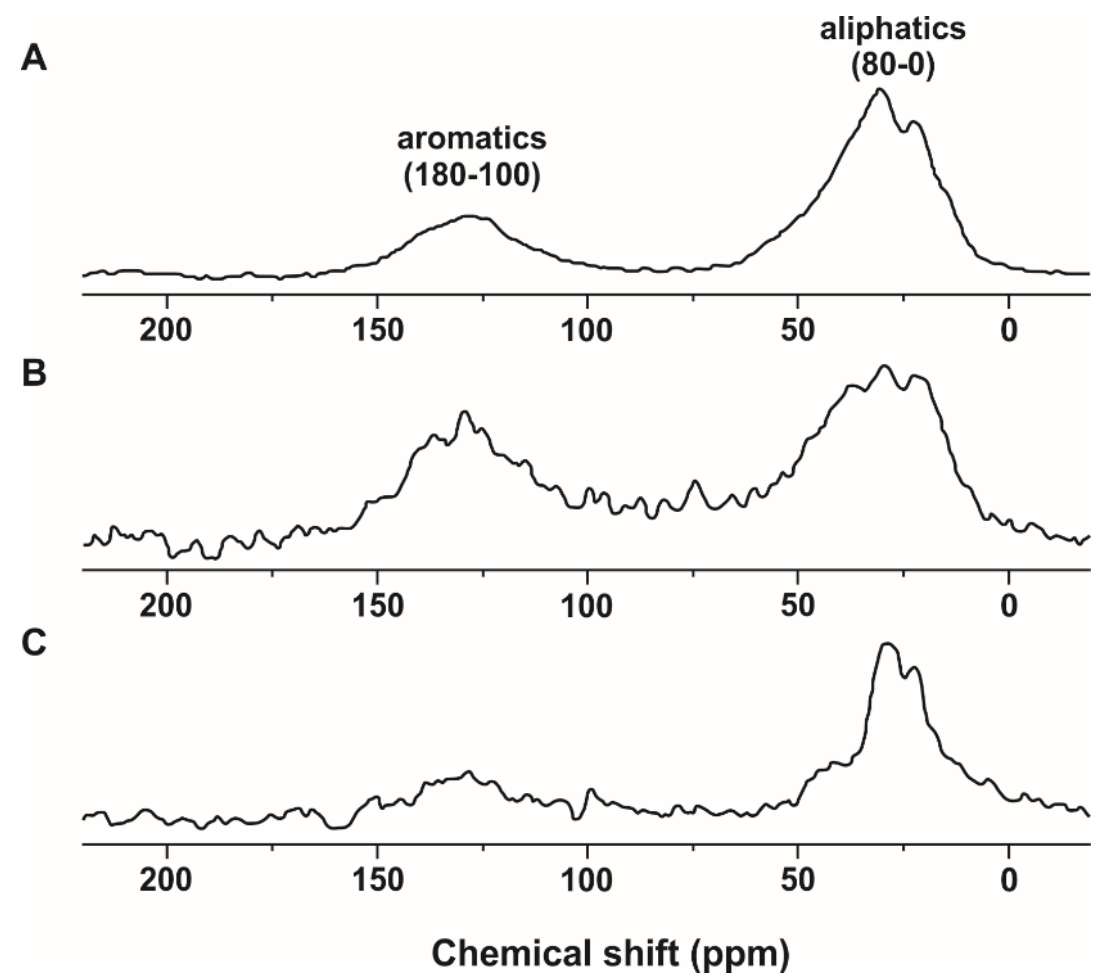

Fig. 13. ${ }^{13} \mathrm{C}-\mathrm{NMR}$ CP-MAS spectra of isolated kerogen from the (A) sample IR-07; (B) sample IR-08 and (C) sample IR-10. 


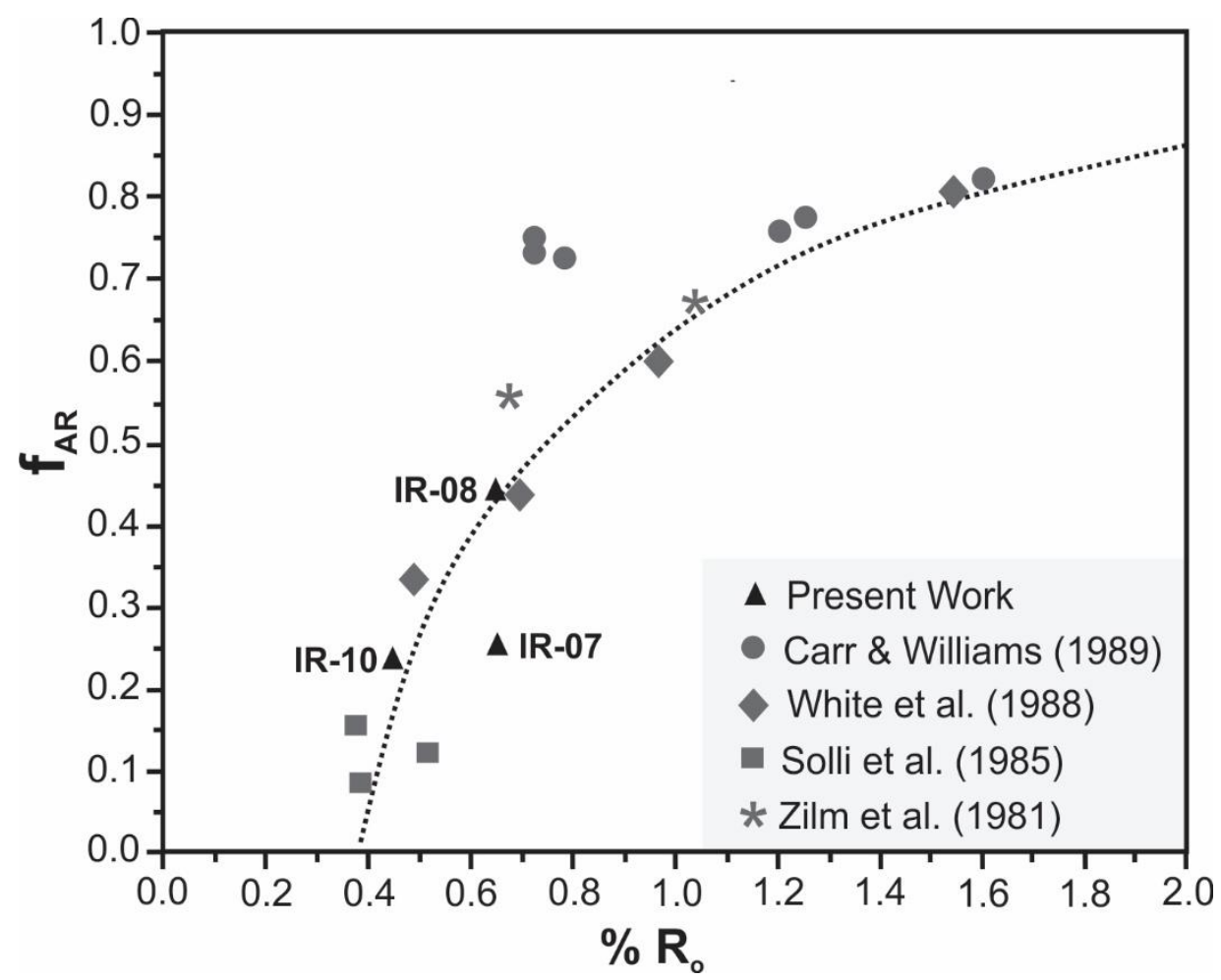

Fig. 14. Aromaticity versus vitrinite reflectance plot of three samples from the Irati Formation compared to previous studies.

\subsection{Thermal maturity of HCFI's}

The variable fluorescence colors founded in hydrocarbon fluid inclusions (Type 2 and Type 3) hosted in the authigenic veins of the Irati Formation in northeastern part of the basin indicate that the hydrocarbon density was modified to varying degrees during crystal growth (Li and Parnell, 2003; Ping et al., 2017). The HCFI's fluorescence dominant populations (orange and yellow) point to densities ranging from 30 to $10^{\circ} \mathrm{API}$ and the presence of intermediate to light hydrocarbons hosted in the authigenic veins of the Irati Formation (Goldstein and Reynolds, 1994). According to Stasiuk and Snowdon (1997), the fluorescence spectra at $550 \mathrm{~nm}$ (Lmax), which is related to an oil with 40 to $50 \%$ of aromatic carbons, suggests that the structure of the hydrocarbons fluid inclusions (liquid phase) might have between 50 and $60 \%$ of aliphatic compounds. Verna et al. (2012) discussed that bright yellow fluorescence in primary fluid inclusions is typical of lower maturity oils. Despite, the absence of a complete chemical characterization in the HCFI's (i.e. by IR spectrometry and GC-MS), the data is consistent with 
aromaticity of the kerogen ( $>60 \%$ of aliphatic hydrocarbons) and the optical fluorescence colors, which points the potential possibility of the Irati Formation in the generation of light liquid hydrocarbons. Thus, this evidence represents similar thermal history between the liquid hydrocarbons trapped as fluid inclusions, in northeastern part of the basin, and the potential generation of light hydrocarbons from the organic-rich shales in the southeastern part of the basin (Fig. 1). However, besides the fluorescence color of liquid hydrocarbons is influenced by the source rock origin and thermal maturity (Stasiuk and Snowdon, 1997), secondary modifications of the petroleum in the reservoir or fracture system can occur, like biodegradation, water washing and/or gas washing (Tissot and Welte, 1984).

\subsection{Temperature of hydrocarbons entrapment}

Quartz and calcite crystals containing HCFl's coeval with AqFl's (Fig. 5E), suggest a fluid flux with water partly miscible with oil and an active petroleum system during the development of these veins. The Irati Formation show HCFl's with Th lower than the Th of coeval AqFl's (Fig. 6G). The expressive difference in Th for the primary AqFl's $\left(135^{\circ} \mathrm{C}\right.$ ) and HCFl's $\left(96^{\circ} \mathrm{C}\right)$ could be due to the potential co-occurrence of a minute water phase in the HCFI's, not optically visible (Permeneyer et al., 2017), as occurred in migration pathways (cemented fractures) documented in the North Sea (Oxtoby et al., 1995; Munz et al., 1998, 2004) and reservoir filling histories as discussed by Munz et al. (1999a). In the northeastern part of the Paraná Basin, the hydrocarbon migration might have occurred concomitant to the first stages of vein growth (Early Cretaceous) due to the presence of primary HCFl's. Primary and pseudo-secondary Type 2 HCFI's (that yield yellow fluorescence) could have migrated in the fractures zones at diagenetic temperatures ranging from 50 to $200^{\circ} \mathrm{C}$ (Fig. $6 \mathrm{G}$ ). A later stage of hydrocarbons migration (or a posterior hydrocarbon pulse), with higher homogenization temperatures $\left(160-250^{\circ} \mathrm{C}\right)$, flowed within the veins of the Irati Formation (Fig. 6F). These temperatures might be related to a fluid flow possibly induced by local pressure gradients, after cooling of the Irati emplaced sill during the Early Cretaceous (Mateus et al., 2014). Gas-rich fluid inclusions $\left(\mathrm{CH}_{4}\right)$ or carbonic rich inclusions $\left(\mathrm{CO}_{2}\right)$ within the veins were not observed either in calcite 
veins of the flood basalt from the Serra Geral Formation or in the veins hosted in the sill of the Paraná LIP. Thus, the results of the fluid inclusion microthermometry data show the minimum trapping temperature of primary HCFl's (96 ${ }^{\circ} \mathrm{C}$ ) and AqFl's $\left(135^{\circ} \mathrm{C}\right)$, leaded by a later migration pulse with trapping of secondary HCFl's at $173^{\circ} \mathrm{C}$ (average). Specifically, these Th combined with the estimation of the HCFl's composition (Permeneyer et al. (2017) and the PVT modelling, suggests an event of light to medium hydrocarbon densities trapped during diagenesis at around $135^{\circ} \mathrm{C}$.

In addition, in the southeastern part of the Paraná Basin, data from Ro $(\% 0.6)$ point to burial temperatures between 60 and $80{ }^{\circ} \mathrm{C}$ (Hunt, 1996) and a window generation of liquid hydrocarbons (Dembicki, 2013). Thus, the Serra Geral magmatism may not have influenced hydrocarbons generation on a regional scale in the basin, but only locally close to the intrusive bodies. This means that the Irati Formation, over the eastern border of the Paraná Basin, reached sufficient depth to generate heterogeneous liquid hydrocarbons (medium to low density), and magmatism is essentially responsible for migration and biodegradation.

\subsubsection{Hydrocarbons classification in quartz veins}

Hydrocarbons trapped as fluid inclusions in quartz veins allowed to establish the original composition of liquid hydrocarbons generated in the Irati Formation (sample quartz-04). The micro-thermometry combined with confocal analysis can gives us the possibility to discriminate the oil types trapped in fluid inclusions. The micro-thermometry data show Th average of $101.4^{\circ} \mathrm{C}$ and the confocal images revealed $F_{v}$ varying from 1.6 to $9.6 \%$ with average of $5.4 \%$ (Table 3). This data permitted the classification of the trapped hydrocarbons as black oil (Thiéry et al., 2002; Bourdet et al., 2008). In the case of the studied fluid inclusions, all trapped hydrocarbons are suggested to classified as black oil (Fig. 9), similar as the North Sea reservoir and the Gulf of Mexico well core samples interpreted by Bourdet et al. (2008). According to Danesh (1998), black oil is the most common type of oil reserves and is characterized by medium to light compounds with a variation of gravity $\left(\mathrm{API}^{\circ}\right)$ relatively small, corresponding to medium and low density fluids. Also, black oil generation may occur from $0.6 \%$ Ro until about 1.1-1.2 (Dembicki, 
2013). In addition, the combination of $F_{v}$ and Th measurements shows a trend which follows a small $F_{v}$ increasing versus a large Th variation (Fig. 9) suggesting post-entrapment modification of the inclusions (Bourdet et al., 2008). Hence, the small vapor bubbles of the HCFI's at room temperature, which means that liquid phase is dominant, and the fluorescence variation showed in petrography corroborate the interpretation of the observed HCFl's as black oil (Fig. 5C and $5 \mathrm{D})$. The potential of the confocal technique combined with micro-thermometry and petrographic data on determine the composition and PVT properties of HCFI's are documented in different geological backgrounds as discussed by Aplin et al. (1999).

\subsubsection{PVT properties of the HCFI's}

The PVT model for the set $A$ (with lower $\beta$ value which represents the methane content in fluid - Thiéry et al., 2002) gives trapping pressures between 500 and 300 bar, corresponding to $50^{\circ} \mathrm{C}$ and $80^{\circ} \mathrm{C}$ hydrocarbon isochores respectively (Fig. 10). This pressure suggests the minimum pressure achieved in filled fractures and corresponds to more than $2 \mathrm{Km}$ depth where the input Th value (135 ${ }^{\circ} \mathrm{C}$ from coeval AqFl's) is the real homogenization temperature considered (Munz, 2001). The highest pressure ( 500 bar) was obtained from a hydrocarbon isochore at $50^{\circ} \mathrm{C}$ indicating the maximum pressure possibly achieved by veins. The set $\mathrm{B}$ was tested to prove that determining fluid trapping pressures is not possible without an uncertainty of 50 bar approximately (Thiéry et al., 2002). Despite the differences in pressure between these sets (around 52 bar) it is reliable to discriminate between hydrostatic and lithostatic regimes during hydrocarbon entrapment. Considered the set $A$ as reference due to lower methane content in the fluid, the variation pressure is interpreted as a result from fluid pressure fluctuation during veining, nevertheless, burial of a reservoir leads to simultaneous pressure-temperature changes (Thiéry et al., 2002). This model points out to the opening of subvertical extensional veins and hydrocarbon fluid inclusions entrapment within subhydrostatic to hydrostatic pressure regime due to an isothermal decompression and an isobaric heating (Fig. 10). These results mean that during the time of hydrocarbon trapping (Early Cretaceous) the Irati Formation was $2 \mathrm{~km}$ deep. Indeed, this pressure could be related to a shallow 
petroleum system (below the isotherm of $80{ }^{\circ} \mathrm{C}$ ), meaning that important weathering processes on hydrocarbons such as the biodegradation can occur. The presence of moderate low salinity fluid flux in veins, possibly mixed with pore fluids (see section below), might be responsible for the biodegradation of hydrocarbons, which is in agreement with orange fluoresce on primary HCFI's observed in subvertical calcite veins (Fig. 5E') and the PVT model estimated. Thus, this shallow petroleum system and the period after the cooling of the intruded sill, promoted the biodegradation on HCFl's in the Irati Formation, as indicated by the trapping conditions and the fluorescence color of the inclusions.

\subsection{Aqueous saline fluid flow in authigenic calcite and quartz veins}

Previous studies in the Permian units of the Paraná Basin revealed that maximum Th from aqueous fluids was higher than $200^{\circ} \mathrm{C}$ (Nomura et al., 2014; Teixeira et al., 2018). The homogenization temperatures (> $\left.200^{\circ} \mathrm{C}\right)$ achieved by aqueous fluids from the veins of the Irati Formation, the veins from the continental flood basalt of the Serra Geral Formation and the veins hosted in the sill of the Paraná LIP, reinforces the regional heating hypothesis caused by burial of the flood basalts, estimated in $1.7 \mathrm{Km}$ thickness. This hypothesis certainly has influenced the thermal maturity of the Irati Formation shales which was mostly controlled by burial.

In the Irati Formation, two groups of ice melting temperatures (Tm ice) are recognized in Type 1 fluid inclusions, one varying from -5 to $0^{\circ} \mathrm{C}$ and other varying from -15 to $-10^{\circ} \mathrm{C}$. These temperatures indicate two salinity groups, one group varying from 0 to $5 \mathrm{wt}$. \% of $\mathrm{NaCl}$ equivalent and other varying from 16 to $21 \mathrm{wt}$. $\%$ of $\mathrm{NaCl}$ equivalent. Despite the high salinity group, the veins are dominated by low salinity fluid (Fig. 6D).

The eutectic melting temperatures (TE) point out the same fluid composition system $\left(\mathrm{H}_{2} \mathrm{O}+\mathrm{NaCl}+\mathrm{CaCl}_{2}\right)$ responsible for calcite and quartz veins development (Roedder, 1984; Goldstein and Reynolds, 1994). Indeed, Nomura et al. (2014) revealed similar temperatures in AqFl's hosted in sub-vertical calcite veins of the Teresina Formation (top of the Permian succession of the Paraná Basin), suggesting a vertical continuity migration (upwards or downwards) through the veining paths cutting the strata. The eutectic temperatures below -40 
${ }^{\circ} \mathrm{C}$ point out to aqueous fluid with divalent cations, such as $\mathrm{Ca}^{2+}$ and/or $\mathrm{Mg}^{2+}$ (Davis et al., 1990). The presence of $\mathrm{Ca}^{2+}$ is possible due to the presence of authigenic calcite (Crawford and Hollister, 1992) on carbonate layers of the Irati Formation. Thus, considering the compositional variation, in terms of salinity, fluids from two generations, one varying from 0 to $5 \mathrm{wt}$. \% of $\mathrm{NaCl}$ equivalent and the second varying from 16 to $21 \mathrm{wt}$. \% of $\mathrm{NaCl}$ equivalent, have percolated these veins. This variation might be representative of the strong interface rock-water interaction and the mixture of pore and connate water during burial and diagenesis. Despite the presence of a higher salinity family in samples calcite01, and quartz-02 of the Irati Formation (Tm ice range from -18 to $-10{ }^{\circ} \mathrm{C}$ ) mostly AqFI's presented $\mathrm{Tm}$ ice range from -3 to $0{ }^{\circ} \mathrm{C}$, with an average of $-1{ }^{\circ} \mathrm{C}$, suggesting a low moderately salinity fluid as responsible for precipitating the quartz and calcite veins hosted in the Irati Formation during the Early Cretaceous (Fig. 15). For fluid history reconstruction or fluid dynamics, fluid mixing and salinity variation, during the development of authigenic veins or filling of oil reservoirs, are relevant features in sedimentary basins worldwide (Bodnar, 1990; Nedkvitne et al., 1993; George et al., 2007; Baron et al., 2008; Cao et al., 2010; Suchý et al., 2010; Bourdet et al., 2012).

The $\delta^{13} \mathrm{C}$ values measured in the studied calcite veins are in the range of carbonate rocks from meteoric origin enriched in ${ }^{12} \mathrm{C}$ with $\delta^{13} \mathrm{C}$ values varying between -15 and $-1 \%$. The marine carbonates are depleted in ${ }^{12} \mathrm{C}$ with $\delta^{13} \mathrm{C}$ values close to $\pm 0 \%$ (Hoefs, 2004). The $\delta^{18} \mathrm{O}$ values from the calcite veins show low variation in isotopic composition suggesting a single fluid source in meteoric diagenetic zone (Allen and Mathews, 1982; Oehelrt and Swart, 2014). However, as referred before, the possibility of fluid mixture (pore fluid with meteoric fluid flux) during diagenesis is not excluded. The vein differences in the $\delta^{18} \mathrm{OPDB}$ and $\delta^{13} C_{P D B}$ values for all samples suggest a vein development by fluids from salinity close to meteoric fluids ( 0 to $5 \mathrm{wt}$. \% of $\mathrm{NaCl}$ equivalent), except those values ranging from 16 to 21 wt. \% of $\mathrm{NaCl}$ equivalent (basinal brines), which can correspond to pore fluids derivate from carbonate levels of the Irati Formation or evaporite layers from adjacent units (Teresina Formation, Nomura et al., 2014). The isotopic data from the calcite veins indicate that the calcite precipitation occurred based on fluids with salinity close to meteoric/marine waters with possible mixture of pore fluids during diagenesis. Hence, fluid salinity of the veins 
hosted in the Irati Formation, in the continental flood basalt of the Serra Geral Formation and in the sill of the Paraná LIP suggests a cogenetic aqueous saline fluid.

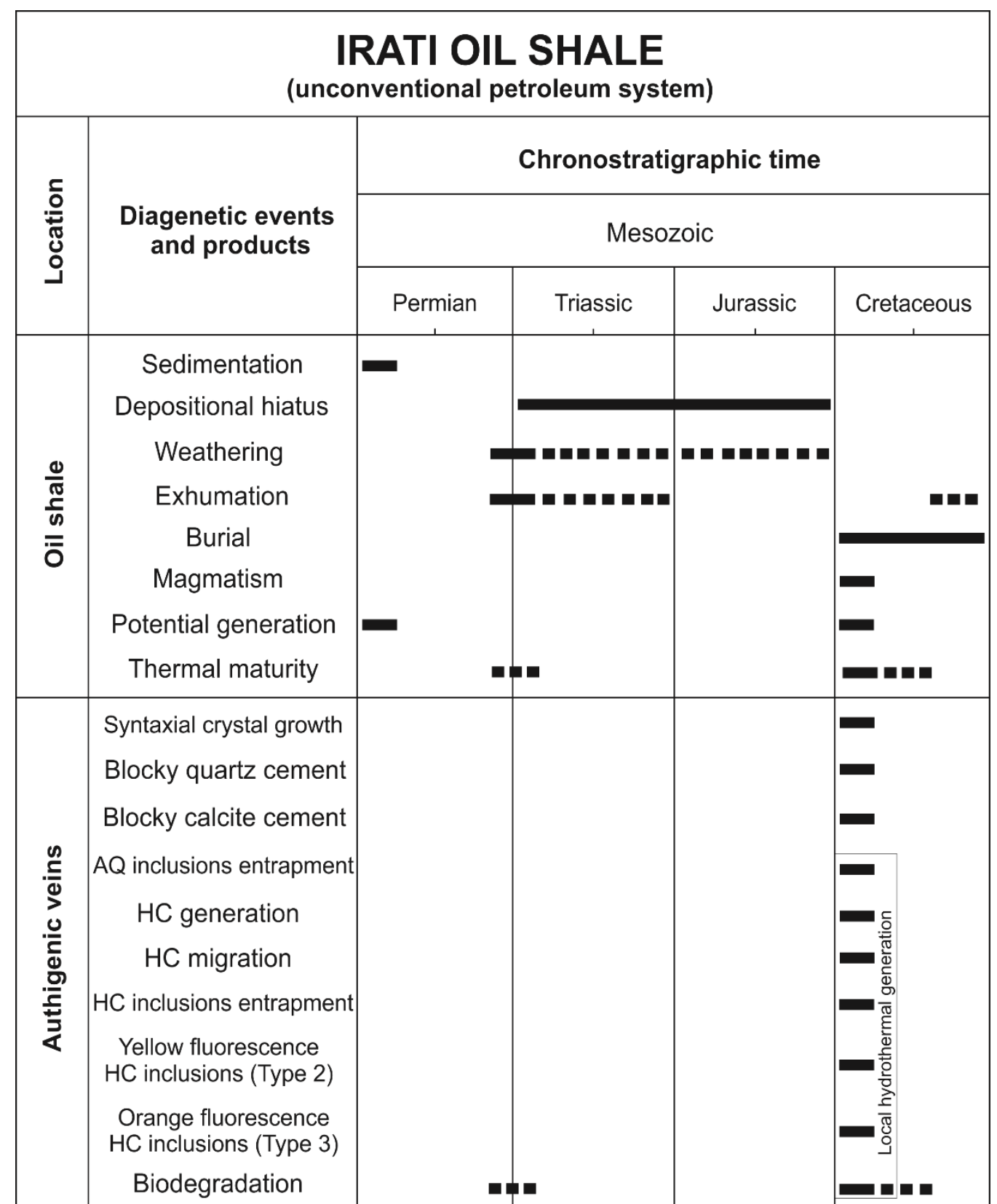

Figure 15. Diagenetic evolution chart of the organic rich shales from the Irati Formation and the authigenic veins. Dashed bars represent uncertainty in the paragenetic time. 


\subsubsection{Post-entrapment modifications in all types of fluid inclusions}

Fluid inclusions hosted in diagenetic minerals can suffer from modifications after entrapment, challenging to track the original conditions of fluid entrapment. The variation of homogenization temperatures of Type 1 inclusions from the veins of the Irati Formation (50 to $330{ }^{\circ} \mathrm{C}$ ) and from the continental flood basalt of the Serra Geral Formation (50 to $250{ }^{\circ} \mathrm{C}$ ) suggest post-entrapment reequilibration process induced by heating (Fig. 16). Fluid inclusions in calcite crystals are susceptible to reequilibration when endured to higher temperatures (more than the trapping temperatures) due to their easy stretching (Prezbindowski and Larese, 1987). Wide dispersion in Th with small variations of $\mathrm{Tm}$ ice values observed in the Type 1 fluid inclusions for all samples (Fig. 16) suggest the stretching phenomenon caused by temperature increase, possibly due to the multiple events of emplacement of igneous bodies during the Early Cretaceous magmatism. In addition, the large variation of Th of primary and pseudosecondary HCFl's with small variation of $F_{v}$ point to post-entrapment modifications as discussed by (Bourdet et al., 2008). Moreover, gas-rich fluid inclusions randomly distributed within the host crystal, with irregular shape, absence of fluorescence and with vapor phase between $40-60 \%$ of the total inclusion (Fig. 5F), can have resulted from thermal reequilibration processes, due to the large variation in Th acquired from primary (Fig. 6G) and secondary Type 2 HCFI's as well (Fig. 6F). 


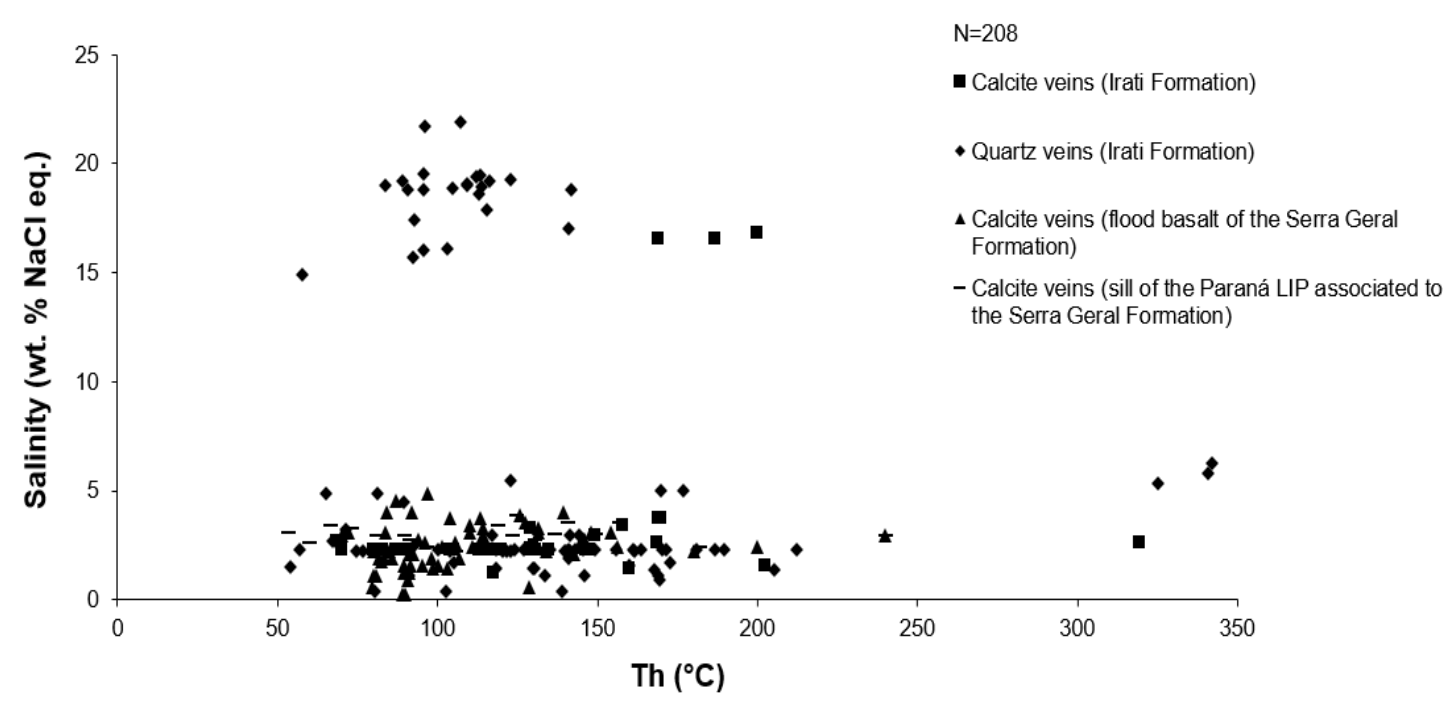

Fig. 16. Homogenization temperatures versus equivalent salinities for quartz and calcite veins hosted in the Irati Formation as well as calcite veins hosted in the Serra Geral Formation. The data suggests the reequilibration phenomena (see Bodnar, 2003).

\section{CONCLUSIONS}

This study has provided new insights into the processes leading to thermal maturity pattern of the Irati organic-rich shales and trapping temperatures, composition and classification of paleofluids (water and oil) occurring as fluid inclusions in diagenetic calcite and quartz veins.

Both the vitrinite reflectance $(\% \mathrm{Ro}=0.6)$ and the kerogen aromaticity $\left(f_{\text {ar }}\right)$ results indicate oil-window maturities for the Irati Formation in southeastern part of the Paraná Basin. In this portion of the basin, the maturity of the organic-rich shales from the Irati Formation was controlled essentially by burial, which indicates that this unit might have reached sufficient depth to generate heterogeneous liquid hydrocarbons (medium to low density). In the northeastern part of the Paraná Basin, the presence of the large intruded sills of the Paraná LIP (Early Cretaceous) allowed higher temperature heating in local zones of the Irati Formation which have contributed to the generation and migration of light hydrocarbons. According to their composition, the liquid hydrocarbons have been generated and migrated in a diagenetic temperature window zone of $50-80{ }^{\circ} \mathrm{C}$ within a fracture system, without reaching the flood basalt cap of the Serra Geral Formation. These HCFl's were classified as black oil due to their Th and $F_{v}$ 
parameters. They are characterized by medium to light compounds with a small variation of gravity $\left(\mathrm{API}^{\circ}\right)$, corresponding to medium and low density oils. Hence, the maturity data is in contrast with our Th values from AqFl's coeval with HCFl's (varying between 50 and $330^{\circ} \mathrm{C}$ ). Thus, we interpret that the fluid temperatures in the fracture system might be responsible for a local hydrocarbons generation and migration (possible hydrothermal generation), and consequently trapped black oil fluid inclusions, within a higher temperature window. Concomitant, a pervasive diagenetic fluid circulation dominated by meteoric/marine waters with moderately low salinity fluids (0-5 wt. \% of $\mathrm{NaCl}$ eq.) have migrated with the HCFl's and precipitate these quartz and calcite veins. Also, this fluid flux may have contributed to hydrocarbon biodegradation processes. A posterior higher temperature $\left(160-250^{\circ} \mathrm{C}\right)$ pulse of oil migration is evidenced by the presence of secondary HCFI's. No gas-rich fluid inclusions $\left(\mathrm{CH}_{4}\right)$ or carbonic rich inclusions $\left(\mathrm{CO}_{2}\right)$ were observed in the studied diagenetic veins which might suggest minor or absence of gas production due to effect of the LIP Paraná over the Irati Formation shales. The PVT model points out to a shallow active petroleum system of $2 \mathrm{~km}$ depth (below isotherm of $80^{\circ} \mathrm{C}$ ) and hydrocarbons trapped under hydrostatic conditions. This corroborates the hypothesis of post-entrapment modifications as biodegradation occurred in the hydrocarbon fluid inclusions.

Acknowledgments: The authors would like to thank Human Resources Training Program in Petroleum and Environmental Geology (PFRH-147 and 241) of Petróleo Brasileiro S.A. and National Council for Scientific and Technological Development (CNPq) (grant 304727/2017-2) for the financial support. They are also grateful to the Multiuser Central Facilities of Federal University of $A B C$ (Brazil) for NMR analyzes and to the Departamento de Geociências, Ambiente e Ordenamento do Território da Universidade do Porto (Portugal) for the use of the Vitrinite Reflectance facilities. We also thanks to Msc. Carlos Mazoca for technical support. 


\section{REFERENCES}

Allen, J.R., Mathews, R.K., 1982. Isotopes signatures associated with early meteoric diagenesis. Sedimentology 29, 797-817.

American Society for Testing and Materials (ASTM)., 2011. Standard test method for microscopical determination of the reflectance of vitrinite dispersed in sedimentary rocks: West Conshohocken, PA, ASTM International, Annual book of ASTM standards: Petroleum products, lubricants, and fossil fuels; Gaseous fuels; coal and coke 5.06, D7708-11, 823-830.

Aplin, A.C., Mcleod, G., Larter, S.R., Pedersen, K.S., Sorensen, H., Booth, T., 1999. Combined use of confocal laser microscopy and PVT simulation for estimating the composition and physical properties of petroleum in fluid inclusions. Marine and Petroleum Geology 16, 97-110.

Araújo L.M., Trigüis J.A., Cerqueira J.R., Freitas L.C.S., 2000. The atypical Permian petroleum system of the Paraná Basin, Brazil. In: Mello M.R., Katz B.J. (Eds.). Petroleum systems of South Atlantic margins. Tulsa, AAPG Memoir 73, 377-402.

Archer, D.G., 1992. Thermodynamic properties of the $\mathrm{NaCl}+\mathrm{H}_{2} \mathrm{O}$ system: II. Thermodynamic properties of $\mathrm{NaCl}(\mathrm{aq}), \mathrm{NaCl} \cdot 2 \mathrm{H}_{2} \mathrm{O}(\mathrm{cr})$, and phase equilibria. Journal of Physical Chemistry 28, 1-17.

Artur, P.C., Soares, P.C., 2002. Paleoestruturas e petróleo na Bacia do Paraná, Brasil. Revista Brasileira de Geociências 32, 433-448.

Bakker, R.J., 2003. Package fluids 1. Computer programs for analysis of fluid inclusion data and for modeling bulk fluid properties. Chemical Geology 194, 323. 
Baron, M., Parnell, J., Mark, D., Carr, A., Przyjalgowski, Feely, M., 2008. Evolution of hydrocarbon migration style in a fractured reservoir deduced from fluid inclusion data, Clair Field, west of Sheetland, UK. Marine and Petroleum Geology 25, 153-172.

Baudino, R., Rodríguez, F., Zencich, S., Calegari, R., 2004. Generation of hydrocarbons by thermal effect of magmatic intrusions: a non-conventional petroleum system. In: Abstracts IX Latin American Association of Organic Geochemistry Congress, Mérida, Mexico, 77p.

Bodnar, R.J., 1990. Petroleum migration in the Miocene Monterey Formation, California, U.S.A.: Constraints from fluid-inclusion studies. Mineralogical Magazine 54, 295-304.

Bodnar, R.J., 2003. Reequilibration of fluid inclusions. In I. Samson, A. Anderson, D. Marshall. (Eds.). Fluid Inclusions: Analysis and Interpretation. Mineral. Assoc. Canada, Short Course 32, 213-230.

Bourdet, J., Pironon, J., Levresse, G., Trittla, J., 2008. Petroleum type determination through homogenization temperature and vapour volume fraction measurements in fluid inclusions. Geofluids 8, 46-59.

Bourdet, J., Eadington, P., Volk, H., George, S.C., Pironon, J., Kempton, R., 2012. Chemical changes of fluid inclusion oil trapped during the evolution of an oil reservoir: Jabiru-1A case study (Timor Sea, Australia). Marine and Petroleum Geology 36, 118-139.

Burruss, R.C., Cercone, K.R., Harris, P.M., 1983. Fluid inclusion petrography and tectonic-burial history of the Al Ali n-2 well: Evidence for the timing of diagenesis and migration, northern Oman fore deep. Geology 11, 567-570.

Cao, X., Yang, J., Mao, J., 2013. Characterization of kerogen using solid-state nuclear magnetic resonance spectroscopy: A review. International Journal of Coal Geology 108, 83-90. 
Cao, J., Jin, Z., Hu, W., Zhang, Y., Yao, S., Wang, X., Zhang, Y., Tang, Y., 2010. Improved understanding of petroleum migration history in the Hongche fault zone, northwestern Junggar Basin (northwest China): Constrained by vein-calcite fluid inclusions and trace elements. Marine and Petroleum Geology 27, 61-68.

Carr, A.D., Williamson, J.E., 1990. The relationship between aromaticity, vitrinite reflectance and maceral composition of coals: Implications for the use of vitrinite reflectance as a maturation parameter. Organic Geochemistry 16, 313-323.

Coelho, C.E., 2005. O estudo de inclusões fluidas na exploração de petróleo. Boletim de Geociências da Petrobras, Rio de Janeiro, Boletim de Geociências da Petrobras 13, 61-80.

Crawford, M.L., Hollister, L.S., 1992. Fluid-rock interactions during Metamorphism. In: Walther, J.V., Wood, B.J. (Eds.). Advances in Physical Chemistry 4, 1-35.

Danesh, A. 1998. PVT and Phase Behaviour of Petroleum Fluids, Developments in Petroleum Science, 47. Elsevier, Amsterdam, 387p.

Davis, D.W., Lowenstein, T.K., Spencer, R.J., 1990. Melting behavior of fluid inclusions in laboratory-grown halite crystals in the systems $\mathrm{NaCl}-\mathrm{H}_{2} \mathrm{O}, \mathrm{NaCl}-\mathrm{KCl}$ $\mathrm{H}_{2} \mathrm{O}, \mathrm{NaCl}-\mathrm{MgCl}_{2}-\mathrm{H}_{2} \mathrm{O}$ and $\mathrm{NaCl}-\mathrm{CaCl}_{2}-\mathrm{H}_{2} \mathrm{O}$. Geochimica et Cosmochimica Acta $54,591-601$.

Dembicki, H., 2013. Challenges to Black Oil Production from Shales. Search and Discovery Article in Geoscience Technology Workshop, Hydrocarbon Charge Considerations in Liquid-Rich Unconventional Petroleum Systems. Vancouver, Canada.

Dyni, J.R., 2003. Geology and resources of some world oil shale deposits: U.S. Geological Survey Scientific Investigations Report 5294, 42p. 
Ernesto, M., Bellieni, G., Piccirillo, E.M., Marques, L.S., de Min, A., Pacca, I.G., Martins, G., Macedo, J.W.P., 2002. Paleomagnetic and geochemical constrains on the timing and duration CAMP activity in Northeastern Brazil. In: Hames, W.E., Renne, P.R., Ruppel C. (Eds.). The Central Atlantic Magmatic Province. American. Geophysical. Union Monography 136, 91-128.

EIA/ARI, 2013. EIA/ARI World Shale Gas and Shale Oil Assessment.

Fang, H., Jianyu, C., 1992. The cause and mechanisms of vitrinite reflectance anomalies. Journal of Petroleum Geology 15, 419-434.

George, S.C., Volk, H., Ahmed, M., 2007. Geochemical analysis techniques and geological applications of oil-bearing fluid inclusions, with some Australian case studies. Journal of Petroleum Science and Engineering 57, 119-138.

Goldstein, R.H., Reynolds, T.J., 1994. Systematics of fluid inclusions in diagenetic minerals. Estados Unidos da América, Tulsa: SEPM (Society for Sedimentary Geology), short courses 31, 199p.

Goldstein, R.H., 2001. Fluid inclusions in sedimentary and diagenetic systems. Lithos 55, 159-192.

Heimdal., T.H, Svensen, H.H., Ramezani, J., Lyer, K., Pereira, E., Rodrigues, R., Jones., M.T., Callegaro, S., 2018. Large-scale sill emplacement in Brazil as a trigger for the end Triassic crisis. Nature, Scientific Reports 8 (141), 1-12.

Hood, A., Gutjahr, C.C.M., Heacock, R.L., 1975. Organic metamorphism and the generation of petroleum. American Association of Petroleum Geology 59, 986996.

Holz, M., França, A.B., Souza, P.A., lannuzi, R., Rohn, R., 2010. A stratigraphic chart of the Late Carboniferous/Permian succession of the eastern border of the Paraná Basin, Brazil, South America. Journal of South American Earth Sciences 29, 381-399. 
Hoefs, J., 2004. Stable Isotope in Geochemistry, 5th ed. Springer-Verlag, Berlin, $244 p$.

Hunt, J.M., 1996. Petroleum Geochemistry and Geology. H. Freeman and Company, $2^{\text {nd }}$ edition. New York. USA. 743p.

Hurter, S.J., Pollack, H.N., 1994. Effect of the Cretaceous Serra Geral igneous event on the temperatures and heat flow of the Parana Basin, southern Brazil. Basin Research 6, 239-244.

Hutton, A.C., Cook, A.C., 1980. Influence of alginite on the reflectance of vitrinite from Joadja, NSW, and some other coals and oil shales containing alginite. Fuel $59,711-714$.

ICCP, 1998, The new vitrinite classification (ICCP System 1994): Fuel 77, 349358.

ICCP, 2001, The new inertinite classification (ICCP System 1994): Fuel 80, 459471.

Janasi, V.A., Montanheiro, T.J., Freitas, V.A., Reis, P.M., Negri, F.A., Dantas, F.A., 2007. Geology, petrography and geochemistry of the acid volcanism of the Paraná Magmatic Province in the Piraju-Ourinhos region, SE Brazil. Revista Brasileira Geociências 37, 745-759.

Janasi, V.A., De Freitas, V.A., Heaman, L.H., 2011. The onset of flood basalt volcanism, Northern Paraná Basin, Brazil: A precise U-Pb baddeleyite/zircon age for Chapecó-type dacite. Earth and Planetary Science Letters 302, 147-153.

Jarvie, D.M., Hill, R.J., Ruble, T.E., Pollastro, R.M., 2007. Unconventional shalegas systems: The Mississippian Barnett Shale of north-central Texas as one model for thermogenic shale-gas assessment. The American Association of Petroleum Geologists 91(4), 475-499. 
Kelemen, S.R., Afeworki, M., Gorbaty, M.L., Sansone, M., Kwiatek, P.J., Walters, C.C., Freund, H., Siskin, M., Bence, A.E., Curry, D.J., Solum, M., Pugmire, R.J., Vandenbroucke, M., Leblond, M., Behar, F., 2007. Direct Characterization of Kerogen by X-ray and Solid-State ${ }^{13} \mathrm{C}$ Nuclear Magnetic Resonance Methods. Energy Fuels 21, 1548-1561.

Li, R., Parnell, J., 2003. In situ microanalysis of petroleum fluid inclusions by Time of Flight-Secondary Ion Mass Spectrometry as an indicator of evolving oil chemistry: a pilot study in the Bohai Basin, China, Journal of Geochemical Exploration 78-79, 377-384.

Liu, E., Wuang, H., Uysal, T., Zhao, J., Wang, X., Feng, Y., Pan, S., 2017. Paleogene igneous intrusion and its effect on thermal maturity of organic-rich mudstones in the Beibuwan Basin, South China Sea. Marine and Petroleum Geology 86, 733-750.

Mateus, A., Riccomini, C., Ezequiel, J.E.C.B.F., Tassinari, C.G., 2014. PermianTriassic maturation and multistage migration of hydrocarbons in the Assistência Formation (Irati Subgroup), Paraná Basin, Brazil: implications for the exploration model. Brazilian Journal of Geology 44, 355-360.

McLimans, R.K., 1987. The application of fluid inclusions to migration of oil and diagenesis in petroleum reservoirs. Applied Geochemistry 2, 585-603.

Miknis, F.P., Jiao, Z.S., Macgowan, D.B., Surdam, R.C., 1993. Solid-state NMR characterization of Mowry shale from the Powder River Basin. Organic Geochemistry 20, 339-347.

Milani, E.J., França, A.B., Medeiros, R.A., 2007a. Rochas Geradoras e rochas reservatório da bacia do Paraná, faixa oriental de afloramentos, estado de Paraná. In: Bacia do Paraná. Boletim de Geociências Petrobrás 15, 135-162. 
Milani, E.J., Melo, J.H.G., Souza, P.A., Fernandes, L.A., França, A.B., 2007b. Bacias sedimentares brasileiras: cartas estratigráficas. Boletim de Geociências Petrobrás 15, 265-287.

Monreal, F.R., Villar, H.J., Baudino, R., Delpino, D., Zencich, S., 2009. Modeling an atypical petroleum system: A case study of hydrocarbon generation, migration and accumulation related to igneous intrusions in the Neuquen Basin, Argentina. Marine and Petroleum Geology 26, 590-605.

Montel, F., 1993. Phase equilibria needs for petroleum exploration and production industry. Fluid Phase Equilibria 84, 343-367.

Montgomery, S.L., Jarvie, D.M., Bowker, K.A., Pallastro, R.M., 2005. Mississippian Barnett Shale, Fort Worth basin, north-central Texas: gas-shale play with multi-trillion cubic foot potential. American Association of Petroleum Geologists 89, 155-175.

Munz, I.A., Iden, K., Johansen, H., Vagle, K., 1998. The fluid regime during fracturing of the Embla field, Central Trough, North Sea. Marine and Petroleum Geology 15, 751-768.

Munz, I.A., Johansen, H., Holm, K., Lacharpagne, J.C., 1999a. The petroleum characteristics of the Frøy field and the Rind discovery, Norwegian North Sea. Marine and Petroleum Geology 16, 633-651.

Munz, I.A., 2001. Petroleum inclusions in sedimentar basins: systematics, analytical methods and applications. Lithos 55, 195-212.

Munz, I., Wangen, M., Girard, J.P., Lacharpagne, J.C., Johansen, H., 2004. Pressure, temperature, time, composition (P-T-t-X) constraints of multiple petroleum charges in the Hid field, Norwegian North Sea. Marine and Petroleum Geology 21, 1043-1060. 
Nedkvitne, T., Karlsen, D.A., Bjørlykke, K., Larter, S.R., 1993. Relationship between reservoir diagenetic evolution and petroleum emplacement in the Ula Field, North Sea. Marine and Petroleum Geology 10, 255-270.

Nomura, S.F., Sawakuchi, A.O., Bello, R.M.S., Méndez-Duque, J., Fuzikawa, K., Giannini, P.C.F., Dantas, M.S.S., 2014. Paleotemperatures and paleofluidos recorded in fluid inclusions from calcite veins from northern flank of the Ponta Grossa dyke swarm: Implications for hydrocarbon generation and migration in the Paraná Basin. Marine and Petroleum Geology 52, 107-124.

Oehlert, A.M., Swart, P.K., 2014. Interpreting carbonate and organic carbon isotope covariance in the sedimentary record. Nature Communications 5, 1-7.

Othman, R., Arouri, K.R., Ward, C.R., McKirdy, D.M., 2001. Oil generation by igneous intrusions in the northern Gunnedah Basin, Australia. Organic Geochemistry 32, 1219-1232.

Oxtoby, N.H., Mitchell, W., Gluyas, J.G., 1995. The filling and emptying of the Ula Oilfield: fluid inclusion constraints. Geological Society, London, Special Publications 86, 141-157.

Pacheco, F.E.R.C., Caxito, F.A., Moraes, L.C., Marangoni, Y.R., Santos, R.P.Z., Pedrosa-Soares, A.C., 2018. Basaltic ring structures of the Serra Geral Formation at the southern Triângulo Mineiro, Água Vermelha region, Brazil. Journal of Volcanology and Geothermal Research 355, 136-148.

Parnell, J., Middleton, D., Honghan, C., Hall, D., 2001. The use of integrated fluid inclusion studies in constraining oil charge history and reservoir compartmentation: examples from the Jeanne d'Arc basin, offshore Newfoundland. Marine and Petroleum Geology 18, 535-549.

Parnell, J., 2004. Titanium mobilization by hydrocarbon fluids related to sill intrusion in a sedimentary sequence, Scotland. Ore Geology Reviews 24, 155167. 
Peate, D.W., Hawkesworth, C.J., Mantovani, M.S., 1992. Chemical stratigraphy of the Paraná lavas (South America): classification of magma types and their spatial distribution. Bulletin of Volcanology 55, 119-139.

Peate, D.W., 1997. The Paraná-Etendeka Province. In: Mahoney, J.J., Coffin, M.F. (Eds.) Large Igneous Provinces: Continental, Oceanic and Planetary Flood Volcanism. American Geophysical Union, Geophysical Monographs 100, 217245.

Peng, D.Y., Robinson, D.B., 1976. A new two-constant equation of state. Industrial Engineering Chemicals Fundamentals 15, 59-64.

Permanyer, A., Martin-Martin, J.D., Khile, J., Márquez, G., Marfil, R., 2017. Oil shows geochemistry and fluid inclusion thermometry of Mid Cretaceous carbonates from the eastern Basque Cantabrian Basin (N Spain). Marine and petroleum Geology 92, 255-299.

Pestilho, A.L.S., Monteiro, L.V.S., 2017. A review on the fundamentals of aqueous and petroleum fluid inclusion study. Terrae Didática 13 (2), 71-92.

Ping, H., Chen, H., Thiéry, R. George, S.C., 2017. Effects of oil cracking on fluorescence color, homogenization temperature and trapping pressure reconstruction of oil inclusions from deeply buried reservoirs in the northern Dongying Depression, Bohai Bay Basin, China. Marine and Petroleum Geology 80, 538-562.

Pironon, J., Canals, M., Dubessy, J., Walgenwitz, F., Laplace-Builhe, C., 1998. Volumetric reconstruction of individual oil inclusions by confocal scanning laser microscopy. European Journal of Mineralogy 10, 1143-1150.

Potter, J., Rankin, A.H., Treloar, P.J., Nivin, V.A., Ting, W., Ni, P., 1998. The preliminary studies of methane inclusions in alkaline igneous rock of the Kola igneous province, Russia: implications for the origin of methane in igneous rocks. European Journal of Mineralogy 10, 1167-1180. 
Prezbindowski D.R., Larese R.E., 1987. Experimental stretching of fluid inclusions in calcite - implications for diagenetic studies. Geology 15, 333-336.

Price, L.C., Barker, C.E., 1985. Suppression of vitrinite reflectance in amorphousrich kerogen - A major unrecognized problem. Journal of Petroleum Geology 8 , 59-84.

Renne, P.R., Deckart, K., Ernesto, M., Féraud, G., Piccirillo, E.M., 1996. Age of the Ponta Grossa dyke swarm (Brazil), and implications to Paraná flood volcanism. Earth Planetary Science Letter 144, 199-211.

Roedder, E., 1984. Fluid inclusions. In: Ribbe, P.H. (Eds.). Reviews in Mineralogy, Mineralogical Society of America 12,646p.

Ross, D.J.K., Bustin, R.M., 2008. Characterizing the shale gas resource potential of Devonian-Mississippian strata in the western Canada Sedimentary Basin: application of an integrated formation evaluation. American Association of Petroleum Geologists Bulletin 92, 87-125.

Ross, D.J.K., Bustin, R.M., 2009. The importance of shale composition and pore structure upon gas storage potential of shale gas reservoirs. Marine and Petroleum Geology 26, 917-927.

Santos R.V., Dantas, E.L., Oliveira, C.G., Alvarenga, C.J.S., Anjos, C.W.D., Guimarães, E.M., Oliveira, F.B., 2009. Geochemical and thermal effects of a basic sill on black shales and limestones of the Permian Irati Formation. Journal of South American Earth Sciences 28, 14-24.

Stach, E., Mackowsky, M.T., Teichmüller, M., Chandra, T.D., Teichmüller, R., 1982. Stach's Textbook of Coal Petrology, Gebrüder Borntraeger, Berlin, 535p.

Solum, M.S., Mayne, C.L., Orendt, A.M., Pugmire, R.J., Adams, J., Fletcher, T.H., 2014. Characterization of Macromolecular Structure Elements from a Green River Oil Shale, I. Extracts. Energy Fuels 28, 453-465. 
Souza, I.V.A.F., Mendonça Filho, J.G., Menezes, T.R., 2008. Avaliação do efeito térmico das intrusivas ígneas em um horizonte potencialmente gerador da Bacia do Paraná: Formação Irati. Revista Brasileira de Geociências 38, 138-148.

Smernik, R.J., Schwark, L., Schmidt, M.W.I., 2006. Assessing the quantitative reliability of solid-state ${ }^{13} \mathrm{C}$ NMR spectra of kerogens across a gradient of thermal maturity. Solid State Nuclear Magnetic Resonance 29, 312-321.

Stasiuk, L.D., Snowdon, L.R., 1997. Fluorescence micro-spectrometry of synthetic and natural hydrocarbon fluid inclusions: crude oil chemistry, density and application to petroleum migration. Organic Geochemistry 12, 229-241.

Stewart K., Turner S., Kelley S., Hawkesworth C., Kirsten L., Mantovani M. 1996. 3-d, 40Ar-39 Ar geochronology in the Paraná continental flood basalt province. Earth and Planetary Science Letters 143, 95-109.

Suchý, V., Dobeš, P., Sýkorová, I., Machovič, V., Stejskal, M., Kroufek, J., Chudoba, J., Matějovský, L., Havelcová, M., Matusová, P., 2010. Oil-bearing inclusions in vein quartz and calcite and, bitumens in veins: Testament to multiple phases of hydrocarbon migration in the Barrandian Basin (lower Palaeozoic), Czech Republic. Marine and Petroleum Geology 27, 285-297.

Teixeira, C.A.S., Sawakuchi, A.O., Bello, R.M.S., Nomura, S.F., Bertassoli, D.J., Chamani, M.A.C., 2018. Fluid inclusions in calcite filled opening fractures of the Serra Alta Formation reveal paleotemperatures and composition of diagenetic fluids percolating Permian shales of the Paraná Basin. Journal of South American Earth Sciences 84, 242-251.

Thiede, D.S., Vasconcelos P.M., 2010. Paraná flood basalts: Rapid extrusion hypothesis confirmed by new ${ }^{40} \mathrm{Ar} /{ }^{39} \mathrm{Ar}$ results. Geology $38,747-750$. 
Thiéry, R., Pironon, P., Walgenwitz, F., Montel, F., 2002. Individual characterization of petroleum fluid inclusions (composition and P-T trapping conditions) by microthermometry and confocal laser scanning microscopy: inferences from applied thermodynamics of oils. Marine and Petroleum Geology 19, 847-859.

Thomaz-Filho, A., Mizusaki, A.MP., Antonioli, L., 2008. Magmatism and petroleum exploration in the Brazilian Paleozoic Basins. Marine and Petroleum Geology 25, 143-151.

Tissot, B.P., Welte, D.H., 1984. Petroleum Formation and Occurrence, $2^{\text {nd }}$ Edition. Berlin, Springer-Verlag, 699p.

United States Geological Survey (USGS)., 2013. National Oil and Gas Assessment, March, Shale Gas Assessment.

Vandenbroucke, M., Largeau, C., 2007. Kerogen origin, evolution and structure. Organic Geochemistry 38, 719-833.

Verna, D., Jadhav, G.N., Biswal, T.K., Jena, S.K., Sharma, N., 2012. Characterization of Hydrocarbon-bearing Fluid Inclusion in Sandstones of Jaisalmer Basin, Rajasthan: A Preliminary Approach. Journal Geological Society of India 80, 505-514.

Wang, Z.Y., Fan, P., Cheng, K.M., 1995. The thermal evolution indicator of carbonete rocks. Science in China Series B-Chemistry. Life Sciences and Earth Sciences 38, 733-740.

Wei, Z., Gao, X., Zhang, D., Da, J., 2005. Assessment of Thermal Evolution of Kerogen Geopolymers with Their Structural Parameters Measured by Solid-State ${ }^{13} \mathrm{C}$ NMR Spectroscopy. Energy Fuels 19, 240-250. 
Wenger, L.M., Baker, D.R., 1987. Variations in vitrinite reflectance with organic facies - Examples from Pennsylvanian cyclothems of the MidContinent, USA. Organic Geochemistry 11, 411-416.

Werner-Zwanziger, U., Lis, G., Mastalerz, M., Schimmelmann, A., 2005. Thermal maturity of type II kerogen from the New Albany Shale assessed by C-13 CP/MAS NMR. Solid state nuclear magnetic resonance 27, 140-148.

Witte, E.G., Shenk, H.J., Muller, P.J., Schwochau, K., 1988. Structural modifications of kerogen during natural evolution as derived from 13-C CP/MAS NMR, IR spectroscopy and Rock-Eval pyrolysis of Toarcian shales. Organic Geochemistry 13, 1039-1044.

Zhang, Y.G., Frantz, J.D., 1987. Determination of the homogenization temperatures and densities of supercritical fluids in the system $\mathrm{NaCl}-\mathrm{KCl}-\mathrm{CaCl}_{2}-$ $\mathrm{H}_{2} \mathrm{O}$ using synthetic fluid inclusions, Chemical Geololy 64, 335-350. 